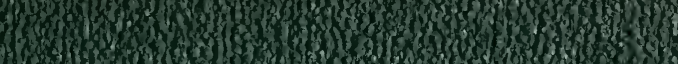
15)

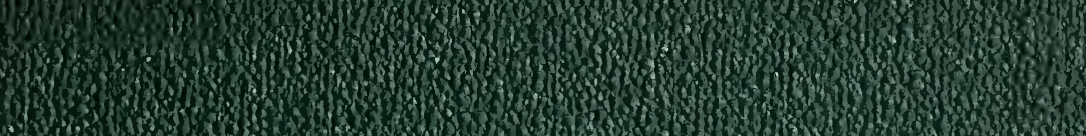
16.

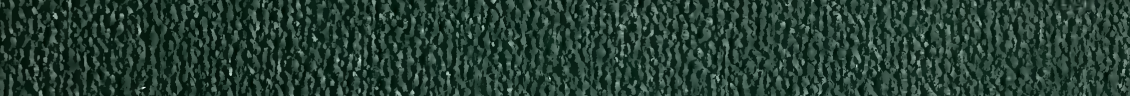

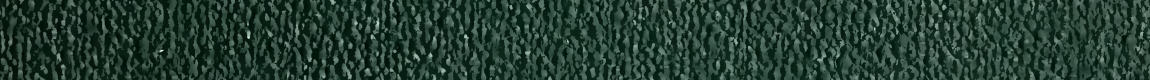

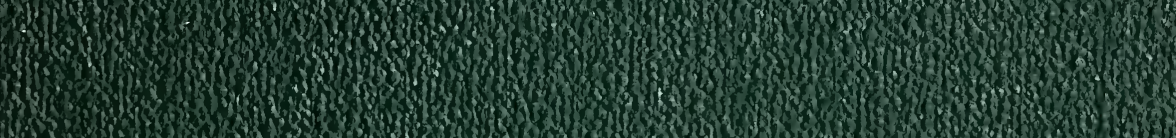
3.1. W.

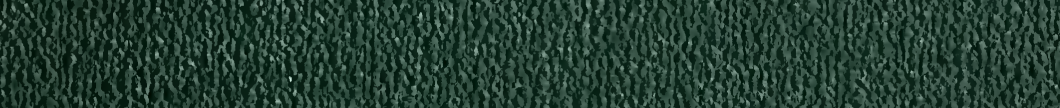

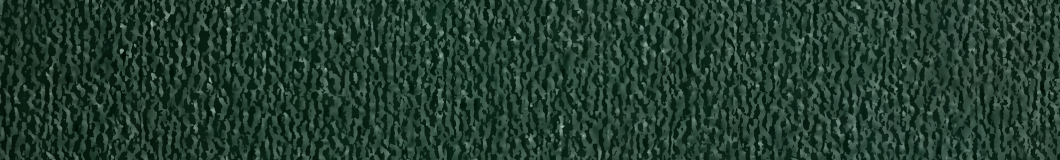

(1)

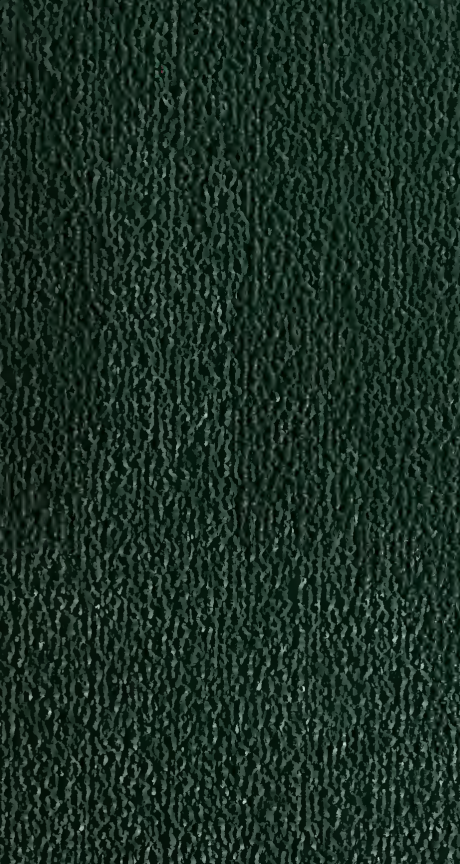

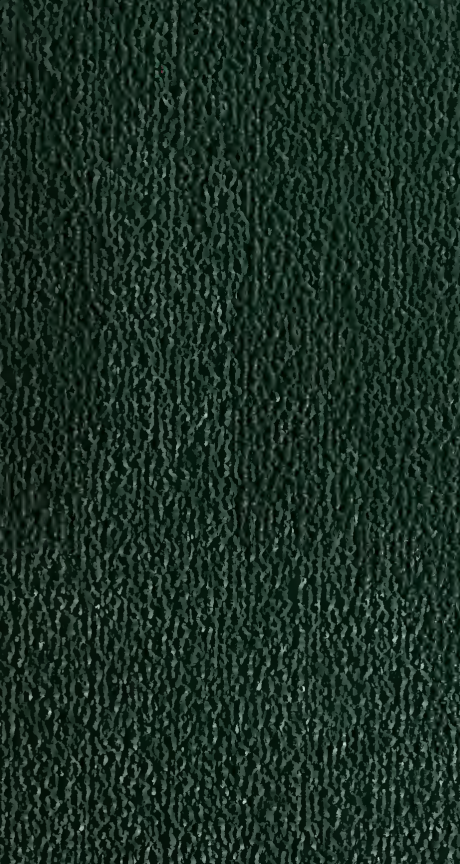

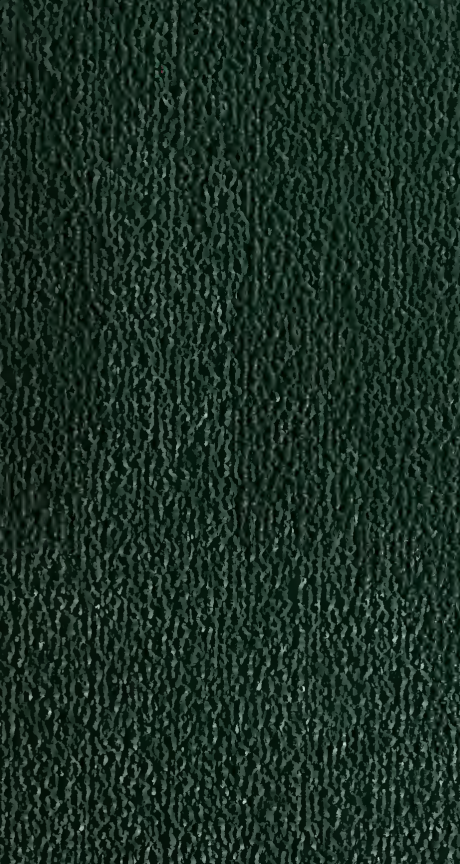

$$
\text { How } 3 \text { s. }
$$

W.

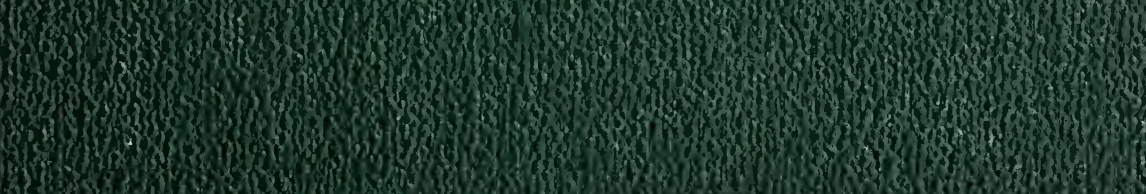
(1) 130 m.

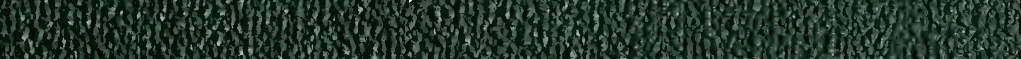

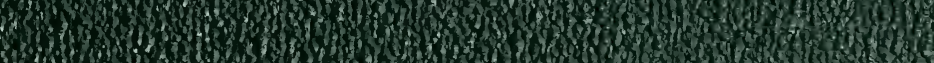

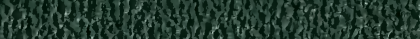
(6) 2.3. (4) fortunh 106in

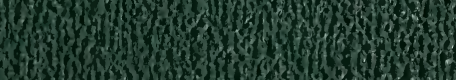

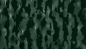


910.3
0
1907 
$581.9(46.9)$ SUB 



\section{FLORULE 'TOULOUSAINE}





\section{FLORULE}

\section{TOULOUSAINE}

$\mathrm{OU}$

\section{ANALYSE DESCRIPTIVE}

DES PLANTES QUI CROISSENT SPONTANÉMENT OU SONT CULTIVÉES EN GRAND DANS LA RÉGION SOUS-PYRÉNÉENNE DE LA

\section{HAUTE-GARONNE}

avec l'indication de leurs propriétés les plus importantes

ouvrage contenant 847 Figures dessinées par L'aUteur

PAR

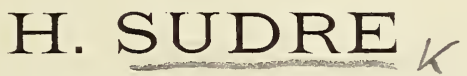

Professeur à l'Ecole normale d'Instituteurs de Toulouse, Nembre de la Société botanique de France.

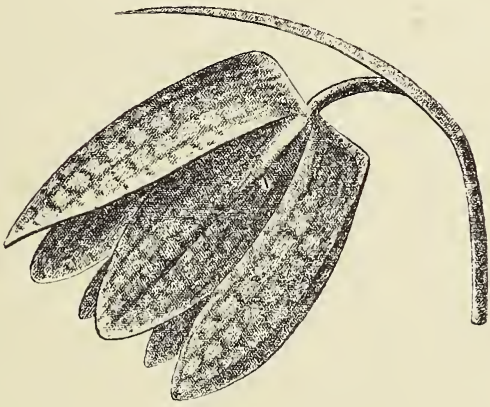

Paul KLINCKSIECK LIBRAIRIE DES SCIENCES NATURELLES 3 , rue corneille, 3 PARIS VIe
J. $11 \mathrm{ARQUESTE}$ LIBLA IRIE ANCIENNE ET MODERNE 34 , rue Saint-Rome, 34 TOULOUSE

\section{ALBI}

IMPRIMERIE NOUGUIES

33, Rue de l'Hòtel-de-Ville, 33

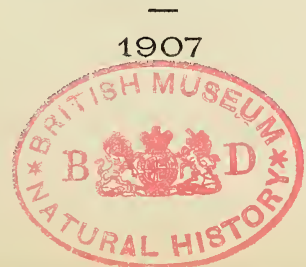


6 MAY. 1911 


\section{PRÉFACE}

L'ouvrage le plus récent relatif aux plantes planérogames de la région sous-pyrénéenne de la Haute-Garonne est la "Flore analytique de Toulouse et de ses environs ", de J.-B. Noulet, dont la $3^{e}$ édition, parue en 1884, est épuisée depuis quelques années. Comme un ouvrage de cette nature est à peu près indispensable aux personues qui veulent connaître la végétation des environs de Toulouse et qui sont peu familiarisées avec l'étude des plantes, j’ai pensé qu'une analyse descriptive détaillée, accompagnée de nombreuses figures, mise au courant des progrès de la science et à la portée des débutants, rendrait de réels services aux instituteurs désireux d'étudiep les végétaux qui les entourent, aux étudiants des Facultés, aux élèves des Ecoles Normales, des Ecoles Primaires Supérieures, des Etablissements d'Enseignement Secondaire, ete., dont les études botaniques deviennent particulièrement intéressantes et fructueuses quand elles sont complétées par de fréquentes herborisations.

Le rayon de cette florule embrasse toute la partie basse du département de la Haute-Garonne, c'est-ì-dire les arrondissements de Toulouse, de Villefranche et de Muret. Cette région, dont l'altitude ne dépasse guère 300 mètres, est formée de terrains appartenant aux époques tertiaire et quaternaire. Les terrains tertiaires, qui se rencontrent sur la plupart des coteaux, sont formés de grès mollasses, de sables et d'argiles souvent accompagnées de calcaire (terres fortes). Les terrains quaternaires occupent surtout les vallées de la Garonne, du Tarn, de l'Her's, du Girou et de quelques autres cours d'ean de moindre importance; ils sont constitués par des sables on des terres argilo-siliceuses (boulbènes) et contiennent fréquemment des galets plus ou moins gros. Parmi les régions les plus intéressantes au point de vue botanique il y a lieu de citer : les coteaux de la rive droite de la Garonne et de l'Ariège avec leurs escarpements et les petits vallons boisés qui les sillonnent ; les forêts de la Ramette et de Bouconne; les bois du Lauragais et en particulier ceux de St-Geniès et d'Aufréri, près de Balma ; les prés des bords de l'Hers, du Touch 
et du Girou; les graviers des rives de la Garonne et de l'Ariège, où se rencontrent assez fréquemment des espèces descendues des Pyrénées; enfin les berges du canal du Midi, où croissent un certain nombre de plantes qu'on chercherait vainement ailleurs.

La végétation des environs de 'Toulouse est aujourd'hui assez bien connue grâce aux recherches de nombreux naturalistes parmi lesquels je citerai Arrondeau, Jeanbernat, Timbal-Lagrave et Noulet, comme ayant le mieux mérité de la flore toulousaine. J'emprunte un grand nombre d'indications de localités aux publications dis ces zélés botanistes. Quant aux genres particulièrement critiques tels que Rosa, Rubus, Hieracium, j'ai eu, pour les élaborer, non senlement de nombreux matériaux provenant de mes propres recherches, mais encore beaucoup d'autres récoltés par Timbal-Lagrave et figurant soit dans l'herbier Boreau du Musée d'Angers, soit surtout dans celui de P.-J. Müller, du Musée de Lausanne, herbier's dont j'ai fait, il y a quelques années, la révision des genres Rubus et Hieracium. Quelques botanistes m'ont obligeamment communiqué le résultat de leurs herborisations daus la Haute-Garonne; c'est ainsi que M. Duffort, pharmacien à Masseube (Gers), m’a donné de précieux reuseignements sur quelques Rosa litigieux, et que M. Marty, autrefois notaire à Lanta et maintenant fixé à Carcassonne, m'a fourni des documents sur la flore du Lanragais, qui lui est tout à fait familière. Qu'ils recoivent ici l'expression de ma vive reconnaissance.

Les formes végétales étant, surtout dans certains genres, de valeur très inégale, j’ai fait usage de caractères typographiques plus petits pour mentionner les espèces secondaires et les variétés. Ainsi, à la page 38 , le $\mathrm{V}$. scotophylla Jord., qui présente trois variétés saillantes, est subordonué comme sous-espèce au . a D B Bess., envisagé comme espèce principale. A la suite de cette dernière plante sont signalées deux formes hybrides dérivées.

J'ai analysé dans cette Florule non seulement les plantes qui croissent spontanément aux environs de Toulouse, mais encore celles qui y sont cultivées en grand ef que l'on y trouve fréquemment à l'état subspontané. Quelques espèces qui ne se rencontrent qu'accidentellement dans la région toulousạine y sont mentionnées; bien que quelques-unes aient disparu des localités où elles avaient été trouvées, on peut espérer les rencontrer un jour sur d'autres points.

Autant que possible j'ai évité d'employer des termes scientifiques peu connus; j'espère que le vocabulaire de la fin du volume et les nombreuses figures que j'ai dessinées et auxquelles je renvoie fré- 
quemment le lecteur, permettront de saisir aisément le sens des mots techniques dont j’ai cru devoir faire usage. Il importe d'observer, au sujet de ces figures, que la plupart sont lessinées de grandeur naturelle et donnent par conséquent les dimensions à peu près exactes de l'organe représenté ; quelques-unes sont amplifiées, et dans ce cas leur grandeur réelle est marquée par une petite ligne droite; d'autres sont réduites et alors l'échelle du dessin est toujours donnée par une fraction. Dans le courant du texte j'ai fréquemment indiqué les dimensions de quelques organes : des mesures précises m'ont paru préférables aux expressions toujours vagues de grand, assez grand, petit, etc., quand celles-ci sont enployées sans termes de comparaison.

Je n'ai donné que les synonymes les plus utiles à connaitre. Quant aux hydrides, je n'ai fait que les mentionner en indiquant les localités oì ils ont été rencontrés; ces plantes, toujours rares, étant intermédiaires entre les parents qui les ont produites et reconnaissables à leur stérilité partielle ou totale.

Comme le botaniste ne se propose pas uniquement de nommer et de collectionner des plantes, mais encore d'en connaittre les propriétés, j’ai signalé les végétaux vénéneux et indiqué sommairement les usages des principales espéces médicinales.

L'impression de cet ourage, par suite de la diversité des caractères typographiques employés, méritait d'ctre surveillée d'une façon particulière. M. Nonguiès s'en est occupé arec un soin extrême el je lui adresse mes plus vils remerciements.

J'espère que cette Florule, ainsi disposée, sera de quelque utilité pour les débutants ; quant aux botanistes expérimentés, ils y trouveront un résumé fidèle de nos connaissances sur la régétation toulousaine. Je n'ai eu d'autre but, en la publiant, que celui de vulgariser dans la Haute-Garonne l'étude aujourd'hui trop délaissée de l'agréable science de fleurs ; puisse cet unique motif mériter à ce petit livre d'être accueilli avec bienveillance.

Toulouse, le 20 mai 1907. 


\section{NOMS JES AUTEURS GITES EN ABREGE}

Ailioni (All.), Andrzeiowski(Andrz.), Arvet-Touvet (Arv.-T.), Babington (Bab.). Balbis (Balb.), Bastard (Bast.), Bellardi (Bell.), Bentham (Benth.), Bernhardi (Beruh.), Bertoloni (Bert.), Besser (Bess.), Bicbenstein (Bicb.), Boonuinghausel (Bomningh.), Borckhausen (Borckh.), Boreau (Bor.), Boulay et Gillot (Boul. et Gill.), Braun Al. (A. Br.). Brotero (Brot.), Cassini (Cass.), Cavanilles (Cav.), Chaubard (Chaub.), Clairville (Clairv.), Crépin (Crép.). Curtis (Curt.), Danthoine (Danth.), De Candolle (D. C.), Delarbre (Delarb.), Déséglise (Dés.), Desfontaines (Desf.), Desportes (Desp.). Desrousseaux (Desr.), Desvaux (Desv.), Dufrêne (Dufr.), Dumortier (Dumort.), Dunal (Dun.), Ehrhart (Ehrh.). Forster (Forst.), Fries (Fr.), Gaertuer (Gaertn.), Gaudin (Gaud.), Gawler (Gaw.), Genevier (Gen.), Gilibert (Gilib.), Gmeliı (Gmel.), Goodenough (Good.), Godron (God.), Grenier et Godıon (G. G.), Grisebach (Griseb.), Gussone (Guss.), Haller (Hall.), Hoffmann (Hoffm.), Hornemann (Horn.), Hudson (Huds.), Jacquin (Jaç.), Jordan (Jord.), Jordan et Fourreau (J. et. F.), Kitaibel (Kit.). Kocler (Kocl.), Linné (L.), Lamarck (Lamk.), Lapeyrouse (Lap.), Lehman (Lehm.), Lejeune (Lej.), L’Héritjer (L’Hér.), Libert (Lib.), Loiseleur-Deslongchamps (Lois.), Mérat (Mér.), Mertens et Koch (Mert. et K.), Michaux (Michx.). Miller (Mill.), Müller P.-J. (P.-J. Müll.), Murray (Murr.), Nees von Esenbeck (N.), Nestler (Nestl.), Noulet (Noul.), Pallas (Pall.). Palisot de Beauvois (P. B.), Persoon (Pers.), Poiret (Poir.), Pollini (Poll.), Pourret (Pourr.), Ramond (Ram.), Redouté (Red), Reichard (Reich.), Rejchenbach (Reich.), Retzius (Retz.), Reuter (Reut.), Richard L. C. (Rich.), Rcmer (Rom.), Rouy et (amus (R. et C.), S'Amans (S. Am.), Salisbury (Salisb.), Sclırader (Schrad.), Schreber (Schreb.), Scopoli (Scop.), Sebastiani (Seb.), Seringe (Ser.), Smith (Sm.), Solander (Sol.). Soyer-Willemet (Soy.-Will.), Spenuer (Spenn.). Sprengel (Spreng.), Sudre (Sud.), Swartz (Sw.), Tenore ('Ten.), Thuillier (Thuill.), Timbal-Lagrave (Timb.), Timeroy (Timer.), Trinius (Trin.), Ventenat (Vent.), Vıllars (Vill.), Wallenberg (Wahl.), Waldstein (Waldst.), Walpero (Walp.). Wallroth (Wallr.), Weihe (Wh.), Weilie et. Nées (W. ot N.), Wenderoth (Weı:d.j, Willdenow (Willd.), Wickstrom (Wjckst.), Wimmer (Wimm.), Withering(With.). 


\section{ANALYSE DES ORDRES}

1 - Plante pourvue de fleurs, se développant par graines (PHANÉROGAMES). . . . . . . . . . . . 2

- Plante sans fleurs (CRYPTOGAMES). . . . . . . . 87

2 - Ovules renfermés dans un ovaire clos; plante non résineuse

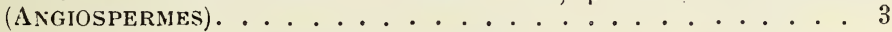

- Orules non renfermés dans un ovaire; arbres ou arbustes résineux; à feuilles très étroites et ordinairement persistantes (Gymospermes) . . . . . . . . Conifères p. 218

3 - Embryon à 1 cotrlédon (Pl. XX. f. 9) ; plante herbacée ; tigc sans écorce distincte, présentant, quand on la coupe en travers, une surface ponctuéc (Pl. XX, f. 11) ; feuilles à nervures ordinairemont simnles et parallèles ; enveloppe florale à 3 ou 6 divisions, ou réduite à quelques écajlles (Monocotylédones). . . 76

- Embryon à 2 cotylédons (Pl. XX, f. 8) ; tige à écorce distincte (Pl. XX, f. 10); feuilles à nerrures ramifiées (Dicotylédones). 4

\section{DICOTYLEDONES (")}

4 - Fleurs ayant une corolle et un calice .......... 5

- Fleurs à une seule cnveloppe, le plus sourent petites et verdâtres, quelquefois à organes sexuels (étamines, pistil) nus (MONOCHLAMYDÉES). . . . . . . . . . . . 55

5 - Corolle dialypétale, indépendante du calicr, insérée ainsi que les étamines au-dessous de l'ovaire (Pl. XX, f. 1), qui est supère et libre (THALAMIFLORES) . . . . . . . . . . . . . 6

- Corolle dialypétale ou gamopétale.insérée ainsi que les étamines sur le calice (Pl. XX. f. 2, 3), portant quelquefois les étamines (Pl. XX, f. 4); ovaire libre ou adhérent au tube du calice et infère (CALICIFlORES) . . . . . . . . . . . . 20

- Corolle gamopétale. portant les étamines (Pl. XX, f. 5) ; ovairc presque toujours libre, supère (COROLLIFLORES).. . . . . 41

Dialy PÉtaies

\section{THALAMIFLORES}

6 - 4-6 pétales inégaux et multifides; étamines nombreuses ; capsule; f. alternes. . . . . . . Résédacées p. 36

- Pétales entiers, échancrés ou bifides. . . . . . . . . 7

7 - Etamines nombreuses, libres . . . . . . . . . . . 8

- Etamines nombreuses, + ou - soudées par leurs filets, au moins

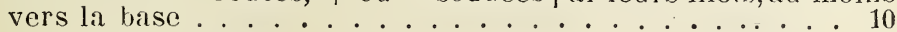

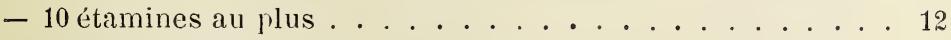

(*) Si la plante est diö̈que on pourra aller au no 89. 
8 - Baie; stigmates sessiles ; plante aquatique, à f. entières .

Nymphéacées p. 23

Fruit sec .................... . . . . . .

9 - 2 sépales caducs ; 4 pétales ; capsule ou silique

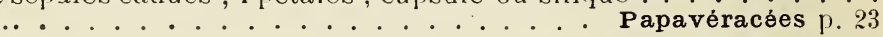

- 3 sépales au moins ; akènes ou follicules. . Renonculacées p. 17

- 3 sépales au moins; capsule à $3,5,6.10$ valves; f. simples, entières, presque toujours opposées . . . . . . Cistinées p. 36

10 - Filets des étamines réunis en un tube qui recourre l'ovaire ; 5 jétales; f. alternes. ........... Malvacées p. 47

- Filets des étamines simplement soudés vers leur base en lusieurs faisceaux. . . . . . . . . . . . 11

11 - Herbes ou arbustes à f. entières, opposées ; fl. jaunes, à 3-5 strles................. Hypéricinées p. 45

- Arbres à f. alternes, à fl. blanchâtres, en corymbe, à 1 stýle.. .

Tiliacées p 40

12 - Plante charnue, d'un blanc jaunâtre, sans f. ; parasite. .......................... Monotropacées 48

- Plante herbacée, pourvue de feuilles rertes . . . . . . . 13

- Arbrisseau . . . . . . . . . . . . . 19

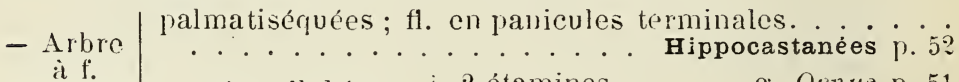

opposées, palmatilobées j2étamines.... g. Ornus p. 51 ou pennatiséquées. 8 étamines. . . . Acérinées p. 52

13 - 4 sépales, 4 pétales opposés en croix, 6 étamines tétradynames; silique ou silicule; f. alternes. . . . . C crucifères 1). 25

- Non comme ci-dessus. . . . . . . . . . . . . 1t

11 - Corolle irrégulière, sans éperon ; 3 pétales soudés à 8 étamines; capsule ; fi. en grappes; f. entières, lancéolées.

Polygalacées p. $3 \dot{8}$

- Corolle irrégulière, pourvue d'un éperon ; 4 pétales ; ; étamines en 2 faisceaux; fl. en grappes ; f. alternes, très découpées. .

Fumariacées p. 24

- Corolle irrégulière, pourvue d'un éperon ; 5 pétales, 5 étamines ; capsule à 3 valves; 11 solitaires; f. alternes. . Violacées p. 37

— Corolle régulière. . . . . . . . . . . . . 15

15 - Feuilles 3 -foliées : 5 pétales, 10 étamines, soudées ì la base ; capsule ............... Oxalidées P. 50 - F. bi-tripennatiséquées, alternes; stigmate simple . . . . . . . . . . . . . . . . . . 51

- F. paripennées, opposées; stigmateà5 rayons. Zygophyllées $\uparrow .51$

— F. ni trifoliées ni pennatiséquées . . . . . . . . . . . 16

16 - 5 carpelles distincts, prolongés en bec et disposés autour d'un axc central ; 5 pétales, 10 étamines ; f. palmatinerviées . . .

Géraniacées p. 49

— Non comme ci-dessus ; f. entières. . . . . . . . . 17

17 - F. verticillées ; plante aquatique ; 4 pétales blancs . . . .

- Non comme ci-dessus............... 18 
18 - Fruit à une seule graine; fl. très petites, blanches ou verdâtres. Paronychiacées p. 88

- Fruit |Capsule à la fin uniloculaire, à graines nombreuses, ì plusicurs graines. rarement baie ; f. opposées, rarement vertlcillées $\cdot 3 \dot{8}$ Capsule â 6-10 loges monospermes . . . Linacées p. 48

Arbuste grimpant, à vrilles opposées auxf. palmatinerviées........... . Ampélidẻes p. 5?

19 - Fruit Arbrisseau dressć, épincux, à f. simples (PI. I, f. 23), charuu. alternes ; 6 pétales, 6 étamines.. . Berbéridées p. 23 Arbrisseau dressé, non épineux, à f. opposées ; 5 pétales, 10 étamines ........ Coriariées 7.51

- Fruit sec, à 3-5 angles ; f. opposées ; $4-5$ étanines

Célastrinées p. 53

\section{CALICIFLORES}

20 - Corolle dialypétale, papilionacée ; 10 étamines ; yousse. . . . . .............. Légumineuses 1). 54

- Cololle dialypélale, non papilionacée. . . . . . . 21

- Corolie gamopétale. . . . . . . . . . . . . . 35

21 - Etamines nombreuses (plus de 12); f. alterues. . Rosacées p. 69

- Etamines nombreuses; tige charnue, sans feuilles. Cactées p.85

- 12 étamines au plus; tige feuillée. . . . . . . . . 22

22 - Arbrisscau ou arbuste grimpant, à fr. charnu (baie) . . . . 23

- - Id - dressé, non parasite........ 24

- Plante herbacéc . . . . . . . . . . . . . 29

- Plante parasite sur les arbres, f. opposćes, fruit visqueux. . . .

Loranthacées P. 98

23 - Fl. en ombelle ; f. éparses, persistantes; fruit nolr. . . . . .

Araliacées p. 97

- Fl. en grappe ou en corymbe ; f. caduques. . Ampéiidées p. 52

24 - F. très petites, imbriquées, persistantes; fl. petites, en épis. . :

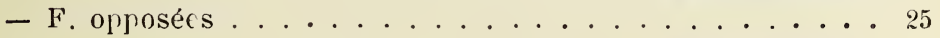

- F. alternes . . . . . . . . . . . . . . 27

25 - F. entières, caduques ; calice à 4 dents très courtes; 4 pétales, 4 étamines; drupe. . . . . . . . Cornacées p. 98

- Non comme ci-dessus. . . . . . . . . . . . . 26

26 - Baic ; ctamines oppusées aux pétales. . . . Rhamnées p. 53

- Capsule à 3.5 angles ; étamines alternaut avec les pétales. . .

Célastrinées p. 53

27 - Ovaire infère ; baie; feuilles lobées. . . Grossulariées p. 83

- Ovaire supère................... 28

| coriaces, persistantes, épineuses ; fl. blanches ; fruit

28 - Feuilles rouge............. Ilicinées p. 53 simples, non épincuses ; fleurs verdâtres; fruit noir. 
- F. imparipennées ; fl. blanchàtres ; fruit pourpre brun

29 - Ovaire infère; 2 ou 4 pétales. . . . . . . . . . . 30

- Ovaire infère; 5 pétales, 2 styles. . . . . . . . . 31

- Ovaire supère ou demi-infère. . . . . . . . . . . . 32

30 - Plante aquatique; f. verticillées, pennatiséquées, à sęments

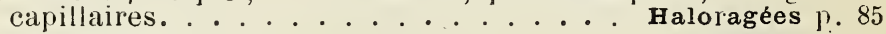

- F. la plupart ou toutes simples...... Onagrariées p. 86

31 - Capsule à plusieurs graines, terminée par 2 becs; fl. blanches, en cyme ou en corymbe. . . . . . Saxifragacées p. 83

- 2 akènes se séparant à la matırité ; 5 étamines. . . . . . . . .

Ombellifères p. 89

32 - Follicules en nombre égal à celui des pétales; f. cliarnues. . .

- Fruit simple, capsulaire. . . . . . . . . . 33

33 - 2-3 sépales; plante charnue, couchée, à f. entières. . . . . . .

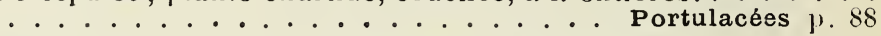

- Calice â $8-14$ dents, sur 2 rangs ; 4-7 pétales. . • . • 86

- Calice à 4-5 divisions. . . . . . . . . . . . . . 34

$34-8,10$ étamines ; capsule à 2 becs ; fl. blanches. . . . . .

- 3, 5 étamines; plantes grêles, ordint couchécs, à fleurs très petites, verdâtres........... Paronychiacées p. 88

\section{Gamopétales}

35 - Fl. (au moins les mâles) disposées en capitule sur un réceptacle commun et entourées d'un involucre à plusieurs folioles (Pl.

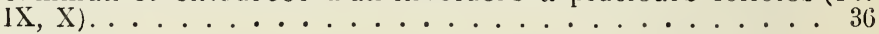

- Toutes les fleurs non en capitule involucré.. . . . . . . 38

36 - Monoïque; fl. petites, verdàtres, les mâles en capitule, les femelles, 1-2, daus un involucre ligneux (Pl. IX, f. 1, 2). . . . . . ......................... Ambrosiacées p. 128

- Toutes les fleurs en capitule; 5 étamines . . . . . . . 37

37 - Capsules à graines nombreuses; f. simples, alternes.. . . • . .

Campanulacées p. 129

- Akène. Allthères adhérentes entre clles. . Composées p. 105 Anthères libres; f. opposécs. . . Dipsacées p. 103

38 - F. verticillées; tige à 4 angles; ovairc infère; 2 akènes ou 2 baies...................... Rubiacées p. 99

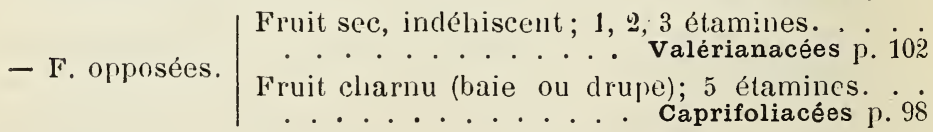

- F. alternes........................... 39

39 - Plante herbacée

Tige grimpante ou couchée; fl. uniscxuées ; fruits charnus. ....... Cucurbitacées p. 82 
- Ovaire infère, Tige non grimpante; 11 . hermaphrodites; fruit adhérent

- Oraire libre; plante ligneuse; calice et corolle à 5 divisions

Ericacées P. 130

40 - Etamines indépendantes de la corolle régulière ; 2.5 stiomates ..................... Campanulacées p. 129

- Etamines soudées en tube, indépendantes de la corolle irrégulière et bleue................ Lobéliacées p. 129

- Etamines portées par la corrlle; 1 stigmate: fl. petites, blan-

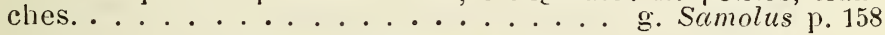

\section{COROLLIFLORES}

41 - Fl. petites, en capitule entouré d'un involucre; corolle bilabiée:

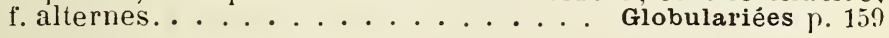

- Fl. non en capitule involucré. . . . . . . . . . 42

42 - Plante verte.

- Plante 4 étamines didynames; corolle irréqulière; tiọe non verte, dresséc ou nulle..... Orobanchées p. 146 sans f., 5 -4 élamines; corolle régulière ; tige volubile... parasite. .............................. 133

43 - 5 étamines à filets soudés en tube et portant une couronne colorée; corolle régulière; f. opposées. . Asclépiadées 1 . 132

- Etamines peu ou point soudées, ne portant pas de couronne. 44

44 - 2 étamines; plantes herbacées; fruit sec. . . . . . . 45

- 2 étamines; arbres ou arbrisseaux. . . . . . . . . . . . 46

- Plus de 2 étamines..................... 47

45 - Tige à 4 angles; 4 akènes; f. opposées ; corolle à 2 lèvres. . . g. Salvia p. 152

- Capsule; corolle presque régulière, à 4-5 divísions. . . • j.

46 - Corolle $\mid$ Calice et corolle à $5-8$ divisions. . Jasminées p. 131 régulière Calice et corolle à 4 divisions; f. opposées.

- Corolle bilabiée; 4 akènes; f. opposées. g. Rosmarinus p. 153

47 - 8, 10 étamines; f. charnues, orbiculaires, concaves.

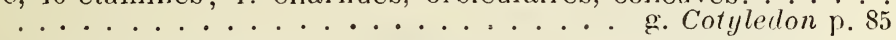

- 5 étamines (rarement 4 ), opposées aux lobes de la corolle, qui est régulière; 1 style; capsule. . . . Primulacées p. 158

- 4, 5 étamines (rarement plus), alterues arec les lobes de la corolle.................. 48

48 - Corolle régulière. . . . . . . . . . . . . . 49

- Corolle irrégulière................ 53

Fl. très petites, non colorées, en épj dense ; cap-

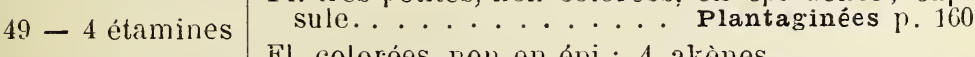

Fl. colorées, non en épi ; 4 akènes. . . . is

- 5 étamines, ou 4 (rarement $6,7,8$ ) mais alors f. glabres, oppo-

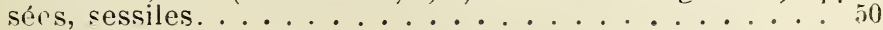


50 - 4 akènes; f. alternes, rudes ; 11. en cymes scorpioïdes.

Borraginèes p. $13 \dot{4}$

- 1-2 follicules; f. entières. opposées, persistantes ; fl. bleues, soli-

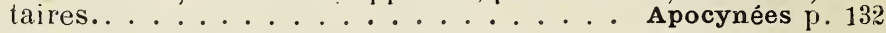

- Capsule ou baie. ................. 51

51 - Corolle en cloche, à limbe entier; f. alternes ; 5 étamines capsule.................................. 132

- Corolle à lobes apparents.. . . . . . . . . . . . . 52

52 - Capsule à 1 loge ou à 2 loges incomplètes ; f. opposées.

Gentianées p. 132

- Fruit à 2 loges complètes; f. alterues; 5 étamines égales. . . .

Solanées p. 138

- Fruit formé de 2 capsules monospermes; f. orbiculaires-réniformes : tiges radicantes. . . . . g. Dichondra p. 226

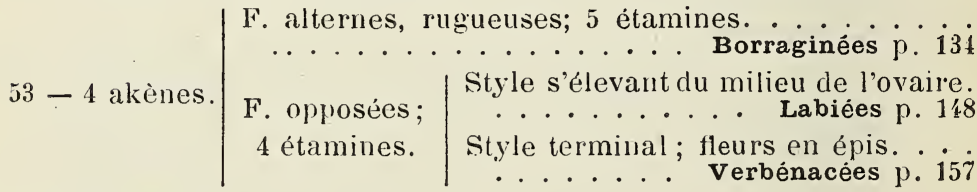

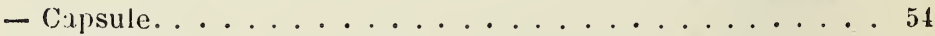

51 - 2 étamines; plante aquatique, à f. divisées en lanières capillai-

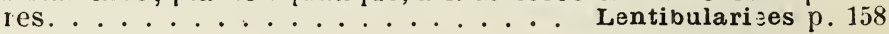

- 4 étamines didynames. . . . . . . Scrofulariacées p. 141

- 5 étamines, dont 2 plus longues; f. alternes; corolle presque régulière, ord. jaune. ........ Verbascacées p. 139

\section{MONOCHLAMYDEES}

55 - Carpelles nombreux, libres ; piusieurs akènes ou follicules ; périgone coloré, à $4-10$ divisions libres. Renonculacées p. 17

- 10-12 carpelles soudés, 10 étamines ; fruit charnu, noir ; f. alter-

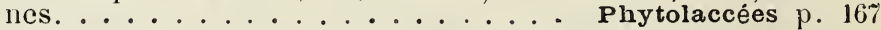

- 6 stigmates en étoile sur l'ovaire; périgone tubuleux, irrégulier; f. alternes, larges; capsule.. . . Aristolochiées p. 168

- Non comme ci-dessus. . . . . . . . . . . . . 56

56 - Arbre ou $\mid$ Fl. en chatons (au moins les mâles) (Pl. XX, f. 6, 7).

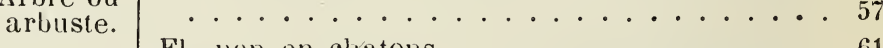

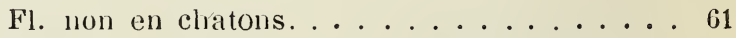

- Plante herbacée.................... 61

57 - Chatons globuleux; f. alternes, palmatilobées. . . . . . .

- Non comme ci-dessus. ................. 58

58 - Plante dioïque ; f. simples; capsule; graines poilues. . . . . .

Salicinées p. 175

- Plante monö̈que (Pl. XX, f. 6)............. 59

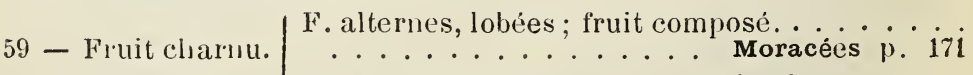
Arbre. $\quad$ F. opposées et pennées; fruit simple.... .

- Fruit sec ; f. alternes.............. 60 
60 - Eruit + ou - envelopré par un involucre foliacé ou ligneux ; fl. màles seules cn chatons ....... Cupulifères p. $17 \%$

- Fruit non involucré; f1. mâles et fl. femelles en chatons nais-

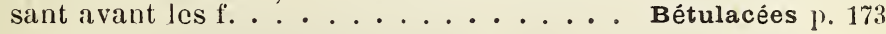

61 - Fruit charnu; plante non parasite............ 62

- Fruit charnu; plante parasite sur les arbres; baies glutincu. ses ; f. opposées, entières. . . . . . Loranthacées p. 98

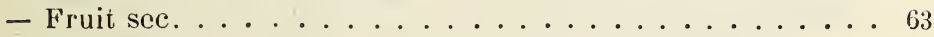

62 - F. palmatilobées; fl. très petites, renfermées dans un réceptacle charnu (figue).......................... Ficás 1\%. 171

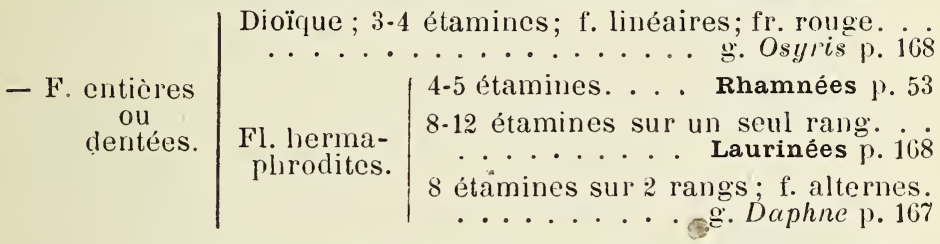

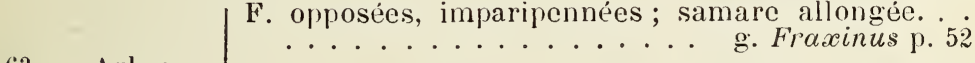

63 - Arbre

f. cadurques.

F. alternes,

2 fois pennées; gousse.

...... g. Gleditschic p. $5 \dot{5}$

dentées; samare suborbiculaire. . .

Ulmacées p. 172

- Arbuste à f. persistantes, opposées; capsule à 3 loges. . . .

64 - F. verticillées, au moins les inféricures. . . . . . . 65

- F. opposées ou alternes. . . . . . . . . . . . 6 . . 6

| Ovaire infère; 2 akènes.. . Rubiacées 1). 99

65 - Planteterrestre Ovaire supère; capsule à 3 valves. . . . .

- Plante aquatique, submergée ; f. linéaires ou à divisions capil-

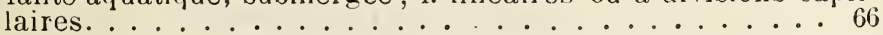

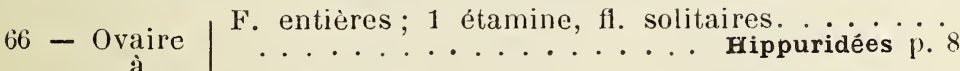

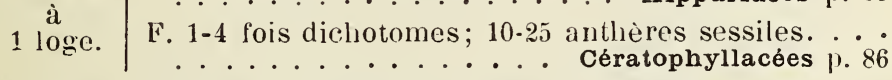

- Ovaire à 4 loges; f. pennatiséquées ; 8 étamines. . .

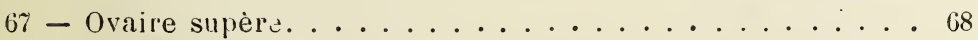

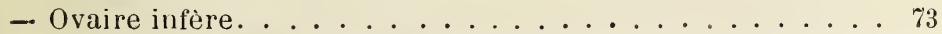

68 - Fruit à 4 coques monospermes; plante aquatique, à f. opposées, i fl. solitaires; 1-2 étamines. . . . . Callitrichacées p. 85

- Fruit à 2-3 coques monospermes; plante terrestre.

Euphorbiacées j. 168

- Capsule globuleuse, à plusieurs graines; 6 étamines; piante des lieux humides....................................... 86

- Fruit à 1 seule graine. . . . . . . . . . . . 69 
69 - F. mnnies | d'une gaine membrancuse; 3 -5 étamines; f. alter-

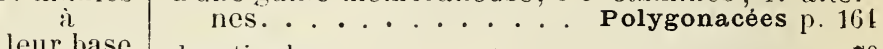
leur base de stipules................... 70

- Feuilles dépourvues de stipules et de qaîne. . . . . . . 71

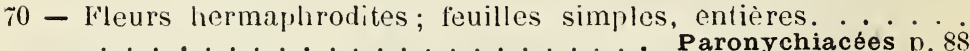

- Fl. unisexuées 4 sépales; feuilles ovales. . Urticacées p. 171 ou polygames 5 sépales; f. opposées, palmatinerviées.

71 - F. linéaires, opposées, soudées à leur base (cornèes). . . . . . ................................ Scleranthus p. 88

- F. ordiut alternes, non connées ; fl. petites. . . . . . 72

2 - 8 étamines sur 2 rangs ; f. linéaires. . . . . . . Lygia p. 167

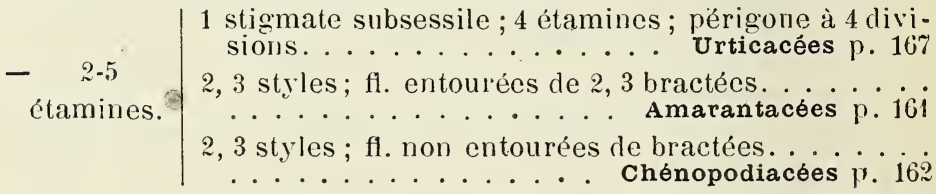

73 - Fl. (au moins les mâles) disposées en capitule sur un réceptacle commun et entourées d'un involucre à plusieurs folioles. . 36

- Fleurs non en capitule jnvolucré. . . . . . . . . . . $7_{t}$

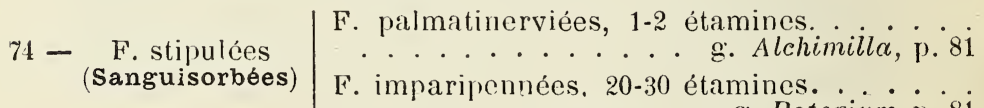

- F. non stipulées, à pétiole parfois engaînant. . . . . . 75

75 - Fruit sec, indéhiscent, à 1 graine; f. linéaires. g. Thesium p. 168

- 2 akèues accolés. .......... Ombellifères p. 89

\section{MONOCOTYLEDONES}

76 - Enveloppe florale (périgone) colorée. . . . . . . . . 77

- Enveloppe florale herbacée ou scaricuse. . . . . . . . 81

77 - Ovaire supère. ................. . 78

- Ovaire Fl. régulières; 3 étamines au moins. . . . . . 80 infère. $\mathrm{Fl}$. irrégulières, en épis; 1 étamine fertile. . . . .

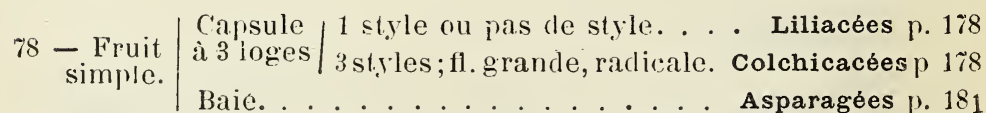

- 6-12 carpelles libres ou soudés à la base seulement; plante aquatique. . . . . . . . . . . . . . . 79

$79-6,12$ étamines ou plus: les 3 divisions externes du périgone vertes et plus petites que les 3 internes. . Alismacées p. 17\%

- 9 étamines; rérigone à 6 divisious colorées; 6 capsules à plusicurs gritiles. . . . . . . . . Butomacées p. $17 \%$ 

diö̈que. Terrestre, à tige volubile ; 6 étamines; baic rouge.

Dioscorées P. 182

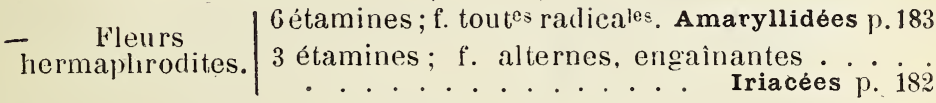

81 - Plante non fixée, flottante, à tige forméc d'articles simulant ıles lentilles (frondes). . . . . . . Lemnacées p. 191

- Plante fixée, $\mid \begin{array}{ll}\text { à f. sagittées, à fl. entourées d'une grande } \\ \text { bractée. . . . . . . . . . Arö́dées p. } 192 \\ \text { à f. non sagittécs. . . . . . . . . . . . } 82\end{array}$

82 - Périgone à 6 divisions sur 2 rangs ; ordinairement 6 étamines ; f. linéaires............. Joncacées p. 192

- Enveloppe florale réduite à 1, 2 écailles ou ayant 4 divisions. 83

83 - Plantes submergées ou à f. supres seules flottantes; 1 ou plusieurs akènes. . . . . . . . . . . . . 84

- Plante terrestre ou des lieux humides, mais à tige émergée. 85

84 - Fl. hermaphrodites, en épi ; périgone à 4 divisions, 4 étamines. ................... Potamogétonées p. 190

- Fl. unisexuées, axillaires ; 1 étamine ; f. opposées ou ternées. .

Naïacées p. 191

85 - Fl. unisexuées, disposées en 2 épis cylindriques très compacts ou en têtes globuleuses. . . . . . . Typhacées $p .192$

- Fl. en épis, munies chacune, à la base, de 1-2 écailles. . . 86

86 - Tíge peu ou point noueuse; gaine des f. non fendue.

Cypéracées p. 19 i

- Tige noueuse; gaine des f. fendue sur toute sa longueur. • j.

Graminées p. 199

\section{CRYPTOGAMES}

87 - Tiges sans f. distiuctes, simples ou à rameaux verticillés ; fructifications en épis terminaux.... Equisétacées p. 220

- Plante feuillée, sans rameaux verticillés. . . . . . . 88

88 - Plante flottante; fructifications globuleuses, naissant en dessous des tiges et des rameaux........ Rhizocarpées p. 221

- Plante non flottante; fructifications naissant sur les feuilles ou disposécs en épi distique......... Fougéres p. 218 


\section{Dicotylédones DioÏQues}

89 - Apros ou arbrisscaux. . . . . . . . . . . . 90

- Plantes herbacées. . . . . . . . . . . . . . 92

90 - Parasite sur les arbres.......... Loranthacées p. 91

- Non Enveloppe florale à 4, 5 divisions. . . . . . . 91 parasite. Enveloppe florale réduite à 1 écaille : des chatons. .

91 - Feuilles pennées. . . . . . . . . . . Rhus p. 53

- Feuilles | orales........... g. Rhamnus 1. 53 simples, l linéaires. ............ g. Osyris p. 168

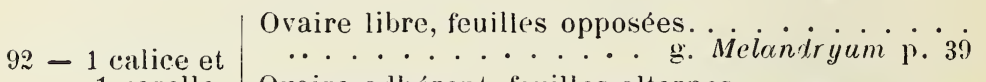
1 corolle Ovaire adhérent, feuilles alternes.........

- 1 seule enveloppe fiorale, herbacée. . . . . . . . 993

93 - Feuilles |à rétiole dépourvu de gaîne. . . g. Spinacia P. 163 alternes, à pétiole munie d'une gaine... g. Rumex p. 164

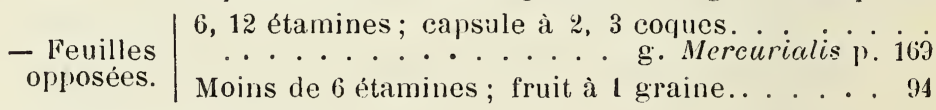

$94-4$ étamines, 4 sépales. . . . . . . . . g. Urtic $\alpha$ p. 171

-5 étamines, 5 sépales; f. palmatinerviées. Cannabinées p. 172 


\section{ABRÉVIATIONS \& SIGNES CONVENTIONNELS}

$\mathrm{CC}$, très commun ; C, commun ; $\mathrm{AC}$, assez commun ; $\mathrm{AR}$, assez rare; $\mathrm{R}$, rare; $\mathrm{RR}$, très rare.

(1), annuel ; (2), bisannuel ; $\mathscr{\Psi}$, vivace ; $\mathfrak{b}$, ligneux.

$f$. , feuille : $f$., fleur ; fr., fruit ; caul., caulinaire.

Env., environ; diam., diamètre sup ${ }^{\mathrm{r}}$, supérieur ; infr, inférieur; ord', ordinairement.

var. ou v. varietas, variété ; $X$ signe d'hybridité $;+$, plus ; -, moins.

fév., ms, av., jn, jlt, at, spt., oct.: férrier, mars, avril, juin, juillet, aout, septembre, octobre.

Cult., cultivé ; Subsp., subspontané ; T., Toulouse.

$M m$., millimètre ; $c m$., centimètre ; dm., décimètre. 


\section{EXPLICATION IDE LA PLANCHE XX}

FIG. 1. - Coupe d'une fleur de Ficaire, plante dialypétale et thalamiflore: $s$, sépales; $p$, pétales; $e$, étamines insérées au-clessous des carpelles $c$, sur un thalamus, $t$. Le pistil est libre et supère.

Fıg. 2. - Coupe d'une fleur de Benoite (grossie 2 fois), plante dialypétale et caliciflore, à pétales $p$ et étamines $e$ insérés sur le calice $c$. Le pistil est libre et supère.

Fig. 3. - Coupe d'une fleur de Prunellier (grossie 2 fois), autre type de plante dialypétale et caliciflore.

Fig. 4. - Coupe d'une fleur de Garance (grossie 4 fois), plante gamopétale et caliciflore. Corolle portant les étamines et insérée au sommet du calice, yui adhère à l'ovaire infère $o$.

Fig. 5. - Coupe d'une fleur de Primevère, plante gamopétale et corolliflore. La corolle porte les étamines et est indépendante du calice $c$; l'ovaire o est libre; il est surmonté d'un style s terminé par un stigmate $t$.

FIG 6. - Rameau de Noisetier, plante monoïque, montrant des chatons femelles $f$ et un chaton de fleurs mâles $m$. En $d$ une fleur mâle grossie.

Fıg. 7. - Fleurs de Saule, plante diö̈que. - A, chaton mâle; $m$, une fleur mâle isolée et grossie ; $B$, chaton femelle; $f$, une fleur lemelle isolée et grossie.

Fíg. 8. - Graine de Pois, nue et ouverte, montrant les 2 cotylédons $c$, la radicule $r$, la tigelle $t$, la gemmule $g$.

Fig. 9 - Fruit (caryopse) d'Aooine, montrant l'albumen a soudé au péricarpe $p$, et l'embryon $(r, t, g)$ à un seul cotylédon $c$.

FIG. 10. - Fragment de tige de dicotylédone âgée le 10 ans.

FIg. 11 - Fragment de tige de monocotylédone (Roseuu).

FIg. 12. - Quelques types de feuilles: $\alpha$, entière; $b$, sinuée; c, dentée; $d$, lobée; $e$, peunatifide; $f$, permatipartite; $g$, pematisérquée ; $h$, imparipennée ; $i$, palmatinervièe. 
PI. XX.

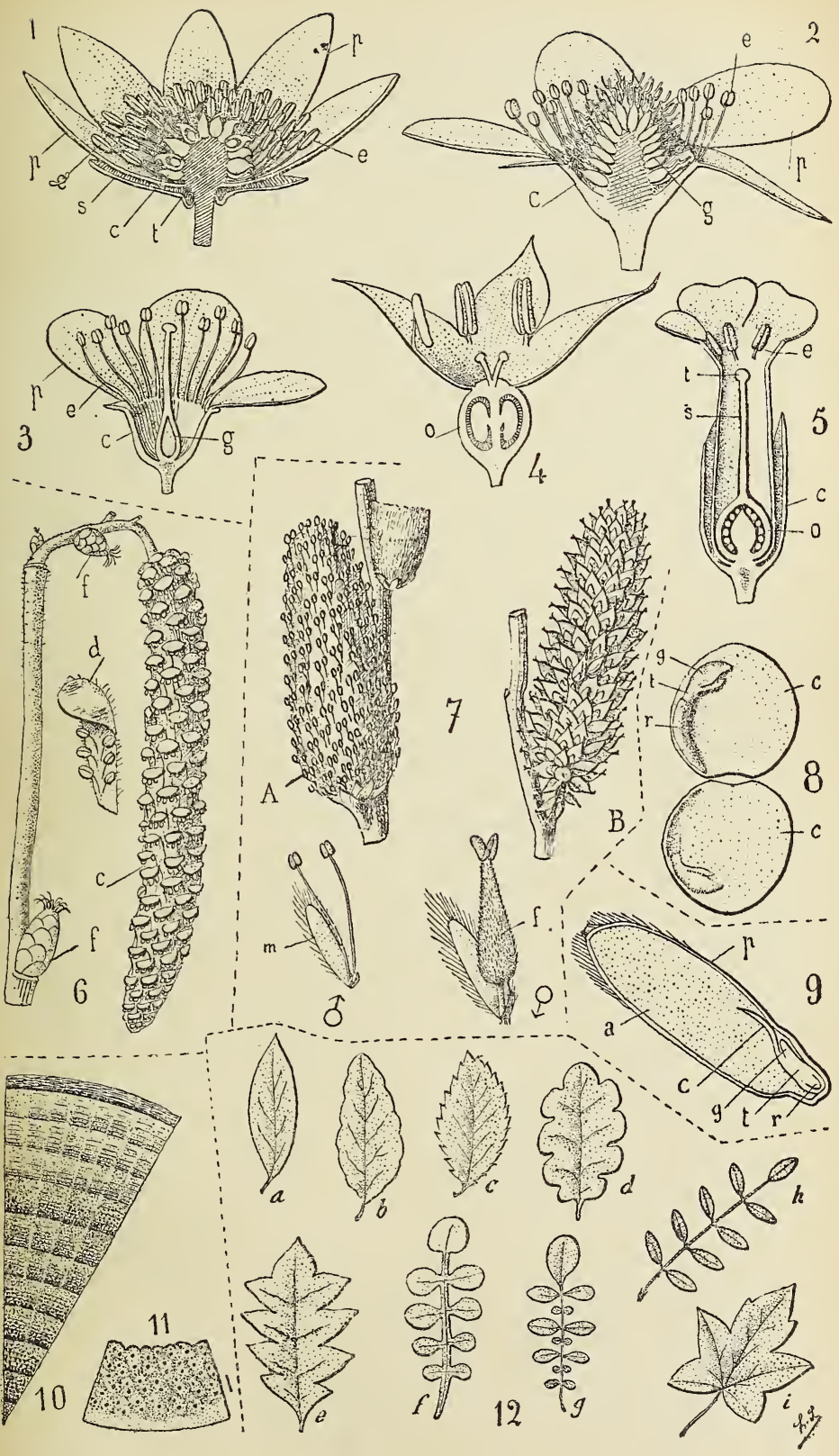




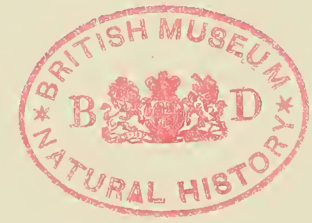




\section{FLORULLE TOULOUSAINE}

......

\section{Embranchement I - PHANÉROGAMES}

\section{Sous-embranchement I - Angiospermes}

\section{Classe I - DICOTYLÉDONES}

Sous-classe I - Thalamiflores.

\section{1 - MENONGULACINE Juss. - Pl. I.}

1 - F. opposées; tige sarmenteuse, grimpante; 4-j sépales ; péta.

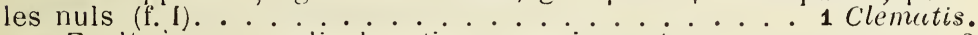

- F. alternes ou radicales; tige non grimpante. . . . . 2

2 - Fl. irrégulières. ordint bleues, en grappes, munies d'un éperon (f. 22 ); 1-5 follicules; f. à divisions linéaires. . . . 12 Delphinium.

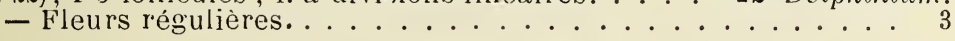

3 - Fruit formé de plusieurs akènes (f. 14). . . . . . . . . 4

- Fruit formé de un oc de plusieurs follicules (f. 18) . . . . . 9

4 - Calice et corolle distincts.............. 5

- Une seule envelopje florale, colorée, pétalö̈de...... 8

5 - F. toutes radicales, à 3 lobes; 3 bractées simulant un calice ; 6-9 sépales (f. 7). . . . . . . . . . . 4 Hépatica.

- Tige feuillée. . . . . . . . . . . . . . 6

6 - Pétales ordinairement rouges, à onglet dépourvu de fossette nectarifère; f. finement découpées (f. 9). . . . . . . . 5 Adonis. - Pétales blancs ou jaunes, à onglet pourvu d'une fossette necta-

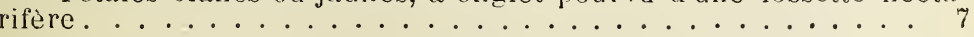

7 - 3 sépales; 6-12 pétales jaunes; plante glabre, à f. cordiformes (f. 16). . . . . . . . . . . . . F Fiearia.

- 5 sépales; pétales, ordinairament 6 , blanes ou jaunes (f. 15) . 
8 - Sépales petits, caducs, plus courts que les étamines; fl. sans involucre (f 4), en panicule; tige feuillée. . . . . . 2 Thalictrum. - Sépales dépassant longuement les étamines; tige ne portant

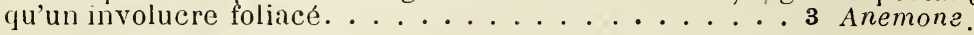

9 - Une seule enveloppe florale, jaune l'or ; f. réniformes (f. 17). .

2 envelopes . . 8 Caltha.

10 - Fleur à 5 épcrons, à 5 sépales colorés (f. 21); 5 follicules libres ou peu soudés à la base.. . . . . . . . . 11 Aquilegia.

- Fl. sans éperon, bleuâtre, à pét. courts ; follicules plus ou moins soudés (f. 20); f. bipennatiséquées, à segments linéraires. 10 Nigella.

- Fl. sans éperon, verdâtre, à 5-20 pétales petits, tubuleux (f 19); f. palmatinerviées. ...................... Helleborus.

\section{1. - ClEMATIS L. - Clématite - Pl. 1.}

Tige grimpante ; f. opposées, pennatiséquées, à 3-7 folioles ; fl. blanches ; styles plumeux (f. 1, 2.) - \ Haies, Zuissons. . . •. . . . . . . . . . C. des haies. C. Witaba L.

Ses jeunes pousses sont mangées en guise d'asperges; ses f. sont vésicantes et irritantes.

\section{2 - THALICTRUM L. -- Pigamon - Pl. I.}

- Carpelles presque sessiles (f. 3); robuste; f.-3 ternatiséquées, glabres; panicule grande ; étamines pendantes, à filets filiformes (f. 4). - भ. Mai-jn. . . . . P. élevé. T. majus Jq.

2-4 carpelles petits, dressés. - RR. Haies et osercies des bords de l'Ariège, $\dot{a}$ Goyrans et $\dot{x}$. Lucroix-Falgarde (Timbal)

- Carpelles pédicellés, pendants, à 3 angles ; filets élargis ausommet. - 4 Mai-jlt. R. Palaminy, bords de la Garonne (Duteyeul). - . P. à l. d'ancolie. 'T. aquilegifolimm L.

\section{3 - ANEMONE L. - Anémone - Pl. I.}

1 - Involucre formé de f. pétiolées semblables aux f. radicales (f. 5).

- Involucre formé de $f$. sessiles et différentes des f. radicales (f. 6$)$.

2 - Fleurs jaunes (f. 气̋). - ₹ Av-mai. AC. Bois, prés humides. St-Martin-du-T., Bouconne, etc. .

- . - A. fausse renoncule. A tom un culoides $\mathrm{L}$.

- Fl. blanches, roses ou lilas - 4 Ms-av. C. Prés, bois, lieux couverts. . . . . A. des bois. A memoroga L.

3 - Involucre à folioles profondément divisées. - q Fév.-av. . ......... A. couronnée. A. conodnania L.

Fleurs blcues - Cultures. Toulouse (Rouy et Foucaud).

.................................. Risiso 
Fleurs d'un rose violacé (f. 6). - Cultures. Pouvouroille.

A. rosea Hanry

- Involucre à folioles peu ou point divisées. — \%. Ms-av. Natur. A. des jardins. A. homonsis L.

9-13 sépales grands et aigus. - Vignes, à St-Simon (Noulet).

A. pavonina Lamk.

\section{4 - HEPATICA Miller - Hépatique - Pl. I}

Fl. solitaires, ord.t violettes (f. 7,8 ). - $\%$. Ms-av. R. Venerque, vallon de Soulbet (Noulet). . H. à 3 lobes. F. Holloba Chaix.

\section{$\ddot{\partial}$ - ADONIS L. - Adonis - Pl. I.}

- Sépales glabres, non appliqués contre les pétales concaves et obovales (f. 9) ; carpelles à bord supérieur sans dent (f. 9 bis). - (I) Mai-spt. G. Moissons. - (Goutte de sang).

- Sépales velus, appliqués contre les pétales plans et oblongs ; carpelles à bord supérieur portant une dent. - (1). Jn-at. R. Moissons. Coteaux de la Garonne. . A. d'été. A .

\section{6 - RANUNCUlUS I. - Renoncule - Pl. I.}

1 - Pétales blanes; carpelles ridés en travers (f. 10 ; plantes aquatiques (g. Batrachium Auct.). . . . . . . . . . 2

- Pétales jaunes ; carpelles non ridés ou ridés seulement au centre des faces.

2 - Feuilles toutes réniformes et à ô lobes (f. 11); pétales à onglet blanc, égalant le calice.- - J Jn-at. R. Mares, fossés, terrains siliceux. Lalande, Pinsaguel (Noulet).

R. à f. de lierre. re nedoncous L.

- F. toutes ou au moins les inférieures à divisions capillaires ; pétales à onglet jaune. . . . . . . . . . . . 3

3 - F. toutes submergées et à divisions linéaires et parallèles; tige de plusieurs mètres de long; pétales grands, dépassant les sépales; réceptacle glabre. - \& Mai-jlt. - R. Rivieres... . . .

- . . . . . R. flottante. Re.

- F. à divisions molles et divergentes; récep tacle poilu. . . 4

4 - Réceptacle hémisphérique; f. ord.t de 2 sortes, les sup. flottantes, à 3-ö lobes; pétales grands, larges, bien plus longs que les sépales. - \%. Av.-jlt. C. Rivières, canaux, mares.

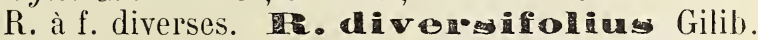

F. toutes submergées, à divisions divariquées. .v. submersus G. G.

Plante formant des gazons dans les lieux asséchés.

. . . . . . . . . . . . . . . . suceulentus Koch. 
- Réceptacle ovale; f. ord. ${ }^{t}$ toutes à divisions filiformes, les supérieures subsessiles; pétales étroits, bien plus longs que les sépales; 12-10 étamines. - q Av.-jn. C. Mares, fossés, ruisseaux.. . - . . . R. à f. capillaires. tre comophyllas Chaix.

Pétales très caducs, dépassant peu le calice ; 5-10 étamines. Plus R. . . . . . . . . . R. de Drouet. R. Drouetii F. Schultz.

$\ddot{\jmath}$ - Feuilles entières ou seulement dentées. . . . . . 6

- Feuilles lobées ou découpées. . . . . . . . . 7

6 - Vivace; f. inférieures ovales ou oblongues; pédoncules non sillonnés, carpelles lisses. - $\%$ Mai-spt. C. Lieux humides, maies, fosses. . . . . R. flammette. P . I lammula L.

- Annuelle ; f. inférieures ovales, en cour ; fleurs plus petites, à sépales glabres ; carpelles à faces tuberculeuses. - (1). Ma $i$-jtt. R. Fossés aquatiques. Croix-Daurade, Léguevin, La Ramette (Noulet). .

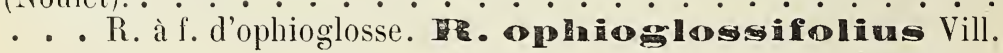

7 - Carpelles très nombreux (plus de 100), disposés en tête oblongue (f. 12).. . . . . . . . . . . . 8

- Carpelles moins nombreux (30 au plus), en tête globuleuse (f. 14).

8 - Glabrescente; f. radicales à $3-\breve{b}$ lobes, les autres profond divisées; fl. petites, d'un jaune pâle ; akènes très petits (f. 12). (1) Mai-sept. AC. Mares, fossés, Toulouse, Poitet.

- . . . . . R. scélérate. Re selenatan L.

- Velue ; souche à fibres radicales renflées; tige 1-3 flore, peu feuillée; pétales grands. - भ. Av.-mai. C. Coteaux, pelouses sèches, terres graveleuses (R. chcrophyllus Auct.)..

....... R. en éventail. Re. flabellatus Desf.

Poils mous, étalés; souvent uniflore. . . . . . . v. mollis Freyn.

Poils de la base apprimés; segments des f. étroits et aigus.

9 - Sépales étalés ou dressés. . . . . . . . . 10

- Sépales réfléchis sur le pédoncule (f. 1\%). . . . . • 14

10 - Akènes (3-8) très grands et épineux (f. 13) ; pétales petits, d'un jaune pâle, dépassant peu le calice. - (1) Mai-jlt. CG. Moissons, cultures. . . . R. des champs. Re anonsis L.

- Akènes plus nombreux, petits, non épineux ; fl. d'un jaune vif................... . . 11

11 - Réceptacle velu. . . . . . . . . 12

- Réceptacle glabre. . . . . . . . . . . 13

12 -- Plante rampante, à stolons radicants ; f. radicales à segment 
terminal longuement pétiolulé ; akènes à bec égalant le 1/3 de leur hauteur. - \%. Av.-oct. C. Lieux humides, prés, fossés, bois. . . R. rampante. Fe. Hepens $\mathrm{L}$.

- Plante peu ou point rampante, sans stolons radicants; f. radicales à 3-ö lobes profonds, incisés; akènes à bec crochu et enroulé, égalant la 1/2 de leur hatuteur. - $\%$. Mai-jlt. Bois couverts. •

R. des bois. He. nomoros id.

F. très relues, à lobes espacés, obovés, trifides. - C. Lauragais, coteaux de la Garonne.

R. Amansii Jord.

13 - Akènes pubescents, à faces convexes; plante glabrescente, de 1-3 dm.; pétales parfois avortés ou déformés. - \%. Av.-mai. AC. Lieux fiais et couverts. - Boids du Touch, La Ramette, Balma, Lanta, etc. . . . . R. tète d'or. He. annoicomns L.

- Akènes glabres, comprimés, bordés, à bec court (f. 14); plante velue. de 3-8 dm., à f. inférieures pentagonales dans leur contour. - 4. Mai-jlt. G. Bois, prés, fossès, boids des chemins.

R. âcre. re acer L.

a. Rhizome court ou nul, on f. à lobes bien plus long's que larges.

Lobes des f.larges; carpelles à bac long. - R.

R. dressée. R. rectus Bor

Lobes des f. très étroits; carp, à bec très court. - R.........

. . . . . . . . R. de Boreau. R. Boræanus Jord.

b. Rhizome allongé; f. à lobes presque aussi larges que lougs.

- Lobes des f. ne se recouvrant pas par leurs bords. - AC.

...................... de Stéven. R. Steveni Andrz.

- Lobes des f. se recouvrant par leurs bords; villosité molle.

Bec des carpelles long et crochu. - C.

. . . . . . . . R. vulgaile. R. vulgatus Jord.

Bec des carpelles très court et peu courbè. - AC

Ob3. - Jurlan (Dixjn. p. 7t a don's le n) n de R. nemorivagus à la plante qu'il avait appelée $R$. Friesınus lans ses Observ. (f. 6 , p. 17), ayant reconnu ijue catte espèce n’était point celle de Fries. C'est donc i tort que MI. Kouy et Foucaud distinguent les 2 formes $R$. Fries xnus et $R$. nemorivagus.

14 - Souche renflée en bulbe à sa base : f. inf. ternées, à folioles tripartites. - \%. Av.-jn. CC. Prés, champs, pelouses.

........... R. bulbeuse Re. bulbosus L.

F. d'un vert clair ; carp. a bec très court. . . . r. rulbifer (Jord.)

Pubescence demi-appliquée; f. d'un vert foncé; carp. à bec plus

long. . . ................ sparsipilus (Jord.).

Villosité abondante, f. tachées de blanc; carp. crands. . . . .

Villosité abondante; f. peu ou point tac lées; carp. petits. . . .

-- Souche non renflée en bulbe à sa base. . . . . . . . 10̆

10 - Réceptacle velu; pédoncules sillonnés; pétales 2 fois plus longs qua les sépales (f. 1Ö). - (1). Mai-sept. AC. Champs humides, bords des eaux (R. Philonotis Ehrh.). . . . . . . R. de Sardaigne. re sarous Grantz. 
- Réceptacle glabre ; pédoncules lisses ; pétales pâles, égalant à peu près le calice. - (1). Ms-jlt. C. Lieu.x frais, fossés, murs,

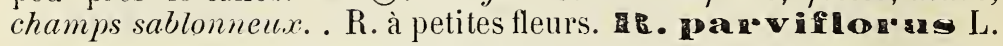

Obs. - Les Renoncules sont àcres et irritantes. La R. scélérate est, à l'état frais, dangereuse pour les animaux.

\section{7 - FICARIA Dillen. - Ficaire - PI. I.}

Souche à fibres renflées en massue ; fl. de 2-3 cm. de diam. (f. 16). - \%. Ms-mai. CG. Champs, haies, bois (F. ranunculoides Roth). . . . . . . F. printanière. vona Huds.

F. grandes, coriaces, presque entières, à lobes de la base rapprochés; fl. plus graudes. - AC. Champs argilo-calcaires. Pouvourville.

$$
8 \text { - CALTHA L. - Populage. - Pl. I. (f. 17). }
$$

Glabre; f. cordilormes, arrondies. - 4. Ms-mai. R. bords des eaux. Le Vernet, Braqueville (Noulet), - (Souci d'eau). . . . . ......... P. des marais. C. Prolustio L L

\section{9 - HELLEBORUS L. - Hellébore. - Pl. I.}

- Tige feuillée; f. pédalées, à 7-11 folioles; bractées sup. entières; sépales dressés. - భ.Fév.-Mai. C. Bois clairs, coteaux,

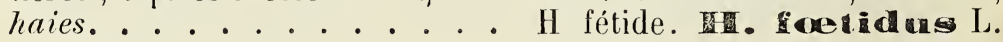

- Tige nue jusqu'aux rameaux ; bractées palmatipartites ; sépales

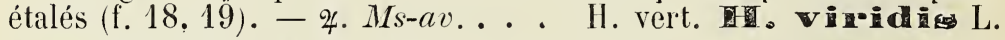

Segments des f. lancéolés, irrégt dentés; pubescenco nulle. C. Lieus frais. . . . . . . . . . . . . . . v. occidentalis. Reut.

On cultive l'H. niger L. (Rose de Noël), à sépales rosés. Les Hellébores sont âcres et irritants ; leur poudre est purgative et vomitive.

$$
10 \text { - NIGELLA L. - Nigelle. - PI. I. }
$$

- Fl. munies d'un involucre semblable aux f. ; capsule globu. leuse (f. 20). - (1). Jn-Jlt. R. Champs cultivés, St-Geniès. - Souvent cultive. . . . . . N. de Damas. N. Samascona L-

- Fl. sans involucre ; capsule rétrécie à la base. - (1) Jlt-spt. . . . . . . . . N. d'Espagne. N. His panica L.

Fl. de $2-31 / 2 \mathrm{~cm}$. de diam., fruit peu ou pas glanduleux - C. Champs cultives. . . . . . . . . N. de France. N. gallica Jord.

$$
11 \text { - AQUILEgIA L. - Ancolie - Pl. 1. (f. 21). }
$$

F. inférieures bi-ternées ; éperon recourbé en hameçon; étamines dépassant les pétales. - \%. Jn-Jlt. AR. Bois couverts. . . . . . . 
Pédoncules non glanduleux. . . . . . . . . A. vulgaris L.

Pédoncules glanduleux; fl. d'un violet foncé. - Bouconne...... A. des collines. A. collina Jord.

\section{2 - DELPHINIUM L. - Dauphinelle - Pl. 1.}

- 1 follicule glabre; bractées simples (f. 22). - (1) Jn-spt. AR. Cultures, vallée de la Garonne (Pied d'alouette).

D. consoude. D. Comsolida L.

- 1 follicule pubescent; bractées inférieures multiséquées. - (1). Jn-spt. G. Cultures. . . . . . D. d'Ajax D. A a d.

- 3 follicules glabres. - (1). Jn-sept. . . . . . . . . . •.

Pétales latéraux à limbe orbiculaire-cordé, bien plus court que l'onglet. - AR. Cultures, moissons. Coteaux de la Garonne.. . . .

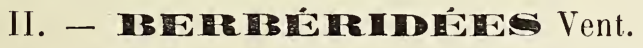

\section{BERBERIS L. - Vinettier - PI. I.}

Fl. jaunes, en grappes pendantes ; baie rouge (f. 23, 23 bis). 4. Av-jn. R. Haies, Pouvourville. (Epine-vinette).

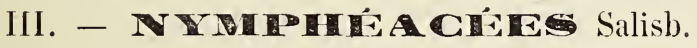

NUPHAR Silth. et Sm. - Nuphar. - Pl. 1.

F. flottantes, ovales, cordées ; ّ̋ sépales, fl. jaunes, (f. 24). - \%. Jn-at. AC. Petites rivières, Le Touch, Pibrac, La Ramette, etc. . . . . N. jaune. N. Iuteum Sibth. et Sm.

Le Nymphæa alba L., à 4 sépales et à fl. blanches, est introduit dans quelques bassins.

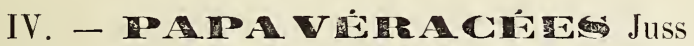

- Fleurs non jaunes; fruit oblong ou globuleux. . . 1 Papaver. - Fl. jaunes $\mid \mathrm{Fl}$ de $1 \mathrm{~cm}$. env ; caps. à I loge. . . 2 Chelidonium. fr. linéaire $\mathrm{Fl}$. de $5 \mathrm{~cm}$ ou plus; caps.à 2 loges... . 3 Glaucium.

\section{1 - PAPAVER Tournef. - Pavot. - Pl. 1.}

1 - Capsules hérissées de poils; f. 2-3 pennatipartites.. . . 2

- Capsules glabres; feuilles pennatipartites.. . . . . . 3

2 - Capsule ovale ou subglobuleuse (f. 25). - (1). Mai-jlt. AC. Champs cultivés. . . P. hispide. Ho. In pidom Link. 
- Capsule allongée en massue (f. 26). - (1) Mai-at. C. Champs cultivés. . . . . . P. argémone. P. nomgemomo L.

3 - Capsule oblongue ou en massue, atténuée à la base (f. 27). (1) Av.-at.. C. Champs cultivés. . P. douteux. P.dulbium I.

Capsule atténuée du sommet à la base. . . . . . . . . . . . .

C............ P. de Lamotte. P. Lamottei Bor.

Caps. retrecie depuis son milieu. . . B

Capsule brusq ${ }^{\mathrm{t}}$ retrécic vers la base. P. modeste, P. modestum Jord.

Stigmates atteignant ou dépassant les bords du disque. . . . . . .

...... P. Lecoqii Lamotte.

- Capsule courte, subglobuleuse, arrondie à la base (f. 28). - (1). Mai-jlt. CC. Moissons, cultures; très polymorphe. . . . . . . . . . . . . . . P. coquélicot. He Heass L.

Obs. - Le P. somniferum L., plante glauque, à f. caul. auriculéesembrassantes, à fi. grandes, est sultivé et se rencontre parfois dans les cultures. Les fleurs du coquelicot sont béchiques; son suc est narcotique.

\section{2 - CHELIDONIUM Tournef. - Chélidoine. - Pl. I.}

Herbe à suc jaune-orangé ; f. pennatiséquées; fl. en ombelle (f. 29). - (2) et \%. Av-oct. C. Vieux murs, haies. . . . . . . . . . . . . . Grande chélidoine. C. majus L.

Plante àcre et caustique.

$$
\text { 3- GLAUCIUM Tournef. - Glaucienne. - Pl. I, f. } 30 .
$$

Très glauque ; f. pennatipartites ; fl. grandes, d'un jaune doré. (I) ou \%. Jn-spt. A R. Rives de la Garonne et de l'Ariège. .

. . . . . . G. jaune. G. flavom Crantz.

\section{V. - TUMI HE A CIRES DC.}

\section{FUMARIA Tournef. - Fumeterre. - Pl. I.}

1 -Fleurs de 3-כ̆ mm., pâles (f. 31); sépales très petits, ovales.

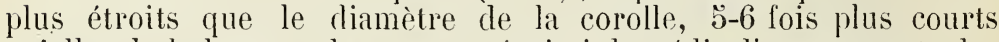
qu'elle, de la largeur du sommet épaissi du pédicelle; segments des f. pliés en gouttière ; fruit aigu. (f. 32):-- (1) Mai-at.AC. Cultures,

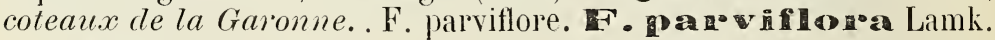

- Fleurs de 5-6 mm. ; sépales ovales, orlbiculaires, plus larges que la corolle et égalant presque la 1/2 de sa longueur. - (1). Avjit. AC. Cultures. . F. à petites fleurs. F. mấchantha Lag.

- Fleurs de 6-11 mm. de long. . . . . . . . 2

2 - Corolle de 6-8 mm., purpurine ; sépales plus étroits que la corolle et égalant le $1 / 3$ de sa longueur ; fruit plus large que long, 
émarginé au sommet (f. 33). - (1). Av.-spt. C. Cultures. . . . F. officinale. F. officimalis $\mathrm{L}$.

- Corolle de 9-11 mm. ; sépales un peu plus larges qu'elle et égalant la $1 / 2$ de sa longueur (f. 34). - - I $M s-j n$. Haies, murs.

F. à vrilles. F. caproolata $\mathrm{L}$.

Fl. d'un blanc jaunâtre (⿳亠㐅了 rechercher).

............... F. à fi. pâles. F. pallidifiora Jord. Fl. roses. - R. Fonsorbes, Plaisance, Bauzelle, Vernet (Noulet).

. . . . . . . . . . . . F. élégante. F. speciosa Jord.

\section{VI. - CRUCHFiereres Adans. - Pl. II.}

1. - Fruit linéaire ou lancéolé, 3-4 fois au moins plus long que large (silique).

- Fruit court, souvent presque aussi large que long (silicule). 16

2 - Silique indéhiscente, composée d'articles distincts ou renftée, oblongue-conique (f. 21, 22). ........... 16 Raphanus.

- Silique ni renflée ni articulée, s'ouvrant par 2 valves (f. 1).. . 3

3 - Graines disposées sur 2 rangs dans chaque loge (f. 4).. . . 4

- Grain es disposées sur 1 seul rang (f. 7)... . . . . . . . . . 7

4 - Pétales veinés de violet; silique à bec grand, comprimé (f. 20); f. pennatifides. ................... 15 Eruca.

- Pétales non veinés de violet; silique à bec court . . . . . 5 5

5 - F. caulinaires lancéolées, entières, glabres, auriculées-embrassantes; fl. blanches. .............4 Turritis.

- Feuilles caul. non entières. . . . . . . . . . . 6 6

6- Silique presque cylindrique, à valves sans nervure médiane (f. 3).

te Silique conp.

(f. 13,14 )

(f. 13, 14); fl. jaunes. ...............11 Diplotuxis.

7 - Fleurs blanches ou lilas. . . . . . . ..... 8

- Fleurs jaunes. ............... 10

8 - Valves de la silique sans nervure; stigmate entier (f.6); f. pennatiséquées. .............. 6 Cardamine.

- Valves de la silique à 1 nervure; $f$ f. presque toujours dentées. 9

- Valves à 3 nervures; f. larges, cordiformes (f. 11), à odeur d'ail (froissées). ................. 9 Alliaria.

9 - Stigmate entier. ............ 5 Arubis.

- Stigmate échancré f fleurs grandes........ 7 Hesperis.

10 - Valves de la silique à $3-5$ nervures. . . . . . . . . . 11

- Valves de la silique à 1 nervure. . . . ....... 12

11 - Styie court, peu apparent (f. 9, 10) ; graines ovales ou oblongues................ 8 Sisymbrium.

- Style allongè (f. 19), contenant souvent quelques graines; graines globuleuses. . . . . . . . . . . . 14 Sinupis.

12. F. entières; fl. odorantes, graines non ailées (f.1). 1 Cheiranthus.

- Feuilles, au moins les inféricures, divisées. . . . ....13

13 - Style court, peu apparent (f. 2); plante glabre, à f. inf. pennatifides ou partites. les caul. auriculées.. ...... 2 Barbarea.

- Style allongé, contenant souvent 1 graine. . . . . . . 14

14 - Graines sphériques; f. souvent glabres. . . . . 13 Brassica.

- Graines oblongues ou ovoïdes; feuilles velues. . . . . . . 15 
15 - Siliques très étalées (f. 16); style régult conique; f. pennatipartites ou séquées. . . . . . . . . . 12 Erucastrum. - Siliques appliquées contre l'axe (f. 12); style étranglé à sa base ; f. sup. entières.

10 Hir'schfeldia.

16 - Pétales jaunes (du moins au moment de l'ouverture de la

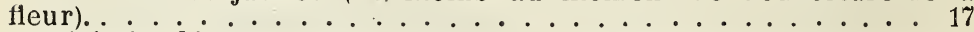
- Pétales blancs, rarement roses ou rougeâtres; silicule non articu-

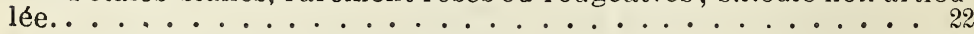

17 - Silicule plane ou presque plane. . . . . . . . . . . . 18

- Silicule ventrue, à valves très convexes. . . . . . . . . . 19

18 - Silicule petite, orbiculaire, pubescente, déhiscente (f. 44).

- . . . . . . . . . Alyssum. - Silicule grande, oblongue, glabre, indéhiscente (f. 29). 22 Isatis .

19 - Silicule articulée, indéhiscente, à article supérieur globuleux (f. 23) . . 17 Rapistrum.

- Silicule non articulée, indéhiscente (f. 38,40,41)... . . 20

- Silicule non articulée, déhiseente (f. $45,46,50) \ldots \ldots . . .21$

20 - Silicule globuleuse, non ailée, à 1 loge monosperme (f. 40). . .

- Silicule non ailée, à 3 loges, une infre monosperme, 2 supres stériles

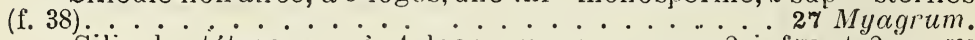
- Silicule tétragone, à 4 loges monospermes, 2 infers et 2 supres (f. $4 !)$.

29 Bunias.

21 - Silicule obovée, à valves univerviées, déprimée sur les bords (f. 50). . . . . . . . . . 36 Camelinu.

Silicule oblongue, à valves convexes et sans nervure (f. 45,46$)$. . .

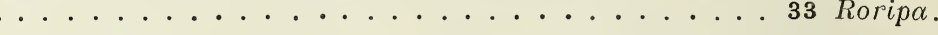

22. - Silicule indéhiscente; sépales non bossus à la base. . . 23

- Silicule déhiscente............... 24

23 - Silicule globuleuse, à bec court (f. 42), à 1 graine spliérique ; pétales inégaux. . . . . . . . . . 30 Calepina. - Silicule bilobée, réniforme (f. 24 ); pétales égaux; f. pennatipartites. 18 Coronopus.

24 - Cloison aussi large que le fruit, qui est plan ou à faces un peu

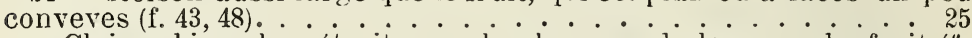
- Cloison bien plus étroite que la plus grande largeur du fruit (f.

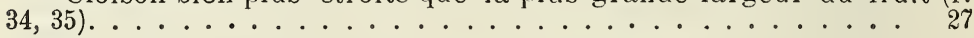

25 - Silicule mince, plane, ovale (f. 43), sans nervure dorsale, de $3 \mathrm{~cm}$. de long environ; fl. violettes. ....... 31 Lunaria. - Silicule à faces convexes, univerviées, atteignant rart 1 cent. de long:

26 - Pétales entiers ou à peine émarginés; tige feuillée.. 34 Draba.

- Pétales profondément bilobés; tige a phylle. . . 35 Erophila.

27 - Pétales très inégaux (f. 31) ; silicule échancrée au sommet; loges à 1 graine (f. 30). . . . . . . . . . . . 23 Iberis.

- Pétales un peu inégaux, très petits; loges à 2 graines; silicule suborbiculaire (f. 32, 33). . . . . . . . . 24 Teesdulea.

- Pétales égaux, petits, blancs. . . . . . . . 28

28 - Silicule en cour à la base, gonflée, à valves non carénées ; f. supérieures auriculées.. . . . . . . 19 Cardaria.'

- Silicule triangulaire, plate, échancrée au sommet, à bords carénés (f. 27, 28) . . . . . . . . . 21 Capsella.

- Silicule oblongue ou suborbiculaire, à bords cárénés ou ailés. 29.

29 - Silicule oblongue, à bords carénés, à loges à 2-3 graines; f. pennatipartites (f. 3\%). . . . . . . . . 26 Hutchinsia.

- Silicule ovale ou orbiculaire, à bords carénés ou ailés; loges 
monospermes (f. $26,26 \mathrm{bis}$ ).

20 Lepidium.

- Silicule oblongue ou orbiculaire, à valves ailées ; loges à 4-8 graines (fr. 34, 35, 36); f. entières ou dentées. . . . . 25 Thlaspi.

\section{SILIQUEUSES}

1 - CHEIRANTHUS L. - Giroflée. - Pl. - II, f. 1.

Fleurs veinées de brun. -- భ. Ms-jn. Naturalisẻ sur les vieux

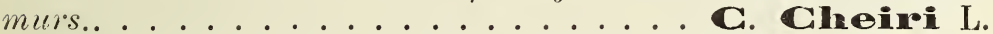

Fl. moins grandes, non veinées; plante blanchâtre.. . . . .

2 - BARBAREA Beckm. - Barbarée. - Pl. II.

1 - F. suppes entières, sinuées ou dentées ; silique à pointe aiguë.

(2). Av-jn. Fossés, bords des eaux. . . . . . . . . .

B. vulgaire. vulsaneis R. Br.

Lobe terminal des f. supres entier ou ondulé (à rechereher).. . . .

$\ldots \ldots \ldots$. . . . . . . . . . Bulgaris R.

Lobe terminal des f. supres sinué-denté; siliques appliquées contre

l'axe. - AC. Tournefeuille, Brax, Léguevin, etc.

. . . . . . . . . . B. des ruisseaux. B. rivularis de Martr.

- F. supres pennalipartites; silique à pointe obtuse. . . . . 2

2 - Siliques de 2-3 cm. de long. - (2). Av.-jn. Haies, champs, pelouses. . . . . . . . . . B intermedia Bor.

Siliques appliquées contre l'axe. - AC.

. . . . . . B. intermédiaire. B. intermedia Bor.

Siliques écartées de l'axe (f. 2). - T. bords de la Garonne... . ...

- Siliques de 4-6 cm., grêles, écartées de l'axe. - (2). Av-mai. C. Prés, champs en friche ( $B$. patula $\mathrm{Fr}$.).

B. précoce. B. DHaccox R. Br.

Les Barbarées ont une saveur prononcée et sont mangées en salade.

3 - NASTURTIUM R. Br. - Gresson. - Pl. II.

- Fl. blanches; f. pennatiséquées, à 3-4 paires de segments ovales. - 4. Mai-spt. C. Ruisseau.x, marais (Cresson de fontaine). .

G. officinal. N. Officinale R. Br.

F. à 4-6 paires de segments lancéolés. - R. Eaux profondes.

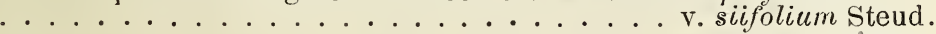

- Fl. jaunes ; f. profond. ${ }^{t}$ pennatipartites, à segments étroits ; silicule égalant à peu près le pédicelle (f. 3). - $\nsucc$. Mai-spt. AR. Bords des eaux, rives de la Garonne.

B. sauvage. He. ilvestre R. Br.

Silicule bien plus courte que le pédicelle. - Mêmes lieux... . $\dot{\text { C }}$.

Le C. de fontaine est un excellent antiscorbutique. 
4 - TURRITIS L. - Tourette. - PI. II, f. 4.

F. glauques ; siliques appliquées contre l'axe. - (2). Mai-jlt. RR. Ramier de Venerque (Noulet). . T. glabre. T.glabra L.

\section{$\ddot{\jmath}$ - ARABIS L. - Arabette. - PI. Il.}

- F. caulinaires non auriculées, lancéolées; siliques écartées de l'axe, à pédicelles étalés. - (1). Ms-jltt. CG. Cultures, murs (Sisymbrinm Thalianum Gay). A. de Thalius. W. Thaliana L.

- F. caulinaires arrondies ou subcordées à la base, embrassantes; siliques serrées contre l'axe, à pédicelles dressés, à valves nerviées jusqu'au sommet (f. 5). - (2). Mai-jlt. AR. Rives de la Garonne. ........... A. hérissée. Inimesuta Scop.

F. caul. à oreillettes étalées; nervure des valves ne dépassant pas le milieu. - RR. Toulouse. . . . . . . A. sagittée A. sagittata DC.

6-CARDAMINE L. - Gardamine. - PI. II.

1 - Pétales grands, larges, 3 fois plus longs que le calice, ordin. lilacés. . . . . . . . . . . . . . . . . 2

- Pétales petits, étroits, blancs, dépassant peu le calice. . . 3

2 - F. sup.res à segment terminal grand, orbiculaire ou ovale, les latéraux décroissants, ovales ou arrondis. - \%. Av.-jn. R. Rives cle l'A riège et de la Garonne.. G. à larges feuilles C. Iatifollia DC.

- F. sup.res à segments tous égaux, étroits (f. 6,7$)$. - భ. Av.jn. G. Lieux humides, bois, prés................. .............. des prés. C. protensis L.

3 - Pétiole des f. muni de 2 oreillettes aiguës embrassant la tige ; siliques ne dépassant pas les fleurs. - (2). Mai-jn. Lieux couverts. Bords de l'Ariège et de la Garonne............... C. impatiente. C. impations $L$.

- Pétiole sans oreillettes. . . . . . . . . . . 4 4

4-F. caul., 1-3, plus petites que les radicales; siliques dépassant longt. les fleurs. - (1). Mars-jn. CG. Cultures.......

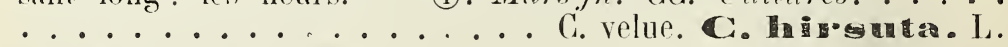

- F. caul., 6-12. ígalant les radicales ou plus grandes ; fleurs peu dépassées par les siliques. - (2) ou \%. - AR. Lieux ombragés, hurmides. Le Termet, St-Geniès, etc. . . . . . . . . . .

La $C$. a larges $f$. et la $C$. des prés sont stimulantes, dépuratives ('t antiscorbutiques.

\section{7 - HESPERIS Tournef. - Julienne. - PI. II, f. 8.}

F. lancéolées, dentées, acuminées ; siliques très longues. -- (2) ou 
4. Mai-jn. R. Rives de la Garonne.

J. des dames. H. matromalis. L.

8 - SISYMBRIUM Tournef. - Sisymbre. - - Pl. II.

1 - F. pubescentes, 2-3-pennatiséquées, à segments étroits. (1). Av.-spt. R. Décombres, murs. Vallée de l'Ariège, St-Martindu-T. . . . . . . . . S. sagesse. Soplaia L.

- F. roncinées-pennatipartites.............. 2

2 - Grappes feuillées; siliques par 2-3 (f. 9) ; à pédicelles de 1-2 mm. - (1) ou (2). Jn-Jlt. Vieux murs, bords du Tarn. . . . . . . . ............... S. corniculé. polyceñam L.

- Grappes non feuillées. .................. 3

3 - Siliques appliquées contre l'axe, courtes, velues, atténuées au sommet (f. 10). - (1). Mai-spt. CG. Lieux incultes, décombres. $\ldots \ldots \ldots \ldots \ldots$. . . . officinal officinalo scop.

- Siliques écartées de l'axe. . . . . . . . . . . . . . 4

4 - Fleurs dépassées par les siliques supérieures glabres : sépales bien plus courts que le pédicelle. - (1) ou (2). Av.-jlt. AR. Vieux

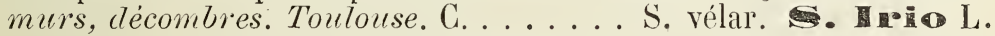

- Fl. non dépassées par les siliques plus ou moins pubescentes; sépales égalant le pédicelle. - I . Mai-jlt..............

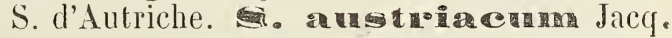

Pédicelles arqués, de $8.10 \mathrm{~mm}$. ; siliques de $15.20 \mathrm{~mm}$., à style de $3 / 4$ de mm. - AR. Ramiers de la Garonne et de l'Ariège. . . . . . . . . . ..................... des montagnes. s. montivagum Jord.

9 - ALliARIA Adans. - Alliaire. - Pl. II, f. 11.

F. dentées, glabrescentes; fl. blanches. - (2). Av-jn. CC. Lieux frais et couverts (Sisymbrium Alliaria Scop.). . . . . . . . . . . A. officinale. orficimalis Andrz.

10 - HIRSCHFELDIA Mœnch. - Hirschfeldie. - Pl. II, f. 12.

Plante d'un vert blanchátre; fl. petites. - (2). Jn-oct. Lieux vagues. AG. Rives de l'Ariège et de la Garonne (Sinapis incana L.). . . . . . . . . H. apprimée. KI. adpressa Mœnch.

\section{1 - DIPLOTAXIS DC. - Diplotaxide. - Pl. II.}

- Pédicelles étalés, 2-3 fois plus longs que la fleur épanouie (f. $13,14)$; fl. de $12-15 \mathrm{~mm}$. de diam., jaune soufre. - భ. Jn-oct. C. Murs, bords des chemins. . . . . . . . . . . . . . . 
- Pédicelles égalant environ la long. de la fl. épanouie; fl. de 仓̋-6 mm. - (1) ou (2). Jn-oct. AG. Graviers de la Garonne.. . . . . . ......... D. des murs. D. munais. if.

\section{2 - ERUSCATRUM Presl. - Fausse roquette. - Pl. II.}

- F. caulinaires à segments inférieurs auriculés-embrassants ; pédicelles inférieurs dépourvus de bractées; fl. d'un beau jaune (f. 15, 16, 17). - (2) ou \%. Jn-spt. R. Ramier de Braqueville. (Diplotaxis Erucastrum G. G.

... . F. à angles obtus. E. Obrasangua lim Schleich.

- F. caul. à segments inf. non auriculés; pédicelles inf. munis de bractées découpées; fleurs pâles. - (1) ou (2). Jn-spt. R. Rives de la Garonne (Diplotaxis bracteata G. G.).

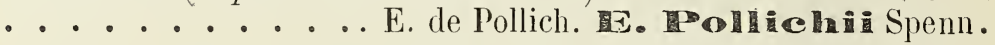

\section{3 - BRASSICA L. - Chou. - Pl. II.}

1 - Siliques courtes, subtétragones, appliquées contre l'axe ; stylle grèle (f. 18). - (1). Mai-oct. C. Décombres, fossés, lieux vagues (Moutarde noire, Sinapis L.). . C. noir.

- Siliques longues, écartées de l'axe. . . . . . . 2

2 - F. sup. sessiles, non embrassantes. - (2) ou $\%$.

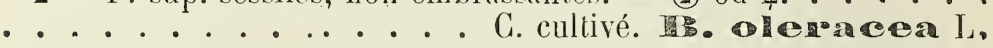

On cultive le C. ver tou sans tête (v. acephala DC). le C. cabus ou pommé (v. crpitata DC), le C.-fleup (v. botrytis DC), le C. rave (v. caulorapa, DC). tites

- F. sup. embrassantes; fl. d'un jaune vif ; f. inf. pennatipar-

3 - F. glabres el glauques; fl. espacées dès l'épanouissement. -

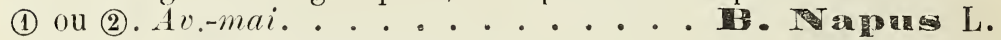

Racine renflée, fusiforme (Navet). ...... v. esculenta DC.

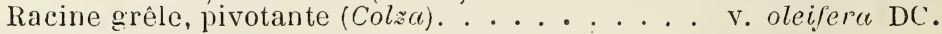

- F. ciliées-hérissées ; fl. rapprochées à l'épanouissement. - (1)

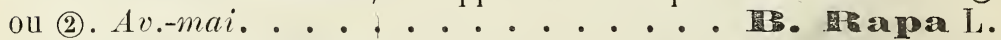

Racine renflée en toupie (Rave). ........ v. esculente GG. Racine grêle (Nuvette)............ v. oleifera DC:

Ces diverses variétés sont subspontanées dans les cultures. Les graines du $B$. nigra servent à la préparation des sinapismes et de la moutarde.

\section{4 - SINAPIS Tournef. - Sénevé. - - Pl. II.}

- F. sup.res dentées; silique à bec presque conique. - (I). Jnoct. R. Cultures. . . . . S. des champs. aremsis L.

Silique longue, à 5 nervures et portant des renflements. - R. . . 
- F. sup.res pennatipartites; 'silique hérissée, à bec comprimé, plus long que les valves (f. 19). - (1). Mai-jlt. AC. Décombres, vieux murs. Vallée de la Garonne (Moutarde blanche). . . . . ............ S. blanc. alba L.

Le $S$. arvensis est très irritant.

$$
\text { 1̋ - ERUCA Tournef. - Roquette. - Pl. II. }
$$

Fl. grandes, blanches ou jaunattres ; bec des siliques égalant la 1/2 de la long. des valves (f. 20). - I . Av.-jn. C. Décombres, murs. . . . . . . . R. cultivée. E. sativa Lamk.

F. glabrescentes; bec des siliques égalant les valves. - Toulouse. (Timbal). . . . . . . . . . R. glabrescente. E. glabrescens Jord.

La Roquette est un excitant stomachique ; on la mange en salade.

$$
16 \text { - RAPHANUS L. - Raifort. - Pl. II. }
$$

1. - Silique renflée, sprongieuse, ne se partageant pas en articles transversaux; fl. blanches ou violetles. - (1). Mai-jlt. Subspontané. (Radis). . . . . . . R. cultivé. re ativa $\mathrm{L}$.

- Silique en chapelet, se partageant en articles transversaux, . 2

2 - Bec de la silique 3-4 fois plus long que le dernier renflement ; pédoncules plus courts que le fruit (f. 21). Fleurs blanches (v. albus F. Gér.), veinées de jaune (v. sulfureus F. Gér.), jaune pâle veinées de violet (v. ochrocyaneus F. Gér.) ou d'un rose violacé (v. violaceus Sud.). - (1). Mai-spt. CG. Cultures (R. Raphanistrum

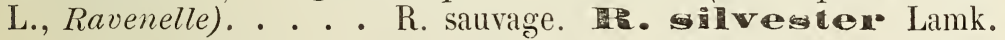

- Bec de la silique 1-3 fois plus long que le dernier renflement; pédoncules plus longs que la silique. dont les segments sont peu nombreux; fl. jaunes (f. 22). - (1), (2) ou \%. Mai-spt. C. Prés, pelouses; vallées du Girou, du Touch, de la Garonne, etc. • . •

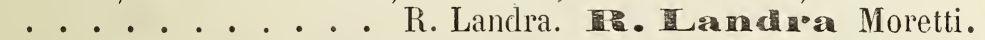

La ravenelle est très irritante et doit être détruite.

\section{SILIGULEUSES}

17 - RAPISTRUM Boehr. - Rapistre. - Pl. II.

- F. inf. pennatipartites; silicules appliquées, hérissées (f. 23)• - (1). Mai-oct. G. Cultures. . . . . . . . . . . . . . ........ R. rugueux. He. Hos gosmen Berger.

- Fruit petit, glabre, à article sup.r de $2 \mathrm{~mm}$. de diamètre. A été trouvé à l'île du moulin Vivent, importé d'Algérie avec les céréales. . . . R. à petit fruit. He. mienocanoum Jord. 
18 - CORONOPUS Rupp. - Corne de cerf. - Pl. II, f. 24.

Tiges couchées ; fleurs petites, blanches, en grappes denses, opposées aux feuilles. - (1). Mai-spt. C. Bords des chemins, décombres. (Senebiera Coronopus Poir.). .

....... G. procombante. C. procumbens Gilib.

$$
19 \text { - CARDARIa Desv. - Cardarie. - Pl. II, f. } 25 .
$$

Feuilles blanchâtres-pubescentes; 'fl. blanches. -- भ. Mai-jlt. G. Plaine de la Garonne. (Lepidium Draba L.). . . . . . . . . . ............... G. drave. C. Droba Desv.

$$
20 \text { - LEPIDIUM L. - Passerage. - Pl. II. }
$$

1 - Feuilles sup.res glabres, non sagittées. . . . . . . 2

- F. sup. pubescentes, sagittées-embrassantes; silicule de $5 \times 4$ mm., échancrée, ailée, écailleuse (f. 26). - (1) ou (2). Mai-jtt. C. Décombres, bords des chemins. . . . . . . . . . ....... P. des campagnes. Lam postro R. Br.

2 - F. caulinaires moyennes ovales-lancéolées ; silicules orbiculaires. - 4. Jn-jlt. RR. Lieux humides. Vallee du Girou, à Bazus ; bords de l'Ariège (Noulet).

- F. caul. étroites, linéaires ou lancéolées. . . . . . . 3

3-1 style; silicule de $3 \mathrm{~mm}$. environ, ovale-aiguë, ni ailée ni échancrée. - \%. Mai-oct. CG. Fossés, décombres, pelouses. . . . .

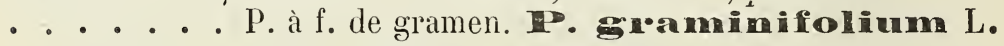

- Silicule suborbiculaire, échancrée au sommet, à bords plus ou moins ailés. . . . . . . . . . . . 4 4

4 - Silicule de $3 \mathrm{~mm}$. environ (f. 26 bis); feuilles vertes, les sup. res dentées. - (1). Mai-août. AG. Le long cies voies ferrées, bords de la Garonne; originaire d'Amérique.

P. de Virginie. L. viroginicum L.

- Silicule de $5 \times 6 \mathrm{~mm}$; f. glauques. - (1). Mai-jlt. Cultivé et subspontané çà et là. (Cresson alénois, nasitort).

P. cultivée. L. Sativiom $\mathrm{L}$.

Cette dernière espèce est employée comme assaisonnement.

21 - CAPSElla Medik. - Capselle. - Pl. II.

- F. pulescentes, les radicales pennatifides ; sépales verts ; siliques à côtés droits ou arqués en dehor's (f. 27). - (1). Ms-déc. CG. Murs, cultures, décombres. - . G. hourse à pasteur. 
- Plante plus ou moins rongeâtre; sépales lavés de pourpre; siliques à bords arqués en dedans (f. 28). - (1). Ms-déc. AC, avec le précédent. . . . . . G. rougeâtre. C. ñubolla Reut.

$\times$ C. gracilis Gren. C. bur'sa-pastoris $\times$ rubellu. - Stérile. - Cè et lì, acee les parents.

\section{2 - ISATIS Tournef. - Pastel. - Pl. II, f. 29.}

F. entières, glabres, les caulinaires embrassantes. - (2). Mai-jn. R. Subspontané, St-Geniès, Buzet (Noulet). . . . . . . . .

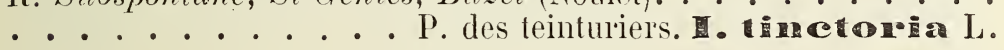

\section{3 - IBERIS L. - Ibéride. - Pl. II.}

- F. pennatifides ou pennatiséquées, à 3-ŏ lobes linéaires ; grappes fructifères courtes. - (1) ou (2). - Mai-jlt. R. Coteaux et rives de la Garonne. . . . . . . 1. pennée. Ho phata L.

- F. caulinaires dentées; grappes fructifères allongées (f. 30, 31). - (1) ou (2). - Mai-oct. CG. Moissons, champs cultivés. .

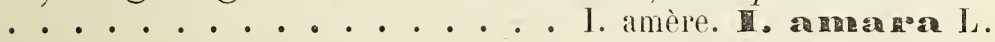

Fl. violettes, plus retıtes, ainsi que la silicule. $R$.

.............. I. des champs. I. arvatica Jord

On cultive dans les jardins les $I$. semperflorens L., à fl. blarches, et umbellata L., à fl. lilacées.

\section{4 - TEESDALEA R. Br. - Teesdalée. - Pl. II, f. 32. 33.}

Pl. de ว̆-1つ̆ cm., à tiges peu feuillées. - (I). Av.-jn. C. Pelouses

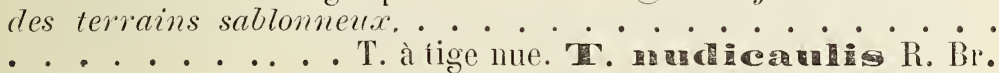

$$
\text { 20 - THLASPI Dill. - Tabouret. - Pl. } 11 .
$$

1 - Silicule grande, orbiculaire, de 12-1 ّ̋ mm. de diam., plane, ailée (f. 34. 3̋̃); plante glabre, à odeur d'ail. - (I). Mai-spt. R. Champs cultivés et coteaux de la Garonne.......... . . . . . . . T. des champs. T. an wenge L.

-- Silicule de 4-5̆ mm. de large, rétrécie à la base.. . . . . 2

2 - Tige glalıre; f. glauques, les caul. larges, amplexicaules ; silicule ailée au sommet et profondément échancrée (f. 36). - (1). Mai's-mai. CC. Bords des chemins, cultures. . . . . . . . .

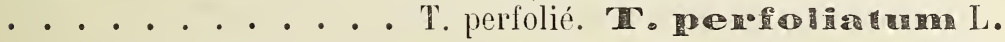

- Tige simple, pubescente à la base; f. caul. oblongues, dentées ; grappe fructifère très longue; silicule cunéiforme, à échancrure peu profonde. Odeur dail. - (2. Av.-mai. RR. T. Ramier

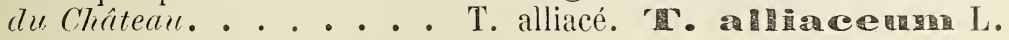


26 - HUTCHINSIA R. Br. - Iutchinsie. - Pl. II, f. 37.

Plante grêle, de 3-10 cm. ; f. à 13-19 lobes. - (I). Mars-mai. RR. Graviers de la Garonne et de l'Ariège. . . . . . . . . .

27 - MYAGRUM Tournef. - Myagre. - Pl. II, f. 38, 39.

Glauque et glabre ; f. caul. sagittées-amplexicaules (f. 39). - (2). Mai-jlt. C. Champs cultivés............... ......... M. perfolié. M. Denoliatum L.

$$
28 \text { - NESLEA Desv. - Neslée. - Pl. II, f. } 40 .
$$

Velue et grisâtre ; f. caul. lancéolées, sagittées-amplexicaules. (1). Mai-jlt. C. Moissons. . . . . . . . . . . . . N. paniculée. Toanicalata Desv.

$$
29 \text { - BUNIAS R. Br. - Bunias. - Pl. II. }
$$

Velue ; f. sup. sessiles ; pétales échancrés. - (1). Av.-jlt. C.

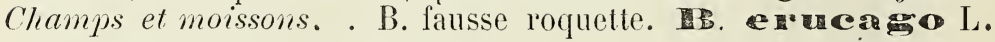

Silicules dépourvues de crêtes. - R... . . . . v. arzensis (Jord.). Silicules subtétragones, à crêtes étroites (f. 41 ). - C.. . . . . . . . $\ldots \ldots \ldots \ldots \ldots$ v. brechyptera (Jord.). Silicules tétragones, à crêtes plus larges que le fruit. - $\mathrm{AC} . . .$.

$$
30 \text { - CALEPINA Adans. - Calepine. - Pl. Il, f. } 42 .
$$

Glabre ; f. caul. embrassantes; fl. blanches. - (1). Av.-jlt. AR. Lieux incultes. Toulouse. St-Martin-du-T., Tournefeuille, etc.

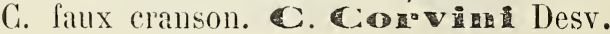

\section{1 - LUNARIA Tournef. - Lunaire. - Pl. II, f. 43.}

F. cordiformes, les sup. sessiles. - (2). Mai-jn. Cultivé et subspontané (Monnaie du pape). St-Jean, l'Union, etc. . . . .

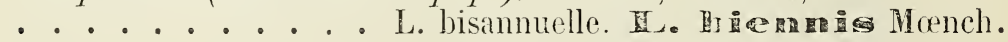

$$
32 \text { - ALYSSUM L. - Alysson. - Pl. II, f. } 44 .
$$

Pétales jaunes, devenant blanes; plante couverte de poils étoilés ; sépales persistants. - (1). Av.-jn. CG. Lieux secs, pierreux.. .

Souvent bisannuel; pétales d'un beau jaune, peu émarginés. Giaviers de la Groponne. . . . . . . . . v. erraticum (Jord.). 


\section{3 - RORIPA Scop. - Roripa. - Pl. 11.}

- Silicules oblongues, de $6-8 \mathrm{~mm}$. de long, égalant le pédicelle (f. 40ั) ; f. pennatipartites, à segments presque entier's. - (2). Maispt. AC. Bords des eaux (R. nasturtioides Spach)... . . . . . .

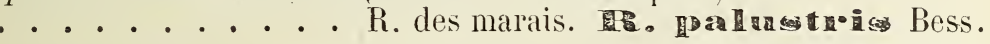
Segments à dents profondes. . . . . . . . v. dissecta R. et F.

- Silicules ovales, 3-4 fois plus courtes que le pédicelle (f. 46). - \%. Mai-sept. AC. Bords des eaux. Portet, La Ramette, etc. (Nasturtium R. Br.). . R. amphibie. Am Dess.

\section{4 - DRABA L. - Drave. - Pl. II, f. 4.7.}

Feuilles caul. auriculées, dentées; silicules glabres. - (1). Av.jn. R. Lieux firais, vieux murs. Rives du Tarn, Blagnac (Nou-

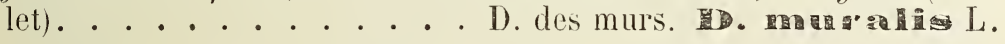

3̋̃ - EROPHILA DC. - Erophile. - (Diaba verna L.). - Pl. 11.

F. toutes radicales, entières ou dentées ; tiges de 3-10̆ cm. - (1).

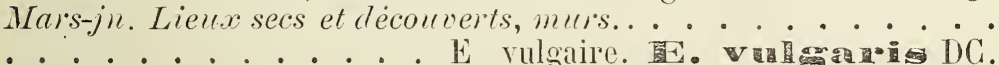

a. - Poils tous ou presque tous simples.

- Silicule peu ou point atténuée à la base (f. 48).

E. glabrescens Jord.

Nince et glabrescente ; fl. de 3 1/2 mm. de diam. ; silicule de $4 \times 21 / 2 \mathrm{~mm}$. - . . . . . . . . E. virescens Jord.

- Silicule sensiblement rétrécic à la basc, de $6 \times 21 / 2$; fl. de $5 \mathrm{~mm}$; - R. ............ E. hirtella Jord.

b. - Poils tous ou presque tous bi-trifides.

- Siliculè courte et très obtuse, de $3 \times 2 \mathrm{~mm}$.; fl. de $3 \mathrm{~mm}$. - R. ... . . . . . . . . . . E. brachycarpa Jord.

- Silicule elliptique-obovale, ayant au moins $5 \mathrm{~mm}$. de long. AC. . . . . . . . . . E. obovata Jord.

- Silicule oblongue ou sublancéoléc, $7-8 \times 2-23 / 4 \mathrm{~mm}$.; poils longs (f. 49). - AC. . . . . . . E. cuneifolia Jord.

- Silicule oblongue, 51/2-61/2×2-21/2 mm. ; f. étroites. - AC. . .

. . . . . . . . . . E. leptophylla Jord.

- Silicule oblongue ; f. larges, poils courts. - AC . . . . .

- Silicule linéairo-lancéolée $7-16 \times 11 / 2-9 \mathrm{~mm}$. f étroites -

. . . . . . . . . . . . . stenocarpa Jord.

- Silicule de 5- $7 \times 23 \mathrm{~mm}$; f flarges, à poils très courts; fl. ordin. grandes. - AR . . . . . . E. majuscula Jord.

Je ne mentionne que les principales sous-espèces de co genre. Les E. vivariensis, medioxima, oblonguta, micrantha. rubella, chlorotica, oblongate Jord., du gr. E. glabrescens, sont C. aux environs de Toulouse. 
36 - CAMELINA Crantz. - Cameline. - Pl. II, f. 50.

F. oblongues-lancéolées; silicules ventrues; graines jaunes. -(1). Mai-jlt. RR. Subspontané dans les cultures. . . . . . . . C. cultivée. C. sativa L.

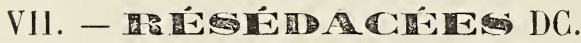

\section{RESEDA L. - Réséda. - Pl. II.}

- F. caul. entières, 3-partites; 6 sépales (rar. ${ }^{\natural} 5,7$ ) accrescents (f. 亏1); pétales blancs. - (1) ou (2). Mai-aoùt. AG. Terrains d'alluvion, vallée de la Garome.

B. raiponce. Fe R

- F. caul. pennatipartites; 6 sépales non accrescents (f. 522); pétales d'un janne verdâtre. - (2). Mai-spt. AG. Lieux incultes, rives de la Garonne. . . . . . . . R. jaune. Peneg L.

- F. toutes simples (f. У3); 4 sépales; fleurs jaunes, en grappe longue. - (2) Mai-spt. AG. Bords des chemins, terres en friche. R. gaude, He. In tecolde L.

On cultive le $\mathbf{R}$. odsrata L., qui differe du R. Phyteuma par ses fleurs odorantes et ses sépales non accrescents. Le R. glauca L., à fl. blatiches, à capsule munie de 4 dents, à feuilies glauques et linéaires, a été trouvé à Palaminy, aux bords de la Garonne (Duteyeul). Descendu des Pyrénées.

\section{VIII. - C I}

1 - Etamines extéricures stériles, à fllets renflés en chapelet ; f. linéaires; fl. jaunes. . . . . . . . . . . . . . . . 3 Fumana.

- Etamines extérieures fertiles; fi opposées, larges. . . . . . 2

2 - Capsule à $1-3$ loges, ì 2-3 valves. . . . . 2 Helianthemum.

- Capsule ì 5, 6, 10 loges; arbrisseau. . . . . . . . . . 1 Cistus.

\section{1 - CISTUS Tournef. - Ciste. - Pl. III.}

F. pétiolées, ovales; fl. grandes, blanches, solitaires ou par 2,3 (f. 1). - h. Mai-jn. C. Bois des terrains siliceu.x. . . . . . . . C. il f. de saule. Ci。

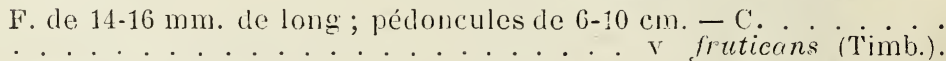
F. de $3-4 \mathrm{~cm}$. de long. - AR. Bouconne. . v. platyphyllus ('Timb.).

\section{2 - HELIANTHEMUM Tournef. - Héliauthème. - Pl. III.}

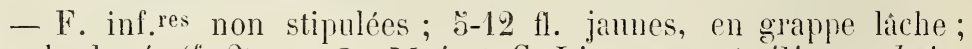
tige herlacée (f. 2). - (1). Mai-at. C. Lieur secs et siliceur, bois.

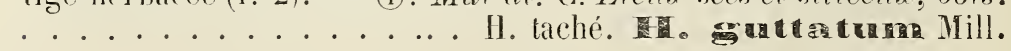


- F. toutes stipulées, blanches en dessous, planes ; tiges ligneuses; fl. jaunes. (f. 3). - భ. Mai-jlt. CG. Lieu.x arides, décoiverts.

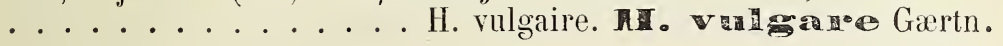

\section{3- FUMANA Spach. - Fumana. - Pl. III.}

F. non stipulées, alternes; pédicelles égalant à peu près la f. florale (f. 4). - \%. Mai-jlt. AG. Coteau.x de la Garonne (Helianthemum Fumana Mill.). . F. couché. F. phoerandbe日ns G. G.

\section{IX. - VIOLACER DC.}

\section{VIOLA Tournef. - Violette. - Pl. III.}

1 - Les 2 pétales sup.rs dirigés en laaut, les latéraux étalés; stigmate non creusé en godet (Violettes) (f. 8). . . . . . . 2

- Les 4 pétales sup.rs dirigés en haut; stigmate creusé en godet (Pensées) (f. 9).

2 - Pédoncules radicaux (naissant de la souche); sépales obtus.

- Pédoncules sur une tige feuillée (f. 8); sépales aigus ; fl. inodores. .

3 - Ni stolons ni tiges latérales couchées; plante velue; fl. inodore (f. 5, capsule). - 4. Mars-mai. C. Haies, prés, bois. . . . . .

Villosité plus courte; des stolons radicants courts; fl. à odecir très légère. - R. Bois, haies, Lardenne, St-Simon, Renéry. . . . . .

- Des stolons radicants ou des tiges latérales couchées; fl. plus ou moins odorantes. ................. 4

4 - F. adultes suborbiculaires, très obtuses (f. 6) ; stipules à cils plus couris que la $1 / 2$ de leur largeur; fl. très odorantes. - \%. Mar's-mai. AR. Haies, buissons. V. odorante. od oroata L.

Pétales blancs dans leur 1/2 inférieure, rapprochés en tube, les latéraux peu ou point barbus. - R. St-Geniès (Timbal) (V. Tolosana Timb.). . . . . . . . . . . V. de Béraul. v. Beraudi Bor.

- F. adultes ovales-oblongues, plus ou moins aiguës (f. 7) ; stipules à cils égalant leur largeur. . . . . . . . . . . . . 气

$\check{\jmath}-\mathrm{F}$. estivales d'un vert clair; fl. d'un blanc pur, à éperon d'un blanc jaunâtre. - \%. Fév.-ms. C. Bois, haies. ............ . . V. blanche Voldo Bess.

F. estivales d'un rert sombre, colorées d'un violet noirâtre. Fév.-ms. . . . . . . . . V. vert sombre. V. scotophylla Jord. Fl. blanches, à éperon blanc. - Pouvourville, à Hue.. 
Fl. blanches, à éperon violacé. - AC. . v. scotophylloides Wiesb. Fl. violacées, à éperon violacé. - AC. . . . v. violacea Wiesb. $\times$ V. multicaulis Jord.; V. albu×odorata R. et F., a été indiqué aux bords du Touch.

$\times \mathrm{V}$. digenea $\mathrm{R}$. et $\mathrm{F}$.; $V$. alba Xsilvestris eor., a été trouré au bois de Tesoque, près Nailloux (Timbal).

6 - Souche terminée par une rosette de feuilles ; éperon non jaune ; pétales violets (f. 8). - భ. Ms-mai. Haies, bois.

........ . . V. sauvage. V. sil vestiós Lamk.

Pétales oblongs ; éperon violet; fl. horizontale. - C.

............... Reichenbachicina (Jord.).

Fl. grandes, violet rougeâtre; robuste. - Lieux ombragés..... .

. . . . . . . . . . . . v. vicina (de Martr.).

Pétales obovales; éperon blanchàtre; fl. verticale. - C. . . . . .

V. Riviniana Rchb.

- Souche continuée par une tige florifère ; pas de rosette terminale ; fl. bleues, à éperon jaunâtre. - q. Av.-jn. RR. Bois, landes

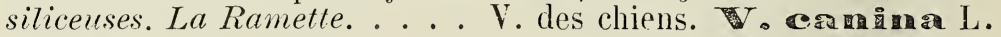

7 - Pétales grands, veloutés, 2-3 fois plus longs que les sépales. - (1). Cultivé (Pensée) et subsp...... ש。

Pétales dépassant peu ou point le calice (f: 9), non veloutés. Ms-spt. C. Moissons, cultures. . . V. des chamjs. V. arvensis Mur.

Les var. Timbali (Jord.), ruralis (Jord.), Deseglisei (Bor.), agrestis (Jord.) ue sont pas rares.

Les fl. du V. odorata sont pectorales, adoucissantes et antispasmodiques; on les emploie en parfumerie.

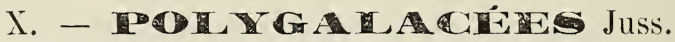

\section{POLYGALA L. - Polygala. - Pl. III.}

1 - Fenilles inf. obovales, en rosette, plus grandes que les caulinaires, qui sont alternes. - \%. Mai-jlt. G. Pelouses, coteaux calcaires. . . . P. du calcaire. 20 Schultz.

- F. inf. plus petites que les caulinaires et non en rosette. . 2

2 - F. infres opposées (f. 10); fl. ordin. bleues (f. 11), en grappes courtes. - q. Av-jn. C. Bruyères (P. clepiessa Wend.). . . . . . ....... P. faux serpolet. P. Serpy

- F. infres alternes ; fl. de couleur variable (f. 12), en grappes lâches. - \%. Av-jn. C. Prés, pelouses............ P. vulgaire. 厚。valgats $\mathrm{L}$.

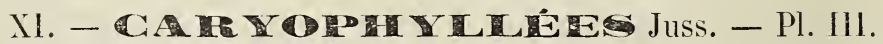

Calice gamosépale (Sílénées). . . . . . . . . . . 39. Calice dialysépale (Alsinées.). . . . . . . . . . . . 41. 


\section{SILENEEES DC.}

1 - Fruit en forme de baie noire; 3 styles (f. 17). . . 4 Cucubalus.

- Fruit | Fleurs hermaphrodites. . . . . . . . . . . 2 capsulaire $/$ Plante diö̈que ; 5 styles; caps. à 10 valves. 3 Melandryum.

2 - Calice accompagné d'un calicule (f. 27 ); 2 styles. . 8 Dianthus.

- Calice 12 styles; capsule à 4 dents ou à 4 valves. . . . . . 3

sans calicule 3 styles; capsule à 6 valves. . . . . . 5 Silene

(f. 16) 5 styles, capsule à 5 valves (f. 14).. . . . . . 4

3 - Pétales à onglet long; calice tubuleux, cylindrique ou ovoüde.

................... 6 Saponaria.

- Pétales à onglet très court ; calice campanulé (f'. 24). 7 Gypsophyla.

4 - Pétales portant 2 écailles à la base du limbe (f. 15). 2 Lychnis.

- Pétales sans écailles. . . . . . . . 1 Agrostemma.

I - AGROSTEMMA L. - Agrostemme. - Pl. III, f. 13, 14.

Plante pubescente; pétales ord. ${ }^{t}$ rouge violacé, grands, dépassés par les sépales. - (1). Jn-jlt. G. Moissons. . . . . . . . . . . . . ................. nielle. A. Githago L.

La farine de ses graines, mélangée à ceilte du blé, ost dangereuse.

$$
2 \text { - LYCHNIS L. - Lychnide. - Pl. III. }
$$

- Plante très blanche-tomenteuse ; pétales pourpres, à limbe à peu près entier (f. 15). - \%. Mai-jlt. Naturalise au bois de Recebedou, près de Portet (Coquelourde)

- Plante verte, visqueuse au sommet; pétales roses, à limbe divisé en 4 lanières. - \%. Mai-jn. G. Prés lumicles........ L. fleur de coucou, C. Hosmencili L.

\section{3-MELANDRYUM Rohl. - Mélandrye. - Pl. III.}

- Fl. blanches (f. 16); calice à divisions triangulaires, obtuses ; capsule à dents dressées. - 2. Mai-at. C. Haies, décombres (Compagnon blanc, Lychnis dioica L.). . . . . . . . . . .

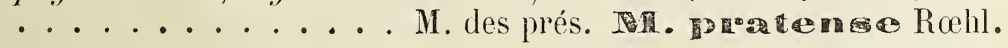

- Fl. roses; calice à dents lancéolées, aiguës; capsule à dents roulées en dehors. - \%. Mai-jlt. AR. Lieu.x couverts. Bords de la Garonne et de l'Ariège (Lychnis silvestris Schkuhr.). . . . . .

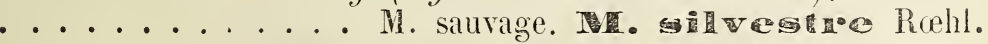

$$
\text { 4-CUCUBALUS Gartn. - Cucubale. - Pl. III, f. 17. (fr.). }
$$

Rameaux étalés-divariqués; f. ovales; pétales d'un blanc verdâtre. - \%. Jn-oct. R. Lieux couverts. Vallons de la rive droite de la Garonne. . . . . . C. porte-baies. C. baceiler L. 


\section{$\check{~}$ - SILENE L. - Silène. - Pl. III.}

1 - Galice glabre, enflé-vésiculeux dès l'épanouissement de la fleur (f. 18); f. glauques et glabres. - 2. Mai-at. C. Cultures, bords des chemins. . . . . . . S. gonflée. infla Sm.

F. très pubescentes-ciliées. - AR. Coteaux tertiaires. Pechbusque.

- Calice glabre, non enflé-vésiculeux au moment de l'épanouissement de la fleur, qui est rose............. 2

- Calice velu ou cilié-glanduleux sur les nervures. . . . . 3

2 - Pétales à onglet non auriculé ; capsule ovoïde, 3-6 fois plus longue que son support glabre. - (1). Mai-jlt. AC. clans les liniè-

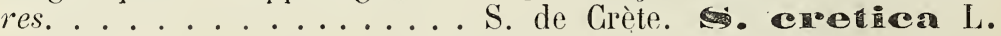

Capsule subglobuleuse, à support plus court. . v. annulata Thore.

- Pétales à onglet auriculé ; capsule oblongue, 2-3 fois plus longue que son support pubescent (f. 19). - (1). Jn-jlt. Moissons. R. Coteaux des bords de l'Ariège.

S. attrape-mouche. mo

3 - Fl. petites, dressées, brièvement pédicellées, en grappe unilatérale (f. 20). - (1). Av.-jlt. C. Terrains siliceux . . . . . . . . S. de France.

Fl. blanches, tiges dressées; calice fructifère dressé. - Léguccin, etc. . . . . . . . . . . v. agrestina (Jord. et F.).

Fl. blanches, tiges étalées; calice fructifère étalé. - La lamette, etc. . . . . . . . . . . . v. oceitanica (Jord. et F.).

Fl. roses, tiges dressées. - Brax, Léguevin, Bouconne. . . . . . . ...................... rosella (Jord. et F.).

- Fleurs non unilatérales. .............. 4

4 Fleurs penchées (f. 21) ; capsule 3-ð̌ fois plus longue que son support. - 4. Mai-at. C. Lieux secs, coteaux, murs . . . . . . . . S. penchée.

- Fl. dresséez; cspzule égalant ou dépassant son support. - \&. - \%. Mai-at. R. Coteaux de la Gaionne, près de Portet. . . . . . . S. d'Italie. iond

Le $\mathbf{S}$. brachypatala Rob. et Cast., à tiges étalées, à fl. brièvement pédicellées, à pétales plus courts que le calice, a été rencontré près de l'écluse du Béarnais. - Amnuel. Mai-jlt.

\section{6 - SAPONARIA L. - Saponaire. - Pl. III.}

- Calice cylindrique (f. 22), sans angles saillants; fl. en cyme compacte; pétales munis d'écailles. - భ. Jn-at. Bords des champs, lieux frais. . . . . . . . S. officinale. ofrien an $\$$ L.

— Calice à õ angles (f. 23); fl. longuement pédicellées ; corolle 
rose, à gorge nue. - (1). Jn-jlt. C. Moissons des terrains tertiai-

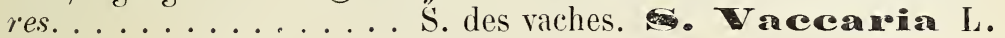

Ia $S$. officinale est amère et tonique; elle mousse avec l'eau comme le savon.

$$
7 \text { - GYPSOPHILA L. - Gypsophile. - Pl. III, f. } 24 .
$$

Pl. de 1-2 dm.; f. linéaires; fl. petites, roses, en cymes lâches. - (I). Jlt-sept. C. Champs siliceux, sables.

G. des murs. Gr. munealis $L^{\circ}$

\section{8 - DIANTHUS I. - OLillet. - Pl. III.}

1 - Calice velu, dépassé par les bractées (f. 2:) ; fl. purpurines, en fascicules denses. - (2). Mai-oct. C. Friches arides, bois (CEitlet velu). . . . . . . . OE. Armeria. D. nomoria L.

- Calice glabre, plus long que les bractées extérieures.. . . 2

2 - Calice dépassé par les bractées intérieures du calicule; fl. petites (f. 26), 1-8, en capitule, ord. ${ }^{t}$ purpurines. - (1). Mai-oct. C.

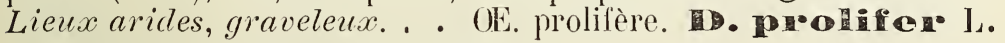

- Calice plus long que le calicule. . . . . . . . . 3

3 - Calice pourpre obscur; 2-8 fl. purpurines en fascicule dense ; pétales dentés. - 2. Mai-spt. C. Bois, friches des coteaux. .

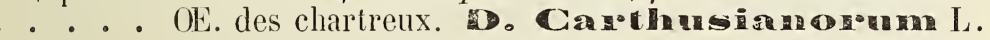

- Fleurs solitaires ou en bouquet lâche. . . . . . . . 4

4 - Limbe des pétales denté ; calicule 4-ð̆ fois plus court que le calice; fl. odorantes (f. 27). - \%. Jn-at. R. Naturalisé sur les vieux murs. . . . . OE. giroflée. Ca. Canyophy

- Limbe des pétales lacinié; calicule 3-4 fois plus court que le calice. - 4. Jn-at. C. Bois humides des coteaux de la Garonne et

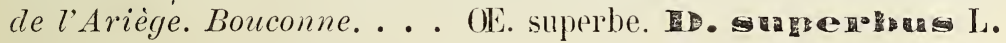

- Limbe des pétales lacinié (f. 28); calicule atteignant la 1/2 du calice. - \%. R. Rochers, pâturages touchant aux Pyrénées (Du-

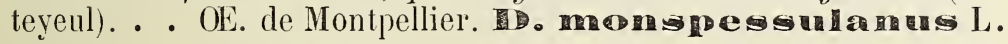

\section{ALSINÉES DC. - Pl. 11 I.}

1 - F. munies de stipules membraneuses. . . . . . . . 2

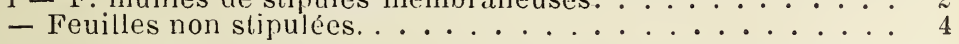

2 - F. ovales ou oblongues; $3-5$ étamines; pétales plus courts que

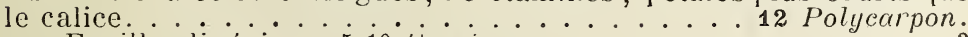

- Feuilles linéaires ; 5-10 étamines. . . . . . . . . 3

3 - 5 styles; capsule s'ouvrant au sommet par 5 valves opposées aux sépales; fl. blanches.............. spergula. 
- 3 styles; capsule s'ouvrant jusque près de la base en 3 valves.

11 Spergularia.

4 - Pétales bipartites ou bifides (f. 31)........... 5

- pétales entiers, dentés ou émarginés.......... 6

5 - 3 styles; capsule à 6 valves. . . . . . . 4 Stellaria.

4-5 |Capsule ovol̈de, à 5 valves bidentées. . . . 1 Malachium.

styles Capsule subcylindrique, à 8-10 dents égales. . 2 Cerustium.

6 - $2-3$ styles; capsule à $3-6$ valves. . . . . . . . . . . 7

4-5 Capsule à 4-5 valves ; feuilles linéaires. . . . . 9 Sagina. styles Capsule s'ouvrant par 8 dents. ....... 3 Mcenchia.

7 - Capsule à 3 valves ; f. linéaires. . . . . . . . . 8 Alsine.

- Capsule à 6 valves. . . . . . . . . . . . 8

8. - Fl. en ombelle; dents de la capsule roulées en dehors.. . . . .

. . . . . . . . . . . . . . . 5 Holosteum.

- Fi. non en ombelle. . . . . . . . . . . . 9

9 - F. à 3-5 nervures principales; graines lisses. . . 7 Mohringia.

- F. à 1 nerrure; graines tuberculeuses. . . . . 6 Arenaria.

\section{1 - MALACHIUM Fries. - Malaquie. -- Pl. III.}

F. ovales-lancéolées, grandes (โ. 29), les sup. sessiles; כ̋ pét., 10 étamines. - \%. Jn-at. Lieux lumides. R. Bords du Touch, Bieau-

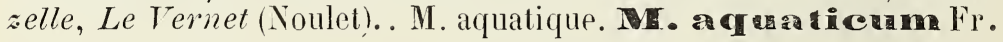

\section{2- CERASTIUM L. - Céraiste. - Pl. III.}

1 - Pétales 2-3 fois plus longs que le calice; pédicelles longs; bractées scaricuses. - q. Av.-mai. RR. T. Pelouses du Jardin des Plantes......... G. des champs. C. an'vensas L.

- Pétales plus courts que le calice ou l'égalant. ..... 2

2 - Pédicelles plus courts que le calice ou l'égalant (f. 30); plante velue-glanduleuse, à bractées herbacées, à sépales barbus au sommet. - (1). Av.-jlt. CG. Champs, bords des chemins. . . . .

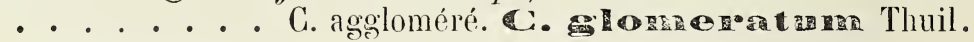

- Pédicelles plus longs que le calice (f. 31). . . . . . . . 3

3-Sépales longuement barbus au sommet; 10 étamines à filets ciliés; plante hérissée; cymes làches. - (I). Av.-jn. C. Friches, champs graveleux. . . . . . . . . . . . - . . C. à courts pétales. C. borechyper alum Desp.

- Sépales à sommet non dépassé par les poils ; étamines à filets glabres. .

4 - Sépales ol,tus, ordint. non glanduleux, scarieux (f. 31, 31 bis); tiges couchées et souvent radicantes à la base. - (2) ou \%. Av-oct. CC. Bords des chemins, mu's, champs, prés. (C. vulgatum Auct.). . . . . . . . C. vulgaire. C. Toiviale Link. 
- Sépales aigus, à pointe glabre; plantes plus ou moins visqueuses; capsule presque droite. . . . . . . . . . 气

5 - Bractées infres largement scarieuses aux bords et au sommet ; ord.' ${ }^{3}$ ćtamines. - (1). Av-jn. C. Pelouses sablonneuses, murs. .

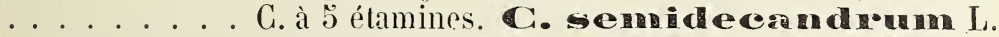

- Bractées inférieures herbacées. - (I). Av-jlt. C. Pelouses

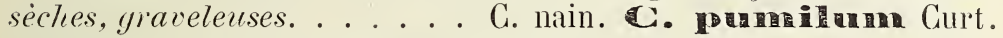

Bractées supres scarieuses; pédicelles arqués; pétales égaux au calice ou 1 fois plus longs (v. litigiosum de Lens).

\section{3 - MENCHIA Ehrh. - Mønchic. - Pl. III, f. 32.}

Glabre et glauque, à f.ćtroites ; 1-3 fleurs tétramères. - (1). Av-mai. AG. Pelouses sèches, fossés, bords des chemins, terrains siliceux (M. erecta Baxter ; Cerastium Fenzl.).

M. tétramère. M. quateromella Ehrh.

\section{4 - STELLARIA L. - Stellaire. - Pl. III.}

$1-\mathrm{F}$. inf.res ovales et pétiolées; pétales égalant à peu près le calice; plante diffuse, à 3-ŏ étamines. - (1). Toute l'année. CG. Cultures, haies, lieux humides (Mouron des oiseaux).

S. moyenne. median Gyr.

Tiges peu rameuses; f. grandes; 10 étamines. - Lieux ombragés.

- R . . . . . . . . S. négligée. S. neglecta Weibe.

Pétales nuls ; $2-3$ étamines ; plante de $5-15 \mathrm{~cm}$ - Lieux secs. - R.

- S. de Boreau. s. Boræana Jord.

- F. infres lancéolées ou oblongues et sessiles. . . . . . 2

2 - Fl. grande ( 1 1 $12-2 \mathrm{~cm}$.), à pétales 1-2 fois plus longs que le calice, à lobes rapprochés (f. 33). - 4. Av.-mai. CG. Haies, bois............ S. holostée. 面olostea L.

- Pétales dépassant peu le calice (f. 34). . . . . . . 3

3 - Pétales à lobes rapprochés; bractées ciliées aux bords; capsule plus longue que le calice (f. 34). - \%. Mai-spt. G. IIaies, bois, fossés. . . . . . S. graminée. grogentin ea I.

- Pétales à lobes divergents ; bractées non ciliées ; capsule égalant le calice. - (1), (2) ou \%. Mai-jll. R. Marécages, bords des ruisseaux, des sources. Le Ternet, T. (Noulet).. ........... S. des marais. andignos Murr.

$$
\text { 丂 - HOLOSTEUM Dill. - Holostée. - Pl. III, f. } 3 \check{.}
$$

Glauque ; f. sup. sessiles, elliptiques ; 3-כ̆ étamines. - (1). Marsmai. AC. Champs cultivés, murs, coteaux tertiaires.

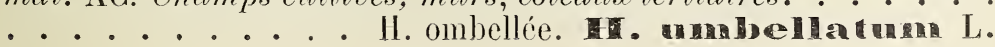


6 - ARENARIA L. - Sabline. Pl. III.

Tiges ordin.t nomhreuses ; f. petites, sessiles, ovales (f. 36) ; cymes làches; capsule ovale-globuleuse, à parois épaisses. - (I). Mai-spt. CC. Murs, champs sablonneux, borls des chemins. . . - . . . S. à f. de serpolet. A. se topyllíiolia I.

Pédoncules très étalés ou divariqués. . . . . . v. patula de Martr.

Tiges grêies; capsule ovale-allongée, mince, non résistante ì la pression. ............... v. leptocleda Rchb.

\section{7 - MEHRINGIA L. - Mœhringie. - Pl. III, f. 37.}

F. ovales, pubescentes, les inf. pétiolées; cymes làches; pétales plus courts que les sépales, 10 étamines. - (I). Mai-jlt. CG. Lieux humides, haies, bois. . M. à 3 nervures.

Tige simple, à ramcaux dressés. - Pouvourville. v. erectı de Martr.

$$
\text { 8-ALSINE Wahl. - Alsine. - Pl. III. }
$$

Grèle et glabre ; f. linéaires, recourbées au sommet ; cymes lâches, à pédicelles dressés (f. 38); sépales glabres. - (1). Maispt. CG. Murs, terres sablonneuses. . . . . . . . .

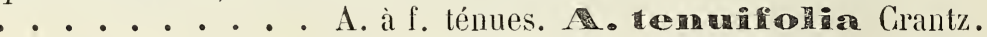

F. non recourbées; cyme très làches et très étalées. - Mêmes lieux, mais plus R.............. laxa (Jord.).

$$
9 \text { - SAGINA L. - Sagine. - Pl. III. }
$$

- Tiges couchées-radicantes, naissant d'une rosette de feuilles (f. 39); 4 sépales obtus, étalés; plante glabre. - (2) ou \%. Av.oct. G. Lieux sablonneux lumides.

- Tiges non radicantes, naissant du collet de la racine ; 4 sépales obtus, très étalés à la maturité (f. 40). - (1). Av.-oct. C. Lieux sablonneux........ S. apétale. apetala L.

sépales appliqués sur la capsule, les 2 externes mucronés (ì rechercher). . . . . . . . . . . . . S. ciliée. S. ciliata Frịes.

$$
10 \text { - SPERGULA L. - Spergule. - Pl. } 11 \text { I. }
$$

- F. sillonnées en dessous; pétales obtus ; graines subglobuleuses, étroitement bordées. - (1). Av-jn. C. Moissons, cultures. .......... S. des champs.

Graines hérissées de papilles blanchàtres, puis roussâtres. - C. .

- F. non sillonnées en dessous; pétales aigus; graines lenticulaires, lisses, à aile blanche, aussi large que le diamètre de la 
graine (f. 41). -- (1). Ms-mai. C. Lieux sablonneux, moissons. . ......... S. à 气̆ étamines.

Le s. Morlsonii Bor.. à pétales obtus, à graines hérissées de papilles blanchàtres et bordées d'une aile roussâtre égalant la $1 / 2$ de la largeur de la graine, est à rechercher dans les terrains siliceux.

11 - SPERgULARIA Pers. - Spergulaire. - Pl. 111.

Plante pubescente et glanduleuse au sommet; I. linéaires (f. 42) ; tl. roses, petites, en cymes feuillées; graines non ailées. - (1) ou (2). Mai-spt. G. Bords des chemins, champs sablonneux.

\section{2 - POLYCARPON Lefl. - Polycarpon. -- Pl. 111.}

F. ovales ou oblongues, les médianes verticillées (f. 43); stipules et bractées argentées. - (1). Mai-oct. C. Boirds des chemins, ter-

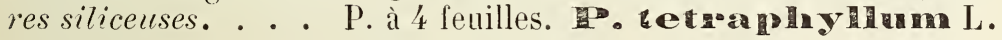

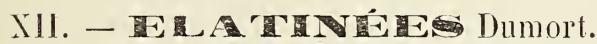

\section{ELATINE L. - Elatine. - Pl. IV.}

Tige é|raisse ; f. submergées, étroites, verticillées par 8-10, les autres plus larges, par 3-כ̆ (f. 1); fl. sessiles. - భ. Jn-spt. AR. Lieux inondés, Bouconne, La Ramette. . . . . . . . . . .

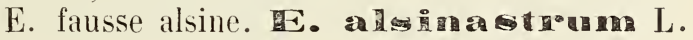

\section{NIII. - H}

- Etamines en 5 faisceaux; sépales inégaux; f. de 15-40 mm. de

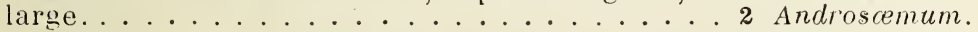
- Etamines en 3 faisceaux; sépales presque égaux; capsule déliscerite jusqu’à la base............. 1 Hypericum.

\section{1 - HYPERICUM L. - Millepertuis. - Pl. IV.}

1 - Tige à 4 angles ailés ; sépales très aigus; f. ovales-elliptiques, sessiles, ponctuées-pellucides. -- \%. Jn-spt. AG. Bords des eaux, fossés (H. tetrapterum Fr.).

— Tige arrondie ou à 2 lignes saillantes. . . . . . . 2

2-Tige et f. velues; sépales aigus, 3 fois plus courts que les pétales (f. 2). - \%. Jn-at. C. Bois, bords des ruisseaux . . . . . - Tige el feuilles glahres. . . . . . . . 3 
3 - Sépales bordés de cils glanduleux (f. 3); f. larges, cordées à la base.

- Sépales non bordés de cils glanduleux; tige à 2 lignes saillantes................. 气

4 - Sépales lancéolés-aigus (f. 3), 2 fois plus courts que les pétales; 1. sup. res seules ponctuées. - \%. Jn-at. G. Bois couverts. .

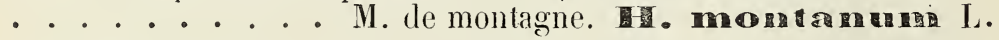

- Sépales ovales-obtus, 3-4 fois plus courts que les pétales; f. toutes ponctuées (โ. 4). - צ. Jn-at. C. Landes. bois siliceux. . .

$\breve{-}$ - Tige dressée, rohuste; f. non cordées, ponctuées (f. 气̋); sépales aigus (f. 6). - ษ. Mai-at. C. Lieux secs, bois, murs. . .

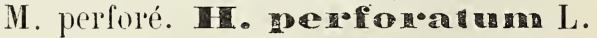

-- Tige grêle, couchée; f. oblongues; quelques sépales obtus ; fl. petites. - \&. Jn-spt. C. Landes, terres caillouteuses.

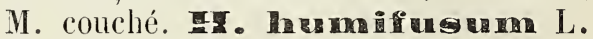

L'infusion de millepertuis est vulnéraire et vermifuge. On cultive l'H. calycinum L.. à $\mathrm{fl}$. de $4 \mathrm{~cm}$. de diamètre ct plus, munies de 5 styles.

\section{2 - ANDROS FMUM All. - Androsème. - Pl. IV.}

- Glabre, inodore ; l. ovales, de 3-4 cm. de large, glaucescentes; sépales obtus; pétales dépassant peu le calice; baie (f. 7). — \&. Jn-jtt. C. Lieux frais, bois, bords des russseaux. . . . . . . . . .

- Odeur fétide; 1. de 15 -25 mm.; sépales aigus ; pétales dépassant longuement (3-4 lois) les sépales; capsule. - 2. Mai-jn. Plante de Corse, cultivée et parfois subspontanée (IIypericum L.). . . . . . A. à odeur de bouc. A. Hach.

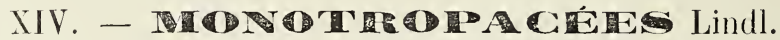

HYPOPITYS Dill. - Suce-pin. - Pl. IV, f. 8.

Tige de 1-4 dm.; fl. odorantes, jaunes, en grappe d'abord penchée. - 2. Mai-jlt. R. Bois, au pied cles arbres. Bouconne, le long de l'Aussonnelle (Noulet). (Monotropa Hypopitys L.). . . . .

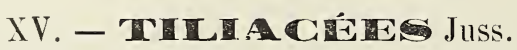

$$
\text { TILIA L. - Tilleul. - Pl. IV, f. } 9 .
$$

- Bourgeons glabres; f. glalıres en dessous (sauf à l'aisselle des 
nervures); fruit subglobuleux, sans còtes. - ந. Jlt. AR. Forêt de Boucomne (T. silvestris Desf.).

T. à f. d'orme. allimifolio Scop.

- Bourgeons glabres ; f. glabres en dessous (sauf à l'aisselle des nervures); fruit elliptique, à côtes saillantes. - 乌. Jlt. (à rechercher). ( $T$. intermedia Auct. non Host.).

T. vulgaire. Th mayne.

On plante les T. platyphylla Scop. à bourgeons et f. velues en dessous. T. argentea Desf, à f. tomenteuses en dessous, et autres. L'infusion de fl. de tilleul est calmante et antispasmodique.

\section{XVI. - A C Adans. -- Pl. IV.}

Calicule à 3 divisions libres (f. 11). . . . . . . 1 Malva. Calicule à 6.8 divisions soudées à la base $(.13)$. . . . 2 2 Althrea.

\section{1 - MALVA L. - Mauve. - Pl. IV.}

1 - Fl. axillaires, solitaires, grandes ; calicule à folioles linéaires ; f. divisées en lanières étroites. - Ұ. Jn-spt. AC. Prés, haies, terrains siticeux. . . . . M. musquée. ME. Mog hata L.

— Fl. fasciculées à l'aisselle des feuilles (f. 11). . . . . . 2

2 - Fl. de $2-3 \mathrm{~cm}$. de diam., d'un violet purpurin (f. 10), à pétales 3-4 fois plus longs que le calice. - (2). Mai-oct. CG. Décombres, lieux incultes. . . . . . . M. sauvage. M. Mo

- Fl. de 1-1 1/2 cm. de diam., à pétales $1-2$ fois plus longs que le calice (f. 11) ; fl. pâles. . . . . . . . . . . 3

3 - Calicule à folioles ovales ou ovales-lancéolées; carpelles rugueux-réticulés. - (1). Mai-spt. AC. Lieux incultes. .. . . . . .

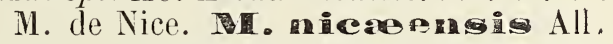

- Calicule à folioles linéaires; carpelles mûrs lisses (f. 11). - (1) ou (2). Mai-spt. C. Lieux incultes. . . . . . . . . . . . .

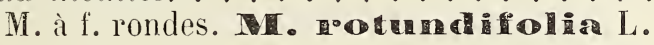

\section{2-ALTH无A L. - Guimauve. - Pl. IV.}

1 - Annuelle : divisions du calice linéaires, hérissées, presque aussi longues que les pétales lilacés (f. 12). - (I. Mai-jlt. C. Lieux incultes, bords des champs. . G. hérissée. A D D.

- Vivace; divisions du calice ovales-acuminées, bien plus courtes que la corolle (f. 13). . . . . . . . . . . 2

2 - F. sup.res palmatiséquées; carpelles glabres (f. 13). - \&. Jn-at. AR. Lieux fiais, haies, vallée de la Garonne, Ste-Foy (M. Marty). ..... G. à f. de chanvre. A. cammahina I. 
- F. ovales, blanchâtres, à 3-ŏ lobes; carpelles tomenteux. 4. Jn-spt. C. Lieux humides. Bords de l'Iers, Fonsegrives, etc. G. officinale. A. oficienalis L.

Toutes les Maloacées sont émollientes. On cultive l'A. rosea Cav., à fleurs grandes et de couleur très variable (Rose trémière. passerose).

\section{XVII. - L T C C}

5 sépales, 5 pétales. . . . . . . . . . 1 Linum.

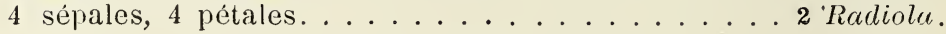

$$
1 \text { - LINUM L. - Lin. - Pl. IV. }
$$

1 - F. toutes opposées, les movennes lancéolées ; fl. petites, blanches. - (1). Mai-oct. C. Pelouses, bois.

, . . . . . L. purgatif. L.

- F. moyennes et sup res alternes. . . . . . . . . . 2

2 - Fleurs bleues; stigmate en massue . . . . . . . . . 3

— Fl. jaunes; stigmate en tête arrondie. . . . . . . . . . 4

- Flenrs roses; stigmate en tête arrondie ; f. linéaires (f. 14). 4. Mai-spt. G. Friches des coteaux.. . . . . . . . . . . . L. à f. ténues. C. Conuifolínm L.

3 - Souche produisant plusieurs tiges; pétales 2 fois plus longs que le calice; graines de $3 \mathrm{~mm}$. - 4. Mai-oct. AC. Prés, pelouses

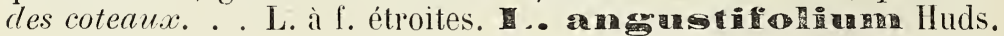

- Une seule tige; pétales 3 fois plus longs que le calice; graines de $\check{5} \mathrm{~mm}$. - (1). Cultivé cà et là, et parfois subspontané

L. cultivé, 而. asitąissimum $\mathrm{I}$.

4 - Panicule lâche, à rameaux glabres; sépales 1 fois plus courts que les pétales et égalant la capsule (f. 15). - (1). Mai-jit. C..

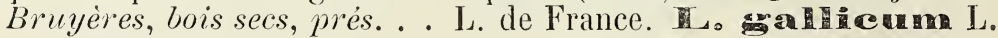

- Panicule dense, à rameaux pubescents; sépales d'un tiers plus courts que les pétales et bien plus longs que la capsule (f. 16). - (1). Mai-ju. Lieux arides, coteaux tertiaires.

L. raide. L, stroictenm i.

Les graines du Lin cultivé sont adoucissantes et diurétiques; on en faít des cataplasınes émollients; son huile est purgative.

$$
\text { 2-RADIOLA Dill. - Radiole. - Pl. IV , f. } 17 .
$$

Naine et glabre; f. ovales, opposées; fl. très petites, blanches. (1). Jn-oct. Lieux sablonneux humides. R. Buconne..

R. faux lin. IR. Iinoives Roth. 


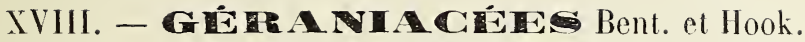

- 10 étamines fertiles; arêtes du fruit glabres à la face internc. ar. quées en arc de cercle (f. 21); f. palmées........ 1 Gercunium.

- 5 étamines seu!ement pourrues d’anthère; arêtes poilues à la face interne et enroulées en spirale à la maturité (f. 23). . 2 Erodium.

$$
1 \text {-- GERANIUM L. - Géranium. - Pl. IV. }
$$

1 - Pétales entiers ou denticulés. . . . . . . . . . 8

- Pétales échancrés ou bifides. . . . . . . . . . . . 2

2 - Pédoncules uniflores; fl. grandes, purpurines (f. 18); f. palmatipartites, à $ّ-7$ segments trifides. -- \%. Jn-spt. CG. Bois, friches des coteaux. . . . . . G. sanguin. Gì. Sang gaineum $\mathrm{L}$.

- Pédoncules à 2, 3 fleur's de couleur claire.. . . . . . . . . 3

3 - F. à segments étroits, atteignant presque le pétiole (f. 19).

- F. à segments atteignant à peine le milieu du limbe. . . .

4 - Pédoncules plus longs que les f.; carpelles glabrescents; pédicelles 4-10 fois plus longs que le calice (f. 19). - (2) ou (1). Av.jlt. C. Haies, bords des chemins, fcultures. . . . . . . . . .

- Pédoncules plus courts que les $\mathrm{f}$.; carpelles velus; pédicelles égaux au calice. - (2) ou (1). Av.-jlt. C. Champs, haies.

$\check{8}$ - Pétales 2 fois plus longs que le calice (f. 20). . . . . . 6

— Pétales dépassant à peine le calice. . . . . . . . . . T

6 - F. infres palmatifides, à ̌ lohes larges, polygonales dans leur contour ; pédicelles fructifères dressés ; fleur's lilas, veinées. - భ. Mai-at. C. Bois des coteaux, ruissean.x. . . . . . . . . . . .

G. noueux. Gor od rogm L.

- F. inf.res palmatifides, à 7 lobes, orbiculaires dans leur contour ; pédicelles fructifères réfléchis ; pétales violets ou lilas (f. 20). - \%. Mai-at. R. Rives de l'Ariége et de la Garonne.

G. des Pyrénées. Tr. pyomaicen $L$.

7 - Valves des carpelles non ridées, pubescentes; pétales d'un violet pâle ; filets des étamines ciliés ì la base. - (1) ou (2). Maisept. C. Décombres, bords des chemins.

- Valves des carpelles ridées (f. 21), glabres ; pétales purpurins (rar. ${ }^{\text {t }}$ blancs) ; filets glabres. - (1) ou (2). Mai-sept. CC. Champs, décombres, bords des chemins. . . . . G. mou. molled L. 
8 - F. palmatifides, les moyennes à $\breve{~ l o b e s ~ ; ~ p e ́ t a l e s ~ r o s e s, ~ e n-~}$ tiers, un peu plus longs que lé calice. - (1) ou (2). Av.-sept. CG. Fossés, murs, bords des chemins. . . . . . . . . . .

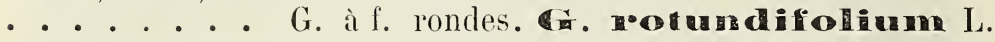

- F. palmatipartites, à ô-7 lobés; pétales d'un violet noir, de 7$10 \mathrm{~mm}$. de large. - \%. Av-jtt. R. Palaminy, bords de la Garonne (Duteyeul). . . . . . . G. livide. I

- F. palmatiséquées, à segments pennatifides; pétales purpurins, 2 fois plus longs que le calice. - (2). CG. Haies, murs, rochers,

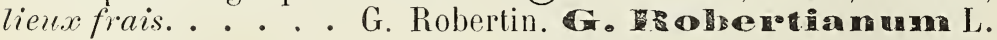

Fl. plus petites, à pétales dépassant peu Je calice. - R. Villenéuveles-Cugnaux ............ G. purpureum Vill.

\section{2 - ERODIUM L'llérit. - Erodium. - Pl. IV.}

1 - F. crénelées ou lobées; pédoncules 3-8-flores (f. 22). - (1). Ms-nov. C. Tertres, murs, champs.

E. fausse mauve. 耳. ninadacondes Will.

Lobes desf. se recouvrant; frut à bec de $24-28 \mathrm{~mm} . . . . . .$.

................. . v. maloaceum (Jord.).

Lobes des f. ne se recouvrant pas ; fruit à bec de $18-20 \mathrm{~mm} .$. . . . v. althooidles (Jord.).

- F. pennatiséquées, à segments plus ou moins divisés. . . . 2

2 - Fruit à bee de 6-8 cm. (f. 23 ) ; étamines à filets ciliés ; pétales purpurins, inégaux. - (1). Av.-jlt. AR. Tertres, bords des chemins; coteaux de la Garomne, canal du Midi.. . . . . . . E. bec de cigogne. C. con

- Fruit à bec ne dépassant pas 40 mm. . . . . . . . 3

3 - Segments des 1 . dentés ou incisés (f 24) ; bractées non acuminées; filets des élamines lertiles bidentés à leur lase. Odeur de musc. - (1) ou (2). Av.-sept. R. Pelouses, bords des chemins.

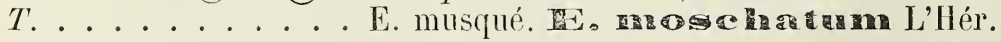

- Segments des f. profondément divisés; bractées acuminées; filets non dentés ; odeur faible, non musquée. - (1) ou (2). CC.

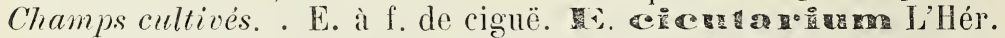

plante à tige courte ou nulle. - Toulouse. . V. tolosanum (Jord.).

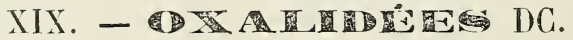

$$
\text { OXALIS I. - Oxalide. - Pl. IV. }
$$

- Tiges radicantes à la base, à f. alternes, stipulées (f. 20̆) ; pétales jaunes ; pédicelles fructifères réfractés. - (1), (2) ou \%. Maioct. CG. Bords des chemins, Lienx cultivés. . . . . . . . . . 
- Souche à stolons souterrains charnus, à tige dressée, non radicante; f. non stipulées; fl. plus grandes; pédicelles fructif. non réfractés. - भ. Jn-oct. R. Rives du Tarn. (A rechercher). . . . .

On cultive l'o. erenata Jacq.. originaire du Pérou et naturalisé dans quelques jardins, à Toulouse.

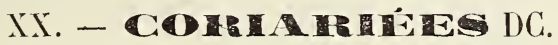

\section{CORIARIA Nissol. - Corroyère. - Pl. IV.}

F. elliptiques-lancéolées, entières (f. 26) ; fl. verdâtres (f. 27), en grappes simples; fruit noir. - b. Av-jlt. C. Haies, friches des

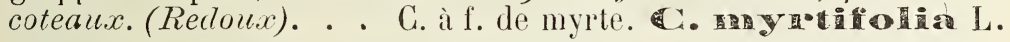

Le fruit du Redoux est très vénéneux.

\section{XXI. - r}

\section{TRIBULUS Tournef. - Tribule. - Pl. IV.}

Tiges couchées; f. à ö-8 paires de folioles; pétales petits, jaunes ; capsule épincuse (f. 28). - (1). Av-spt. RR. Lieux stériles. Coteaux de Pech-David ; près du pont de Blagnac (Noulet). . . . . . . . . . . T. terrestre. To to

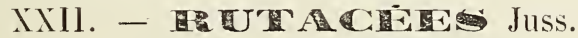

$$
\text { RUTA L. - Rue. - Pl. IV. }
$$

F. à segments obovales; fl. jaunes (f. 29); odeur nausécuse. — భ. Jn-at. Cultivé et parfois subspontané. . . . . . . . .

Plante rubéfiante, irritante, emménagogue. A administrer avec prudence.

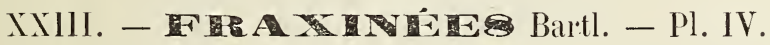

- 4, rarement 2, pétales blanes, très étroits, bien plus longs que le

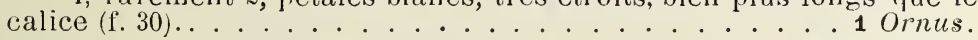

- Calice et corolle nuls. ........... . Fraxinus.

$$
1 \text { - ORNUS Pers. - Orne - Pl. IV, f. } 30 .
$$

Fl. en grappes très fournies; f. imparipennées, à 7-9 folioles elliptiques, dentées. - Ђ. Av.-mai. - Vallon, près de Vieille-Tou-

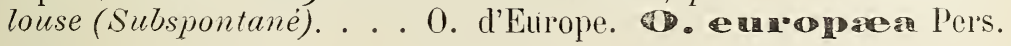




\section{2 - FRAXINUS Tournef. - Frène. - PI. IV.}

Fl. en grappes courtes, opposées ; f. à 气̌-9 paires de folioles plus ou moins dentées ; samare elliptique-oblongue (f. 31). - Ђ. Av.mai. C. Bois, vallons. Planté... F. élevé. Oxeolsion- L.

Fruits très atténués à la base, obtus at sommet; dents prononcées. - R. La Ramette. . . . . . F. à fruits ajgus. F. oxycarpa Willd.

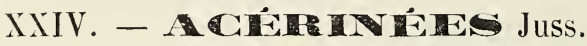

\section{ACER Tournef. - Erable. - Pl. IV.}

- F. vertes en dessous, palmatilobées, à כ̆ lobes; fl. en grappes corymbiformes dressées, sessiles (f. 32, fruit). - h. Av.-mai. C. Bois, haies. . . . . . . E. champêtre. A. campestro L.

- F. à 3 lobes (f. 33); ailes des samares rétrécies à leur base (f. 34). - h. Av.-mai. R. Coteaux calcaires, Couladère, StChristaud. .......................

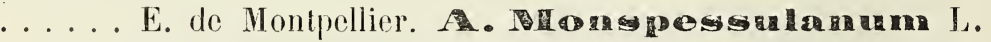

On plante les A. pseudoplatanus L. (Sycomore), à graples pendantes et pédonculées; $\mathbf{A}$. platanoides L. (E. plane), à orappes corymbiformes, pédonculées; et l'A. Negundo L., espèce américaine à f. pennatiséquées, à 3-5 folioles rappelant celles du frêne.

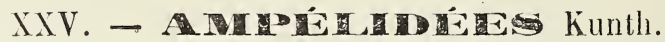

$$
\text { VITIS Tournef. - Vigne. }
$$

F. à 3-ŏ lobes; fl. verdâtres, en panicule ; baie globuleuse. - $\mathfrak{h}$. Cultivé et naturalisé çà et là. . . . . . . V. vinnifera L.

On cultive également l'Ampsiopsis hederacea Michx. (Vigne vierge), à feuilles palmatiséquées.

\section{XXV1. - M}

\section{FESCULUS L. - Marronnier.}

On cultive l'z\$. hippocastanum L., à fl. blanches, tachées de rougge et de jaune, et l'As. rubicunda Lodd., à fl. rouges. 
Sous classe II. - Caliciflores.

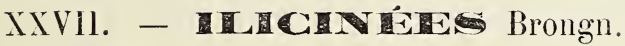

\section{ILEX L. - Houx. - Pl. IV, f. 3̋̈. 36.}

F. glabres ; fl. blanches, agglomérées ; drupes persistantes. Ђ. Fl. mai-jn ; fr. oct. C. Bois, haies dles coteaurx. . . . . . . . . . . . . . . . . . . H. commun, 直, agh

\section{XXVIII. - C R}

EVONYMUS Tournef. - Fusain. - Pl. IV, f. 37 (fruit).

F. elliptiques-lancéolées ; pédoncules à 2-4 fleur's verdâtres. - Y . Mai-jn. AG. Haies, bois. Coteaux de la Garonne, vallée du Touch,

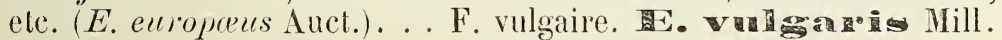

Le fruit du fusain est irritant et purgatif ; son bois fournit un charbon très empinyé par les dessinateurs.

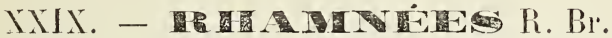

\section{RHAMNUS Tournef. - Nerprun. - Pl. IV.}

1 - F. opposées sur les jeunes rameaux, caduques, ovales ou elliptiques, denticulées, pétiolées ; fl. verdâtres, à tétamines ; rameaux à la fin épineux. - b. Av.-jn. AG. Haies, bois, ter-

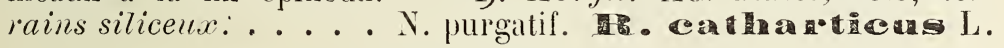

- F. alternes : rameaux non épineux. . . . . . . . 2

2 - F. persistantes, ovales-obtuses, dentelées (f. 38) ; grappes multiflores ; pétales nuls. - h. Fëv.-jn. AR. Coteaux de l'A iriège et

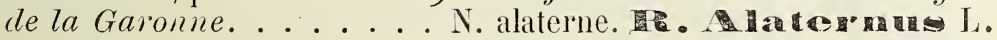

- Feuilles caduques, ovales-aiguës, entières (f. 39); fl. en petits

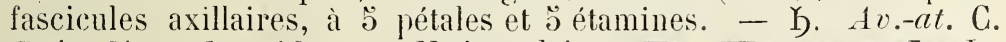
Bois, lieux humides. . . N. bourdaine.

Les drupes de ces arbustes sont purgatives. Le Paliurus australis Gartı., à f. altermes, finement dentées. à fruit hémisphérique, sec et ailé, est planté le long du chemin de Périole. - Jn at.

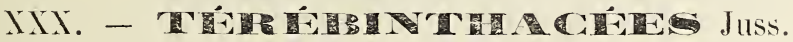

RHUS L. - Sumac. - Pl. IV.

Arluuste de 23 m.; f. à $7-13$ folioles dentées (f. 40); fl. blanches, 
en panicule compacte. - 5. Jn-jlt. R. Entre Cintegabelle et Aute-

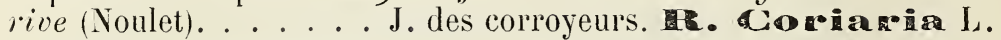

Lc sumre est vénéneux; son écorce est cmplovée à la tannerie. L'Ailanthus glandulosa Desf. (Vernis du Japon), arbre le haute taille, à feuilles imparipennées et à fruit sec indéhiscent (samare), estnaturalisé sur un grand nombre de points. Il est originaire du Japoll.

\section{XXXI. - LEGUMINTUGES Juss. - PI. V.}

1 - Calice à 2 sépales distinets jusqu’à la base ; arbrisseau épineux, à fl. jaunes (f. 8) . . . . . . . . . 9 Ulex.

- Calice fendu en dessus, à 1 seule lèvre (f. 7); f simples. . . .

- Calice à 2 lèrres ou à $4-5$ dents . . . . . . . . . . . . . 2

2 - Etamines libres; Cololle nulle...... 1 Gleditschia. arbres. $\quad$ Corolle papilionacée, rose. . . 2 Cercis.

- Etamines soudées en 1 ou 2 faisceaux. . . . . . . . . 3

3 - F. digitées, à 8-9 folioles (f 1 ) . . . . . . . . 3 Lupinus.

- F. paripennées, parfois réduites à 1 vrille ou à 1 pétiole élarọi en forme de t. linéail'e. . . . . . . . . . . 19

- F. a 1 ou 3 folioles. . . . . . . . . 4

- F. imparipennées . . . . . . . . . . . 15

4 - Etamines monadelphes (a filcts soudés en 1 faisceaı). . . 5

- Etamines diadelphes (1 libre, 9 soudées par les filets) . . . . 8

5 - Calice à 5 divisions profondes, linéaires (f. 9). . . 10 Ononis.

- Calice à 2 lèvres; fl. jaunes. . . . . . . . . . . . . 6

6 - Etendard étroit ; f. simples ; pédicelles courts (f. 4 et 5 ). . . .

- Etendar à limbe oblong ou orbiculaire; f 3 -foliées; gousse

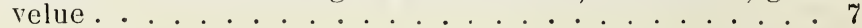

7 - Etendard oblong ; calıce à lèvre supre courte, bidentéc (f. 2).

Etendard o. . . . . 4 Cytisus.

- Etendard orbiculaire ; calice à lèvre supro courte, bidentée (f. 3).............. 5 Sarothamnus.

- Etendard orbiculaire ; calice à lèvre supre allongée (f. 6).

7 Aigyrolobum.

8 - Carène, étamines et style contournés en spirale (f. 32). . . .

- style droit ou arqué. . . . . . . 21 Phaseolus.

9 - Fleurs bleues; gousse indéhiscente, à 1 graine. 16 Psoralea.

- Fleurs jaunes, petites, en ombelles pédonculées ; foliole médiane bien plus grande que les latérales (f. 46).

Nou comm a 33 Coronilla scorpioides.

10 - Stipules développées, foliacées (f. 29). . . . . . . . 11

— Stipules très différentes des folioles (f. 11) . . . . . . . 13

11 - Gousse à 4 angles ailés . . . . . . . . 20 Tetragonolobus.

- Gousse non ailéc|Fl. jamnes. . . . . . . . 19 Lotus

12 - Carène droite, obtuse; graines séparées par un tissu lâche. . .

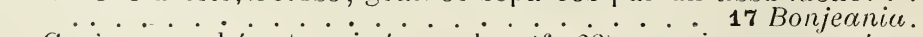

- Carène courbée, terminée en bec (f. 2s); graines non séparées par un tissu làche.......... 18 Dorycnium.

13 - Gousse dépassant peu ou point le calice ; fl. denses, en épis ou en capitules (f. 11).........15 Trifolium. 
- Gousse dépassant sensiblement le calice.

14 - Gousse courte, courbéc en forme de rein, de faux, ou contournéc en hélice (f. 14). . . . . . . . 12 Medicago.

- Gousse longue. linéaire, plus ou moins arquée, à plusieurs graines (f. 15)........... 13 Ti igonella.

- Goussc ovoïde ou oblongue, indéhiscente, à-1-4 graines (f 16), fl. en grappes.. . . . . . . . . . 14 Melilotus.

15 - Etamines monadelphes ; gousse incluse dans le calice.

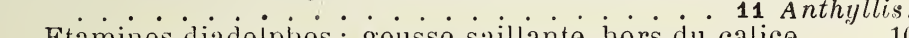

- Etamines diadelphes; gousse saillante hors du calice. . . 16

16 - Gousse à 2 loges longitudinales; fl. jaunâtres ou purpurines.

- Gousse à 1 seule loge, s'ouvrant par 2 valves. 22 Astragalus.

- Gousse divisée en loges ou en articles transversaux (f. 48). 18

- Gousse à 1 seul article, rugueuse (f. 44); fl. roses, en @rappes.

32 Onobrychis.

17 - Arbre épineux ; fl. blanches, en grappes. . . . 24 Robinia.

- Arbuste à gousse très enflée, vésiculeuse (f. 34 ); fi. jaunes

. . . . . . . . . . . . 23 Colutea.

- Plante herbacée ; fleurs purpurines. . . . . . 25 Cicer.

18 - Carène obtuse; gousse linćaire (f. 49). . . . 35 Ornithopus.

- Carènc acuminée ; gousse à articles échancrés en fer à cheval ; fl. jaunes. .......... 31 Hippocrepis.

- Carc̀ne acuminéc; gousse cylindrique . . . . 33 Coronillx.

19 - Tube des étamines tronqué à angle droit. . . . . . . . 20

- Tube des étamines tronqué obliquement. . . . . . . . . 21

20 - Stipules à base large et arrondic. . . . . . . . 31 Pisum.

- Stipules à base aiguë ; une vrille $(\mathrm{f} .40,41) .29$ Lathyrus. f. terminées par , une arête; corolle rougeâtre, devenant bleue..... 30 Orobus.

21 - F. terminées par une arête; plante dressée ; graines oblongues............... 23 Faba.

- F. terminées en vrille; graines lenticulaires ou globulses. 22

22 - Gousse linéaire ou oblongue, ayant ordinairement plus de 2 graines subglobuleuses ......... 27 Vicia.

- Gousse rlomboïdale, comprimée, à $1-2$ graines lenticulaires.

26 Lens.

\section{1 - GLEDITSCHIA L. - Févier.}

Arbre épineux, à f. 2 fois pennées, à gousse grande, brunâtre. ந. Originaire d'Amérique. Cultivé et planté dans les haies aux environs de Toulouse. - F. à 3 épines.

\section{2- CERCIS L. - Cercis.}

Fl. paraissant avant les f., qui sont orbiculaires. - 5. Ms-av. Cult. et naturalisé çà et là. (Arbre de Judée).

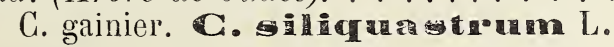

\section{3 - LUPINUS L. - Lupin. - Pl. V.}

- Folioles obovales ou ovales-oblongues, glabres en dessus ; fl. grandes, blanches. - (1). Av-jn. Cultivé et subspontané çà et 
là. L. blanc. allous L.

- Folioles linéaires-oblongues; fl. d'un bleu azuré; gousse de 10-12 mm. de large. - (1). Av-jtt. RR. Champs sablonneu.x. Toulouse. . . . . . L. à f. étroites. K. angugtifolions L.

Gousse de $7-10 \mathrm{~mm}$. de large ; graines de $3-5 \mathrm{~mm}$. de large, jaunàtres (f. 1). - Jn-jlt. AR. Plaines de la Garonne et de liAriege. . . ..................... réticulé. L. reticulatus Desv.

$$
4 \text { - CYTISUS DC. - Cytise. - P. V. }
$$

Arbrisseau de 2-6 dm., à f. trifoliées, à fl. jaunes (f. 2), rapprochées par 2-7 au sommet des rameaux; gousse de 20-32 mm. de long. - Ђ. Mai-jtt. C. Bois, bruyères. La Ramette, Bouconne,

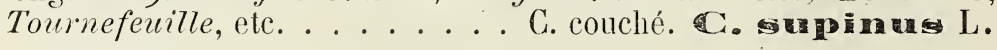

Fl. vernaies en grappes latérales le long des rameaux. - Avec le type................... v. unilateralis Legrand.

Le C. Laburnum L., à fl. grandes, en grappes pendantes, estcultivé et parfois planté daus les laaies.

\section{๖ - SAROTHAMNUS Wimm. - Sarothamnus. - Pl. V.}

F. inférieures 3-foliées, les sup.res simples; fl. grandes, pédonculées (f. 3) ; calice glabre; gousse velue, de $3-4 \mathrm{~cm}$. de long. Ђ. Mai-jlt. CG. Landes, bois (Genêt à balais, S. scoparius Wimm.). . . . . . . S. vulgaire. vilg Wimm.

Alimentaire et tonique. Noircit à la dessication.

$$
6 \text { - GENISTA L. - Genêt. - Pl. V. }
$$

1 - Rameaux non ailés, les anciens non épineux. . . . . . 2

- Rameaux non ailés, les anciens épineux (†. 5). , . . . . . 3

- Rameaux inermes (f. 4), à 3 ailes larges ; fl. en grappes terminales multiflores. - \. Mai-jlt. CG. Bruyères, coteaux secs. • ........... G. à tige ailée. Gr.

2 - Tiges couchées el radicantes; pédicelles non bractéolés ; étendard velu; gousse velue. - Ђ. Mai-jlt. R. Bois des coteaux. Estantens, prés de Muret; Bouconne (Noulet).........

- Tiges dressées ou ascendantes; pédicelles munis de 2 bractéoles; étendard et fruit glabres. - F. Mai-spt. CG. Prés, bois,

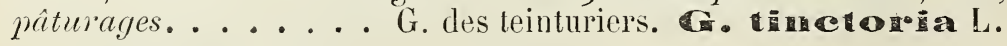

3 - Jeunes rameaux inermes; f. longuement ciliées ; grappes ohlongues; étendard pubescent; gousse velue. - h. Mai-at. C. Bois, bruyeres. . . . G. d'Allemagne. fi.

- Jeunes rameaux épineux; gousse glabre. . . . . . . . 4 
4 - Stipules nulles; f. glabres ; étendard glabre et un peu plus court que la carène (f. 丂). - Ђ. Av.-jn. AC. Coteaux secs. . . .

- Pétiole muni de 2 stipules en forme d'épine; f. un peu pubescentes en dessous; étendard glabre et un peu plus long que la carène. Très épineux. - Ђ. Mai-jlt. R. Graviers de l'Ariëge et de la Garonne (descendu des Pyiénées).

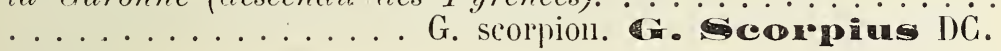

\section{7 - ARGYROLOBIUM Eckl. - Argyrolobe. - Pl. V.}

Tiges de 1-3 dm., couchées ; f. velues en dessous ; $1-3$ fl. jaunes, à corolle dépassant le calice soyeux (f. 6). - Ђ. Mai-jn. R. Friches. Clermont, St-Martin-de-Lasbordes (Genista argentea Noulet). . . -. . . . . A. linnéen. A. Kinnaeanum Walp.

$$
8 \text { - SPARTIUM L. - Spartium. - Pl, V. }
$$

Arbuste inerme, à rameaux jonciformes; fl. grandes (f. 7), jaunes, odorantes ; gousse de $\mathrm{o}-8 \mathrm{~cm}$. de long. - Ђ. Mai-at. G. Coteanx, tertres, bois clairs.

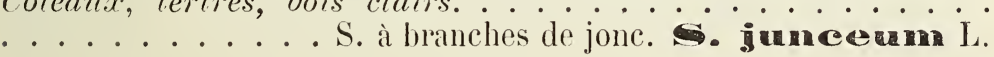

$$
9 \text { - ULEX L. - Ajonc. - Pl. V. }
$$

- Fl. de 14-17 mm. de long; calice velu, rougeattre (f. 8) ; étendard non veiné; ailes plus longues que la carène ; gousse de 6-7 mm. de large, dépassant le calice. - Ђ. Fév.-mai, automne. C. Landes, haies, bois. . . . . A. d'Europe. U. entomsons L.

Fl. de $8.10 \mathrm{~mm}$. de $10 n g$; calice pubescent; étendard non reiné ; ailes égalant la carène; gousse de $4.5 \mathrm{~mm}$. de large, dépassée par le

calice. - Oct.-noo. Portet, a la Baronique. . . ن. Lagrezei Rouy.

$$
10 \text { - ONONIS L. - Bugrane. - Pl. V. }
$$

1 - Fl. roses, en grappes terminales feuillées (f. 9); tiges radicantes à la base, à f. infres 3-foliées. - Ђ. Mai-spt. CG. Cultures, liaies (arrête-bouf). . B. traçante. O. Holle.

- Fl. jaunes.

2 - Fl. grandes (plus de $15 \mathrm{~mm}$. de long), pédonculées; corolle veinée, plus longue que le calice. - \%. Mai-jlt. AG. Graviers de la Garomne. . . . . . . . . . B. gluante. o.

— Fl. petites, subsessiles; corolle plus courte que le calice. - 4 . Jn-at. AR. Coteaux de l'Ariège et de la Garonne. . . . . . . . .

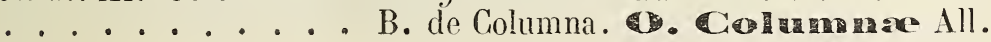




\section{1 - ANTHYLliS L. - Anthyllide. - Pl. V.}

Fl. en capitules denses; calice velu, concolore, devenant vésiculeux ; corolle jaune (f. 10); gousse à pédicule égalant sa longueur. \%. Prés, pâturages, bois. AC. Coteaux de la Garonne. . . . . . .

A. vulnéraire. V. Vulneraria $L$.

Calice pourpre au sommet; corolle rouge. - Grabiers de la Garonne. R. . . . . . . . . . . . A. Dillenii Schultes.

La vulnéraire est employée comme résolutive et entre dans la composition du thé suisse.

\section{2 - MEDICAGO L. - Luzerne. - Pl. V.}

1 - Fruit non épineux. . . . . . . . . . . 2

- Fruit couvert de pointes en forme d'épines; fl. jaunes. . . 5

2 - Fruit réniforme, de $2 \mathrm{~mm}$. environ, indéhiscent; fl. de 2-3 mm., jaunes, nombreuses, en grappes spiciformes ovoïdes (f. 11). (2). Av.-oct. CC. Prés, pelouses, cultures (Minette dorée). … . . . . . . . lupuline. Th Rupulina L.

- Fruit de plus de $3 \mathrm{~mm}$., plus ou moins courbé en faux; fl. jaunes.................... 3

- Fruit de plus de $3 \mathrm{~mm}$., à $1-30$ tours de spire. . . . . . 4

3 - Folioles orbiculaires ou largement ovales; 2-0 fl. sur un pédoncule plus court que la fenille ; gousse pendante (f. 12). - $\%$. Mai-at. AR. Pelouses, pâturages des bords de la Garonne, de l'Hers. etc. (Noulet) ; Ondes (Fiages).. . 
$\ddot{\jmath}$ - Gousse glabre. . . . . . . . . . . . 6

- Gousse pubescente ou velue, ainsi que toute la plante. . . 7

6 - Folioles larges et tachées; stipules dentées ; gousse subglobuleuse, à 4-7 lours, à bord large, à épines entrecroisées. - (1). Mai-jn. CG. Lieux herbeux, prés (M. maculata Sibth.). . . . . .

-- Folioles non tachées ; stipules laciniées; gousse à bord mince, à épines non entrecroisées. - (1). Mai-jlt. C. Coteaux, pelouses sèches. . . . . . . L. hispide. M. In ispida Gaertn.

- Gousse de 4-6 mm. de diamètre. à 11/2-3 1/2 tours de spire..

L. polymorphe. M. polymorpha Villd.

Epines presque droites, égalant $101 / 3$ du rayon du fruit. . . . . . .

Epines crochues, éçalant le så̀on du fruít . v. denticulata G. G.

- Gousse de 7-10 mm. de diam., à 2-4 tours de spire;épines égalant le diam. . . . . . . . . . L. burdane. M. Lappacea Desr.

Fruit à $4-6$ tours. . . . . . . . M. pentucycla DC.

7 - Gousse subcylindrique, glanduleuse, à 4-6 tours, avant 7-9 mm. de diam., à loòd épaissi. - (1) ou (2). Mai-jlt. AR. Pelouses sèches. T., coteaux de la Garonne. - (M. Gerardi Willd.).

L. rigide. Mr. nogidalla Desr.

- Gousse subglobuleuse (f. 14), non glanduleuse, petite, à 3-כ̆ tours, à bord étroit. - (I. Ms-jn. CC. Pelouses sèches, murs . . . ... . . . . . L. naine. M. minima Grufberg,

$$
13 \text { - TRIGONELLA L. - Trigonelle. - Pl. V. }
$$

- Fl. très petites, jaunes, $\breve{-10 ̆ ~ e n ~ o m b e l l e s ~ s e s s i l e s ~ ; ~ g o u s s e s ~ d e ~}$ 9-12 mm. de long (f. 15). - (1). Ms-jn. R. Pelouses, firches. Coteaux de la Garonne, berges des canaux. Grenade, au Polygone (Fages). . . . T. de Montpellier. T. Monspeliaca L.

- Fleurs grandes (12-15 mm. de long), blanches, solitaires ou géminées; gousse de 6-9 cm. - (1). Av.-jn. Cultivé et subspontane... . . . T. fenu-grec. T. foenume ghraecume L.

$$
14 \text { - MELILOTUS Tournef. - Mélilot. - Pl. V. }
$$

1 - Fl. blanches ; gousse petite, glabre, ovoïde (f. 16) ; tige de วั-12 dm. - (2). Jn-spt. C. Vallées de la Garonne et du Tarn. . . . M. blanc. Mr. alloa Desr.

- Fl. jaunes, longues de $2-3 \mathrm{~mm}$., odorantes; gousse subglobuleuse, de $2-3 \mathrm{~mm}$. de long. - (I). Mai-jn. RR. Lieux cultivés. Braqueville (Noulet). (M. parviftora Desf.).

- Fl. jaunes, de $5-6 \mathrm{~mm}$. 
2 - Pétales égaux ; gousse de 5 -6 mm. de long, à poils apprimés, brune à la maturité. - (2). Mai-spt. AC. Lieu.x frais ; rives de la Garonne. . . . . M. élevé. Mollissima Thuill.

- Pétales inégaux (f. 17) ; gousse de $3 \mathrm{~mm}$. de long, glabre, noire à la maturité. - (2). Mai-spt. AC. Tertres, bords des champs. M. des champs. In a romsis Wallr.

\section{0 - TRIFOLIUM L. - Trèfle. - Pl. V.}

1 - Fleurs jaunss, à calice glabre ; gousse stipitée. . . . 2

- Fl. blanches ou roses, rarement d'un blanc jaunâtre, mais alor's calice velu.

2 - Etendard lisse, à limbe caréné ; capitules à 3-15̆ fl. (f. 18) ; style 6 fois plus court que la gousse. - (1): Mai-oct. C. Pelouses, prés. . . . . . . . T. nain. ' mo mus Relh.

— Etendard strié, à limbe plan; capitules multiflores. . . . 3

3 - Stipules arrondies à la base ; pédoncules raides; style 4 fois plus court que la gousse. - (1). Mai-oct. C. Bois, pelouses . . . .

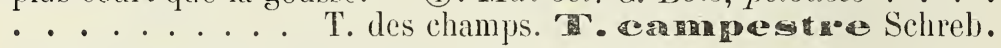

Fl. pâles, en capitules petits; tiges couchées. . . . . . . . . .

............ (T. procumbens Schreb.) v. Schreberi Rouy.

- Stipules auriculées à la base ; pédoncules fins ; style égalant à peu près la longueur de la gousse. - (1). Mai-at. C. Prés, pelouses. ............ T. étalé. T. ratens Schreb.

4 - Fl. pourvues de bractéoles . . . . . . . . . . . . . . . .

— Fleurs dépourvues de bractéoles. . . . . . . . . . 10

$\check{\partial}$ - Cullice devenant enflé-vésiculeux, bilabié ; capitules axillaires ; fl. roses . . . . . . . . . . . . . 6 6

- Calice ne devenant pas enflé-vésiculeux. . . . . . . . . . 7

6 - Bractéoles grandes, égalant les calices ; corolle non renversée ; tiges radicantes. - 4 Mai-spt. C. Prés, bords cles chemins..

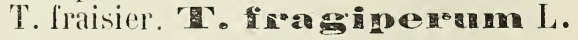

- Bractéoles petites; corolle renversée; liges non radicantes. (1) ou (2). Av-jn. RR. Pelouses, le lor g du canal du Midi (Noulet) T. renversé. '毕。

7 - Capitules dépourvus d'involucre. . . . . . . . 8

- Capitules entourés d'un involucre dentelé ; fl. l'oses, petites. (1). Mai-jn. R. Pelouses seches, bords des bois. Vallée du Touch

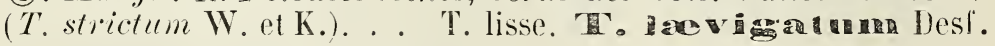

8 -... Capitules sessiles à l'aisselle des feuilles, globuleux (l. 19); f. sup. opposées, fl. roses. - I. Mai-jlt. AC. Lieure secs, bords 
des chemins . . . . . T. aggloméré. T. glomen•antum L.

- Capitules plus ou moins pédonculés . . . . . . . . . . 9

9 - Pédoncules radicaux ou presque radicaux, longs; tiges rampantes et radicantes; fl. blanches. - 2. CC. Bords des chemins. T. rampant. T. nepens L.

- Pédoncules axillaires; tiges dressées ou ascendantes, non radicantes; fl. roses. - \%. Jn-spt. AC. Bois, pelouses, bords des chemins.......... T. élégant. T. elesans Savi.

10 - Capitules tous axillaires, à 2-ô fl. ferliles (f. 20) s'enfonçant à la fin dans le sol, les sup. stériles; corolle blanche, striée de rose. - (1). Ms-spt. G. Pelouses des terrains sablonneux... . . . . . T. souterrain. T. ald a

- Non cómme ci-dessus. . . . . . . . . . . . 11

11 - Capitules les uns terminaux, les autres axillaires . . 12

- Capitules tous terminaux, non axillaires . . . . . . 1 .

12 - Capitules pédonculés, oblongs; folioles étroites oblongues ; corolle blanche ou rosée, dépassée par les dents du calice. - (1) ou (2). Mai-spt. Champs siliceux . . . . . . . . . . . T. des champs. a revense $\mathrm{L}$.

- Plante très velue; tube du calice très velu.

Dents du calice 2-21/2 fois plus longues que le tube subolobuleux. .

T. Brittingeri Weit.

Dents du calice 12 fois plus longues rue le tube ovoüde.

T. agrestinum Jord.

- Plante glabrescente; calice peu velu . . . . . T. gracile Thuil.

- Capitules sessiles.

13 - Nervures latérales des folioles arquées en dehor's; calice à dents raides ; fl. blanches. - (1). Mai-jn. AC. Pelouses sèches. . .

- Nervures latérales des folioles droites. . . . . . . 14

14 - Dents du calice fructilère conniventes; stipules lancéolées ; graine de $1 \mathrm{~mm}$. - (1). Jn-jlt. C. Bois des teriains siliceu. . . .

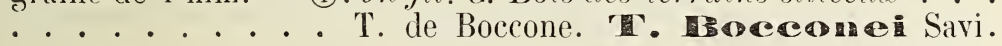

- Dents du calice fructifère divergentes; stipules triangulaires ; graines de près de $2 \mathrm{~mm}$. de diam. - (1). C. Pelouses, lieux caillostenx: vallée de la Garonne. . T. strié. T.

10 - Tule du calice à nervures nombreuses (20 ou phrs) (f. 21 ).

- Tube du calice à 10 nervures. . . . . . . . . $17^{\circ}$

16 - Corolle rosée, égalant à peine le calice; capitules courts. -- 
(1). Mai-jn. AG. Lieuxarides, prés.

- T. bardane. T. lappaceum $\mathrm{I}$

- Corolle purpurine, dépassant le calice (f. 21) ; capitules gros, allongés. - భ. Jn-at. C. Bois. . . T. rouge. T. Nubens L.

17 - F. sup.res alternes; capitules allongés........ 18

- F. sup.res opposées. . . . . . . . . . . . 19

18 - Folioles larges, toutes obovées-cunéiformes; fl. d'un rouge vif. - (1). Mai-jlt. Cultivé et subsp. çà et là (Farouch). . . . . . . . . . . . T. incarnat. T. incanomem L.

Fleurs d'un blanc rosé . . . . . . . . . . v. Molinerii DC.

- Folioles linéaires ou linéaires-lancéolées ; fl. roses. - (1). Av.jlt. C. Lieux herbeux et sablonneux. . . .

19 - Calice fructifère ouvert, à dents divergentes; corolle blanche ou rosée, dépassant le calice. - I). Mai-jn. AC. Prés lnumides; vallées de l'Hers et clu Touch, T.

T. maritime. T. maritimum Huds.

- Dents du calice non divergentes (I. 23).

20 - Fleurs d'un blanc jaunâtre, à corolle 2 fois plus longue que le calice. - 4. Mai-aout. CC. Prés, lieux herbeux.

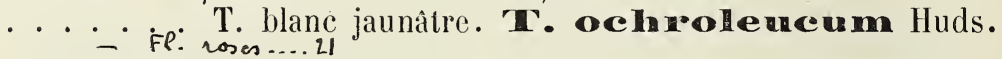

21 - Stipules à partie libre large, brusquement contractée en pointe ; calice pubescent extérieurement. - భ. Mai-spt. GG. Piés, pâturages. . . . . . . T. des prés. T. pratenso L.

Plus robuste et cultivé. . . . . . . . T. cultivé. T. saticum Mill.

- Stipules à partie libre étroite, atténuée en pointe (f. 22); calice glabre extérieurement; fl. purpurines (f. 23). - \&. Mai-jlt. C. Bois............ T. moven. T. medium L.

\section{6 - PSORALEA L. - Psoralier. - Pl. V.}

Odeur de bitume; fl. en capitules multiflores (f. 24). - 2. Maioct. C. Tertres, coteaux de la Garonne. .......... P. bitumeux. biruminosa $\mathrm{L}$.

\section{7 - BONJEANIA Reichb. - Bonjeanie. - Pl V.}

- Stipules bien plus longues que le pétiole (f. 25 ) ; rameaux arrondis; gousse ovoïde (f. 26 ). - 5. Mai-jlt. AC.Friches; coteaux de la Garonne, Balma. (Lotus I.).

B. hérissée. Ir. Inilosuta Reichb.

- Stipules égalant à peine le pétiole ; rameaux anguleux ; gousse cylindrique. - Ђ. Mai-jn. Lieux lumides. Rencontre autiefois 
près ile Pech-David : a rechercher. (Lotus L..).

18 - DORYCNIUM Tournef. - Doryenie. - Pl. V.

Tiges frutescentes, de 2-4 dm.; folioles sublinéaires, semblables aux stipules (f. 27, 28, fl.). - భ. Jn-jlt. C. Coteaux secs et aridles. . ....... D. frutescente. D. suffiruticosum Vill.

\section{9 - LOTUS I. - Lotier. - PI. V.}

1 - Pédoncule portant 5 -14 fleurs de 11-13 mm. de long; souche rampante, stolonifère ; tiges robustes, fistuleuses. - 4. Mai-at. C. Lieux humidles et herbeux. . . . . . . . . . . L. des marais. C. uliginosus Schkuhr.

- Pédoncule à 1-6 fleurs; sonche ni rampante ni stolonifère. . 2

2 - Fleurs de $11-12 \mathrm{~mm}$. de long ; ombelles de 4-6 fl. ; tige pleine; stipules ovales (f. 29) ; folioles olovées. - \%. Mai-at. CG. Pelouses, pâturages. . . . . . L. corniculé. C. coñniculatus L.

Fl. de $1 \mathrm{~cm}$., par 1.5 ; folioles et stipules étroites. . . . . . . . . .

- Fl. de moins de $1 \mathrm{~cm}$. de long, 1-4 par ombelle. . . . 3

3 - Pédoncules 1-2-flores; étendard ne verdissañt pas ă la dessication; gousse étroite, de 2-3 cm. de long (f. 30). - (I). Av.-jlt. AC. Bords des champs, terrains graveleux. . . . . . . . . . L. étroit. L. angusissimusi $L$.

- Pédoncules 2-4-flores ; étendard verdissant à la dessication ; gousse de 8-15 mm. de long sur 2 de large. - (I). Mai-jtt. R. Pelouses. Lardenne, St-Simon (Nonlet).

L. hispide. In Is pidus Desf.

$$
\text { 20. - TETRAgONOLOBUS Scop. - Tétragonolobe. - Pl. V. }
$$

Tiges simples; pédoncules uniflores; étendard jaune, strié de brun (f. 31). - \%. Mai-jlt. AC. Prés humides, fossés.

21 - PHASEOLUS Tournef. - Haricot. - Pl. V. f. 32.

Tige volubile; f. à 3 folioles. - (I. Jn-at. Originaire de l'Inde ; cultivé. . . . . . . . P. vulgaire. Ho vulgaris $\mathrm{L}$.

\section{2 - ASTRAGALUS L. - Astragale. - Pl, V.}

1 - Fl. d'un jaune verdâtre; f. à 9-13 folioles grandes, ovales ou elliptiques. -- भ. Mai-spt. AC. Lieux herbeux; rives de l'Ariège 
et de la Garonne. . . . A. réglisse. A. glyeyphyllus L.

- Fl. d'un violet pourpre (f. 33); f. à 18-41 folioles oblongues. - भ. Av.-jn. R. Friches des coteanx calcaires. Montgiscard, ramier de Tenerque (Noulet).

....... A. de Montpellier. A. monopessalanus I.

L'A. falcatus Lamk. (A. en faux), à fl. jaunàtres, nombreuses, à f. ayant 15-21 folioles elliptiques, est une espèce oriqinaire de Russie qui paraît être un succédané du Medicago sativa. C'est M. le Dr Clos, directeur du Jardin des Plantes de Toulouse, qui le premier a appelé l'attention des agriculteurs sur cette nouvelle légumincuse four ragère.

23 - COLUTEA L. - Bagnenaudier. - PI. V. f. 34.

F. a 7-11 folioles obovales; grappes de 3-ŏ fl. - ho. Mai-jn. Planté et parfois presque naturalisé.

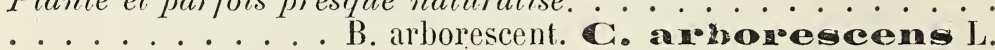

\section{4 - ROBINIA L. - Robinier.}

F. à 11-2o folioles elliptiques; fl. odorantes. - b. Av-jn. Planté le long des voies ferrees.

...... R. faux acacia He psendomeracia $\mathrm{L}$.

$$
\text { 20 - CICER 1. - Pois chiche. }
$$

F. à 1 ö-17 folioles dentées; pédoncules uniflores. - (1). Jn-jlt.

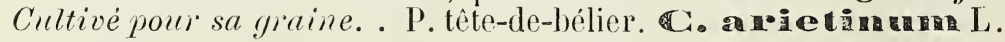

\section{6 - LENS Tournef. - Lentille.}

10-14 folioles oblongues ; 1-3 fl. blanches ou violacées. - (1). Jnjlt. Cultivé pour sa giaine. Subsp. dans les moissons. . . . . . . . .... L. comestible. I. eserarenta Monch.

$$
27 \text { - VICIA L. - Vesce. - Pl. V. }
$$

1 - Corolle bien plus longue que les divisions du calice.. . . 2 - Corolle égalant ou dépassant à peine le calice (G. Ervum L.). . . . . . . . . . . . . . . . . . 12

2 - Pédoncule plus court qu'une fleur (f. 33̈). . . . . . . . 3

— Pédoncule bien plus | 1-马̆ fleurs.. . . . . . . . . . . . 9 9 long que les fleurs, portant $\mid$ un grand nombre de fl. . . . . . 10

3 - Fl. axillaires, solitaires ou par 2 , à pédicelles très courts. . 4

- Fl. par 1-ŏ au sommet d'un pédoncule axillaire ; folioles ovales. 
4 - Calice régulier ; gousse sessile. . . . . . . . 5

- Calice irrégulier ; gousse stipitée. . . . . . . . . 6

$\check{b}-\mathrm{F}$. sup. res à vrille rameuse; fl. de $18-30 \mathrm{~mm}$. de long; graines lisses. - (1). Mai-at. ................ . . . . . . . . V. commune. communis Rouy.

- Fl. ordinair.t violacées, de $2-3 \mathrm{~cm}$. de long; f. supres à folioles obovales ou oblongues ; gousses jaunàtres à la maturité. - Cultivé et subsp. dans les moissons. . . . . . . . . V. cultirée. v. sativa L.

Gousse bosselée, à graines jaunes, marbrées. . v. torulosa (Jord.)

- Fl. ord. violettes, de moins de $2 \mathrm{~cm}$.; f. supres à folioles étroites ; gousses noirâtres à la maturité. - C. Lieux incultes, haies. . . . .

........... V. à f. étroites. v. angustifolia Reichdt.

Robuste; gousse de $5.7 \mathrm{~mm}$. de large . . . . . v. segetalis Koch.

Corolle d'un blare lilacé. . . . . . . . . . v. For'steri (Jord.)

- F. sup. res à villle simple ou presque nulle; fl. de $6-7 \mathrm{~mm}$. de long; graines tuberculeuses. - (1). Ms-mai. AC. Pelouses des terrains sablonneux. . V. fausse gesse. V. Iathyroides L.

6 - Corolle purpurine ; 3-6 paires de folioles linéaires, échancrées. - (1). Mai-jn. RR. Lieux secs. Colomiers; Toul., vallon du

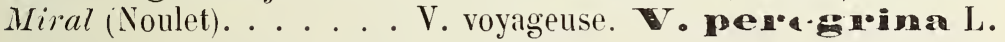

— Corolle jaunâtre; gousses velues. . . . . . . . . 7

7 - Etendard glabre ; folioles arrondies au sommet (f. 35). (1). Mai-jtt. C. Moissons. ....... V. jaune. V. Iutea L.

- Etendard velu ; folioles tronquées ou échancrées au sommet. (1). Mai-jlt. R. Moissons, T., Pech-David, Calvinet (Noulet). ( $\mathrm{V}$. hybricla L.). . . . . . . . . V. de Linné. T Li Innaei Rouy.

8 - F. à 5-7 paires de folioles entières (f. 36) ; grappes unilatérales ; fl. bleuậtres (rar. ${ }^{\mathrm{t}}$ blanches ou jaunâtres) - \%. Av.-oct. CC. Haies, buissons. . . . . . . V. des haies. sepium L.

- F. à 1-3 paires de folioles grandes, entières ; fl. purpurines ; calice à dents inégales. - (I). Mai-at..

V. de Narhonne.

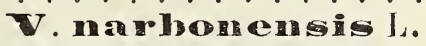

Folioles toutes dentécs (f. 3i). - C. Prés, bois, haies

$V$. ¿̀ $f$. dentées en scie. v. serratifolia Jacq.

9 - Fl. purpurines, de 17-19 $\mathrm{mm}$. de long ; calice à dents égales; f. à 1-3 paires de folioles. - I. Av-jn. AC. Bords des champs, moissons. . . . . . V. de Bithynie. bithynica I.

— Fl. ayant moins de $1 \mathrm{~cm}$. de long ; 3-ら paires de folioles. . 11

10 - Calice non bossu à la base ; fl. blenes ; étendard à limbe aussi long que l'onglet (f. 38) ; hile égalant le 1/3 de la circonl'érence de la graine. - \%. Mai-at. C. Haies, prés, bois.. . . . . . .

. . . . . . . V. à bouquet. V. Cineca L.

Etendard à limbe 2 fois plus long que l'onglet; hile égalant Je $1 / 4$ 
de la circonf. de la graine. - Jn-spt. C. Memes lieux. . . . . . .

. . . . . . . . a f. menues. v. tenuifolia Roth

- Calice irrégulier, bossu à la base ; fl. grandes $14-15 \mathrm{~mm}$. de long), violettes; étendard à limbe 2 fois plus court que l'onglet; hile égalant le 1/7 de la circonf. de la graine. - (1) ou (2). - A rechercher clans les moissons : parfois cultivé...........

V. velue. voros Roth.

Moins velue; fl. non pendantes; grappes non plumeuses ; 10-12 paires de folioles. - C. Cultures, moissons. (V. varia Host.). . . . . .

11 - Pédoncules 1-2-flores, égalant la corolle lilas, veinée ; gousse à 3-4 graines. - (I). Mai-jlt. C. Moissons, cultures, haies.

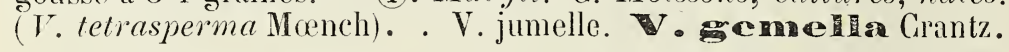

- Pédoncules 2-ö-flores, dépassant longuement la corolle rose bleuâtre ; gousse à $\tilde{j}, 6$ graines. - (1). Mai-at. C. Moissons, liaies, lieux cultivés (Ervum DC.) . . V. grêle.

12 - Gousse velue, de 8 - $10 \mathrm{~mm}$., à 2 graines (1. 39) ; fl. très petites (3 mm.), d'un blanc bleuatre. - (1). Mai-at CC. Broussailles, lieux sablonneux (Evvum L.). V.hérissée. T.

- Gousse glabre, noueuse, de 16-20 mm., à 3-4 graines ; fl. de 7-8 mm., roses. - (1) Av-jlt. Cultivé et paifois subspontané (Eis ; Evoum L.) . . . . . . V. ers. W. Willd.

\section{8 - FABA Tournel. - Fève.}

1-3 paires de folioles ; grappes de 3-ŏ fl. blanches, à carène tachée de noir. - (1). Mai-at. Cultivée, originaire de l'Asie . . . • •. .......... F. vulgaire. V. vongens Moench.

$$
29 \text { - LATHYRUS I. - Gesse. - Pl. V. }
$$

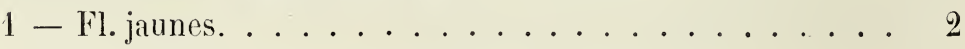

- Fl. blanches, rosées, bleuitres ou purpurines. . . . . 3

2 - Pétioles sans folioles; stipules grandes, foliacées ; fl. ordin. solitarires (f. 40). - (1). Mai-jlt. CG. Moissons, haies. . . . . .

- 1 paire de folioles . . . . . . . . . . . . . . 8

3 - F. toutes sans folioles, réduites à unpétiole foliacé rappelant une f. de graminée ; fl. purpurines, par 1-2. - (1). Mai-jlt. C. Haies, moissons, boids des bois. G. de Nissole. T. Iisoin L.

- Pétioles tous pourvus de folioles. . . . . . . . 4

4 - Gousse velue; pédoncules 1-3-flores ; 1 paire de folioles (1.41); fl. de $1 \mathrm{~cm}$. environ, d'abord violacée puis bleuâtre. - (2). Mai-jlt. C. Moissons, cultures, bords des champs. . . . . . . 
— Gousse glabre ; pédoncules à 1-2 fleurs. . . . . . . . 5ั

— Gousse glabre ; pédoncules à 3-10 fl. grandes (14-20 mm.). 9

$\check{\partial}$ - Style tordı sur son axe ; graines anguleuses. . . . . . 6

- Style non tordu; fl. rougeâtres, de $1 \mathrm{~cm}$. de long. . . . 7

6 - Gousse ollrant 2 ailes sur le dos ; fl. de 15 mm., d'un blanc bleuatre; graines blanchâtres. - (1). Mai-jn. Cultive, subsp. dans les moissons. (Gesse)...... G. cultivée. I. ative L.

- Gousse sans ailes; fl. de 10-13 mm., rougeatre; graines brunes. - (1). Mai-jn. R. Cà et là. Moissons, cultures: parfois cultivé (Jarosse). . . . . . . G. chiche. 面, Cireon L.

7 - Stipules plus longues que le pétiole ; pédoncule articulé vers le milieu, plus court que le pétiole; graines orbiculaires-comprimées. - (1). Mai-jlt. G. Bois, pelouses.

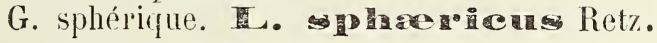

- Stipules égalant le pétiole; pédoncule articulé au sommet; bien plus long que le pétiole; graines cubiques. - (1). Mai-jlt. $C$. Moissons, lieux sablonneux. . . . . . . . . . . .

8 - Pédoncules 1-2-flores, ne dépassant pas la f. ; fl. de 12-14 mm. - (1). Mai-jn. R. Moissons. Périole, Lalande, Launaguet (Noulet).. . . . . . . G. annuelle. 面。

- Pédoncules 3-12-flores, dépassant beaucoup la f.; fl. de 9-10

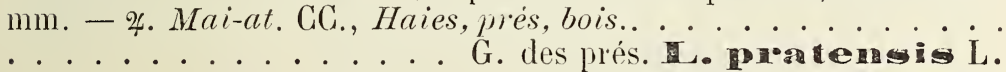

9 - Fl. odorantes, par 3-气̆, roses ; tiges et pétioles non ailés. 4. Jn-at. R. IIaies, fossés. T., à Rangueil. . . . . . . . . .

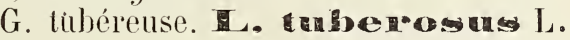

- Fleurs inodores, par 4-10 ; tiges et pétioles ailés. . . . . 10

10 - Fl. grandes ( $2 \mathrm{~cm}$. ou plus), d'un rose vif (f. 42) ; gousse de 6-8 cm. de long ; hile égalant le 1/3 de la circonférence de la graine. - 4. Jn-at. C. Haies, bords des bois.

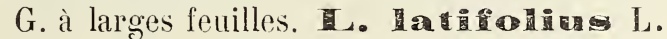

- Fl. de $15 \mathrm{~mm}$. de long environ, d'un rose sale, devenant bleuâtre; gousse de $\breve{-6} \mathrm{~cm}$. de long ; hile égalant la 1/2 de la circonférence de la graine. - \%. Jn-at. R. Buissons, haies, bords des

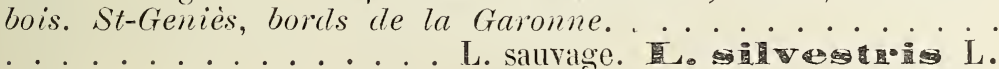

Pétioles laroment ailés ; folioles des f. infres ovales-oblongues, grandes ; corolle plus grande. - Sous Pech-Duvid (Noulet). . . . ................. v. grandifiorus Reichb. 


\section{0 - OROBUS L. - Orobe. - Pl. V.}

- Souche tuberculeuse, stolonifère; tiges ailées; 2 -4 paires de folioles; pédoncules 2-4-flores (f. 43). - భ. Av.-jn. C. Bois.....

0 . tubéreux. O. Tuberosus L.

- Souche non tuberculeuse; tiges non ailées; 3-6 paires de folioles; pédoncules 4-8-flores. - భ. Mai-jlt. AC. Bois : Bouconne, Pibrac, Balma, etc. . . . . . . 0. noir. O. nigen L.

\section{1 - PISUM Tournef. - Pois.}

- Fl., 1-2, de 2-3 cm., ordin. ${ }^{t}$ blanches; f. à 2-6 folioles ovales ; gousse de $6-7 \mathrm{~cm}$. - (1). Av-jlt. Cultivé. .

............... P. cultivé. sativum $\mathrm{L}$.

- Fl. de 15̆-20 m., d'un rouge bleuâtre; f. à 2-4 folioles ; gousse de 4-こ̆ cm. - (1). Mai-at. C. Moissons, cultures. . . . . . . . . . P. des champs. anevere L.

\section{2 - ONOBRYCHIS Tournef. - Esparcette. - Pl. V, f. 44.}

6-12 paires de folioles oblongues; fl. nombreuses, roses, veinées de rouge, en grappes denses ; étendard égalant la carène. - \%. Maijlt. Cultivé (sous le faux nom de luzerne) (O. sativa Auct.). . . . .

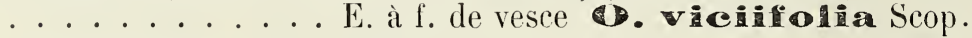

Tiges diffuses, plus grêles; fl. plus petites ; floraison plus tardive. - Coteaux incultes. . . . . . . . . . . . v. collina St-Lager.

\section{3 - CORONILLA L. - Coronille. - Pl. V.}

1 - Onglet des pétales 2 fois plus long que le calice (f. 40 ) ; arbrisseau à fl. jaunes, par $2-3$; f. à 2 -'t paires de folioles. - ந. Av.jlt. C. Bois dles coteaux. . . . . C. faux séné. C. Emenus L.

— Onglet des pétales dépassant à peine le calice. . . . . . 2

2 - Corolle blanche, panachée de rose et de lilas ; f. à 7 - 12 paires de folioles; ombelles à 12-15 fl. - 4. Mai-jtt. AG. Lieux herbeux ; bords du Tarn et de la Garomne. . . . . . . . . . . . .

- Corolle jaune f f glauques.

3 - F. à 3-4 paires de folioles petites; ombelles à $6-10 \mathrm{fl}$ - 4 .

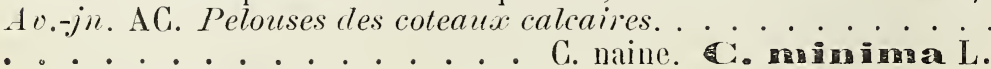

- F. la plupart 3-foliées, à foliole terminale plus grande (f. 46) ; ombelles à 2-4 fl. - (1). Av.-jn. C. Champs cultivés. . . . .

C. quene-de-scoppion. C. Corporides Koch. 
34 - HIPPOCREPIS L. - Hippocrépide. - Pl. V, f. 47.

F. à 5-7 paires de folioles; ombelles à 6 - 12 fl. ; pédoncule 2-3 lois plus long que la 1. - \%. Av.-jn. C. Coteaux secs, graviers de la Gaionne. ........ H. chevelue. 目. comosar L.

\section{$30 ั$ - ORNITHOPUS L. -- Ornithope - Pl. V.}

1-Ombelles à 1-ŏ fl. jaunes, dépourvues de f. bractéale; plante glabre; f. à 3-6 paires de folioles. - (1). Av.-jn. R. Pelouses sablonneuses : bords de l'Hers (O. exstipulatus Thore).

0. sans bractées. O. elba' a ctealus Brot.

- Ombelles munies d'une f. bractéale imparipennée ; plantes velues.

2 - Corolle jaune; 7-18 paires de folioles petites; ombelles à 3-ä fl. ; gousse à bec crochu, à $\partial-8$ articles oblongs (f. 48). - (1). Msmai. G. Pelouses sablonneuses. . . . . . . . . . . . . .

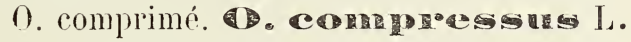

- Corolle hlanche, de 4-ó mm. à étendard strié de rose ; 7-12 paires de folioles petites; ombelles à $3-\bar{t} \mathrm{fl}$.; gousse à bec presque droit, à 4-7 articles ellipsoïdes (f. 49). - (I). Av.-jtt. C. Terresgra-

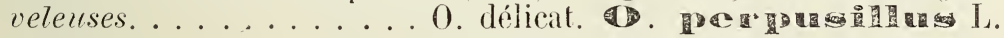

- Corolle rose. de 6-7 mm.; pédoncule plus long que la f.; f. florale petite, ne dépassant pas les calices. - 1. Ao.jit. C. Mêmés lieux. . . . . . . . . . . . . . . rose o. roseus Dufour.

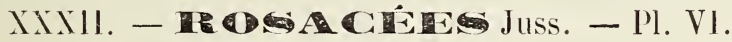

1 - Corolle mulle (f. 24); calice à 4, rart 5 divisions; 1-2 carpelles. ................... III Sanguisorbées.

- Une corolle.

2-1 seul carpelle ; ovaire libre ; fruit charuu. à 1 novau (drupe) ; f. simples............... I Amygdalées.

- Plusicurs carpelles, rart 1 ; fruit sec ou charnu. . . . . . 3

3 - Ovaire libre, ì carpelles distincts. ordint insérés sur un réceptacle, rart reufermés dans le tube du calice (Rosa); stipules plus ou moins soudées au pétiole; f. composées. II Rosinées.

- Oraire soudé au calice, à 1-5 carpelles; fruit charnu, couronné jar les dents du calice. ......... IV Pomasées.

\section{1. - AMYGDALÉES DG.}

1 - Fruit glauque; noyau à bord ventral caréné ... 1 Prunus.

- Fruit nou glauque ; noyau à bord rentral muni de 3 côtes. . . . 2 Cerasus.

1. - PRUNUS L. - Prunier.

1 - Noyau presque lisse; drupe petite, dressée, hleuatre. acerbe ; 
rameaux plus ou moins épineux. - - fl. Av.-mai: fr. oct.-nov. CG. Haies. (Buisson noir, prunellier). . . . . . . . .

P. épineux. S.

Peu épineux ; drupe de $15-20 \mathrm{~mm}$. ; fl. plus grandes. - La Ramette P. fruticans Weihe.

- Noyau rugueux; drupe grosse, penchée, non acerbe. . 2

2 - Jeunes rameaux à villosité fine ; fruit subgloluleux. - ந. fl. ms-mai; fr. jlt-sept. R. Haies. Environs de T. . . . . . . . P. sauvage. 宜。吕sititia $\mathrm{L}$.

- Jeunes rameaux glabres, fruit oblong; arbrisseau non épineux. - Ђ. Cultivé et subsp. dans les haies. Originaire de la Perse.. . . P. domestique. Domestica L.

\section{2 - CERASUS Juss. - Cerisier.}

- Fl. en fascicules ombelliformes naissant souvent avant les I.; fruit petit, d'un rouge noirâtre; arbre. - h. Av.-mai. AG. Bois. (Mérisier). . . . . . C. des oiseaux. C.

On cultive les C. Juliana DC., à fruit plus ou moins noiràtre et à suc rouge (Gruigne), et C. Duracina DC., à fruit plus pâle et à sue incolore (Bigurreau).

- Fl. petites, odorantes, en grappes corymbilormes, naissant après les f.; f fruit noir, de la grosseur d'un poís. - h. îl. av.-mai ; fr. jtt.at. AC. Buissons, haies (Bois de S.te-Lucie).

\section{M}

Le c. vulgaris Mill., moins élevé que le c. avium, à rameaux pendants, à fruits rouges. acides. est cultivé sous plusieurs variétés et subsp. sur les coteaux de la Garonne - (Improprement Guignier). Le c. laurocerasus Lois., à f. persistantes, à fl. en grappes dressćes. est fréquemment planté ; ses feuilles, riches en acide cyanlıydrique, sont vénéneuses

On cultive encore : Armeniaca vulgaris Lamk. (Abricotier), Amygdalus commnnis L. (Amandice $1^{\circ}$ ), Persica vulgaris Mill. (Pêcher ${ }^{\circ}$ )

\section{II. - ROSINÉES Rouy et Camus. - Pl. VI.}

1 - Carpelles renfermés dans le tube du calice (f. 21, 23). . . . . 2

- Carpelles nus, non enveloppés par le tube du calice (f. 6,8). 3

2 - 1-3 carpelles dans ull calice à tube sec (f. 23 ); fl. jauncs. . . . ................... . Agrimonia.

- Carpelles nombreux, dans un calice â tube charnu (f. 21). 6 Rosa.

3 - Fruit formé de petites drupes (drupéoles) disposées en tète globuleuse (f. 6); pas de calicule. . . . . . 1 Rúus.

- Carpelles secs, disposés en un seul verticille ; pas de calicule; fl. blanches (f. s).......... . 2 Spircea.

- Carpelles secs, disposés sur un réceptacle ; un calicule (f. 13). 4

4 - Styles terminaux, accrescents (f. 10) ; fl. jaunes ; f. penmatiséquées, à segment terminal plus grand. . . . . 3 Geum.

- styles latéraux. . . . . . . . . . . . 5 
5 - Réceptacle sec, persistant.

5 Potentilla.

- Réceptacle charnu-succulent, caduc à la maturité (f. 11) ; 11 . blanches; f. 3-foliées........ 4 Fragaria.

\section{1 - RUBUS Tournef. -- Ronce. Ђ. - Pl. VI.}

1 - Aiguillons égaux ou presque égaux, disposés sur les angles du turion (f. 3) ; glandes nulles on rares; f. caul. ö-nées (F⿱ lacantini Dum.).

- Aiguillons souvent très inégaux, accompagnés de glandes pédicellées (f. 4) (更éténacanthio Dum.). . . . . . . 3

2 - Turion dressé, glabre; f. ordin. ${ }^{`}$ vertes en dessous, les caul. ö-nées; inflorescence panciflore; sépales verts sur le dos, bordés de blanc (Suberecti P.-J. Müll.). - Jn. . . . . . . . . 4

- Turion arqué-procombant; f. vertes ou un peu grises-tomenteuses en dessous ; inflorescence ramifiée ; sépales grisâtres-tomenteux ; plante croissant le plus souvent dans les bois (Silvatici P.-J. Müll.). - Jn-jlt.

- Turion arqué-procombant ; f. blanches-tomenteuses en dessous ; inflorescence ramifiée; sépales gris-tomenteux, réfléchis ; glandes nulles; plantes des haies, des lieux découverts (Discolores P.-J. Müll.). - Jn-jlt.

3 -. Stipules étroites ; inflorescence en grappe; drupéoles nombreuses, noires, non glauques à la maturité (Append iculati Gen.). 18

- Stipules larges ; inflorescence courte, corymbiforme ; drupéoles peu nombreuses, grosses, pruineuses à la maturité; turion glauque, arrondi (Triviales P.-J. Müll.). — Jn. . . . . . 27

\section{I. - Suberecti P.-J. Müll.}

4 - Foliole caul. terminale largement ovale, en coeur, les 2 inf. sulbsessiles; étamines plus courtes que les styles ; sépales étalés. -

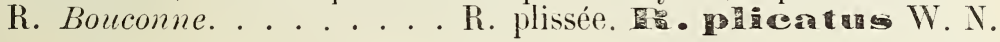

- Foliole caul. terminale entière ou peu émarginée ; folioles inf.res pétiolulées. - R. Bouconne, còté de Mérenvielle.

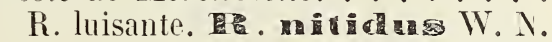

\section{II. - Silvatici P -J. Müll.}

与- Calice étalé après l'anthèse ; inflorescence à aiguillons rares (f. 2) (Grati Sud.). Gen.)

Calice réfléchi; f. toutes vertes en dessous (Euvirescentes

- Calice réfléchi ; leuilles supérieures un peu discolores (Discoloroides Gen.).. . . . . . . . . . . 8

6 - Foliole canl. terminale obovée ( $\{$. 1) ; étamines blanches, sty- 
les verdatres (f. 2). - AG. Bouconne. . . . . . . . . . ...... R. des aulnaies. TR. cethraphilus Gen.

- Foliole caul. terminale ovale ; pétales, étamines et styles d'un rose très vif. - AR. Bouconne.

7 - Turion glabre ; f. glabrescentes en dessous ; folioles acuminées; pétales et styles roses. - Bouconne, AC. Fonsegrives. . .

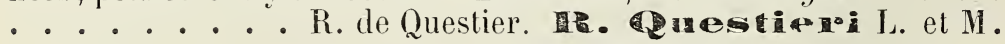

Foliole caul. terminale obovée, cuspidée ; fi. blanches. - Bouconne, vers Mondonville ............. R. amblypetalus Sud.

- Turion velu ; f. velues en dessous; inflorescence à aiguillons forts. - Bouconne ? (Timbal). . . . . . . . . R. tolosanus Sud.

8 - Inflorescence non glanduleuse, ou à quelques glandes rares

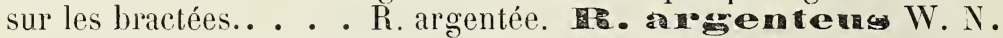

a) - Foliole caul. terminale ovale, entière à la base; pétales, étamines et styles roses. . . . . R. Rncarnatus P.-J. Hüll.

- Inflorescence feuilléc, allongée, carpelles velus. - Bois de Fronton. Gaby, près de Grizolles. - AC. . . v. conformis.

- Aiguillons forts ; pétales grands, larges ; carpelles glabres. - Bouconne, aux t-chemins. ..... v. callichroanthus.

- Aiguillons forts; folioles moins larges; denticulation régulière. - Bouconne. .......... v. pseudo-nemoralis.

b) - Foliole caul. terminale large, échancrée à la base . . . . . . R. consobrinus Sud.

- Foliole caul. terminale orbiculaire; fl. d'un rose vif. - Bou. conne, vers Mérenvielle......... v. erythrander.

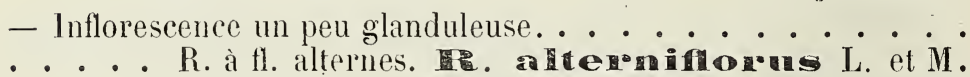

- Turion glaucescent ; fol. caul. terminale obovale ; étamines blanches. - Balma, ì Peffau . . . . . R. obvallatus Boul. et Gill.

- Turion uon glaurque ; étamines rouges. - Sous St-Geniès.

. . . . . . . . . . . . . R. Nouleti sud.

R. pugionifer Müll. et Timb. ; (R. incarnatus v.conformis $\times$ ulmifolius). - Bel-Soulel, Grisolles, fossés du Grand-Bois.

III. - Discolores P.-J. Müll.

9 - Turion glaugue-pruineux; f. à tomentum ras en dessous; pollen parfait. - CG. Haies. (R. rusticanus Merc.). . . . . .

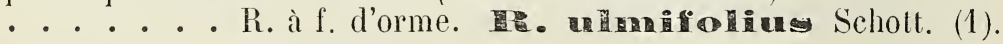

$\times R$. platypetalus Timb. et M. (R. ulmifolius $\times$ lacertosus). $-L a$ Ramette, Fronton, it Gaby.

$\times$ R. nothus Sud. (R. ulmifolius $\times$ Lloydianus). - La Salvetat, Bouconne, Grizolles, La Ramette.

$\times$ R. pulverulentus Sud. (R. ulmifolius $\times$ tomentosus). - La Fi $\alpha$ mette.

(1) Pour l'étude des formes de ce groupe, extrêmement polymorphe, consulter mes Rubus des Pyjénées, $p$. 192 et suivantes. 
- Turion non glauque; f. pubescentes en dessous; axe de l'inflorescence poilu. . . . . . . . . . 10

10 - Turion à poils épars ou glabre; inflorescence ramifiée, à pédoncules étalés ; étamines longues et nombreuses ; pétales ovales; folioles inférieures des f. caul. pétiolulées (Hedycarpi Focke). 11

- Turion canaliculé, souvent glabre (f. 3) ; inflorescence à pédoncules ascendants ; folioles inf.res des f. caul. brièvement pétiolulées; ronces souvent peu discolores, à fl. blanches ou rosées. (Candicantes Focke). . . . . . It. thy posoid eus Wimm. 13

- F. très discolores, les caul. assez souvent en partie 3-nées, à dents larges, obtuses, rappelant le $R$. tomentosus ; noyau des drupéoles oblong (Subtomentosi Sud.). . . . . . . . 14

11 - Turion pubescent, à faces planes; foliole caul. terminale rhombée. . . . . . R. élégante. R. lepidus P.-J. Müll.

Pédoncules ascendants; fl. blanches. - Bouconne, Balma. . . . . . v. stenophyllus (P.-J. Müll.)

- Turion pubescent, canaliculé ; foliole caul. terminale ovaleoblongue ; fl. pâles. - Balma. . ............. ........ R. pubescente. PR. pubescens Weihe.

Foliole caul. terminale à base large, courtement petiolulée. - AC: Balma, St-Clair, Aufiéri, Fronton...... R. evagatus Sud.

- Turion glabre, canaliculé ; rameaux glabrescents. . . . 12

12 - Inflorescence très armée d'aiguillons, à pédoncules étalés ; pétales obovés. - AC. Bouconne, bois de Fronton. . . . . . .

R. goniophylloides Sud.

- Inflorescence peu armée, à pédoncules ascendants ; pétales grands, largement ovales; robuste. - AG. Bouconne, Balma, Mondonville, $T$., etc.. . . . . . . ME. laceretosus Sud.

$\times$ R. Bosquetianus Timb. et Müll. (R. lacertosus $\times$ ulmifolius). Balma, da Peffau, Prats, Mondonville.

13 - Turion glabre ; foliole caul. terminale étroitement ovale, échancrée. - AC. Balms, Bouconne, etc. .... R. candicans Wh.

Foliole caul. terminale entière à la base. - Fonsegrives, Bouconne.

.............. R. goniophyllus M. et L.

Foliole caul. terminale largement ovale. - Balma.

- Turion pubescent ; inflorescence fenillée ; folíole caul. terminale à base large. - Balma, ̀̀ Pefjau, Fronton, etc. . . . . . . . . ............... . . . phyllostachys P.-J. Müll. Foliole caul. terminale obovée. - Bois de Quint. . R. Leventi Sud. Clair.

$\times \mathbf{R}$. semicanescens Sud.(R. thyrsanthus $\times$ tomentosus). - Balma, $\dot{a}$ St-rlair.

14 - Turion glabre ou à poils rares. . . . . . . . 1 ङ 
- Turion distinctement velu.

10 - Fl. doubles, blanches, stériles ; turion un peu canaliculé. Pèriole, haies... . . . . . . . . . R. Linkianus Ser.

- Fleurs simples, fertiles. . . . . . . . . 16

16 - Foliole caul. terminale large, suborbiculaire, échancrée ; turion canaliculé. - Haies, coteaux............. R. des Ardennes. Ir anduennensis Lib.

- Turion glabre; fl. blanches ; inflorescence large. - Bois de Fronton.. . . . . . . . . . . . R. vicarius Sud.

- Foliole caul. terminale moins large, courtement pétiolulée. Fronton, La Ramette, Beuumont. . . . . . . . . R. malacus Sud.

- Foliole caul. terminale étroite, entière à la base; peu robuste. - AC. Fronton, Balma, Colomiers. . . . . R. collicolus Sud. $\times \mathbf{R}$. ampliflorens Sud (R. collicolus $\times$ ulmifolius). - Grizolles, bois de Fronton.

17 - Foliole caul. terminale ovale-elliptique ; f. glabres ou it poils rares en dessus. - Bouconne, Balma, St Geniès. R, subvillosus Sud.

F. supérieures tomentelleuses en dessus ; fl. roses. - Balma, $a$ St-Clair.................. R. Riparti Gen.

\section{IV. - Appendiculati Gen.}

18. - Turion anguleux ; 1. 3-ŏ-nées, très blanches-veloutées en dessous, à dents larges ; inflorescence souvent dépourvue de glandes, à bractées larges; pétales d'un blanc jaunâtre (Tomentosi Wirtg.).

- F. sup. res seules un peu discolores ; inflorescence très glanduleuse ; f. caul. らૅ-nées. . . . . . . . . . . . . 20

- Feuilles toutes vertes en dessous ; inflorescence très glandu-

19 - F., au moins les supérieures, tomentelleuses en dessus.

Turion glabre ou à poils rares, canaliculé: inflorescence non glanduleuse. - Balma, La Ramette, etc.

R. tomenteuse. rre comentoses Borckh.

Turion très velu et plan.

- Inflorescence non glanduleuse ; foliole caul. terminale suborbiculaire. - La Ramette. ... . . . . . . R. tomentosiformis Sud.

- Inflorescence glanduleuse ; foliole caul. terminale rhombée. -

La Ramette

R. tomenticaulis Sud.

- F. toutes glabres et luisantes en dessus ; turion glabre. AC. La Ramette, Balma, Bouconne, etc.

R. de Lloyd. R. Lloydianus Gen.

Turıon très velu; inflorescence un reu glandulcuse. - Bouconne. ......................... subparilis Sud.

20 - Turion à aiguillons peu inégaux, les tuberculeux rares ou 
nuls (Vestiti).

- Turion à aiguillons très inégaux, les petits tuberculeux, rendant la tige très scabre-raboteuse (Raduloe) (f. 4). . . . . . 22

21 - Turion très velu, obtus; calice réftéchi ; pétales roses. - C. Balma, Aufréri, Aigrefeuille... . . . . . . . R. densipilus Sud.

- Turion glabrescent ; calice lâchement relevé; dents très flnes. R. Balma (Timbal)........... R. ellipticifrons Sud.

22 - Inflorescence garnie d'aiguillons forts et nombreux. . 23

- Inflorescence à aiguillons fins et rares. . . . . . . 24

23 - Calice fructifère nettement réfléchi (f. 5); turion glabre ou à poils épars; fl. blanches. . . . . Pre

- Turion à poils épars ; panicule à rameaux très étalés ; foliole caul. terminale en cour à la base. - AC. Bouconne, Balma, à Peffau, Fronton. . . . . . . . . . . . R. pustulatus P.-J. Mïüll.

Turion glabre ; péloncules ascendants ; foliole caui. terminale obovér ou rhom tée-obovéc. - Bois de Quint. . R. papulosus M. et Lef.

- Calice fructilère réfléchi ; turion très velu ; fl. roses. - RR. Bouconne, vers Pujaudran.

......... R. déchirée. He. Müll.

- Calice fructifère étalé; turion glabre; fl. blanches. - AC. Bouconne, vers Pujaudran. . . . . . R. subrotundus Sud.

24 - Turion glabrescent ; foliole caul. terminale obovée ; fl. rosées (f. こ̌). - AR. Balma, à Aufiéri, à Peffau ; Quint. . . . . - . . . . . R. apiculée. 1E. apiculatus Wh.

$\times \mathbf{R}$. amabilis Sud. (R. apiculatus $\times$ ulmifolius). - Bois l'Aufréri.

- Turion très velu, glauque ; foliole caul. terminale largement ovale. - AR. Fonsegrives. . . . . . R. lauracensis Sud.

25. - Turion anguleux, velu ; calice réfléchi; f. caul. כૅ-nées ; fl. blanches. - R. St-Geniès. . . R. brune. HF . usseus Wh.

- Ces caractères non réunis ; calice fréquemment relevé. • 26

26 - Etamines plus courtes que les styles; pétales roses; turion velu, obtus. - R. Bois de Fronton. . R. obscuriformis Sud.

$\times \mathbf{R}$. defectus Sul. (R. obscuriformis $\times$ Lloydianus). - Grizolles, bois de Fronton.

- Etamines plus courtes que les styles; pétales blanes; turion glabre. - R. Bouconne, à Pujaudran, près de Tillère. . . . .

- Etamines égalant les styles ; pétales blancs ; turion velu, ar-

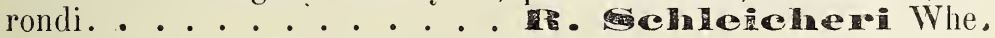

Calice réfléchi; glandes courtes. - Bois d'Aufréri . . . . . . . .

R. mucronipetalus P.-J. Müll. 
V. - Triviales P.-J. Müll.

27 - F. 3-nées ; pétales blancs, orbiculaires ; calice relevé (f. 6) ; précoce. - C. Lienx frais, champs cultivés . . . . . . .

- F. 5-nées, un peu discolores; pétales roses ; calice réfléchi. AR. Fonsorbes. . . . . . . R. Martrini Sud.

obs. - Il existe beaucoup d'hybrides du $R$. casius et des autres espèces de ce genre; ils constituent le $R$. dumetcrum Auct. J'ai observé les suivants :

$\times$ R. defectivus Sud. (R. goniophylloides $\times$ cosius). - Lu Salvetat.

$\times \mathbf{R}$. ambifarius P.-J. Müll. (R. thyrsanthus $\times$ cæsius). - Aufréri.

$\times \mathbf{R}$. assurgens Boul. et Bouv. (R. cosius $\times$ ulmifolius). $-\mathrm{AC}$. $A i$ grefeuille, Fonsegrices, etc.

$\times$ R. amplifoliatus Sud. (R. ulmifolius $\times$ casius). - AC. St-Geniès, Balma, Quint, etc.

$\times$ R. leucophæus P.-J. Müll. (R. cæsius $\times$ tomentosus). - La Salvetat.

Lc R. Idæus I. est culivé sous le nom de framboisier.

$$
\text { 2 - SPIRÆA L. - Spirée. - Pl. VI. }
$$

- F. à 4-9 paires de segments ; carpelles contournés en spirale (f. 7). - 4. Jn-at. AC. Lieux humides, bords de la Garonne. . •

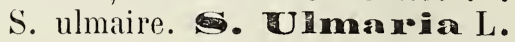

- F. à 15-20 paires de segments ; carpelles non contournés en spirale (f. 8, 9). - ४. Mai-jlt. C. Prés, bois.

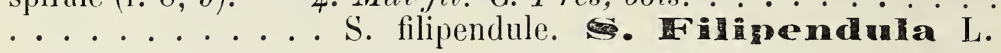

Plantes amères et toniques; les fleurs sont prises en guise de thé.

$$
\text { 3- GEUM L. - Benoîte. - Pl. VI, f. } 10 \text { (akène). }
$$

F. à $5-7$ segments ; stipules foliacées ; 5 pétales jaunes. at. CC. Haies, bois. . . . B. des villes. G. unobmum L.

Les racines sont amères et astringentes.

\section{4 - FRAGARIA I. - Fraisier. - Pl. Vl.}

- Divisions du calice réfléchies ou étalées à la maturité du fruit (f. 11). - - 4. Av.-jn. C. Bois, haies

- Divisions du calice appliquées sur le fruit mûr. - Mai-jn. C. Bois. . . . . . F. des collines. F. collima Ehrh.

Folioles clliptirues; pétales dérassant le calice, qui dépasse le calicule . . . . . . . . . . r. consobrina (Jord. et F.).

$$
\check{\jmath} \text { - POTentilla L. - Potentille. - Pl. Vi. }
$$

I -. Fleurs blanches; f. radicales 3-foliées ....... 2 
- Fleurs jaunes. .............. 4

2 - Pétales plus courts que le calice; folioles obovées; à 7-9 dents - 4. Ms-mai. AC. Bois des collines.

P. à petites fleurs. Hon

- Pétales plus longs que le calice. . . . . . . . . 3

3 - Pétales dépassant peu les sépales; folioles latérales suborbiculaires. - 2. Av.-mai. C. Bois, haies.

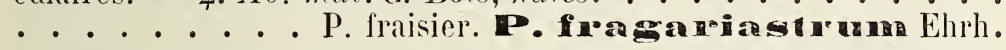

- Pétales dépassant longuement les sépales; folioles latérales oblongues ou ovales. - \%. Mai-jlt. C. Bois, bruyeres (P. splendens Ram., P. Vaillantii Nestl.) .

4 - F. imparipennées, à $150-23$ folioles tomenteuses-argentées. 4. Jn-spt. R. Prés, bords des chemins; Le Vernet, Fenouillet. • . . . . . . . . P. ansérine. Amsenorina L.

- F. digitées (f. 12).

$\check{y}-$ F. blanches-lomenteuses en dessous, à bords enroulés (f. 12) ; pétales égalant le calice. - భ. Mai-jtt. C. Lieux graveleux, pelouses, muis. . . . . P. argentée. P. a gegentea L.

Tig̨es étalées ou couchées, pubescentes... . . v. demissa (Jord.).

Tiges redressŕes, poilues. . . . . . . . v. argrntata (Jord.).

- F. vertes en dessous ; pétales dépassant le calice. . . . . 6

6 - Calice et calicule à 4 divisions; 4 pétales; tiges non radicantes. - 4. Mai-jlt. C. Pelouses, bois (Tormentilla erecta L.). • . . . . . P. tormentille. P. Tomentilla Neck.

- Calice et calicule à อ̆ divisions; 气̆ pétales (f. 13). . . . . 7

7 - Tiges radicantes aux nœuds; f. à č folioles dentées; carpelles tuberculeux. - \%. Jn-at. CG. Bords des chemins, champs. . . •. . . . . . . . P. rampante. P. Herams L.

- Tiges non radicantes; $f$. à $\breve{b}-7$ folioles; carpelles mûrs lisses (f. 13, fi.) - Ұ. Ms.-jn. C. Coteaur, pelouses, bois secs. . . . . •

Toutes les Potentilles sont astringentes.

$$
6 \text { - ROSA I. - Rosier. - Pl. VI. }
$$

1 - Styles agglutinés en une colonne saillante au-dessus du disque (f. 14); stipules supérieures des ramuscules florifères étroites,

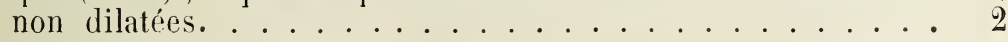

- Styles libres, uon saillants au-dessus du disque (f. 21); stipules supérieures ordinairement plus larges que les moyennes ; tiges dressées.. 
2 - Styles soudés en colonne grêle égalant les étamines; disque presque plan; sépales extérieurs entiers ou à appendices latéraux petits ; tiges sarmenteuses. . . . . . . . . . . 3

- Styles agglutinés en colonne glabre moins longue que les étamines ; disque conique ; sépales munis d'appendices nombreux. ऽ

3 - Colonne stylaire presque toujours velue (f. 14); f. moyennes ordin.t ${ }^{\mathrm{C}}$-foliolées ; folioles coriaces, luisantes, persistantes, à dents superficielles ; bractées primaires étalées ou réfléchies. - \%. Maijn. C. Haies, buissons.

R. toujours vert. Fe sempervirens L.

- Colonne stylaire glabre; f. moyennes ordin. ${ }^{7}$-foliolées ; folioles minces, non luisantes, caduques; bractées primaires restant dressées. -- Ђ. Mai-jn. CG. Haies, bois. .

-. . . . . R. des champs. Te. a énsis Huds.

Folioles grandes; plante robuste et multiflorc. - AC.

4 - F. moyennes des rameaux florifères ڤ̆-foliolées; fl. grandes, le plus souvent solitaires; tiges à aiguillons courbés, entremêlés d'acicules et de glandes. - ந. AC. Bois, fossés, lieux frais. . .

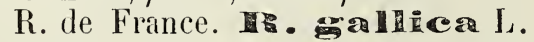

a) -3-5 folioles orbiculaiı es pétales roses, maculés de blanc. Bois de La Ramette. . . . . . . . . . . . . R. cordata Cariot.

b) - 5 folioles ovales ou elliptiques, à dents simples ; pétales rouges. - Bois de Fonsorbes (Timbal). . . . . . . . R. rubra Lmk.

c) - 3-5 folioles orales ou elliptiques, à dents composćes-glanduleuses.

- Rameaux ineımes ; corolle rose ; folioles ovales-elliptiques. Colomiers ('l'imbal). . . . . . . . . . R. incarnata Mill.

- Ramcaux aiguillonnés ; corolle rouge ; folioles ovales. - Bouconne, T. . . . . . . . . . . R. pumila Jacq.

$\times$ R. Polliniana Spreng. ; (R. gallici Xarvolisis Focke). - LuRcmette, Brax, Léguevin.

$\times \mathbf{R}$. Schleicheri H. Braun ; (R. arvensis $\times$ gallica). - Bouconne (Timbal).

$\times$ R. Boreykiana Bess. ; (R. gallica $\times$ dumetorum Christ). - Bois de Foncorbes ('Timbal).

$\times$ R. subdola Déségl.; (R. gallica×agrestis Christ). - La Ramette (Timbal).

$\times$ R. genevensis Puget; (R. gallica $\times$ tomentosa Christ). - La Ramette ('Timbal).

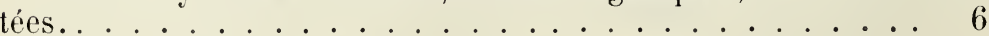

5 - Styles glabres; stigmates étagés, rapprochés en tête oblon-

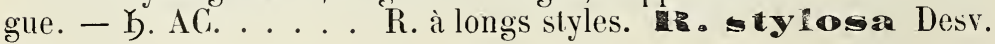

Dents simples; pédicelles hispides-glandu!eux ; fl. roses. - C. Haies. . . . . . . . . . . . . v systyla (Bast.).

Dents composées-glanduleuses ; pédicelles lisses. . . . . . . 
6 - Folioles pubescentes-soyeuses; aiguillons arqués (f. 16) ou presque droits (f. 17), jamais crochus (f. 15); pédicelles presque toujours glanduleux....................... 14

- Non comme ci-dessus. . . . . . . . . . . 7

7 - Aiguillons grêles, presque droits ; f. grandes, à nervures + ou - glanduleuses en dessous, à dents composées-glanduleuses ; pédicelles hispides-glanduleux; fl. grandes. . . . . . . 10

- Non comme ci-dessus. . . . . . . . . . . 8

8 - Folioles chargées en dessoủs de glandes odorantes ; aiguillons crochus, souvent inégaux. . . . . . . . . 11

- Folioles sans glandes en dessous, ou à glandes rares et sur les nervures s^condaires; sépales réfléchis (f. 21 ) ; styles libres ; stipules supérieures dilatées. . . . . . . . . . 9 9

9 - Aiguillons crochus (f. 15) ; folioles à dents composées-glanduleuses et très ouvertes (f. 20 ), les sup. res lavées de rouge ; pédicelles longs et grêles, hispides-glanduleux ; styles ord.t glabres. -

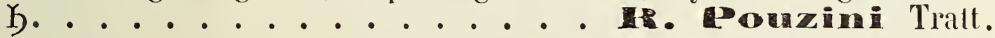

Folioles petites (moins de $16 \mathrm{~mm}$. de long), ovales. - Toulouse (Timbal). . . . . . . . . . . . . v. subintrans Gr.

- Ne possédant pas ces caractères réunis. - Ђ. Mai-jn. C. et très polymorphe. . . . . R. des chiens. He. canina L.

$$
\text { a - Folioles glabres }
$$

- Dents des folioles simples (f. 18).

Pédicelles lisses. - C. Partout. . . . . . . . R. lutetiana Lem. Pédicelles hispides-glanduleux. - R. St-Martin-du-T. ........................... andegavensis Bast.

- Dents plus ou moins composées-glanduleuses (f. 19, 20) ; pédicelles lisses. - CC. . . . . . . . . . . . R. dumalis Bechst.

- Dents simples.

\section{b - Folioles pubescentes en dessous}

Pédicelles hispides-glanduleux. - A rechercher. R. Deseglisei Bor. Pédicelles lisses fl. blanches. - St-Geniès, Balma, Venerque. . f . . . R. obtusifolia Desv. f1. roses. - Grizolles. . R. dumetorum Thuil. - Dents plus ou moins composées-glanduleuses, pédicelles lisses. - AC. . . . . . . . . . . R. tomentella Lém.

Obs. - Je passe sous silence un grand nombre de var. du groupe du $R$. dumalis et de quelques autres.

10 - Sépales réfléchis ou étalés, glanduleux sur le dos; fl. roses. - Ђ. . . . . R. de Jundzill. Bt - Jandzillii Bess.

Folioles pubescentes en dessous, à glandes peu odorantes; fruits ellipsoïdes. - La Ramette, Balma, Bouconne. . .'volosana C'hrist.

11 - Pédicelles lisses; folioles elliptiques ou oblongues, + ón atténuées-cunéiformes à la base, aiguës au sommet; fl. pâles ; sépa- 
les non glanduleux sur le dos.

- Pédicelles hispides-glanduleux ; folioles peu ou point atténuées à la base, souvent obtuses ; sépales glanduleux sur le dos. . . . 13

12 - Stigmates en capitule glabre ou glabrescent ; sépales réfléchis et promptement caducs. - Jn-jlt. C. Haies, coteau $x$.

R. des champs. a gromis Sav.

- Stigmates en capitule + ou - hérissé ; sépales redressés ou étalés-dressés et persistants jusqu'à la coloration dı fruit. - Jnjlt. RR. St-Genies... R. elliptique. Re. elliptica Tausch.

13 - Stigmates en capitule glabre ou glabrescent ; sépales réfléchis et promptement caducs; corolle rose. - Jn-jlt. C. ....... R. à petites fleurs. Fe. michontha Sm.

Présente un grand nombre de variétés que je passe sous silence.

- Stigmates en capitule hérissé ; sépales étalés-redressès et persistants jusqu'à la coloration du fruit. - Jn-jlt. AC.

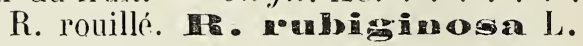

Plus élancé ; folíoles un peu atténuées à la base ; aiguillons longs, grêles. - AC. . . . . . . . . . v. Timbali (Crép.).

$\times$ R. ladanifera Timb. ; (R. agrestis $\times$ rubiginosa). - Chemin de Balma (Timbal).

$\times$ R. præstans Duffort ; (R. rubiginosa $\times a g$ restis). - Colomiers, $\dot{a}$ Pujouanne, chemin de Tournefeuille, où il a été découvert par M. Duffort, qui ni'en a indiqué l'unique buisson.

14 - Folioles très pubescentes; sépales réfléchis ou étalés (f. 22). - R. . . . . . . R. tomenteux. He tomentosa Sm.

-F. supres à dents simples ; fruits subglobuleux. - Grizolles, vers Gaby. . . . . . . . . . . . v. properata Boullu.

- F. toutes à dents composées-glanduleuses.

F. toutes ì nerrures secondailes non glanduleuses. - La Ra. mette............... v. giobulos $a$ Rouy.

F. inf. et moyennes seules à nervures secondaires glanduleuses. - La Rumette. . . . . . . . . . . . v. annesiensis (Dés.).

F. toutes à nerrures secondaires glanduleuses. - La Ramette. . . ..................... Seringeana (Dum.).

Obs. - Le R. aiba L. (R. gallica×canina Crép.) est cultivé ; il est subspontané près de Léguevin, chemin de Bouconlie.

\section{7 - AGRIMONIA Tournef. - Aigremoine. - Pl. VI.}

F. pennatiséquées, à ŏ-7-9 segments; grappes allongées (f. 23, calice). — \&. Jn-sept. CG. Lieux herbeux. . . . . . . . . . . . . .............. A. eupatoire. A. Eupatono L.

Tonirue et astríngente ; s'emploie en gargarismes contre les angines.

$$
\text { III. - SANGUisorbÉES Juss. - Pl. VI. }
$$

F. imparipennées ; 20-30 étamines. . . . . . 1 Poterium. Feuilles palmées ; 1-4 étamines . . . . . . . 2 Alchimilla. 


\section{1 - POTERIUM L. - Pimprenelle. - Pl. VI.}

F. radicales à 9-2つ folioles; fl. verdâtres (f. 24), en épis très courts. - (2) ou \%. - CG. Prés, bois.

P. sanguisorbe.

- Fruits à angles munıs de crêtes minces. égalant au moins la $1 / 2$ de la largeur du fruit, à faces chargées de fossettes profondes.

.. P. muricatum Spach.

- Crêtes n’égalant pas la 1/2 de la larg. du fruit.

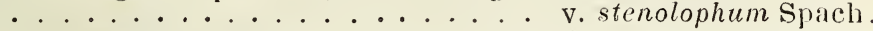

- Fruit à angles obtus, à crêtes épaisses, à faces rugueuses, + ou - réticulées........ P. dictyocarpum Spach.

\section{2 - ALCHIMILLA Tournef. - Alchimille. - Pl. VI.}

F. tripartites, à stipules engainantes ; fl. verdâtres, en fascicules opposés aux f. (f. 2气ั). - (I). Mai-spt. CG. Moissons, champs maigres. A. des champs. A. a versis Scop.

\section{IV - POMACEES DC.}

1 - Fruit à noyaux. . . . . . . . . . . . . . . 2

- Fruit à pépins . . . . . . . . . . . . . . 3

2 - Calice à divisions foliacées; 5 styles, 5 noyaux (f.26). 1 Mespilus.

- Calice à divisions non foliacées; 1-3 styles ; 1-3 noyaux. . . .

3 -- Fruit à 5 loges contenant chacune 10-15 graines. 6 Cydonia.

- Fruit à loges contenant 2 graines. . . . . . . . . . . 4

4 - Endocarpe péu distiuct, se confondant arec le mésocarpe . . .

- Endocarpe distinct, coriace . . . . . . . . . . 5

5 - Fruit non ombiliqué à sa base ; styles libres. . . . . 4 Pirus.

- Fruit ombiliqué à sa base; siyles soudés à la base.. 5 Malıs.

1 -- MESPILUS L. - Néflier. - Pl. VI. f. 26 ( $\mathrm{fr}$.).

F. olblongues; fl. grandes, solitaires. - h. Fl. mai. - AG. Haies,

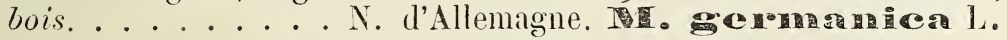

\section{2 - CRAT EGUS I. - Aubépine. - Pl. VI, f. 27 (fl.).}

- Jeunes rameaux glabres; nervures transparentes; pédicelles glabres; divisions du calice étalées-recourbées. - - . Fl. Mai. (..

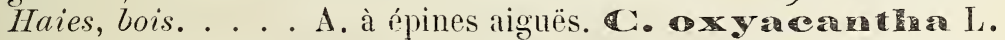

- Jeunes rameaux souvent velus; nervures opaques; pédicelles pubescents; divisions du calice appliquées sur le fruit; 1 style. GG. Planté dans les haies.

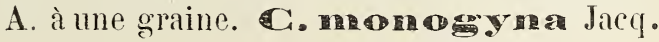


Pédicelles et calices velus. - Braqueoille. . . v. kyrtostyla Beck.

Le fruit (senelle) de ces plantes est astringent.

\section{3 - SORBUS L. - Sorbier. - Pl. VI.}

- F. imparipennées, à 13-17 folioles ; fruit dèvenant brun. 5. Fl. mai-jn. Bois des coteaux. Souvent cultivé.

S. domestique. domestica L.

- F. lobées, vertes en dessous (f. 28). - Ђ. Mai. C. Bois (Alisier des bois). . S. antidysentérique. tom a lis Crantz.

- F. doublement dentées, blanches-tomenteuses en dessous. 5. Mai. AR. La Ramette, Bouconne. . . . . . . . . . . . S. alisier. A $\rightarrow$ r a crantz.

\section{4 - PIRUS I. - Poirier.}

F. ovales, égalant le pétiole ou plus longues. - \$. Av.-mai. . . . ......... . . P. commun. T. commenmis L.

F. glabres à l'état adulte, ainsi que les pédicelles ; bourgeons glabres. - Balma, Pechbusque. . . . . . . P. piraster Lor.

F. et pedicelles relus à l'état adulte ; bourgeons velus. - A recher-

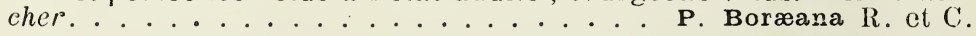

\section{5 - MALUS Medik. - Pommier.}

F. blanches-tomenteuses en dessous à l'état adulte ; fruit à saveur douce. - Ђ. Mai. Cult. et subsp. ........ P. commun. Comminis Lamk.

F. vertes et glabres en dessous â l'état adulte ; fruit acerbe. - AR. Bois, haies. . . . . . . . . . P. acerbe. Mo acerba Mérat.

\section{6 - CYDONIA Tournef. - Coignassier.}

F. ovales, entières, cotonneuses en dessous. - Ђ. Av.-mai. Naturalisé clans les lıaies. (C. vulgaris Per's.).

G. commun. C. mation

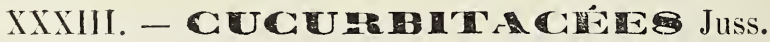

Plante couchée, sans vrilles ; fruit oblong, épineux. 1 Ecballium. Plante grimpante, à vrilles; baie globuleuse. . . . 2 Bryona.

\section{1 - ECBALLiUM C. Rich. - Ecballie. - Pl. VI.}

F. triangulaires; fl. jaunes (f. 29). - \%. Jlt.-spt. C. Décombies, bords des chemins. T. Montaudran, etc. (Momordique). .......... E. élastique. E. laterom Rich.

La racine est purgative et le fruit diurétique. 


\section{2 - BRYONA L. - Bryone. - Pl. VI.}

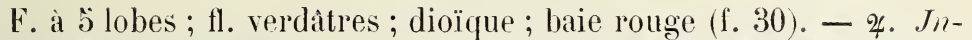
jlt. C. Haies, buissons. . . . . B. diö̈que. B. dionea Jacq.

La racine de la Bryone diö̈que a une saveur âcre ; c'est un purgatif énergique.

On cultire : Cucurbita maxima Duch. (Courge), Lagenaria vulgaris Ser. (Gourde), Cucumis Melo L. (Melon), Cucumis sativus (cornichon, :oncombre).

\section{XXXIV. - S I I I IGACHES DC.}

\section{SAXIFRAGA L. - Saxilrage. - Pl. VI.}

- Plante de 2-12 cm., à racine grêle; 11 . de 4-6 mm. de long (f. 31). - (1). Av.-jn. C. Murs, toits, lieux graveleux. . . . . . .

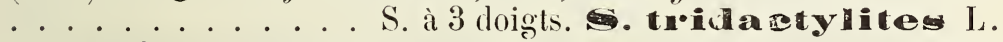

- Plante de 2-4 dm., à souche munie de bulbilles; fl. de 12-15 mm. de long (f. 32). - భ. Mai-jn. Prés, pelouses giaveleuses. . .

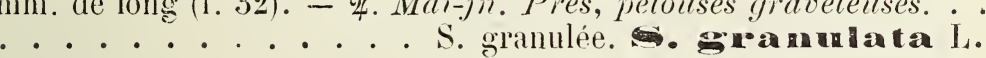

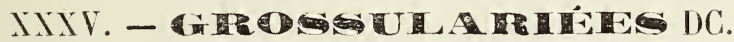

\section{RIBES I. - Groseiller.}

On cultive les R. Grossularia L. (Gros. ¿ maquereaux), à pédoncules 1-3-flores, à rameaux épineux et à fruit gros ; R. rubrum L. (Gr. commun', à ficurs vertes, en grappes, à baies rouges ou blanches, et le $\mathbf{R}$. nigrum L. (Cassis), à fl. rougeâtres et à baies noires.

\section{XXXVI. - CRE SEUCACIESG DC.}

1 - F. radicales orbiculaires ; corolle gamopétale, diun blanc jaunâtre ............ 5 Cotyledon.

- Corolle dialýpétale ou à pétales à peine soudés à la base. . . 2

2 - Sépales, pétales, étamines et carpelles 3-4; f.opposées. 1 Tillcea.

- Sépales, pétales, étamines et carpelles 5 ou plus. . . . . . . 3

3 - 6-20 pétales un peu soudés ; f. planes, celles des rejets stériles disposées en rosette......... 4 Sempervivum.

- Ordint 5 , rarement $6-7$ pétales, libres .......... . 4

4 - Tiges toutes annuelles, florifères, robustes; f planes, grandes. ...............2. Anacampseros.

- Souche émettant des tiges florifères annuelles et des rejets stériles couchés, feuillés et vivaces ; f. petites, charnues, sollvent demi-cylindriques ou cylindriques. . . . . 3 Sedum. 
1 - TILLÆeA L. - Tillée. - Pl. Vi.

Tige de $2-6 \mathrm{~cm}$. ; f. très petites, + ou - rougeâtres ; fl. blanches, petites (f. 33, 34). - (1). Ms-jn. C. Lieux caillouteux. T., Bouconne, etc. . . . . . . . . T. mousse. T. muscosa L.

\section{2- ANACAMPSEROS Bauh. -- Anacampseros. - Pl. VI.}

- Tige de 2-6 dm., à f. oblongues, très atténtées à la base (f. 3ä) ; fl. purpurines (f. 36). - 4. At-spt. G. Bois, lieux couverts. (Sedum purpureum Link.). . A pourprée. A . purpurea Nob.

On cultive l'A. spectabilis Sud. (Sedum spectabile Bor.), qui se rencontre quelquefois dans le voisinage des maisons, sur les murs.

\section{3 - SEDUM L. - Orpin. - Pl. VI.}

1 - Fl. blanches ou rosées. . . . . . . . . . . 2

- Fl. jaunes. ................ 5

2 - F. planes, élargies, entières ; panicule lîche (f. 37). - (1). Jn-spt. AG. Haies, murs. Eno. de T. . . . . . . . . . . .

0 . faux oignon. Cepaea $\mathrm{L}$.

- F. étroites, ovoüdes on cylindriques (f. 38). . . . . . . 3

3 - Fl. sessiles, rongeâtres ; plante de 4-12 cm., pubescenteglanduleuse (f. 38). - (1). Mai-jtt. CG. Lieux arides, murs. (Crassula rubens Murr.). . . . . O. rougeâtre. Houbens L.

- Fleurs pédicellécs. . . . . . . . . . 4 4

4 - F. opposées sur les tiges florilères (f. 39), presque globuleuses; pétales ovales. - Ђ. Jn-at. RR. Vieux murs. T., quai StPierre. . . . . o o à f. épaisses. allasylayllum L.

- F. toutes éparses, oblongues; pétales lancéolés. - \%. Jn-at. AC. Murs, toits. . . . . . . . O blanc. allbum L.

$\check{5}-\mathrm{F}$. obtuses, courtes $(3 \mathrm{~mm}$.) ; tige de $4-8 \mathrm{~cm}$. ; 4-气̃ pétales d'un jaune vif. - 2. Jn-at. AC. Vieux murs, toits.

0 acre. ace $\mathrm{L}$.

- F. mucronėes ; $6-8$ pétales. . . . . . . . . . . . 6

6 - Etamines à filets à peu près glabres; tiges de 20-20̃ $\mathrm{cm} .-2$. Jn-jlt. Murs, friches des cotean.x.

Non glauque ; crmes penchées arant l'anthèse. $-\mathrm{CC} \ldots \ldots \ldots$

- Etamines à filets poilus à la hase ; tiges de 3-6 dm. ; fl. pâles. 4. Jll-at. G. Toits, mus, coleaux. . . . . . . . . . . . 


\section{4 - SEMPERVIVUM I. - Joubarbe.}

Tige velue-glanduleuse, de 2-っ dm.; fl. roses. - \%. Aouit-spt. C. Murs, toits. . . . . . J. des toits. Teccoriam I.

$$
\text { こ - COTYLEDON Tournef. - Cotylédon. - Pl. VI. }
$$

Fl. verdattres ou rougeatres (f. 40), en longue grappe. - \%. Maijn. R. Vieu.x murs, laaies, rochers siliceux. Env. de T. (Nombril

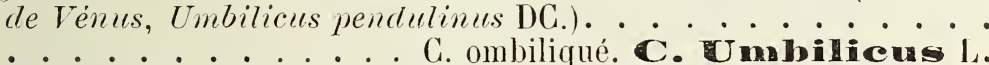

Le Cactus opuntia L. (Ordre des CACTÉ ES DC), à tige charnue, articulée, à fl. grandes. sessiles, jaunàtres, est naturalisê sur quelques murs. - Mai-jn. T., Tournefeuille.

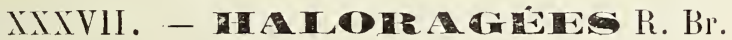

\section{MYRIOPHYLLUM Vaill. - Myriophylle. - Pl. VI.}

- Bractées supérieures entières, ne dépassant pas les fl. toutes verticillées (f. 41). - 4. Jn-at. CC. Eaux tranquilles. C. du Midi, Garonne. . . . . . . . en épi.

- Bractées sup res pennatifides, dépassant les fl. toutes verticillées (f. 42). - \%. Jn-at. Avec le précélent; plus R.

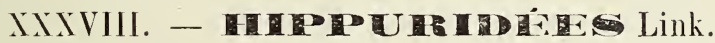

\section{HIPPURIS L. - Pesse. - Pl. Vl.}

Tiges raides, fistuleuses ; fl. sessiles, vertes, verticillées par 812 (f. 43). - \%. Jn-at. AR. Etangs, fossés, mares. La Ramette, Pibrac, Le Vernet (Noulet). . P. commune. Ti. Vulganaris L.

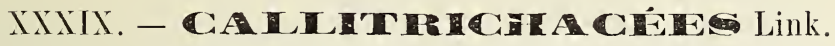

\section{( ALLITRICHE L. - Gallitriche. - Pl. VI.}

1 - Fruits pédicellés, au moins les inférieur's; styles réfléchis, caducs; f. infér ieures linéaires. - 4. Mai-spt. AR. Eaux vives, ruisseaux, fontaines. C. pédonculée. C.pedunculata DG.

- Fruits tous sessiles ou subsessiles. . . . . . . . 2

2 - Loges du fruit à dos muni d'une carène aiguë ; styles dressés, caducs. - \%. Mai-spt. C. Mêmes stations. . . . . . . . . . . . . . . . . . . . C. printanière. C. venomalis Küt\%. 
- Loges du lruit à dos muni d’une carène ailée ; f. toutes obovales (f. 4.4); styles persistants (f. 40, 46), divergents puis réfléchis. - భ. Mai-spt. C. Mêmes stations............... . . . . . . C. des étangs. C. 1 a dia

F. inférieures linéaires. . C. à fruits larges. C. platycarpa hütz.

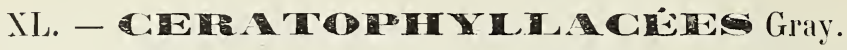

\section{CERATOPHYLLUM L. - Cornifle. - Pl. VI.}

- F. 1-2 fois dicholomes (f. 47); akène muni à sa lase de 2 épines latérales (f. 48). - \%. Jlt.-spt. C. Cours d'eau, fossés, canaux. . . . . . . . C. nageant. C. demeromm L.

- F. 3-4 fois dichotomes (f. 49); akène sans épines à sa base. \% Jlt-spt. C. Mêmes stations.

C. submergé. C. mismenom $\dot{L}$.

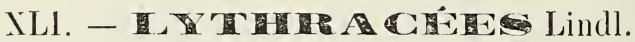

Tube du calice allongé, subcylindrique; style filiforme ; fl. purpurines. . . . . . . . . . . . . . 1 Lythrum.

Tube du calice court, en coupe; style presque nul. . . 2 2 Peplis.

\section{1 - LYTHRUM L. - Salicaire. - Pl. VI.}

- Fl. grandes ( . 50), fasciculées, en épi terminal feuillé ; 12 étamines. - \&. Jn-spt. C. Fossés, saussaies. lieux humides. . . . ......... S. commune L. alicania I.

— Fl. petites, 1, 2 à l'aisselle de chaque feuille (f. 5̈l) ; õ étamines. - (1). Mai-spt. C. Fossés, lieux lumides.

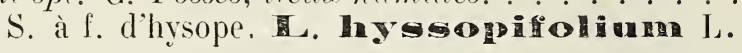

La Salicaire commune n'est plus usitée comme plante médicinale; elle peut servir à embellir les bassins, les pièces d'eau, etc.

$$
2 \text { - PEPLIS L. - Péplide. - Pl. VI. }
$$

Tiges de 5゙-30 cm. ; 1. opposées, obovées ( . 52) ; pétales petits, roses, parfois nuls (f. כ3). - (1). Mai-spt. C. Bords des eau.x, fossés, mares. . . . . . P. pourpier.

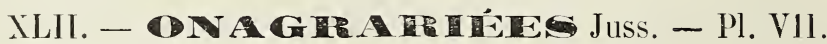

1 - Calice à 2 dirisions; 2 étamines (f. 4) . . . . . 3 Cirecea.

- Calice à 4 divisions ; 8 étamines . . . . . . . . . . . . 2

2 - Capsule linéaire (f. 2 ); graines munies d'une aigrette; fl. roses ou rouges. . . . . . . . . 1 Epilobium. 
- Capsule oblongue (f. 3 ) ; graines sans aigrette ; fl. jaunes. .

2 Enothera.

\section{1 - - EPILOBIUM L. - Epilobe. - Pl. VII.}

1 - Stigmates rapprochés en massue; tige à 2-4 lignes +ou-

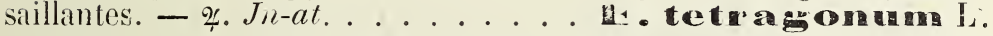

- Sourhe à courts rejets terminés par des rosettes de feuilles; f. caul. sessiles, décurrentes par le prolongement du limbe. - C. Lieux humides, jossés. . . . . . . . E. adnée. E. adnatum Griseb.

- F. caul. subsessiles, décurrentes par le pétiole. - Bisannuelle. Mêmes stations. . . . . . . E . de Lamy. E. Lamyi F. Schultz.

- Stigmates étalés en croix (f. 1). . . . . . . . . 2

2 - F. toutes pétiolées; fl. penchées avant la floraison. - \&. $J_{h-}$ at. R. Rives de l'Ariège. E. de montagne. M. montanum L.

- F. supérieures sessiles ; tl. dressées avant la floraison (f. 2). 3

3 - Fl. d'un rose pâle, de $7 \mathrm{~mm}$. de diam. environ. - \&. $J n$ spt. G. Fossés, bords des eaux.

E. à petites fleurs.

- Fl d'un rose pourpre, de $2 \mathrm{~cm}$. environ de diam. (f. 2). 4. Jlt-at. C. Bords des eaux, lieux frais . . . . . . . . . .

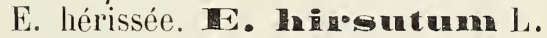

\section{2 - ENOTHERA L. - Onagre. - Pl. VII, f. 3 ( ( r.).}

Fl. grandes, jaunes, inodores; pétales égalant les $2 / 3$ du tube du calice. - (2). Jn-spt. AR. Terrains vagues, bords de la Garonne.

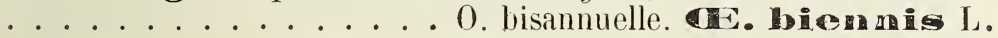

$$
\text { 3- CIRCÆA L. - Circée. - Pl. VII, f. } 4 \text { (fl.). }
$$

F. opposées, ovales-lancéolées; grappes sans bractées. - భ. Jnspt. AC. Bois, lieux couverts. .............. C. des parisiens. C. luteriama L.

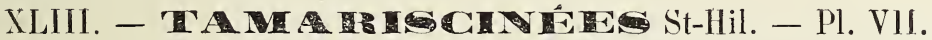

Style nul ; filets soudés à leur partie inférieure (f. 5). 1 Myricaria. 3 styles; filets à peine soudés . . . . . . . . . 2 Tamarix.

1 - MYRICARIA Desv. - Myricaire. - Pl. VII, f. 气̆ (fl.).

Arbuste à f. linéaires, à fleurs blanches ou violacées, en grappes lâches. - Ђ. Mai-jlt. R. Ramier de Venerque (Noulet).......

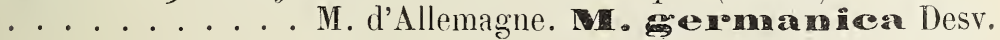


2 - TAMARIX L. - Tamarix. - Pl. VII, f. 6 (épi).

Boutons globuleux; capsule pyramidale; arbuste de 1-4 m. - 5 . Jn-at. Cult. et subsp. . . . . T. de France. T. gallica L.

\section{XIIV. - O O Tuss. - Pl. VII.}

Fl. jaunes, sessiles ; capsule s'ouvrant transversalement (f. 7). . . . ........................ 1 Portulaca. Fl. blanches; capsule trivalve, à 3 graines (f. s).. . . 2 Montia.

\section{1 - PORTULACA Tournef. - Pourpier. - Pl. VII, f. 7 (caps.).}

Tige couchée, charnue; f. sessiles, oblongues. - (1). Jn-spt. C.

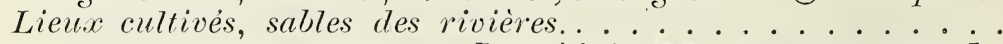
P. cultivé. H. Olereca L.

On le mange en salade.

$$
2 \text { - MONTIA L. - Montie. - Pl. VII. }
$$

Tiges de 2-כૅ cm., en touffes isolées; f. d'un vert jaunâtre (f. 9) ; fl. (f.8) en cymes terminales. - (1). Av.-at. CG. Terrains siticoargileux humides, mares desséchées. .

II. naine. M. minoro Gmel.

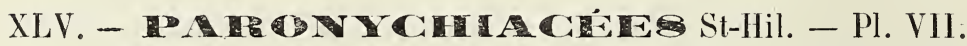

F. dépourrues de stipules, opposées, linéaires (f. 10) ; capsule indéhiscente. .............. 1 Scleranthus. Feuilles |F. opposées; fl. verdâtres; 2 stigmates. . . 2 Herniaria. stipulées. $\quad$ F. alternes; fl. blanches ; 3 stigmates. . . 3 Corrigiola.

\section{1 - SCLERANTHUS L. - Scléranthe. - Pl. VII.}

Fl. verdâtres, en cymes fenillées (f. 10); calice à divisions aigües (f. 11). - (1). Mai-spt. G. Champs sablonneux. . . . . . . . . . . . . . .

\section{2 - HERNIARIA Tournef. - Herniaire. - Pl. VII.}

Pl. velue, couchée; fl. sessiles (f. 12); sépales velus. - (1) ou (2).

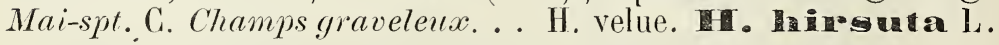

$$
3 \text { - CORRIGIOLA L. - Corrigiole. - Pl. VII. }
$$

Glabre et glaucescente; tiges étalées ; grappes denses (f. 13, 14, bouton). - (1). Jn-oct. R. Bords des riviéres. Rives du Tarn et de la Garome.. . . . . . . C. des rivages. C, Hictonalis L. 


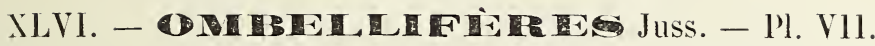

1 - Fl. en verticilles rapprochés ; f. orbiculaires-peltées (f. 15). .

1 Hydrocotyle.

- Fı. en capitules (f. 16), sur un réceptacle pailleté ; f. épineuses.

2 Eryngium.

- Fl. en ombelle irrégulière, les mâles pédicellées, les hermaphrodites subsessiles; f' palmatipartites (f. 17). 3 Sanicula.

- Fl. en ombelles parfaites, régulières. . . . . . . . . 2

$2-\mathrm{F}$. entières ; fl. jaunes; un involucelle (f. 40). . 22 Bupleurum.

- F. 1 ou plusieurs fois pennatiséquées......... 3

3 - Fl. jaunes ou d'un vert jaunàtre. . . . . . . . . . 4

- Fl. blanches ou rosées, parfois d'un blanc rerdàtre. . . . 10

4 - Plante pubescente ; f. pennatisćquées ; fr. ovale-orbiculaire (f. 54). ................... 5

- Plante glabre................... 6

5 - Ombelles à $10-20$ rayons ; f. inf. à $3-5$ segments. . . . . . .

- Ombelles à 4-10 rayons ; f. iuf. à 5-11 segments. 34 Pastinaca.

6 - F. découpées en lanières fines, capillaires, 3-4 fois pennatiséquées : involucre et involucelle nuls ........ 7

- F. â segments + ou - élargis............ . . 8

7 - Plante annuelle ; fruit comprimé, ovale, entouré d'un bord large (f. 55)................... 35 Ancthum.

- Plante vivace ; fruit non comprimé, oblong, non bordé (f. 31). .

14 Foniculum.

8 - Fruit oblong (f. 32), non à 2 lobes ; involucre à $1-2$ folioles .

- Fruit à 2 boles (f. 33,51$) \ldots \ldots \ldots$

9 - Fruit gros $(5 \times 4 \mathrm{~mm}$.) ; f. sup. 3 -nées, à segments larges ; involuere nul.............. 16 Smyrnium.

- Fruit petit $(21 / 2 \times 2 \mathrm{~mm})$; f. sup. triséquées, à segments étroits. ............ 30 Petroselinum sativum.

10 - Fruit à bec de $2-5 \mathrm{~cm}$. de long (f. 35 ) ; f. à divisious linéaires. .

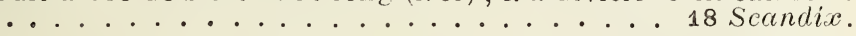

- Fruit à bec nul ou jeu marqué, ne dépassant pas $3 \mathrm{~mm}$. de

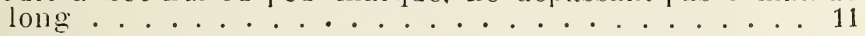

11 - Fruit pubescent, velu ou hérissé de pointes. . . . . . 12

- Fruit glabre, ayant au moins 2 côtes élargies en aile membra-

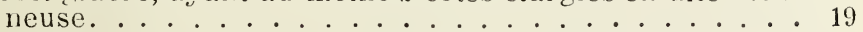

— Fruit gIabre, à côtes non ailées et peu saillantes. . . . . 21

12 - Fruit couvert de poils mous ou couchés. . . . . . . . 13

- Fruit distinctement hérissé. . . . . . . . . . 14

13 - Fruit comprimé, suborbiculaire, de $5 \times 4 \mathrm{~mm}$. (f. 53) ; involucre et involucelle à plusieurs folioles .....33 Tordylium.

- Fruit ovoüde, non comprimé (f. 30 ), involucre uul ou presque

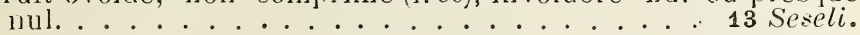

14 - Folioles de l'involucre pennatiséquées; fruit comprimé. à côtes secondaires munies d'un rang d'aiguillons (l'. 19). 4 Duucus.

- Folioles de l'involucre simples ou nulles . . . . . . 15 
15 - Fruit ovoïde-aigu, atténué en un bec de $1 \mathrm{~mm}$. (f. §6)

- Fruit dépourru de bec. . . . . . . . . . . 16

16 - Fruit ovoïde, lérissé sur toute sa surface (f. 24), ayant $3 \mathrm{~mm}$. de long.............. 8 Torilis.

- Fruit hérissé sur les côtes, ayant de 8 à $10 \mathrm{~mm}$. de long. . . 17

17 - F. pennatiséquées ; fruit ovoïde (f. 21) ; involucre et involucelle à 2.5 bractées ......... 6 Turgenia.

- F. bi-tri-pennatiséquées . . . . . . . . . . 18

18 - Involucre nul ou à 1 foliole ; ombcllc à $2-3$ rayons ; fruit ellipsoïde, à aiguillons robustes (f. 22). . . . . . 7 Caucul's.

- Involucre à plusieurs folioles; ombelle à 3-10 rayons ; côtes secondaires à 2.3 rangs d'aiguillons (f. 20). . . . 5 Órlaya.

19 - F. pemnatiséquées, à segments larges ; fruit de 710 sur 6 mm., comprimé-aplani, obovale-orbiculaire (f. 56) ; tige hérisséc. .

36 Heracleum.

- F. 2-4 fois pennatiséquées; tigc glabre ou presque glabre. . 20

20 - Côtes de la marge des akènes soudées et formant une bordure autour du fruit (f. 57) . . . . . . 37 Peucedanum.

- Côtes de la maı ge entrc-baillées (f. 58); pétales cntiers, ácumi-

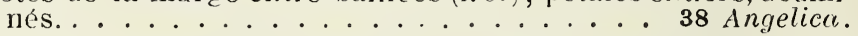

21 - Fruit non comprimé latéralement, reuflé; plante glabre. . 22

- Fruit comprimé latéralement . . . . . . . . . 24

22 - Frnit globuleux, de $3 \mathrm{~mm}$. de diam. (f. 26 ) ; plante fétide; involucre nul. ........... 10 Coriandrum.

- Fruit formé de 2 akènes distincts, subglobuleux (f. 25) ; plante fétide............... 9 Bilora.

- Fruit plus long que large . . . . . . . . . . 23

23 - Calice à dents nulles (f. 29); racinc grêle. . . . 12 Ethusa.

- Calice à 5 dests (f. 27); souche a flbres + ou - renflées. . . .

24 - Fruit subglobuleux, de $11 / 2 \mathrm{~mm}$. de large; involucre et inrolucelle nuls. ........... 32 Apium.

- Fruit plus long que large ............. . 25

25 - Involucelles nuls ainsi que l'involucre; f. pennatiséquées.. . 25 Pimpinella.

- Involucelles à 1 ou plusicurs folioles . . . . . . . 26

26 - iruit atténué au sommet en un bec couıt; involucre nul ou à 1 foliole.......................... Anthriscus.

- Fruit atténué au sommet, mais sans lec (f. 38$)$. . . . . 27

- Fruit non atténué au sommet, ovoüde ou cllipsoïde (f. 49). • 28

27 - Tige nue à la basc ; souche subglobulcusc $(1-2 \mathrm{~cm}$. de liam.) ; f. glabrescentes...........21 Conopodium.

- Tige feuillée à sa base ; souche non globuleuse.

28 - Folioles de l'involucre à $3-5$ segments filiformes; plante cla. bre...................... 29 Ammi.

- Folioles de l'involucre simples. . . . . . . . . . 29

29 - Fruit oroïde-subglobuleux, presque à 2 lobes, à côtes saillantes, ondulées (f. 34)................ 17 Conium.

- Fruit à côtes non ondulées . . . . . . . . . . 30 
s0 - Plante aquatique ou des lieux humides, glabre. . . . . 31

- Plante des lieux secs; f. pennatiséquées . . . . . . . . 33

31 - Tige presque nue dans sa moitié sup.ro ; involucre à plusieurs bractées courtes........... 27 Carum.

- Tige feuillée jusqu'au sommet. . . . . . . . . . 32

32 - Intervalles des côtes munis de 3 bandelettes superficielles; pritales émaróinés ; fruit ovoïde (f. 42) ; ombelles grandes, terminales, a $20-35$ rayons. . . . . . . 24 Sium.

- Intervalles des côtes à 3 bandelettes profondes ; pétaies émarginés; fruit globuleux, à 2 lobes (f. 41); ombelles la plupart latérales, opposées aux feuilles à $8-20$ rayons inégaux. . . .

- Intervalles des côtes à 1 bandelette ; pétales cntiers ; fruit ovö̈de ; ombelles opposées aux feuilles, à $4-12$ rayons; involucre à $0-2$ bractées. . . . . . . . 31 Helosciadium.

33 - Calice à 5 dents; ombelles à $8-12$ rayons; segments des f. linéaires (f. 46)........... 26 Ptychotis.

- Calice à dents nulles; ombelles à 2-6 raỹons inégaux . . . 34

3' - F. sup.res à divisions linéaires, étroites; tige de 5-18 dm. (f. 48). ...................... 28 Sison.

- F. sup. à divisions ovales-lancéolées ; tige de 3-6 dm. (f. 50). . 30 Petroselinum segetum.

\section{1 - HYDROCOTYLE Tournef. - Hydrocotyle. - Pl. VII.}

Tige rampante, rameuse; fl. petites, blanches ou rosées (I. 15). \%. Jn-spt. R. Lieux humides; ruisseau de St-Martin-de-Lasbordes; canal du M. . . . H. vulgaire. H. vallogatois L.

\section{2 - ERYNGIUM L. - Panicaut. - Pl. VII.}

F. inf. bipennatipartites ; involucre à 4-6 folioles (f. 16) ; fl. blanches ou un pęu bleuâtres. - \%. Jlt.-sept. CG. Lieux incultes, bords des chemins. . . . P. champètre. E. campostro L.

La racine du Panicaut est apéritive et diurétique.

\section{3 - SANICULA Tournef. - Sanicle. - Pl. - VII, f. 18 (fr.).}

F. glabres (f. 17); ombelle à 2-8 rayons; pétales blancs ou rougeâtres. - 4. Mai-at. C. Bois humides. Aufréri, Pech-David, etc. . . . . . . . . . S. d'Europe. S. eunopaea L.

La racine de cette plante est amère et astringente.

$$
\text { 4-DAUCUS L. - Carotte. - Pl. VII, f. } 19 .
$$

F. bipennatiséquées; ombelles à la fin en nid d'oiseau. - (2). Mai-oct. CG. Pâturages, cultuies............. C. commune. D. Ciatia

Aiguillons du fruit dentiformes, ascendants. - Toulouse... . 
$\check{~}$ - ORLAYA Hollm. - Orlaya. - Pl. VII, f. 20.

- Ombelles à כ̆-8 rayons ; involucre à つ̆-8 folioles, - (I). Jn-at. GG. Moissons, terrains argilo-calcaires.

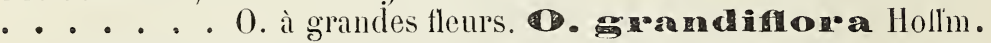

- Ombelles à 2-3 rayons; involucre à 2-3 folioles (f. 20). - (1). Jn-at. G. Avec le précédent. . . . . . . . . . . . . 0. à large fruit. Dotyear hach.

\section{6 - TURGENIA Hoffm. - Turgénie. - Pl. VII.}

F. rudes-pubescentes; ombelles à 2-4 rayons; fruit de $1 \mathrm{~cm}$. de long (1. 21). - (1). Mai-at. C. Cultures, terrains argilo-calcaires.

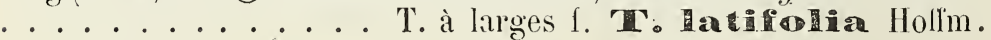

\section{7 - CAUCALIS Hoffm. - Caucalide. - Pl. VII.}

Ombellules à 2-3 fruits de $8-10 \mathrm{~mm}$. de long (f. 22). - (1). Maijlt. CG. Moissons, champs argilo-calcaires...........

C. fausse carotte. C.

\section{8 - TORILIS Adans. - Torilis. - PI. VII.}

1 - Ombelles opposées aux feuilles, à 2-3 rayons, les fructifères subglobuleuses (f. 23). - (I). An.-jlt. C. Lieux secs, incultes, haies, tertres. . . . . . T. nouluse. T. modosa Grotn.

- Ombelles terminales............. 2

2 - Involucre nul ou à 1 foliole; ombelles planes, à 3-8 rayons (f. 24, fr.). - (I). Jn.-spt. CG. Moissons, fossés, bords des bois.

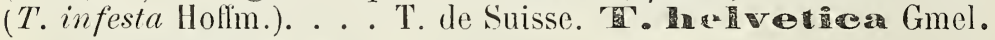

- Involucre à 5 folioles; ombelles convexes, à 4-12 rayons. (2). Mai-spt. CG. Haies, ruisseaux, bords des chemins (T'. Anthriscus Gmel). . . . . T. rougcâtre. T. Trbella Monch.

$$
9 \text { - BIFORA Hollim. - Bifora. - Pl. VII. }
$$

- Ombelles à 2-3 rayons ; fruit mamelonné au sommet (f. 25). (1). Av-mai. R. Moissons. Clermont, Pech-David (Noulet).

B. à 2 bosses.

- Ombelles à $5-7$ ravons; fruit non mamelonné. - (1). Av.-mai. R. Beaupuy, Nailloux (Marcais), canal du M., entre Oudes et Castelnau (Fages). . D . Badians M. Bieb.

10 - CORIANDRUM L. - Coriandre. - PI. VII, f. 26.

F. sup. 2-3-pennatiséquées; ombelles à วั-18 rayons. - (I). Jh.Jlt. Cult. et parfois subsp.. . . . C. cultivé. C.Sagivam I. 
11 - ENANTHE. - OEnanthe. - Pl. VII.

1-Ombelles fructifères planes en dessus, à 6-12 rayons (f. 27, fr.) ; fibres de la souche terminées par des renflements ovoïdes. 2. Jn-jlt. CG. Bois, prés secs. . . . . . . . . . . ...... OL. boucage AE. pimpinolloidos L.

- Ombelles fructifères convexes ou hémisphériques. . . 2

- Ombelles fructilères globuleuses. . . . . . . 3

2-F. radicales à segments larges, les sup. à divisions linéaires ; ombelles à $8-150$ rayons grêles ; pétales extérieurs arrondis à la lase ; fibres renflées en massue au sommet. - \%. Jn-jlt. R. Prés marécageux. Tournefeuille, vallée du Touch.......... . . . . . . OE. de Lachenal. GE. Kachenalii Gmel.

- F. toutes à segments linéaires; ombelles à วั-10 rayons grêles; pétales extérieurs cunéiformes à la lase; filıres rentlées dès leur base. - \%. Jn-jlt. AR. Lieux humides, Canal du M.; prés

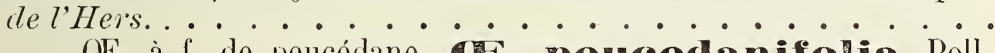
- OE. à f. de peucédane. Edoucedanifolia Poll.

3-Tige fistuleuse; f. inf. 2-3-pennatiséquées; ombelles ordint. à 2-4 rayons courts el épais (f. 28, fr.). - 2. AC. Borls cles eaux, fossés. Canal du M., Launagnet, etc. . . . . . . . . . .

Toutes ces plantes sont vénéneuses.

\section{2 -.. ETHUSA L. - Ethuse. -. Pl. VII.}

F. 2-3 fois pennatiséquées, à odeur vireuse par le froissement ; ombelles à 4-20 rayons inégaux; fruit de $3 \times 2 \mathrm{~mm}$. (f. 29). - (1). Jn-spt. RR. Ne se recontre quiexceptionnellement chez nous. (Petite ciguë). . . . E. des chiens. AR. Cyanamium L.

Très vénéneuse.

$$
13 \text { - SESELI I. - Séséli. - Pl. VII. }
$$

F. inf. à contour oblong, 3-pennatiséquées, à segments linéaires ; ombelles à 6-10 rayons; fruit glabrescent (f. 30). - \%. Jlt.-spt. CG. Escarpements des coteaux calcaires

S. de montagne.

\section{4-FEENICULUM Tournef. - Fenouil. - Pl. VII, f. 31 (fr.).}

Tige de 8-10े dm., robuste ; ombelles fournies, - \& ou (2). Jlt-at. C. Escavpements des coteaux. Cultive. (F. vulgare Gaertn.). . . F. à f. capillaires. capón

15 - SiLAUS Bernh. - Silaüs. - Pl. VII.

Stolons nuls ; f. 2-3 fois pennatiséquées; ombelles à 7-15̆ rayons ; 
fruit oblong (f. 32). - 4. Jn-spt. AC. Pres humides (S. pratense Crantz). . . . . S. jaunatre. Ilavescens Bernh.

\section{6 - SMYRNIUM Tourmef. - Maceron. - Pl. V1I, f. 33 (fr.).}

Tige de 6-12 dm. ; f. luisantes, 2-3-ternatiséquées. - (2). Mai-jn. R. Lieux humides. T., au vélodrome du Bazacle, à St-Cyprien. • . . . . . . . M. potager. Olusanum L.

On l'utilisait autrefois comme plante d'assaisonnement; on lui préfère aujourd'hui le céleri.

$$
17 \text { - CONIUM L. - Ciguë. - Pl. VII. }
$$

Tige de 8-12 dm., + ou - tachée de pourpre; ombelles à 12-20 rayons; fruit de $3 \mathrm{~mm}$. (f. 34); fétide. - (1) ou (2). Jn-at. C. Lieux frais, décombres. - (Grande ciguë).

Très vénéneuse; deux gouttes de conicine déterminent la mort d'un chien er quelques minutes.

$$
18 \text { - SCANDIX Tournef. - Scandix. - Pl. VII. }
$$

F. pubescentes, 2-3-pennatiséquées ; ombelles à 2-3 rayons ; fruit de $4-6 \mathrm{~cm}$. de long (f. 30). - (1). Mai-at. CC. Moissoris, champs cultivés. . S. peigne de Vénus. Pecten eneris L.

\section{9 - ANTHRISCUS Pers. - Anthrisque. - PI. VII.}

1 - Fruit ovale-lancéolé, couvert d'aiguillons crochus (f. 36) ; ombelles à 3-7 rayons. - (1). Mai-jn. AC. Haies, décombres. . . .

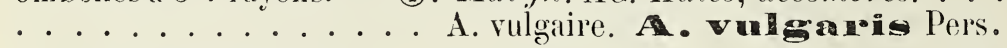

- Fruit sans aiguillons. ............ 2

- Ombelles latérales presque sessiles, à 3-č rayons ; fruit linéaire, de $1 \mathrm{~cm}$. de long, à bec de $3 \mathrm{~mm}$. - (I). Mai-at. Cultivé. (Ce)-

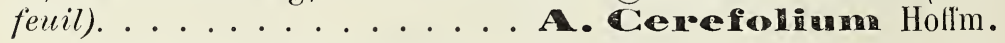

- Ombelles toutes longuement pédonculées, à 7-16 rayons ; fruit de $6 \mathrm{~mm}$. de long, à bec très peu apparent. - భ. Mai-jn. C. Piés, bois, haies, lieux couverts

A. sauvage. $\Leftrightarrow$ investros Hoffm.

20 - CHÆROPHYLLUM L. - Cerfeuil. - Pl. V11, f. 37 (fl.).

Tige de 3-10 dm., hérissée ; racine fusiforme; fruit de 6-7 mm. de long (f. 37 bis); ombelles à $6-12$ rayons. - (2). Jn-jlt. C. Bois, liaies.............. pènché. C. cemanum L.

21 - CONOPODIUM Koch. - Conopode. - Pl. VII, f. 38 (fr.).

F. 2-3-pennatiséquées; ombelles à 8-12 rayous grêles. - \%. Jnjlt. AC. Bois secs. . . . . C, dénudé, C, denudatum Koch. 
22 - BUPLEURUM Tournef. - Buplèvre. - Pl. VII.

1 - Involucre à 1-ว̆ folioles ; f. linéaires-acuminées ; ombelles terminales, à 2-4 rayons inégaux (f. 39, fr.). - (1). Jn-at. AC. Champs sablonneux, pelouses arides.

- Involucre nul ; f. perfoliées. . . . . . . . . . . 2

2 - Folioles de l'involucelle étalées après l'anthèse; ombelles à 2-3 ravons. - (1). Jn-jlt. RR. et accidentel; moissons (B. protractum Hoffg. et Lk.). . . B. subovale. TB. ouloovatum Link.

- Folioles de l'involucelle dressées après l'anthèse (f. 40); ombelles à 3-8 rayons (f. $40 \mathrm{lis}$, fruit). - (1). Jn-jlt. G. Lieux cultivés, terrains argilo-calcaires . . . . . . . . . . . . . . B. à f. rondes. He hotundilolium $L$.

\section{3 - BERULA Koch. - Bérule. - Pl. VII, f. 41 (fr.).}

Tige de 4-8 dm.; f. pennatiséquées, à segments irrégulièrement incisés-dentés (f. 41 bis). - - \%l. Jlt.-spt. C. Fossés, bords des étangs, cours d'eau. . . . B. à f. étroites. Mb. angustiliolia Koch.

$$
24 \text { - SIUM L. - Berle. - Pl. VII, f. } 42 \text { (fr.). }
$$

Tige de 8-12 dm.; f. pennatiséquées, à segments dentés (f. 43 ). - 2. Jlt.at. AR. Eaux tranquilles, fossés. - St-Martin-du-T. ; le Vernet (Noulet). . . . . . . B. à larges f. Iadifolioum L.

\section{$2 \check{0}$ - PIMPINELLA L. - Boucage. - PI VII.}

- Tige creuise, sillonnée, anguleuse, de $50-8 \mathrm{dm}$.; f. radicales à segments pétiolulés; akènes rugueux. - \%. Jlt.-spt. AC. Lieux humides et couverts, misseaux. . B. à grandes f. magna L.

- Tige pleine. cylindrique, de 2-6 dm. ; f. radicales à segments sessiles (f. 44); akènes lisses (f. 40̈). - \%. Jlt.-spt. C. Coteaux arides, bois secs, pelouses. . . . B. saxifrage.

Le P. anisum (anis) est cultivé pour sa graine.

$$
26 \text { - PTYCHOTIS Koch. - Ptychotis. - Pl. VIl. }
$$

Involucre à 2-6 folioles réfléchies; plante glabre (f. 46, fruit). (2). Jn-at. AG. Friches des coteaux de la Garonne et de l'Ariège. P. de Timbal. Timbati Jord.

$$
27 \text { - CARUM L. - Garum. - Pl. VII. }
$$

F. pennatiséquées, à segments sessiles, courts, décomposés en 
lanières filiformes rapprochées en faux verticilles (f. 47). - \&. Jnat. AR. Marécages, lieux tourbeux. Bouconne, La Ramette. . . . ......... C. verticillé. C. verticillatum Koch.

$$
28 \text { - SISON L. - Sison. - Pl. VII. }
$$

Tige de $6-10 \mathrm{dm}$. ; ombelles nombreuses, petites, à 3-4 rayons, le central plus court ; fruit de $3 \mathrm{~mm}$. de long (f. 48). - (2). Jlt-at. AR. Lieux couverts, haies, bois, bords des misseaux. Coteaux de l'Ariège, Lauragais.. . . . . . S. amome.

$$
29 \text { - AMMI Tournef. - Ammi. - Pl. VII. }
$$

- Ombelles à rayons très nombreux ( $50-100$ ), épạissis et connivents après l'anthèse ; f. 2-3-pennatiséquées, à segments linéaires. (1). Jn-jlt. AG. Bords des champs, surtout dans le Lauragais. . .

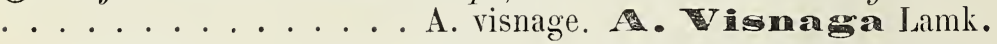

- Ombelles à rayons grêles, ni épaissis ni convergents après l'anthèse; f. 1-2-pennatiséquées, les inférieures à segments ovales ou lancéolés (f. 49, fruit). - (1). Jn-jlt. C. Champs, vignes. . . . . .................... élevé. Majus $\mathrm{L}$.

- F. inf. à segments étroits, lancéolés. . . . v. intermedium G. G.

- F. toutes à segments linéaires. - C. . . v. glaucifolíum Noulet.

\section{0 - PETROSELINUM Hoffm. - Persil. - Pl. VIJ.}

- F. pennatiséquées; ombelles à 2-6 rayons inégaux (f. 50,51$)$; fl. blanches. - (1) ou (2). Jlt-spt. C. Moissons, haies.... . . . .......... P. des moissons. P. edum Kock.

- F. 2-3-pennatiséquées; ombelles à 8-16 rayons; fl. d'un vert jaunâtre. - (1) ou (2). Jn.-spt. Cultivé et sulsp... • • • • • • •

\section{1 - HELOSCIADIUM Koch. - Hélosciadie. - Pl. VII.}

Tiges radicantes, fistuleuses ; f. submergées à divisions linéaires, les aériennes à segments ovales-lancéolés, dentés (f. 52); involucelles à folioles larges, membraneuses aux bords. - \%. Jn.-at. C. Ruisseanx, fossés. .... H. nodiflore. M. Todillomen Koch.

\section{2 - APIUM L. - Ache.}

Tige fistuleuse; 1. pennatiséquées, à segments incisés; plante odorante. - (2). Jlt-spt. Cultivé et parfois sulspt. (Céleri) . . . . . A. odorante. A.

33 - TORDYLIUM Tournef. - Tordyle. - Pl. VII.

Tige rude, de 3-10 dm.; f. pennatiséquées, les inf. à segments 


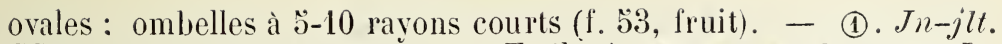
CG. Haies, broussailles . . . T. élevé. T. ma ximmm L.

\section{4 - PASTINACA Tournef. - Panais. - Pl. VII.}

- F. inf. à כ̌-l1 segments, les raméales étroites; ombelles à 4-10

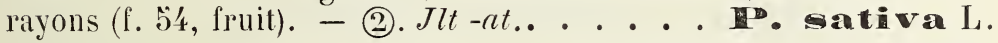

Ombelle centrale plus grande ; f. inf. larges, à contour ovale, à segments grands, - C. Lieux incultes, pâturages, saussuies . . . . . .................... sauvage. P. silvestris Mill. Racine charnue; f. glabres. - Cultivé. . . . . . v. edulis DC.

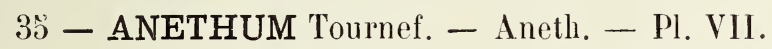

Tige de 1-4 dm. ; plante à odeur de fenouil (f. כ̌ŏ, fruit.). - (1). Av.-jlt. Cultivé comme carminatif (Ecarlate).........

\section{A. odorant. A. Siraveolems I.}

$$
36 \text { - HERACLEUM L. - Berce. - Pl. VII. }
$$

- Fleurs d'un jaune verdattre; f. cendrées-blanchâtres en dessous. - 4. Jn.-at. R. Prés, bois, terrains siliceux. Léguevin (Timbal). . . . . H. de Lecoq. H. Lecoqii G. et G.

- Fl. blanches ou rosées, les extérieures rayonnantes; f. inf. à 3-əٌ segments ; ovaire pubescent. -- \%. Jn.-spt. . . . . . . . . •

........ B. faux panais. Th. phondy yom L.

Robuste; f. amples, à segments larges ; fruit suborbiculaire (f. 56). - Rives de la Garonne et de l'Ariège. . . . . . . v. pratense R. et C.

\section{7 - PEUCEDANUM Tournef. - Peucédane. - Pl. VII.}

- Pétioles flexueux, en zigzag; f. 3-pennatiséquées, à segments cunéiformes, divariqués (f. 57, fruit.). - \%. Jlt-spt. AR. Friches, bois, terrains siliceux. Bouconne, La Ramette, etc. . . . . . . . .

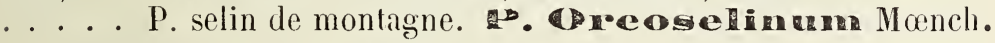

- Pétioles droits; 1. 2-3-pennatiséquées, glauques en dessous, à scgments larges. - Jlt.oct. CG. Bois, friches des coteaux. . . . .

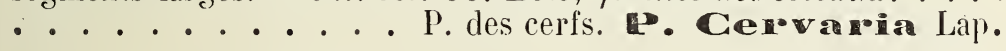

$$
38 \text { - ANGELICA L. - Angélique. - Pl. V11. }
$$

Robuste; f. à segments ovales-lancéolés; ombelles à 20-30 ravons (f. 58). - (2) ou భ. Jlt-spt. C. Lieux lumides, prés. Bords de la Garonne, du Touch, etc. . A. sauvage. A. ilvesis I.

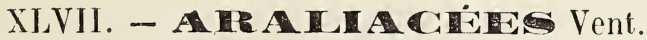

HEDERA Tournef. - Lierre. - Pl. VIII.

F. alternes, coriaces, persistantes ; fl. (f. l) en ombelles; haie 
noire. - Ђ. Spt.-oct. CG. Rochers, murs, bois.

.................. grimpant. He Hix L.

Les fruits sont vomitifs et purgatifs, et il est prudent de ne pas en faire usage.

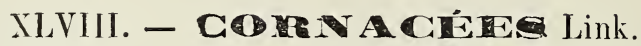

CORNUS Tournef. - Cornoniller. - Pl. VIII.

Fl. blanches (f. 2), en cymes corymbiformes; drupe noire. $-\mathfrak{\zeta}$. Mai-jn. CG. Haies, bois... . C. sanguin. C. mainea L.

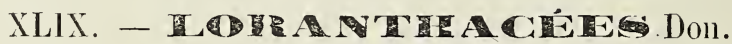

\section{VISCUM Tournef. - Gui. - Pl. VIII.}

Arbuste à tige di-trichotome; baie blanche (f. 3). - Ђ. Fl. ms.av.; fr. at-spt.C. sur les pommiers, poiriers, aubépines, érables, peupliers, etc. . . . . . G. blanc. album L.

Son fruit fournit la glu; il est purgatif.

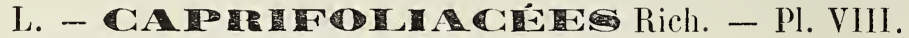

1 - Corolle tubuleuse-labiée; style long, filiforme (f. 7 ). 3 Lonicer'x.

- Corolle régulière, rotacée ; style nul. . . . . . . . . . 2

2 - F. pennatiséquées, glabres; 3-5 stigmates. . . 2 Sambucus.

F. simples, dentées ou lobées ; 3 stigmates. . . . . 1 Viburnum.

\section{1 - VIBURNUM L. - Viorne. - Pl. VIII.}

1 - F. palmatilobées, stipulées, vertes en dessous (f. 4); fruit rouge. - 5. Mai-jn. R. Bois. Bouconne, La Ramette. . . . . . ............ . . . obier. Topulus L.

Fl. stériles, en corymbe globuleux. - (Cultivé. Boule de neige). .

.......................... sterilis Coss. et G.

- F. entières ou dentées, sans stipnles. . . . . . . 2

2 - F. entières, coriaces, persistantes; haie d'un llleu noirâtre.

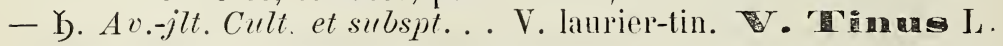

- F. dentées; tomenteuses en dessous ; fruit d'abord rouge puis noir. - Ђ. Av.-mai. C. Haies, bois. . . . . . . . . . ............... cotonneuse

\section{2 - SAMBUCUS Tournef. - Sureau.}

- Tige herbacée; f. à $ّ-11$ segments, à stipules foliacées. Fétide. - \%. Jn-jlt. C. Champs argilew.x. . . S. yèble. $\mathbf{S}$. Ebulus L. 
- Tige ligneuse ; f. à 3-7 segments, à stipules nulles ou très petites. - Y. Jn-jlt. AC. Bois frais, haies.

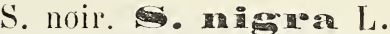

Les fl. du $S$. noir sont sudorifiques; ses baies sont purgatires; les fruits de l'yéble sont employés en teiuture.

3 - LONICERA L. - Chèvrefeuille. - Pl. VIII.

1 - Volubiles; fl. odorantes, en têtes terminales et en faux verticilles

- Non volubiles; fl. par 2 sur des pédoneules axillaires; 2 baies rouges distinctes (f. 丂). - ந. Mai-ju. C. Haies, bois.

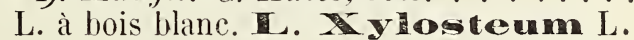

2 - F. obovées, les sup.res soudées à leur base (f. 6) ; corolle glabre (f. 7). - ந. Mai-jlt. C. Haies, bois, sur les coteaux. . . . . .............. d'Etrurie. J. or Santi.

- F. ovales, les sup res distinctes par la base ; fl. pubescentesglanduleuses. - h. Mai-at. C. Bois, haies.

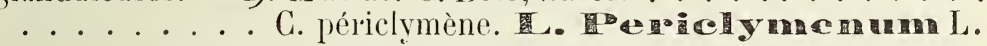

Le L. Caprifolium L. (Chéorefeuille des jardins) est fréquemment cultivé ; il diffère du L. etrusca par ses f. ora'es et ses fleurs en bouquet sessile (et non pédonculé) au centre des 2 dernières feuilles. Le symphoricarpus racemosa Mich. (Symphorine), a baies blanches et persistant longtemps, est naturalisé dans quelques haies; il est originaire du Canada.

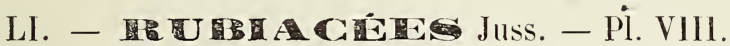

1 - Corolle rotacée, plane, à $4-5$ divisions étalées (f. 9 bis). . . 2

- Corolle à tube + ou - allongé, en entomnoir ou en cloche(f.18). 3

2 - Fruit charnu, noir (baie); corolle à 4-5 divisions . . 1 Rubia.

- Fruit sec (2 akènes); corolle à 4 divisions . . . . 2 2 Galium.

3 - Calice à 6 dents profondes, accrescentes, couronnant le fruit (f. 20).............. 5 Sherardia.

- Calice à limbe nul ou à 4 dents peu marquées. . . . . . 4

4 - Fl. en cyme au sommet des rameaux ; 2 akènes globuleux. . . ............... 3 Asperula.

- Fl. en épis, entourées chacune de 2.3 bractées (f. 19); 2 akènes

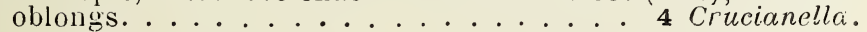

\section{1 -- RUBIA Tournef. - Garance. - Pl. VIII.}

- F. coriaces, persistantes, uninerviées, par 4-6 (f.8); stigmates en tête. - భ. Jn-jlt. C. Lisières des bois, haies.

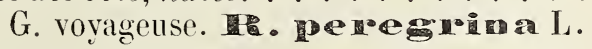

- F. minces, non persistantes, munies en descous d'un réseau de nervures secondaires; stigmates en massue. - q. Jn-at. R. Autrefois cultivé et rarement naturalisé au voisinage des. villages. , 


\section{2 - GALIUM I. - Galiet. - Pl. VIII.}

1 - F. trinerviées, verticillées par 4 (f. 9); fl. jaunes (f. 9 bis), en cymes axillaires, à pédoncules bractéolés. - \%. $A v \cdot-j n$. CC. Haies, bois. . . . G. croisette. G. Cruciata Scop.

- F. uninerviées. . . . . . . . . . 2

2 - Fl. jaunes, odorantes, en panicule dense ; f. linéaires, par 6 12 ; lobes de la corolle obtus. -- భ. Jn-spt. CG. Pelouses, bois secs.

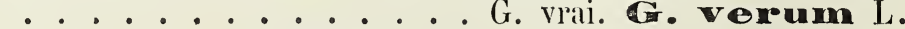

- Fl. blanches olı blanchâtres. . . . . . . . . 3

3 - Tiges non scabres; f. mucronées au sommet; plantes vivaces....................... 4

— Tiges à angles + ou - scabres; f. mucronées ou non. •

4 - Plante robuste, de $2-15 \mathrm{dm}$.; f. étroitement oblongues; panicule + ou - ample; corolle à lobes + ou - apiculés. - \%. Jnspt. CG. Haies, buissons, lieux herbeux. . G - Mollung L.

$a$ - Tige de $8-15 \mathrm{dm}$. : f. par $6-14$; fl. petites. en panicule ample ; pédicelles fructifères étalés ou divariqués; floraison en in-at. - CC. . . . . . . . G. élevé. G. elatum Thuill.

$b$ - Tige de $2-6 \mathrm{dm}$. ; f. par 8 ; fl en panicule étroite ; pédicelles fructifères dressés (f. 10!; floraison en mai-jlt. - AC.

. . . . . . . . . . G. dressé. G. erectum Huds.

$\times$ G. ochroleucum Wolf. (G. Mollugoxverum). - Çà et lì, avee les parents.

- Plante de 1-4 dm. ; f. étroitement lancéolées ou linéaires; panicule difluse, formée de corymbes + ou - làches. - భ. Jn-at. Pelouses sèches, coteaux. . G. commun. Commme Rouy.

a - Panicule à rameaux nombreux. + ou -entrelacés (f. 11); tiges couchées, diffuses. - A rechercher sur les cotcaux calcaires.

G. de Jordall. G. Jordani Loret et Barr.

b - Panicule à rameaux peu nombreux, non entrelacés; tiges + ou - ascendantes et radicantes. - C. Bois secs, terrains siliceux. . . . . . . . G. en ombelle. G. umbellatum Lamk.

- Touffes compactes, gazonnantes; corolle blanche, de $31 / 2-4 \mathrm{~mm}$.; corymbes lâches, pauciflores. v. Nouletíanum(Baill.et Timb.).

- Plante d'un vert jaunâtre ; fl. plus petites, un peu verdâtres, plus nombreuses. . . . . v. chlorophyllum (Baill. et Timb.).

- Touffes làches, non gaznnantes ; f. très rudes-scabres ; fl. blanches, petites, en corymbes peu fournis. - C...... v. scabrifolium Rouy.

$\check{\partial}-\mathrm{F}$. obtuses, non mucronées, par 4-6, de 10-1气 nm. de long; panicule lâche, à pédicelles fructifères divariqués (f. 12). - 4. Maijlt. - C. Marais, fossés, bords des canaux.

G. des marais. M. Ma dustro L.

F. longues (15-30 mm. de long) et étroites; rameaux ascendants. - R.

La Ramette, Croix-Daurade (Noulet). . . . G. constrictum Chaub. 
— F. mucronées, aiguës ou cuspidées (f. 13). . . . . 6

6 - Fleurs en cyme terminale paniculée. . . . . . . 7

- Fl., 1-3, en petites cymes axillaires; plantes annuelles. • 8

7 - Vivace et des marais ; f. par $ّ-7$ (f. 13) ; fl. blanches; pédicelles fructifères divariqués; fruit glahre. - \%. Mai-spt. AG. Prés humides, lieux fangeux.

- Annuel et des lieux secs; f. par 乞̌-8; fl. d'un vert souvent rougeatre. - (1). Jn-at. Lieux secs, bois, boids des chemins, champs. G. de Paris. Gr. paroisiense L.

Panicule étroite, oblongue, à rameaux peu étalés. - CC. . …

8 - Tiges renflées-hérissées aux noeuds; fl. dépassant les f. ; pédoncules fructifères droits; fruits hérissés. - (1). Jn-spt. CG. Haies, buissons.......... G. gratteron. G a

- Tiges ni renflées ni velues aux noeuds; fl. plus courtes queles f.; pédicelles fructifères recourbés (f. 14); fruits tuberculeux. - (1). $J n$ spt. AC. Cultures, moissons des coteaux.

G. à 3 cornes. G. With.

\section{3 - ASPERULA L. - Aspérule. - Pl. ViII.}

1 - F. glauques, linéaires, par 6-10 (f. 15) ; fl. blanches, à tube court (f. 16), en large cyme multiflore. - \%. Mai-jlt. AC. Coteaux de la Garonne, Pech-Davirl, Vieille-Toulouse. (A. glauca Bess., Galium glaucum L.). . . A. faux galiet. . D. B.

- F. vertes; corolle à tube long (f. 18). . . . . . . 2

2 - Fl. bleues, en capitules terminaux, dépassées par les bractées ; f. sup.res par 6-8, linéaires. - (1). Mai-jlt. CG. Moissons, terrains argilo-calcaires. . A. des champs. ons $\mathrm{L}$.

- Fleurs blanches ou rosées; plantes vivaces. . . . . 3

3 - Corolle en cloche ; f. planes, minces (f. 17), par 6-8; fruit couvert d'aiguillons. - \&. Mai-jn. RR. Bois. St-Agne, vallon de Niquet (Noulet). . . . . A. odorante. A. od on L.

-- Corolle en entonnoir (f. 18); f. linéaires, ordin. ${ }^{t}$ par 4 ; fruit tuberculeux. - q. Jn-spt. C. Pelouses arides, graviers, coteaux

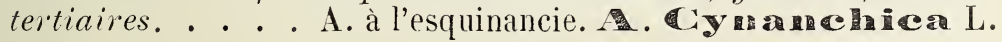

\section{4 - CRUCIANELLA L. - Grucianelle. - Pl. VIII.}

F. linéaires, par 4-6; fl. en épis quadrangulaires panachés de vert et de blane (f. 19). -- I . Jn-jlt. AR. Pelouses sèches. La Ramette, Pech-David (Noulet). . C. à l. étroites. C. an zoustiolion L. 
̋ - SHERARDIA L. - Shérarde. - Pl. VIII.

Tige de 1-3 dm. ; f. lancéolées, par 6 (f. 20); fl. d’un rose lilacé. (1). ou (2). Mai-jlt. CG. Lieux incultes et cultivés. .......... S. des champs. a a vonsis $\mathrm{L}$.

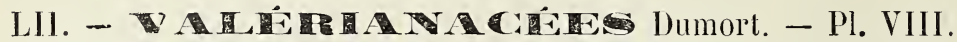

1 - Corolle munie, à sa base, d'un éperon ; 1 étamine (f. 21) . . . .

- Corolle sans éperon (f. 22); ordint 3 étamines. . . . . .

2 - Fruit muni d une aigrette (f. 23 ) ; plantes robustes, vivaces . .

..................... 2 Valeriana.

- Fruit sans aigrette ; plantes grêles, annuelles. 3 Valerianella.

1 - CENTRANTHUS DG. - Centranthe. - Pl. VIII.

- F. entières, glaucescentes. ovales-lancéolées; fl. rouges ou blanches (f. 21). - Vivace. Mai-at. Vieux murs. Aviynonet, ete. C. rouge. c. ruber DC

- F. caul. supres pemnatipartites; fl. blanches ou rosées. - Annuel.

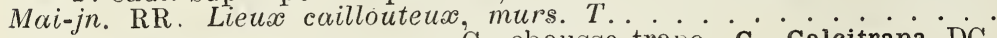

2 - VALERIANA Tournef. - Valériane. - PI. VIII.

Tige de $\check{0}-10 \mathrm{dm}$. ; f. toutes pennatiséquées, à $11-1 \check{\text { sogments }}$ oblongs ; fl. ord.t rongeattres, en corymbe (f. 22, 23). - భ. Jn-at. C. Bois, bords des inissseaux. . V. olficinale. omperatis $\mathrm{L}$.

Plus grèle; f. à segments plus nombreux et plus étroits. - Coteaux de la Garonne . . . . . . . . . . . . . . . . . v. minor Koch.

La souche de la Valériane agit sur le système nerreux; son odeur forte attire les chats. On cultive lo V. Phu L., dont les f. caul. ont 2-3 paires de segments entiers.

\section{3-VALERIANELLA Tournef. - Valérianelle. - Pl. VIII.}

1 - Limbe du calice à peu près nul, à dents peu ou point visibles sur le firuit; bractées obtuses. . . . . . . . . . 2

- Limbe du calice + ou - visible sur le fruit, denticulé, moins large ou aussi large que le fruit; bractées aiguës. . . . . . 3

- Limbe du calice grand, en coupe, plus large et aussi long que le fruit, à 6-12 dents crochues; fl. en têtes subglobuleuses. . . ठ̆

2 - Fruit plus large que long, ordin.t glabre, ridé (f. 24); loges stériles plus grandes que la fertile, qui est munie sur le dos d'un épaississement prononcé ; cymes compactes. - (1). Av.-jn. CG. Lieux cultivés (Mâche, doucette).. . . . . . . . . . . . .

$$
\text { V. potagère. olito Poll. }
$$

- Fruit 2 fois plus long que large, non ridé, concave sur l'une 
de ses faces (f. 2ö, coupe). - (1). CG. Av.-jn. Lieux cultivés .. . .

3 - Calice à limbe court, à 3 denticules obtus, inégaux ; fruit à 2 sillons longitudinaux (f. 26); corymbes plans. - (1). $A v \cdot-j n$. C. Moissons. (V. pumila DC.).

- Calice à lim be apparent, trompé + ou - obliquement. . 4

4 - Limbe du calice très oblique, aigu, denticulé, plus étroit et plus court que le fruit; inflorescence lâche.

a). Fruit ovoïde-ventru (f. 27), à 3 lobes séparés par des sillons inégaux; loges stériles contiguës et plus grandes que la fertile. (1). Mai-jlt. C. Moissons, cultures. (V. dentata Auct.).

V. fendue. W. ronnos Bast.

Calice à $1-2$ denticules à peine visib'es ou entier. - C. Auricula DC:

b). Fruit ovoïde-conique (f. 28), plan-conrexe ; loges stériles filiformes, séparées par un intervalle oblong. - (1). Ji-at. CG. Cultu-

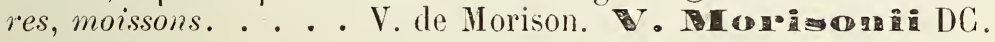

- Limbe du calice formant une couronne complète à $4-6$ dents, aussi longue et aussi large que le fruit (f. 29); cymes compactes: fruit ordn.' velu, ovoïde. - (1). Mai-jlt. C. Moissons, cul-

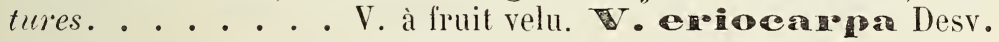

๖ - Limbe du calice glabre, à 6 dents dressées (f. 30); face ventrale du fruit présentant une fossette oblongue. - (1). AG. Moissons, cultures. . . . . . . V. couronnée. V. conomata DC.

- Limbe du calice velu sur les 2 faces, à 6 dents étalées (f. 31), souvent bifides; fossette de la face ventrale ovale. - (1). Mai-jn. R. Moissons. Coteaux de l'Ariège et de la Garonne. . . . . . .......... V. en disque. discedidea Lois.

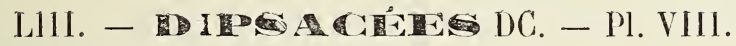

1 - Réceptacle chargé de paillettes (f. 32). . . . . . . . 2

- Réccptacle sans paillettes, mais hérissé de soies; calice à limbe terminé par (6-10 arêtes (f. 36).. . . . . 2 Knautia.

2 - Paillettes du réceptrcle non épincuses; folioles de l'involucre non épineuses. . . . . . . . . . . . 3 Scabiosa.

- Paillettes du réceptacle et folioles de l'involucre épineuses (f. 32). . . . . . . . . . . 1 Dipsacus.

1 - DIPSACUS Tournef. - Cardère. - Pl. VIII.

1- F. caul. non soudées à leur base; capitules globuleux (f. 32), de $2 \mathrm{~cm}$. environ, non dépassés par les folioles de l'involucre (f. 33, 
fruit). - (1). Jn-spt. R. Rives de l'Ariège, descendu des Pyrénées. - F. caul. largement réunies à leur base ; capitules de $3-50 \mathrm{~cm}$.

2 - Folioles de l'involucre aiguillonnées (f. 34) ; paillettes du réceptacle glabres (f. 30̈); f. entières ou dentées. - (2). Jlt-spt. C. Bords des chemins, lieux incultes.

C. sauvage. Dilvesine Mill.

F. caul. pennatifides ; fl. blanches. - Moins $C$.

.... C. laciniée. Do laciniatus L.

- Folioles de l'involucre inermes; paillettes du réceptacle à pointe épineuse courbée en dehors. - (1) ou (2). Jlt-at. Culticé (Chardon à foulon).......... C. à foulon. fub tomume Mill.

\section{2 - KNAUTIA Coult. - Knautie. - Pl. VIII, f. 36.}

- Fl. extérieures rayonnantes; f. sup. pennatifides ou pennatipartites, rarement presque entières (f. 36, fruit). - (2) ou భ. Jn-spt. G., surtout dans les terrains argilo-calcaires, cultures.

........... K. des champs. KR. arovensis Coult.

- Fl. extérieures peu ou point rayonnantes ; f. entières ou dentées. - R. Rives lle l'Ariège .

K. à f. de scabieuse. Ix. dipsarifolia F. Schultz.

\section{3 - SCABIOSA L. - Scabieuse. - Pl. VIII.}

1 - Corolle à 4 divisions ; f. toutes simples, entières ou dentées ; calicules velus, à limbe divisé en 4 lobes. - భ. Jlt-oct. CG. Bois, prés, pâturages. ........ S. succise . ucoisa L.

- Corolle à ô divisions ; f. caul. pennatiséquées. . . . . . 2

2 - Calicule à limbe court, spongieux, courbé en dedans (f 37 , fruit) ; capitules fructifères oblongs (f. 38); fl. lilas. - (1) ou (2). Jnspt. Lieux secs, pelouses, tertres.

Plante velue, rameuse, à f. caul. profondément pennatipartites. CC.

Capitules grands, à corolles d'un pourpre foncé - Cultivé. (Fl. des veuves). . . . . . . . . . . . v. atripurpurea G. G.

- Calicule à limbe membraneux, en forme de collerette plissée (f. 39) ; capitules fructifères sulgglobuleux (f. 40). - 4. Jn-oct. C(.

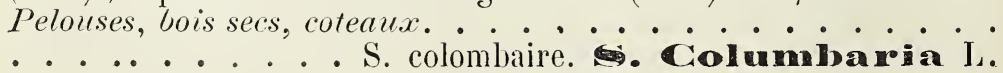

$a$ - Arêtes du calice 1 1/2 fois plus longues que la couronne; feuilles très pubescentes. . . . . . . v. Loretiana (Timb,)

$b$ - Arêtes du calice 3 fois plus longues que la couronne.

- Rameaux dressés; f. pennatiséquées, à segments profondı divisés.

v. permixta (Jord.) 
- Rameaux étalés ; f. bipennatiséquées, à segments profondt divisés............. v. patens (Jord.).

c - Arêtes du calice 4 fois plus longues que la couronne, élargies à leur base ........... v. pratensis (Jord.).

\section{LIV. - COBLOSTES Adans.}

1 - Corolles toutes ligulées, bisexuées ; styles non rentlés au-dessous des stigmates.......... III Liguliflores 35

- Corolles du centre du capitule tubuleuses. . . . . . . . 2

2 - Corolles toutes tubuleuses, celles de la circonférence parfois un peu irrégulières; style ord.t renflé au-dessous des stigmates............. II Cynarocéphales 19

- Corolles de la circonférence ordinairement ligulécs-rayonnantes, celles du centre tubuleuses; styles nou renflés audessous des stigmates......... I Corymbifères 3

3 - Aigrette du fruit à 3-5 arêtes épineuses; f. opposées, fl. jaunes. 13 Bidens cernuus.

- Aigrette du fruit à $2-5$ paillettes caduques ; fl. jaunes. . . . .

- Akènes, au moins ceux du centre, surmontés d'une aigrette poilue....................... 4

- Akènes nus ou couronnés d’une membrane. . . . . . . . 11

4 -- Tige florifère sans feuilles, ne portant que des écailles. . . 5

- Tige florifère à feuilles opposées; fl. purpurines (Pl. IX, f. 34).

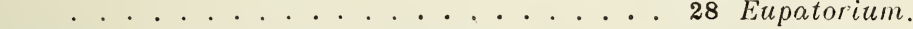

- Tige florifère à feuilles alternes. . . . . . . . . 6

5 - Capitule solitaire; fl. jaunes (Pl. IX, f. 33) . . 26 Tussilago.

- Capitules nombreux, en grappe ; fl. rosées. . . 27 Petasites.

6 - Akènes de la circonférence nus (PI. IX, f. 20, 31) ; capitules jaunes.......................

- Tous les akènes munis d'une aigrette de poils entouréc à sa base d'une couronne dentéc ou fendue.

a) - Akènes à côtes, surmontés d'une couronne dentée ou fen-

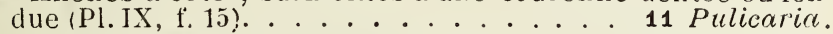

b) - Akènes sans côtes, contractés en col au sommet, à couronne courte (Pl. IX, f. 14)...... 10 Cupularia.

- Tous les akènes munis d'une aigreito de poils égaux ou presque égaux................. . . 7

7 - Folioles de l'involucre sur un scul rang, en partic soudées, entourées, à la base, de petites bractées formant uncalicule.

25 Senecio.

- Folioles de l'involucre libres, sur 2 ou plusieurs rangs. • . 8

$\delta$ - Fl. ligulées blanches, roses ou purpurines . . . . . . 9

— Fl. ligulées jaunes. . . . . . . . . . . 10

9 - Corolles de la circonférence filifurmes; fl. d'un blane jaunâtre................ 5 conyza.

- Corolles de la circonférence ligulées, dressées (Pl. IX, f. 4). . .

4 Erigeron.

10 - Réceptacle nu ou à peinc alvéolé ; anthères ayant à la basc 2 appendices flliformes. ......... 9 Inula. 
- Réceptacle à alvéoles bordés d'une membrane dentée; anthères sans appendices. . . . . . . . 1 Solidago.

11 - Réceptacle nu. . . . . . . . . . . . . 12

- Réceptacle muni de paillettes. . . . . . . . . . . . 16

12 - Fl. ligulées jaunes. . . . . . . . . . . . 13

- Fl. ligulées blanches. . . . . . . . . . . . . 14

13 - Fl. ligulées sur 1 seul rang; akènes de la circonférence à 3 faces et 2 ailes; plante glabre. . . . . 22 Chrysanthemum.

- Fl. ligulées sur 2 ou plusieurs rangs; akènes + ou - courbés en arc (Pl. IX, f. 35). ............ 29 Calendula.

14 - F. à peu près toutes radicales, entières ou dentées; akènes lisses. . . . . . . ........ . Bellis.

- Tige Réceptacle devenant conique; akènes à 3-5 côtes sur feuillée la tace interue (PI. IX, f. 2: 2 ) ; f. bipennatiséquées ; plante glabre........ 18 Matricaria.

Réceptacle plan-convexc; akènes munis de côtes tout autour................. 15

15 - Corolles du certre à tube comprimé-ailé; akènes du centre saus courome. . . . . . . . 21 Leucanthemum.

- Corolles du centre à tube cylindrique; akènes tous munis d'une couronne (Pl. IX, f. 25); f. pennatiséquées...... 20 Pyrethrum.

16 - Akènes de la circonférence plus grands, à 2 ailes ; fl. jaunes (Pl. IX, f. 16). ........... 12 Pallenis.

- Akènes tous de même taille. . . . . . . . . . 17

17 - Akènes lisscs (PI. IX, f. 20, 21) ; capitules petits, en corymbe, unicolores, blancs ou rosés . .......17 Achillea.

- Akènes + ou - munis de còtes; capitules à fl. du centre jaunes, celles de la circonf. bianches......... 18

18 - Corolles, au moins celles du centre, à tube élargi à la base en une membrane qui coifle une partie de l'ovaire; akènes arronds au sommet; pl. aromatique. ...... 15 Úrmenis.

- Corolles non comme ci-dessus; akènes tronqués au sommet (Pl. IX, f. 19); f. bipennatiséquées. . . . . 16 Anthemis.

19 - Fleurs bleues, munies chacune d'un involucre (PI. IX, f. 36) et formant un capitule globuleux. . . . . . 30 Echinops.

- Involucre commun à un grand nombre de fleurs. . . . . 20

20 - Aigrette à 3-5 arêtes (Pl. IX, f. 17); f. opposées. . . 13 Bidens.

- Aigrette nulle ou en forme de couronne membrancuse courte ; t1. jaunâtres. . . . . . . . . . . . . . 21

- Aigrette formée de paillettes persistantes et libres, . . . 222

- Aigrette formée de poils fins, libres ou soudis. . . . . . 24

21 - Réceptacle nu; akènes ınunis d'une couronne (Pl. IX, f. 24). . . ........................

- Réceptacle nu; akènes sans couronne; capitules de 2-3 min. de large (Pl.IX, f. 29). ........ 23 Artemisia.

- Réceptacle pailleté; fl. grandes. . . . . . 41 Centaurea.

22 - Limbe des corolles à peine distinct; réceptacle à paillettes 3 partites. .............. 32 Xeranthemum.

- Limbe des corolles à 4.5 divisions. . . . . . . . . . . 23

23 - Folioles de l'involucre épincuses et semblables aux f.; akènes à 4 angles (Pl. X. f. 8). . . . . . . 43 Kentrophyllum. 
- Folioles de l'involucre non semblables aux feuilles; akènes comprimés (Pl. X, f. 4). . . . . . 41 Centaure $\alpha$.

24 - Folioles de l'involucre soudées, sur un seul rang (Pl. IX, f.

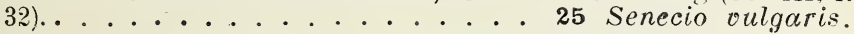

- Folioles de l'involucre libres, imbriquées ou sur 1, 2 rangs. 25

25 - F. opposées, à 3-5 lobes lancéolés; fl. purpurines, en capitules petits (Pl. IX, f. 34)........28 Eupatorium.

- Non comme ci-dessus. .............. 26

26 - Capitules très petits, de $6.8 \mathrm{~mm}$. au plus, souvent agglomérés; plantes blanches-cotonneuses. . . . . . . 27

- Capitules plus grands, de plus de $12 \mathrm{~mm}$, ordint distincts. 28

27 - Réceptacle muni de paillettes à la circonférence (Pl. IX, f. 6-9). . . . . . . . . . 6 Filago.

- Réceptacle $\mathrm{Fl}$. femelles sur 2-3 rangs; involucre brunâtre ou nu jaune pâle (PI. IX, f. 10). . . 7 Gnaphalium.

Fl. femelles sur 1 seul rang; involucre jaune l'or (Pl. IX. f. 11).......8 Helichrysum.

28 - Fl de la circonférence filiformes, sur plusieurs rangs; capitules petits............ 5 Conyza.

- Fl. toutes égales ou celles de la circonférence plus dévelop-

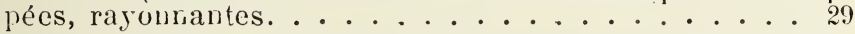

29 - Aigrette persistante; f. larges; fl. purpurines; réceptacle pailleté .................... 40 Serratula.

- Aiqrette persistante ; f: linéaires ; fi. jaunes ; réceptacle à alvéoles dentés................ 3 Linosyris.

- Aigrette caduque, à poils.

30

30 - Très courts. libres; involucre à folioles crochues au sommet (Pl. X, f. 1)............ 39 Arctium.

- Plumeux et soudés en 3, 4 faisceaux (Pl. IX, f. 37); f. épincuses................... 31 Carlina.

- Soudés en anneau à la base, lisses ou denticulés. . . . . 31

- Soudés en anneau à la base, cilićs ou plumeux. . . . . . 32

31 - Folioles de l'involucre épineuses au sommet et sur Jes côtés (Pl. IX, f. 42) ...........34 Silybum.

- Folioles de l'involucre non épineuses ou épineuses sculement au sommet (Pl. IX, f 45-47)....... 38 Carduus.

32 - Fl. purpurines, celles de la circonférence stériles et raronnantes; f. épineuses (Pl. IX, f. 40, 41)... 33 Galcetites.

- Fl. toutes hermaphrodites et égales. . . . . . . . . 33

33 - Alvéoles du réceptacle bordés d'une membrane dentée (PI. IX, f. 43); involucre épineux........ 36 Onopordon.

- Réceptacle garni de paillettes ou de filaments; akènes à 4

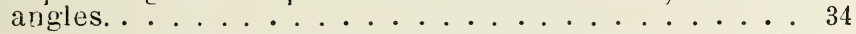

34 - Réceptacle pailleté; plante de 5-20 cm., à capitules médiocres (Pl. X. f. ' . ......... 42 Carduncellus.

- Réceptacle poilu; plante robuste, à capitules très gros.

- Réceptacle garni de paillettes; akènes comprimés. 37 Cirsium.

35 - Paillettes du réceptacle grandes, entourant les akènes; plante épineuse (Pl. X, f. 45), à tl.jaunes . . . . 70 Scolymus.

- Non comme ci-dessus. 
36 - Fl. bleues ; akènes portant de nombreuses petites écailles.. . . ................ 63 Cichorium.

- Fleurs jaunes; akènes dn centre portant 4, 5 soies raides et scabres (Pl. X, f. 38). . . . . . . . . . 64 Tolpis.

- Fleurs jaunes; akènes nus au sommet. . . . . . . . . 37

- Akènes terminés par des paillettes lancéolées, non scabres.

- Akènes munis d'une aigrette poilue. . . . . . . . . . . . . . . . 48

37 - F. toutes radicales; involucre à folioles sur un seul rang (Pl. $\mathrm{X}$, f. 42).............68 Arnoseris.

- Tige Akènes externes divergents, enveloppés par les fofeuilléc lioles de l'involucre, quisont accrescentes (Pl. X, f. 4.1). . . . . . . . 67 Rhagadiolus.

Akènes non divergents; folioles de l'involucre dressées, non accrescentes (Pl. X, f 44). 69 Lampsana.

38 - Fleurs bleues; réceptacle hérissé de soies; involucre à folioles membraneuses. . . . . ....62 Catanunche.

- Fleurs jaunes; réceptacle nu; involucre à 1 seul rang de folioles. . . . . . . . . . . 39

39 - Akènes tous subcylindriques (Pl. X, f. 39, 40); tige feuillée. . - Akènes du centre comprimés-ailés, ceux de la circonf subcy. lindriques; f. toutes radicales. . . . . . . . 66 Hyoseris.

40 - Akènes à aigrette formée de roils élargis à la plbase et plumeux......................... 41

- Akènes à aigrette formće de poils non élargis à la base, + ou - denticulés, mais non plumeux.......... 46

41 - Involucre double, l'exterue à folioles larges, cordées; akènes à long bec............. 56 Helminthia.

- Involucre à folioles toutes sur 1 rang; akènes terminés en bec............................ 42

- Involucre à folioles imbriquées; fl. jaunes. . . . . . . . 43

$42-$ F. inf. peunatifides; fl. jaunes (Pl. X, f. 31). 57 Urospermum.

- F. entières, linéaires (Pl. X. f. 34) . . . . 60 Tragopogon.

43 - Réceptacle à paillettes cadurues; aigrette à soies sur 2 rangs (Pl. X, f. 35). . . . . . . . . . . 61 Hypochueris.

- Réceptacle nu ou fimbrillifère; f. toutes radicales. . . . . . 44

- Réceptacle nu ou fimbrillifère; tige feuillée. . . . . . 45

44 - Akènes de la circonférence terminés en couronne membraneuse, ceux du centre plolongés en bec supportant l'aigrette (Pl. X, f. 25. 26).. . . . . . . . . 53 Thrincia.

- Tous les akènes atténués au sommet, mais non terminés en bec (Pl. X, f. 2i). . . . . . . . . . 54 Leontodon.

45 - Aigrette caduque et à poils soudés en anneau à leur base (Pl. x, f. 29). . . . . . . . . . . 55 Pieris.

- Poils de l'aigrette non soudés en anneau. . . . . . . . 46

46 - F. pennatiséquées; akènes munis d'un pied creux et renflé (Pl. X, f. 33!........... 59 Podospermum.

- F. entières; akènes sans pied . . . . . 58 Scorzonera.

47 - Akènes retrécis en un bec qui supporte l'aigrette (Pl. X, f 50).

- Akènes non terminés en bec............. 50 
48 - F. toutes radicales ; hampe fistuleuse, portant 1 seul capitule. .............. 45 Taraxacum. \begin{tabular}{c|c} 
- Tigè & Akènes comprimés-aplanis, brusq.t terminés en bec (Pl. \\
feuillée & $\mathrm{X}, \mathrm{f} .12)$
\end{tabular}

Akènes subcylindriques. . . . . . . . . . 49

49 - Akènes dentés-écailleux à la basc du bec. . . 44 Chondrilla.

- Pas de dents à la base du bec des akènes (PI. X. f. 19) . . .

50 - Akènes de 2 sortes, ceux du centre subcrlindriques, ceux de la circonférence gros et courts (Pl. X. f. 16, 17). 48 Pterotheca.

- Akènes tous de même forme. . . . . . . . . . . 51

51 - Akènes comprimés, striés (Pl. X, f. 14); involucre renflé vers son milieu, resserré au sommet. ......47 Sonchus.

- Akènes subcylindriques, atténués au sommet; aigrette blanc de neige.. . . . . . . . . . . 50 Crepis.

- Akènes subcylindriques, tronqués au sommet; aigrette d'un

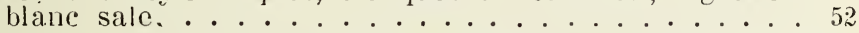

52 - Réceptacle à alvéoles à peine fimbriés. . . . 51 Hieracium.

- Réceptacle garni de soies aussi longues rue les akènes; plante cotonneuse........... 52 Andryala.

\section{I. - CORYMBIFÈRS Juss.}

\section{1 - SOLIDAGO L. - Solidage. - Pl. IX.}

F. pubescentes, les inf. pétiolées, dentées, ovales-lancéolées ; panicule feuillée (f. 1). - భ. Jn-spt. R. Bois, bruyères. Bouconne, Colomiers. . . . S. verge d'or.

Le $\mathbf{S}$. glabra Desf., plante glabrescente, à f. lancéolées, à capitules petits, unilatéraux, est quelquefois cultivé et.se trouve naturalisé aux bords du 'Tarn.

\section{2 - BELLIS L. - Pâquerette. - Pl. IX.}

Capitules solitaires sur des pédoncules nus (f. 2), rar feuillés à la base (v. caulescens Rochebr.). - 4. Ms-oct CG. Pelouses, prés . . $\mathrm{P}$. vivace. Tiserering $\mathrm{L}$.

\section{3 - LINOSYRIS Lob. - Linosyris. - Pl. IX, l. 3 (fl).}

Tige ordint simple, très feuillée ; capitules en corymbe. - $\%$. At-oct. AR. Friclies des coteaux : Balma, C. à Lanta (M. Marty), coteaux de la Garonne. (Chrysocoma Linosyris L.) . . . . . . .

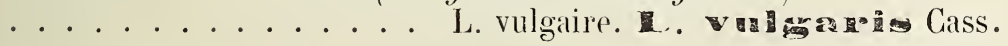

\section{4 - ERIGERON L. - Vergerette. - Pl. IX.}

- Panicule allongée, à capitules petits. nombreux (f. 4); ligules blanches. - (1). Jlt-spt. GG. Cultures, lieux vagues. Originaire de l'Amérique du $N$. . V. du Canada. HE. 
- Panicule corymbiforme, lâche, à capitules médiocres; ligules d'un rose violacé. - (2). Jn-oct. G. Friches, pelouses des coteaux. V. âcre.

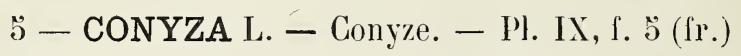

Plante pubescente, de 2-ă dm. ; f. lancéolées ; corvmbe lâche. (1). Jn-oct. Décombres, murs. AC. T'.

\section{C. ambiguë. C. ambigua I)C.}

$$
6 \text { - FILAGO L. - Cotonnière. - Pl. IX. }
$$

1 - Capitules par 8-20\%, en glomérules subglobuleux, ayant plus d'un $\mathrm{cm}$. de large ; involucre à folioles cuspidées . . . . . 2

- Capitules par 2-6, en lascicules, ne dépassant pas $8 \mathrm{~mm}$. de large ; involucre à folioles non cuspidées. . . . . . . 3

2 - F. caul. non ou peu atténuées à la base ; capitules à J̃ angles peu marqués, en glomérules nou dépassés par les f. florales. - (1). Jn-spt. CG. Coteaux, champs siticeux . . . . . . . . .

C. d'Allemagne. F. Genamica L.

Tomentum blanc; involucre à folioles jaunâtres au sommet.. . . .

$\ldots \ldots \ldots \ldots . . . \ldots$. . . . . canescens G. G.

Tomentum jaune-verdâtre; involucre à folioles rougeâtres au som-

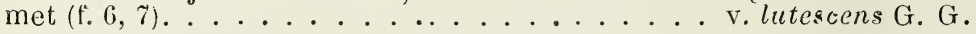

- F. caul. atténuées à la base ; capitules à $ّ$ angles (f. 8) ; glomérules dépassés par les f. florales. - (1). C. Moissons, bords des champs, surtout dans les terres argito-calcaires.

C. spatulée. Er. spath

3 - F. florales dépassant les glomérules (f. 9). - (1) Jlt.-spt. C. Moissons, terrains siticeux. - C. de France.

- F. florales dépassées par les glomérules de 2-ô capitules. (1). Jn-spt. C. Moissons, champs siliceux.

C. naine. min inders Pers.

\section{7 - GNAPHALIUM L. - Gnaphale. - Pl IX.}

- F. caul. demi-embrassantes ; capitules en cyme corymbiforme non feuillée. -- (1). Jlt.-spt. AC. Terres sablonneuses lumides,

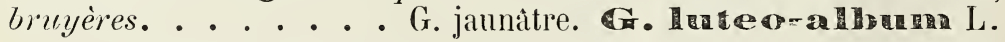

- F. caul. très atténnées à la base ; capitules en glomérules denses, entourés de bractées qui les dépassent (f. 10). - (1). Jn-oct. AC. Lieux humides des terrains siliceux.

\section{8 - HELICHR YSUM Giertn. -- Hélichryse. - Pl. IX.}

- Capitules subglobuleux (f. 11), à folioles + ou - litches, d'un 


\section{$-111-$}

beau jaune, les internes élargies au sommet. - - Jn-spt. AR. Coteaux et rives de la Garonne. . Il. stiechas. HI. staecha DC.

- Capitules plus petits, subcylindriques, à folioles d'un jaune påle, les internes non élargies au sommet. - b. Jn-spt. • . . .

. . . . . H. à f. étroites. H. angustifolium DC.

F. vertes en dessus, très longues; akènes non glanduleux. $-A$

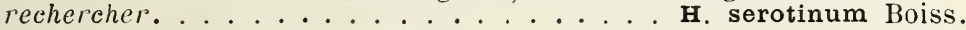

On cultive l'H. orientale DC. (Eternelle).

$$
9 \text { - INULA L. - Inule. - Pl. IX. }
$$

1 - Involucre à folioles extermes foliacées ; plante de $8-12 \mathrm{dm}$., à f. tomenteuses en dessous ; capitules grands (f. 12). - h. Jlt-at. R. Lieux couverts. Le Vernet. Parfois cultivé.

- Involucre à folioles externes non foliacées ; capitules médiocres

2 - Ligules très courtes, ne dépassant pas l'involucre; f. sup. atténuées à la base, sessiles (f. 13). - (2) ou \%. Jlt.-oct. C. Lieux secs, firches, lieux pierreux. . . . I. conyze. Conyza DC.

- Ligules bien plus longues que l'involucre; f. glabrescentes, les caul. élargies à la base, embrassantes. - \%. Jn-at. AR. Bois secs. La Ramette, Colomiers, Bouconne etc.

L'aunée est un stimulant des organes de la digestion et de la circulation ; c'est un emménagogue populaire; on l'emploie surtout en médecine rétérinaire.

$$
10 \text { - CUPULARIA God et Gr. - Cupulaire. - Pl IX. }
$$

Plante odorante, à f. sup. linéaires, sessiles; capitulespetits (f. 14); ligules courtes. - (1). At-nov. C. Champs argileux, vignes. G. fétide. C.

$$
11 \text { - PULICARIA Gærtn. - Pulicaire. - PI. IX. }
$$

- Ligules ne dépassant pas l'involucre ; pédoncules très courts ; plante létide. - (1). Jn-spt. C. Lieux humides, fossés clesséchés. . . ........... P. vulgaire. volgonoris Gritn.

- Ligules dépassant nettement l'involucre (f. 1气) ; pédoncules grêles; f. radicales détruites à la floraison. - $\%$. Jn-oct. CC. Bords des chemins, fossés.

P. dysentérique. H. ysontorica Gartn.

$$
12 \text { - PALlenis Cass. - Pallénis. - Pl. IX. }
$$

Plante velue; f. caul. demi-embrassantes ; capitules (f. 16) soli- 
taires à l'extrémité des rameaux. - (2). Jn-at. G. Lieux secs, friches, pelouses (Asteriscus G. G., Bupletalmum L.). . . . . . ............ P. épineux. spinosa Cass.

$$
13 \text { - BIDENS L. - Bident. - Pl. IX. }
$$

- Capitules penchés; f. lancéolées, sessiles, + ou - soudées à la base; akènes à 3-ô arêtes. - (1). Jlt-oct. C. Bords des eaux, rives de la Garonne. . . . . . . . . B. penché. RB. cenomens.

- Capitules dressés; 1. ordin.' 3-partites; akènes à 2-3 arêtes (f. 17). - (1). Jn-oct. CG. Bords des eaux, fossés. . . . . . . . .

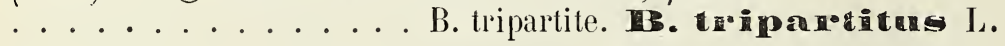

\section{4 - HELIANTHUS L. - Hélianthe.}

- Racine non tubéreuse; capitules très grands, penchés. - (1).

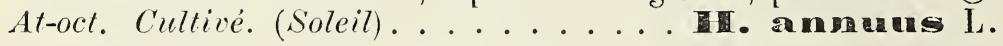

- Racine tubéreuse ; capitules dressés, médiocres. - భ. At-oct.

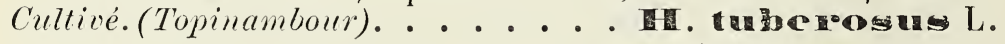

$$
10 \text { - ORMENIS Cass. - Ormène. - Pl. IX. }
$$

- Paillettes du réceptacle aiguës; corolles du centre à tube appendiculé. - I). Jn-spt. C. Terres sablonneuses, graviers. (Anthemis mixta L.). . . . O. bicolore. D. Dorlon Cass.

- Paillettes du réceptacle obtuses ; corolles du centre à tube non appendiculé (f. 18). - 4. Jn-spt. AC. Bords des chemins, pelouses, tervains siliceux. (Anthemis L.). O. noble. Molbilis J.Gay.

L'O. noble est fébrifuge et apéritive; mâchée, elle provoque la salivation.

$$
16 \text { - ANTHEMIS L. - Anthémide. - Pl. } 1 \mathrm{X} \text {. }
$$

1 - Réceptacle convexe, ne s'allongeant pas ; corolles du centre à tube ailé ; paillettes du réceptacle spatulées. - (1). Mai-at. CG. Moissons, lieux incultes . . A. élevée. A. alcissima L.

paillettes du réceptacle dépassant les corolles et terminées en pointe piquante. . . . . . . . . . . . v. Cota Rouy.

- Réceptacle devenant conique-allongé ; corolles du centre à tube peu ou point ailé . . . . . . . . . . . 2

2 - Akènes à côtes lisses ; paillettes contractées en pointe raide dépassant, à la fin, les corolles du centre. - (1). Mai-spt. C. Cultures, terrains siticeux. . A. des champs. A anomsis $\mathrm{L}$.

- Akènes à côtes tuberculeuses (I. 19), paillettes linéaires, caduques, sauf les centrales; ordt glabre, fétide. - (1). Mai-spt. CC. Moissons, cultures, bords deschemins. A. fétide. Cotala L. 
17 - ACHILLEA L. - Achillée. - PI. IX.

- Capitule hémisphérique ; 8-12 ligules aussi longues que l’involucre ; f. dentées. - భ. Jn-spt. AC. Lieux frais, fossés. La Ramette, Brax, Colomiers, etc ......... A. sternutatoire. A. Hanica L.

- Capitule ovoïde, à ligules plus courtes que l’involucre et peu nombreuses (f. 20, 21, fr.) ; f. bipennatiséquées. - \%. Jn-oct. CG. Bords des chemins, des bois, prés.

A. millefeuille. A.

18 - MATRICARIA L. - Matricaire. - Pl. IX.

- Réceptacle allongé-conique, creux (f. 23); akènes à ร̌ côtes (f. 22); plante aromatique. - (1). Av--jlt. CC. Lieux cultivés. . .

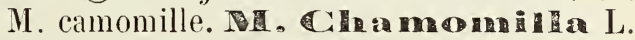

- Réceptacle ovoïde, plein ; akènes comprimés, à 3-4 angles ; plante presque inodore. - I. Jn-oct. CG. Lieux cullivés, sables des rivières .......... M inodore. M. ins Iora $\mathrm{I}$.

19 - TANACETUM I. - Tanaisie. - Pl. IX, f. 24 (fr.).

Pl. odorante; $f$. pennatiséquées, à segments très divisés ; capitules jaunes, en corymbe. - ४. Jn-oct. Cult. et subspt. près des liabitations. . . . . . . . . T. vulgaire. T. valgano L.

On cultive aussi le T. balsamita L. (Menthe-coq), à feuilles ovales, dentées, à odeur suave. Les tanaisies sont toniques et vermifuges.

\section{0 - PYRETHRUM Scop. - Pyrèthre. - Pl. IX, f. 2Ö (fr.).}

- F. caul. sessiles, auriculées et demi-embrassantes, à 10-15̆ paires de segments divisés; souche rampante. - \%. Jn-at. C. Bois, coteaux secs, calcaires ou argilo-calcaires (P. corymbosum Willd.)

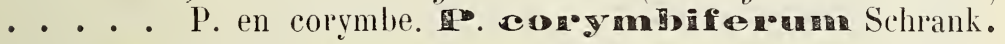

F. presque bipennatiséquées, à divisions fines, peu dentées. . v. tenuifolium Led.

- F. caul. pétiolées, à 4-8 paires de segments ovales, incisés ; souche non rampante. - \%. Jn-spt. Cultivé et naturalisé cà et láa, vieux murs, haies (Matricaire, Matricaria L.). ....... P. matricaire.

21 - LEUCANTHEMUM Tournef. - Leucanthème. - Pl. IX.

- F. caul. auriculées, deni-embrassantes (f. 26), oblongues, dentées ou incisées ; tige pubescente, de 4-7 dm (f. 27, capitule). - ₹.

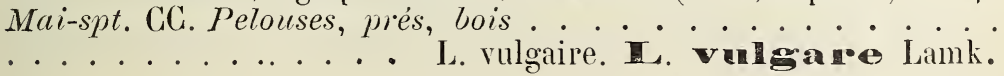


- F. caul. non auriculées, linéaires, étroites; plante de 2-3 dm. - 2. Jn-at. R. Rives de la Garonne et de l'Ariège; descendu des Pyrénées. . . . . L. de montagne. T. moncanum DC.

Le L. maximum DC., plante glabre, robuste, ¿̀ f. finement dentécs, à capitules très grands, a été également rencontré sur les rives de l'Ariège. - Jlt-at.

\section{2 - CHRYSANTHEMUM Tournef. - Chrysanthème. - Pl. IX.}

- F. dentées, 3-fides ou pennatilobées ; akènes du centre subcylindriques (f. 28). - (1). Mai-at. RR. A été trouvé à Guilheméry. C. des moissons. C. segzetum L.

- F. bipennatipartites ; akènes du centre comprimés, à marge interne ailée. - (1). Mai-jlt. Cultivé et subsp. (Marguerite dor'ée).

C. couronné. C. comonnaronum L.

\section{3 - ARTEMISIA L. -- Armoise. - Pl. IX.}

1 - Involucre glabre, luisant; capilules ovoïdes, de $2 \mathrm{~mm}$. de large (f. 29); f. 1-2 fois pennatiséquées. - \%. At-oct. CG. Lieux incultes, coteaux, graviers. . . . . . . . . . . . .

A. champêtre. A cammosthos L.

- Involucre blanchâtre, pubescent-tomenteux. . . . . . 2

2 - F. vertes en dessus, blanches en dessous, 1-2 fois pennatipartites, à segments larges. - \%. Jlt-spt. C. Lieux vagues, bords des chemins. . . . . . . A, vulgaire. . vulganois I.

- F. blanches-tomenteuses sur les 2 faces, $2-3$ fois penmatiséquées, à segments larges. - \%. Jlt-at. AC. Lieux arides; sou-

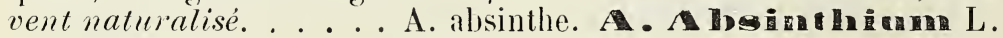

L'A. vulgaris est un emménagogue populaire; l'A. Absinthium sert à la préparation de la liqueur d'absinthe.

\section{4 - DORONICUM L. - Doronic. - Pl. 1X, f. 30, 31 (fr.).}

- 1-ă capitules grands; 1. radicales suborbiculaires, cordées, les caul. sup. embrassantes. -- \%. Mai-jlt. R. Lieux ombragés. Bords du Tarn; à rechercher dans le Lauragais (D. Pardalianches

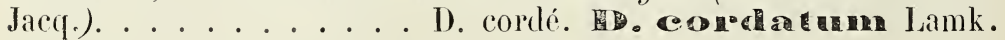

$$
20 \text { - SENECIO L. - Séneçon. - Pl. IX. }
$$

1 - Fl. ligulées nulles; lige rameuse, de 1-4 dm. ; f. penuatifides, les sup. embrassantes; calicule à 8-10 écailles (f 32). - (1). Toute l'amnee. C.. Lieux cultivés, décombres.

\section{S. vulgaire. vulgaroin L.}

- Fl. ligulées distinctes, roulées en dehors ; l. pennatiséquées; calicule à 4, כ̌ écailles; tige de 4-10 dm. - (1). Jn-oct. R. Bois, 
terrains siliceux. Buset, Bessières.

- Fl. ligulées étalées-rayonnantes, très distintes. . . . . 2

2 - Souche rampante; akènes tous pubescents; tige robuste, pubescente-floconneuse ainsi que les f. et l'involucre. - \%. Jlt-oct. C. Bords des ruisseaux, des bois, páturages. . . . . . . . . S. à f. de roquette. encirolina $\mathrm{L}$.

- Souche courte, tronquée ; akènes de la circonférence glabres; plante glabre ou un peu aranéeuse ; écailles du calicule très courtes. - (2) ou q. Mai-spt. CC. Prés, pelouses.

............. S. Jacobée. Ja colpara J.

a) - F. caul. à segments presque égaux.

- Corymbe serré ; f. oblongues dans leur contour. Vivace. - C. .

- Corrmbe lâche ; obovales dans leur contour. Bisannulle. Bois. . . . . . . . . . . . s. nemorosus Jord.

b) - F. caul. à segment terminal bien plus grand que les autres.

- F. toutes pemnatipartites ou pennatiséquées; tige rameuse; capitules de 15-20 mnn. de large, sur des pédoncules grêles. AC. Prés humides. . . . . . . . . s. erraticus Bertol.

- $\mathrm{F}$. inf. réduites au lobe terminal ou à lobes latéraux très petits; capitules de $2 \mathrm{~cm}$., sur des pédoncules un peu épaissis. - R. Lieux humides; bords du Touch.,. S. aquaticus Huds.

\section{6 - TUSSILAGO L. - Tussilage. - Pl. IX, f. 33 (cap.).}

F. orbiculaires-cordées, anguleuses. - \%. Ms-av. C. Lieux

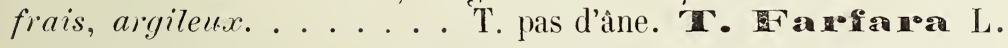

Ses fl. sont adoucissantes et pectorales; ses f. s'emploient pour faire des cataplasmes maturatifs.

\section{7 - PETASITES Tournef. - Petasite.}

F. suborbiculaires-cordées, dentées, vertes en dessous ; fl. odorantes.- Janv.-ms. Cult. et naturalisé çà et là. Pech-David, T. (Nar.losmia Reich., Hétiotrope d'hiver). .

P. odorant. Treans Presi.

$$
28 \text { - EUPATORIUM L. - Eupatoire. - Pl. IX. }
$$

Tige de 8-15 dm. ; capitules nombreux, ordin.t $ّ$-flores (f. 34). — 4. Jlt.-spt. CG. Lieux humides, bords des eaux. . . . . . . .

29 - CALENDULA L. - Souci. - Pl. IX.

F. oblongues; fl. d'un jaune pâle ; capitules solitaires (f. 35้, fl. 
de la circonf.). - (I). Av,-oct. C. Lieux incultes, friches, vignes. . . ......... C. des champs. C. alovensio L.

On cultive le C. offlcinalis L., à fl. d'un jaune safran vif, à capilules plus grandis que dans le C. artensis.

\section{II. - GYNAROCÉPHALES JUSS.}

\section{0 - ECHINOFS I. - Pl. IX.}

- F. 1-2 fois pennatifides, épineuses; involucre à folioles glabres (f. 36). - q. Jlt-at. AR. Lieux incultes, bords des chemins. Vallés du Tarn............ E ritro. E. Fitron L.

\section{1 - CARLINA Tournef. - Carline. - Pl. IX.}

- Involucre à folioles rayonnantes, oblongues et d'un beau jaune. - (2) ou \%. Jlt-spt. AC. Friches, bords des chemins.

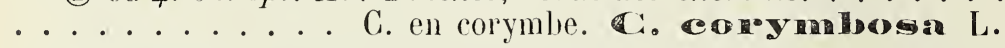

- Involucre à lolioles rayonnantes, linéaires, blanches ou d'un jaune pâle, ciliées (f. 37, fragment d'aigrette). - (2). Jlt-spt. C. Lieux secs, friches des coteaux, bords des chemins. . . . . . . . C. vulgaire. C. valon $\mathrm{L}$.

\section{2 - XERANTHEMUM I. - Immortelle. - Pl. IX.}

Plante tomenteuse ; involucre subcylindrique (f. 38), à folioles extérieures cotonneuses (f. 39, fr.). - (1). Jn-spt. CC. Lieux incultes, moissons, friches.

I. à capit. cylindriques.

33 - GALACTITES Mcench. - Galactite. - Pl. IX, f. 40 (fr.).

F. pennatipartites, blanches en dessous, épineuses (f. 41). - (1). Jn-at. CG. Lieux incultes, fossés, bords des chemins.. . . . . . . . ........ G. tomentense. Gr. Tomrentosa Monch.

$$
34 \text { - SILYBUM Adans. - Silybe. - Pl. IX. }
$$

- F. grandes, pennatifides, maculées de blanc ; capitules grands (1. 42); t1. purpurines. - (2). Jn-at. C Lieux incultes (Chardon

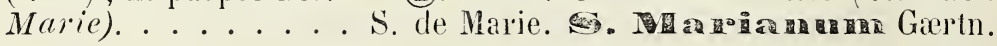

$$
300 \text { - CYNAPA L. - Artichaut. }
$$

- F. bipennalipartites ; involucre épineux. - q. Jlt-at. Cult. et

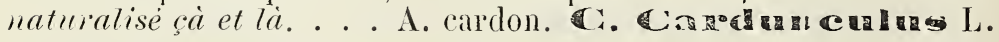

- F. pennatipartites; involucre à lolioles mucronées. - Ұ. JnJlt. Cultivé....... A. commun. C. collymers I. 
36 - ONOPORDON L. - Onoporde. - Pl. IX, f. 43 (réceptacle).

- Tige de 6-18 dm., aranéeuse, ailée-épineuse ; capitules aranéeux, grands. - (2). Jn-at. C. Lieux incultes.. . . . . . . . . . . 0 . acanthin. O. A canthiosini $\mathrm{L}$.

\section{7 - CIRSIUM Adans. - Cirse. - Pl. IX.}

1 - Face supérieure des f. couverte d'épines. . . . . . 2

- Face sup. des f. dépourvue d'épines. . . . . . . . . 3

2 - F. caul. longuement décurrentes; capitules ovoïdes, moyens, à folioles de l'involucre longt. atténuées en épine. - (2). Jn-oct. CG. Lieux incultes. . . C. lancéolé. C. I ancecolatum Hill.

Fl. pâles; involucre vert et glabrescent, à écailles tcrminées en épine courte. - C. . . . . . . . . v. virens Rouy.

Fl. purpuril:es; f. blanches-tomenteuses en dessous ; capitules gros, à écailles très épineuses. . . . . . . . v. nemorale Nagali.

- F. caul. non décurrentes; capitules suliglobuleux, grands, à folioles de l'involucre terminées par une épine laible. - (2). Jn-spt. C. Lienx incultes, terrains argilo-calcaires.

C. laineux. C. eloioplinom Scop.

3 - F. caul. oblongues-lancéolées, sessiles, + ou - décurrentes, denticulées, vertes, glabres, ciliées. - \%. Jn-at. R. Rives de la

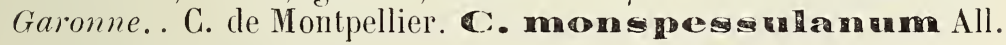

- F. pennatipartites. .

4 - F. caul. longuement décurrentes, à segments 2-3-fides ; capitules ord ${ }^{t}$. sessiles, agglomérés au sommet de la tige et des rameaux (f. 44). -- (2). Jn-spt. AC. Marais, bords des eaux. . . . . . ........... C. des marais. C. palustre Scop.

- F. caul. non décurrentes ............ ¿

5 - Capitules sessiles ou brièvement pédonculés, agglomérés au sommet des rameaux; fl. unisexuées. - \%. Jn.-at. CC. Moissons, cultures, bords des chemins.

C. des champs. C. anvenso Scop.

- Capitules solitaires au sommet des rameaux.

6- Tige de 3-8 dm., nue supérieurement ; f. à lobes divergents, les caul. demi-embrassantes. - Ұ. Jn-spt. Bois, prés. . . . . . .

C. tubéreux. C. tuberosum All.

Souche à fibres renflées; f. pennatipartites; tige rameuse. - Bords de l'Her's, de la Garonne. . . . . . . . . . . . . c. bulbosum DC.

- Tige nulle ou de 1-2 dm. ; l. toutes pétiolées ; capitules grands. - \%. Jn-at. C. Bois secs, pelouses. . • • • • • • • • 


\section{8 - CARDUUS L. - Chardon. - Pl. IX.}

1 - Capitules subcylindriques (f. 40̈), petits, (6-8 mm. de diam.), agglomérés ; tige ailée jusqu'au sommet (f. 46, fr.). - (I) ou (2). Mai-jlt. C. Lieux incultes, rlécombres.

- Capitules subglobuleux, ordint. solitaires. . . . . . 2

2 - Capitules gros (3-4 cm. de diam.), penchés; folioles de l'involucre larges, munies d'une épine étalée. - (2). Jn-oct. C. Plaine de la Garonne........ C. penché. Cis mutans L.

- Capitules moyens (de 1-2 cm.) ; folioles de l'involucre étroites.

3 - Folioles externes et médianes de l'involucre très inégales, dressées ou ascendantes, obtuses, à pointe très courte ; capitules à la fin penchés, sur des pédoncules nus. -- q. Jn-at R. A èté rencontré aux bords de la Garomne.

C. terne. CD。 allo

- Folioles externes et médianes de l’involuere - ou - étalées ou arquées. - (2). Jn-at. AC. Lieux incultes. . . . . . . . . . .

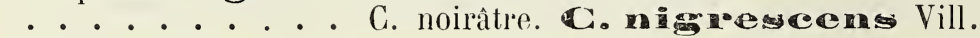

a-Pédoncules courtement dénudés ; capitules généralement dressés.

Folioles de l'involucre peu piquantes, les moyemes recourbées.

Folioles inférieures réfléchies. . . . v. recuroatus (Jord.).

Folioles inférieures dressées.. . . . v. austrulis (Jord.).

Folioles de l’involucre très piquantes, les moyennes élalées. .

$b$ - Pédoncules longuement dénudés; capitules + ou - penchés.

Folioles de l'involucre toutes courbées en dehors à leur sommet (f. 47). . ........... v. vivariensis (Jord.).

Folioles de l'involucre toutes dressées. . . r. Martrini ('Timb.).

\section{9 - ARCTIUM L. -- Bardane. - Pl. X.}

- Capitules gros (diam. 3-4 cm.), longuement pédonculés, en corymbe ; involucre vert et glabre; akènes de 6-8 mm. de long. (2). Jlt-spt. R. Rives de la Garonne et de l'Ariège. (Lappa major

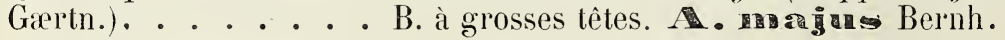

- Capitules moyens (diam. 15̆-20 mm.), brièvement pédonculés ; involucre aranéeux, + ou - rougeâtre (f. 1) ; akènes de 4-ŏ mm. de long. - Jn-at. G. Bords des chemins, lieux incultes. (Lappa minor DC.)...... B. à petites têtes. mo mos Bernh.

plantes amères et sudorifiques, employées contre les rhumatismes. 
40 - SERRATULA L. - Sarrète. - Pl. X, f. 2 (capitule).

— Plante de 5-8 dm. ; f. caul. pennatipartites; grappes corymbiformes. - q. Jlt-oct. C. Bois, bruyères.

\section{1 - Centaurea I. - Centaurée. - Pl. X.}

1 - Involucre à folioles non épineuses. . . . . . . . 2

- Involucre à folioles terminées par une épine allongée. . . 7

$2-F$. entières ou n'étant pas toutes profond. ${ }^{t}$ découpées. . 3

— F. toutes profondément divisées, à segments étroits. . . . 6

3-Fl bleues (f. 3) : f. inférieures pennatipartites, les sup. linéaires, non décurrentes. - (2). Mai-jlt. C. Champs cultivés. . .

- Fl. purpurines ou violacées. . . . . . . . . . . . 4

4 - Involucre à appendices concaves, orbiculaires, les inférieurs frangés ou lacérés, cachant les folioles; akènes ordin. ${ }^{1}$ sans aigrette. - 4. Mai-at. G. Prés, champs. . . . . G. jacée. C. Bacoa L.

Capitules plus petits; feuilles étroites, linéaires-lancéolées.

C. decipiens Thuil.

Plante blancliâtre-pubescente; appendices peu frangés. - Coteaux.

- Involucre à appendices plans, les inférieurs et les moyens pectinés-ciliés .

5 - Akènes sans aigrette ; capitules subglobuleux, gros, à appendices noirâtres, ceux de la base à cils 1-2 fois plus longs que lat largeur de la partiè entière. - \%. Jn-spt. G. Prés, bois.

- Fr. plus étroites, linéaires-lancéolées; appendices faures. - Col-

lines.. . . . . . . . . . . . . . c. serotina Bor.

- F. étroites; appendices inférieurs étroits, écartés, réfléchis au sommet, laissant voir les folioles. - Coteaux. c. microptilon Gren.

- F. étroites; appendices inf. étalés; cils 2-3 fois plus longs que la largeur de la partie entière. ......... c. Debeauxii G. G.

- Akènes munis d'une aigrette égalant le 1/6 de leur long. (f. 4); capitule.j gros, globuleux, noiratres; appendices des folioles suborbiculaires, appliqués, à cils 2-4 fois plus longs que la largeur de la partie entière. - \%. Jlt-spt. R. Prés. Espanès, à Borde-Haute (Noulet). . . . . . . . C. noire. C, nigg L.

Capitules ovoïdes, à appendices ellipticues ; rameaux longs et grêles. - Bois, Lauragais. . . . . . . . . . . c. nemoralis Jord.

6 - Involucre grand (1 1/2-2 cm. de long), subglobuleux ; f. caul. profondément pennatipartites ; akènes à aigrette roussître. - భ. 
Jlt-at. C. Cultures : terrains argilo-calcaires.

C. scabieuse. C. Scabiosa L.

- Involucre petit (4-6 mm. de large) ; f. caul. pennatipartites ; akènes petits, à aigrette blanche. - (2). Jn-spt. R. Graviers de la Garonne. . . . . . . C. paniculée. C. pamicullata L.

7 - Involucre à écailles munies d'appendices hordés de 3-ô épines peu inégales, peu vulnérantes (f. こ) ; f. rudes, les caul. non décurrentes. - (2). Jn-oct. AG. Rives du Tarn et de la Garonne. G. rude. C. aspera L.

Appendices à épines droites, non recourbées. - Rives du Tarn. .

- Involucre à écailles munies d'appendices prolongés en 1 épine longue et vulnérante (f. 6). . . . . . . . . . 8

8 - Fl. purpurines; f. non décurrentes ; akènes sans aigrette. (2). Jlt-spt. GC. Lieux incultes. . . . . . . . . . . . . . ......... C. chausse-trape. C. Calcirmapa L.

- Fl. jaunes ; l. décurrentes ; akènes à aigrefte plus longue qu'eux. - (1). Jlt-sept. G. Moissons, graviers; plaine de la Garonne. ......... G. du solstice. C. $\Leftrightarrow$ ollotitialis L.

La plupart des Centaurées sont amères et toniques.

42 - CARDUNCELLUS Adans. - Cardoncelle. - Pl. X.

- F. la plupart pennatipartites, non épineuses ; tige souvent presque nulle; capitules solitaires, à fl. bleues (f. 7). - భ. Jn-jlt. R. Coteaux calcaires, Haut-Lauragais. ............

C. sans épines. CA. mitissimans $\dot{D} \dot{C}$.

43 - KENTROPHYLLUM Neck. - Kentrophylle. - Pl. X.

F. coriaces, épineuses, glanduleuses-visqueuses ; capitules solitaires; fl. jaunes (f.8, akène). - (1).Jn-spt. C. Lieux incultes. . . . . K. laineux. IK. Ianden $\mathrm{taC}$.

\section{III. - LIGULIFLORES DG.}

\section{4 - CHONDRILLA L. - Chondrille. -- Pl. X.}

Tige de 5 - $8 \mathrm{dm}$, à rameaux allongés, à f. étroites ; capitules cylindriques, petits, à 7-12 fl. jaunes (f. 9). - (2). Jn-spt. C. Champs, vignes, graviers. . . . . . C. effilée. C. juncea L.

$40 ّ$ - TARAXACUM Hall. - Pissenlit. - Pl. X, f. 10 (akène).

Plante glabre, à fl. jaunes. - భ. Mrs-nov. GC. Prés, pelouses.

P. officinal. T. officinale Wel, 
$a$ - Involuire à folioles externes étalées ou réfléchies (f. 11).

- Folioles externes non calleuses-bidentées, dépourvues de corne calleuse. - C. . . . . . T. Dens-Leonis Desf.

F. profondément pennatipartites, à segments très étroits, nombrenx. dentés ou laciniés. - R. Champs argileux. Vicille. Toulouse. . . . . . . v. laciniatum (de Martr.).

- Folioles externes calleuses-bidentées au sommet, réfléchies; akènes gris ou rouge bruu (v. erythrospermum Jord.). AC. Cotecux........... T. lævigatum DC.

$b$ - Involucre à folioles externes appliqués; f. pẹ divisćes. - $M a$ récages. AR............ T. palustre DC.

$$
46 \text { - LACTÜCA L. - Laitue. - Pl. X. }
$$

1 - Capitules cylindriques, à 气̌ folioles égales, munies à leur base de 3-ð petites écailles ; panicule làche ; f. pennatiséquées, lyrées. I). Jtt-at. R. Bois, murs, haies. Tient à $S^{t}-$ Sulpice-la-Pointe et prob. 'clans le Lauragais.

L. des murs. I. Tumorio E. May.

- Capitules cylindriques-oblongs, à folioles imbriquées. . . 2

2 - Capitules pédicellés ; panicule lâche; bec égalant l'akène (f. 12) grisâtre et velu au sommet; f. roncinées-pennatifides ou partites. (2). Jn-spt. Lieux incultes, haies.

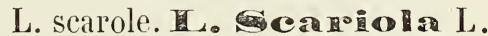

F. oblongues, denticulées. ........ v. dubia (Jord.).

- Akènes d'un pourpre noir, glabrescents au sommet; fl. pâles; - C. . . . . . . . . . . L. vireuse. L. virosa L. Fl. d'un beau jaune. . . . . . . . . v. flavide GG.

- Akènes d'un brun grisâtre, velus au sommet; corrmbe muni de larges bractées embrassantes. - Cult. ainsi que plusieurs de ses variétés. (Laitue). . . . . . . . . . . . . L sativa I.

- Capitules subsessiles, en grappe très étroite; akènes grisâtres, à bec 2 fois plus long qu'eux; f. caul. entières (f. 13). -- (2). Jlt-

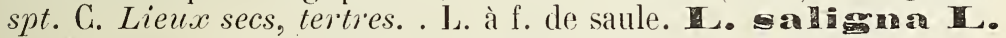

Le L. sativa fournit le lactucarium, employé pour combattre l'insomnie, les névralgies intestinales et les palpitations de cour.

\section{7 - SONCHUS L. - Laitron. - Pl. X.}

1 - F. caul. pétiolées, subpennatiséquées, les caul, à pétiole sagitté-amplexicaule ; corymbe lâche; akènes non bordés (f. 14). (1) ou (2). Jn-oct. R. Murs. T., aux Beaux arts. . . . . . . . . . . . . . . L. délical. teneroime Li.

- F. caul sessiles. . . . . . . . . . . 2

2 -- Akènes bordés, lisses, à 3 côtes saillantes ; f. caul. à orcillettes arrondies, appliquées contre l'axe (f. 15). - (1). Jn.-oct. C. Lieux cultivés. . . . . . . L. rude. a por Hill.

- Akènes non bordés, rugueux, à côtes peu saillantes; f. caul. à 
oreillettes acuminées, étalées; f. peunatifides. (1). Jn-oct. CG Cultures. . . . . I. des lieux cultivés. olen`enceus L.

F. pennatipartites, à divisions étroites. . . . . v. lacerus Wallr.

$$
48 \text { - PTERotheCA Cass. - Ptérothèque. - Pl. X. }
$$

- F. toutes radicales, dentées ou lyrées ; capitules en corymbe ; fl. jaunes (f.. 16, 17 akènes). - (I). Ms.-jn. CG. Cliamps cultivés. ....... P. de Nimes. P. memaugensis Cass.

\section{9 - BARCKHAUSIA Mœnch. - Barckhausie. - Pl. X.}

1 - Akènes du centre à bec plus long, ceux de la circonférence à bec plus court qu'eux ; plante fétide, blanchâtre ; pédoncules penchés avant l'anthèse. - I). Jn-spt. C. Lieux incultes. . . . . .

B. fétide. Fo roetida DC.

- Akènes tous à bec de même longueur ; pédoncules dressés. 2

2 - Involucre à folioles oltuses, pubescentes, non hispides ; réceptacle velu. - (2) ou \%. Mai-at. CG. Prés, bords des champs. . .

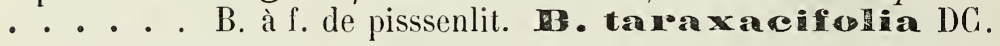

Tiges couchées ou ascendantes, nombreuses, non feuillées. - Coteaux secs. Vieille-Toulcuse. . . . . . . . . B. recognita DC.

- Involucre à folioles aiguës, hérissées de soies raides (f. 18); réceptacle glabre (f. 19, akène). - (1) Jn-spt. CC. Champs cultivés.......... B. hérissée. B. setosa DC.

$$
50 \text {-- CREPIS L. - Crépide. - Pl. X. }
$$

1 - Capitules pauciflores, à involucre glabre ; plante feuillée et visqueuse inférieurement. - (1). Mai-at. C. Coteaux, champs maigres. . . . . . . C. élégante. C. pulehna l.

- Capitules multiflores ; plante non visqueuse.. . . . . . . 2

2 - Capitules grands ; akènes jaunâtres, longs de 4-6 mm., à 13 côtes ; f. caul. auriculées-embrassantes, non sagittées ; folioles de l'involucre velues à la face interne. Faciès du B. taraxacifolia. (2). Mai-jn. Prés, fossés, champs argileux (à rechercher)..

\section{(i. bisannuelle. C. Dienmis $\mathrm{L}$.}

- Capitules petits ou médiocres; akènes à 10 stries ; f. caul. sagittées; folioles de l'involucre glabres à la face interne. . . . . 3

3 - F. glabres ou glabrescentes; involucre à folioles externes apprimées ; akènes de $2-3 \mathrm{~mm}$. ; réceptacle glabre ; stigmates jaunes (f. 20, capitules). - (1). Jn-oct. C. Lieux herbeux, graviers. . . . . . . . . . C. verdâtre. C. vinems L.

Tiges grêles, diffuses ; pédoncules longs, flns ; capitules petits . 
Robuste ; capitules plus gros (diam. $6 \mathrm{~mm}$.) ; pédoncules et involucres hérissés de poils noirs ; stigmates livides. - A rechercher dans les prairies urtificielles........... . c. agrestis W. K.

- F. hérissées-rudes ; involucre à folioles externes étalées ; réceptacle fibrilleux; stigmates bruns. - (2). Mai-at. R. Lieux secs, pâturages. De Venerque à Corronsac; Balma, à Aufrèri (Noulet)......... C. de Nice. C. Niceeensis Balbis.

\section{1 - HIERACIUM L. - Epervière. - Pl. X.}

1 - Akènes de 3-4 mm., non crénelés au sommet; poils de l'aigrette inégaux, subbisériés ; plantes non stolonifères (Archieracium Fr.)

- Akènes de $2 \mathrm{~mm}$. au plus, crénelés au sommet; poils égaux, sur un seul rang; plantes souvent stolonifères (Pilosella Fr.). . 8

2 - F. radicales presque toujours desséchées au moment de la floraison (qui a lieu en août-spt.) ; involucre à glandes peu apparentes; tige ordinairement très leuillée.......... 3

- F. radicales non desséchées an moment de la floraison (en avjlt.); involucre poilu ou glanduleux ; tige nue ou feuillée. . . . ら

3 - Involucre à poils rares ou nuls, à folioles extérieures recourbées au sommet (f.21) ; f. étroites ; panicule + ou - ombelliforme; stigmates jaunes. - \%. At-oct. C. Bois.

E. en ombelle. H. en mollatam L.

- Involucre à écailles presque toujours appliquées ; panicule corymbiforme.

4 - Akènes noirattres à la maturité; réceptacle denté ou laciniéfibrilleux; f. radicales toujours détruites au moment de la floraison. - 4. Bois, bruyères. . . . . . E. boréale. H. Dor'ealo Fr.

$\alpha$ - Involucre à poils entremêlés, les non glanduleux abondants. E. des buissons. H. dumosum Jord.

$b$ - Involucre à poils à peu près tous glanduleux.

-- Tige poilue-hérissée, rude jusqu'au sommet . . . . . . . . .

- Tige mollement hérissée, lisse supérieurement.

Stigmates livides. E. des broussailles. H. virgultorum Jord. Stigmates jaunes. . E. des chênaies. H. quercetorum Jord.

- Akènes roussîtres ou marron; réceptacle nu ou denticulécilié ; stigmates livides; f. inférieures souvent rapprochées en fausse rosette. - \%. At-spt. Bois. . . . . . . . . . . - . . . . E. subhérissée. Mr. Sabli

כ - Tige à 3-7 feuilles non maculées, les moyennes sessiles et † ou - embrassantes; ligules à dents ciliées - . Jn-jlt. . . . . E. ailée. Tr. allatmo Lap.

F. glaucescentes, glabrescentes; stigmates livides. - R. Coteaux d'Eaunes (Timbal). . . . . . . . . v. cuneatum (Arv.-'T. et Gaut.). 
F. vert pàle, poilues; stigmates jaunes. - R. Coteaux d'Eaunes (Timbal). . . . . . . . . . . v. ovatum (Arv.-T.).

- Tige à 1-1ว̆ feuilles; f. radicales et les caulinaires inférieures presque toujours rétrécies en pétiole (f. 22), jamais embrassantes; ligules à dents glabres. . . . • . . . . . • . 6

- Tige à $0-1$ feuille ; f. radicales brusquement contractées à la base ou même échancrées (f. 23). • • • • • • • • • . 7

6 - F. vertes, non glauques ; involucre à poils églanduleux nuls ou peu abondants, à folioles obtuses ; réceptacle non lacinié-fibrilleux ; floraison en jn-jlt. - భ. Jn-jlt. C. Bois.

$a-$ F. maculées, au moins les inféricures. .

....... E. rapprochée. H. approximatum Jord.

F. larges, faiblt. dentées, les caul. 3-6. - Bouconne. . . . . .

F. plus petites, les caul. 3-4. - Bois de Pressac (Timbal). . .

$b$ - F. non maculées; stigmates jaunes; involucre à poils tous glanduleux. . . . E. de l'argile. H. argillaceum Jord.

Tige très scabre ; 4-6 f. larges. - Bouconne, Balma, Venerque, Rebigue. . . . . . . . . . v. asperatum sud.

Tige lisse dans le haut, de 7-10 dm., très feuillée. - Bouconne, Fonsorbes, Venerque. . . . . . . H. finitimum Jord.'

$c$ - F. won maculées; stigmates d'un jaune + ou - sale ; invo. lucre à poils les uns olanduleux les autres égianduleux. Venerque, Rebigue, Bouconne, Aureoille. H. deductum Sud.

- F. + ou - glauques, souvent maculées, 1-ŏ sur la tige; involucre à écailles aiguës, à poils le plus souvent entremêlés, les uns glanduleux les autres églanduleux ; réceptacle presque toujours lacinié-fibrilleux; floraison en mai-juin. - \%. Bois, rochers. . . . . .

\section{a - Feuilles maculées.}

- Tige rude, à 2-5 feuilles; involucre à poils entremêlés; stigmates d'un jaune sale. - St-Geniès, Rebigue, Aufréri....... . H. divisum Jord.

F. vertes, fortement maculées, les caul. 1-3. - Bouconne. . . . . H. asperatum Jord.

F. vertes, fortement maculées, les caul. \%-4; stigmates jaunes. Bouconne, Venarque. . . . . . . . H. tinctum Jord.

b- F. non maculées, pâles, glaucescentes.

- Tiqe rude; stignates jaunes; f. caul. (2-4) lancéolées-acuminées, faiblement dentées. - Buzet, Venerque. H. commixtum Jord.

F. profondément dentées; capitules plus grands, à poils égianduleux nombreux. - ('Bouconne, Bu!ma, ele. H. Watsoni Jord.

7 - F. † ou - glauques, fréquemment maculées, bordées de poils ordinair. ${ }^{t}$ raides-sétilormes; inflorescence le plus souvent dichotome ; stignates somvent jatmes. - భ. Av.-mai et octobie. -Bois, terlies. . . . . H. précoce. W. 
$\alpha$ - Involucre à poils les uns simples, les autres glanduleux.

- F. oblongues, non maculées; pédoncules iongs. - Bouconne, Balma............. H. bounophilum Jord.

$b$ - Involucre à poils glanduleux ; stigmates jaunes

- F. ovales-cendrées, non maculées, poilues sur les 2 faces. - Venerque, aux Maurices........ H. cinerascens Jord.

- F. subglaucescentes, maculées, à poils mous. - C. Aufréri, Bouconne, etc............... furcillatum Jord.

$c$ - Involucre à poils tous glanduleux; stigmates livides; f. maculées. - Laurugais. . . . . H. recensitum Jord.

- F. vertes, non glauques, non maculées, à poils mous ; inflorescence à pédoncules arqués; involucre à poils tous gglanduleux. - $\%$. Mai. C. Bois.. . . . . . E. des murs. F. mmeonemm L.

a - Stigmates jaunes.

- F. ovales-oblongues, grossièrt. dentées. - C. Venerque, Bouconne, Balma. . . . . . . . . . H. exotericum Jord.

F. grandes, largement ovales, cordiformes. - Bouconne. . . . . H. cardiophyllum Jord.

b - Stigmates livides.

- F. radicales largement ovales, tronquées ou cordées à la base. Bouconne, Balma. . . . . . . . H. gentile Jord.

- F. radicales ovales-lancéolées, échancrées, ord.t grossièrement dentées. - Bouconne....... Macrodon Sud.

8 - F. vertes en dessous ; 1-6 capitules peu ou point hérissés de poils églanduleux; ligules concolores, jaune citron. - \%. Mai-spt. AR. Prés lıumides,bois. Bouconne, St-Martin-du-T. . . . . . .

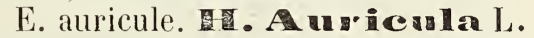

- F. + ou - blanches-tomenteuses en dessous ; involucre à poils blancs ordin. ${ }^{t}$ abondants; capitules solitaires, à ligules de la circonf. souvent rougeâtres en dessous. - \%. Mai-spt. C.. Lieux

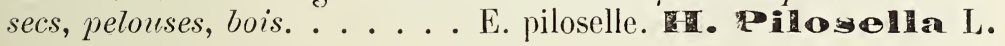

\section{2 - ANDRYALA L. - Andryale. - Pl. X.}

- Plante blanchâtre ; involucre glanduleux ; f. entières ou sinuées (f. 24). - (1) ou (2). Jn-spt. . . . . . . . . . . . . .

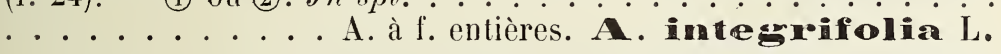

F. inf. pennatifides ou roncinées. - C. Lieux pierreux, bords des chemins............. v. sinucta Willk.

ว3 - THRINCIA Roth. - Thrincie. - Pl. X, f. $20 \%, 26$ (fr.).

F. $\perp$ ou - velues-hérissées ; capitules solitaires; ligules de la circonf. livides en dessous. - (2) ou \%. Jn-oct. C. Iieux incultes, prés, murs... . . . . . T. hérissée. T. In R Roth.

ऽ̌ - LEONTODON L. - Liondent. - Pl. X.

- Tige simple, portant 1 capitule penché avant la floraison; poils 
de l'aigrette sur 2 rangs. - *. Mai-spt. C. Bois, pres. . . . . . . ........... L. hispide. 直, hispidum L.

- Tige rameuse, à plusieurs capitules ; aigrette à 1 rang de poils (f. 27). - *. Jlt-spt. C. Lieux incultes, herber.x. . . . . . .. . ........... L. d'automne. K. a zatumnaie $l_{1}$.

5̋̆ - PICRIS L. - Picride. - Pl. X, f. 28 (capitule), 29 (akène).

Plante de 3-10 dm., hérissée-rude ; 1. sup. sessiles ; corymbe

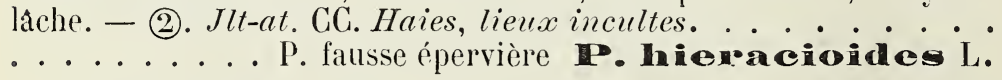

\section{6 - HELMINTHIA Juss. - Helminthie. - Pl. X.}

Plante couverte de soies raides; f. sup. embrassantes (f. 30) ; capitules en corymbe; fl. jaunes. - (1). Jlt-spt. CG. Lieux frais, fossès, bords des champs. . . . H. vipérine. H耳. echioides Gaertn.

\section{7 - UROSPERMUM Juss. - Urosperme. - Pl. X.}

Capitules grands (f. 31), solitaires, sur des pédoncules épaissis. \%. Jn-at. CG. Prés, pâturages, friches des coteaux. . . . . . . . . . . . . . U. de Dalechamp. U. Haleehamipii Desi.

$$
58 \text { - SCORZONERA L. - Scorzonère. - Pl. X. }
$$

Racine noire; f. lancéolées; fl. jaunes (f. 32). - (2). Mai-jlt. Cultivé. . . . . . . . S. d'Espagne. Rispanica L.

\section{こ9 - PODOSPERMUM DC. - Podosperme. - Pl. X, f. 33 (fr.).}

Tige droite, à rameaux ascendants, à f. peu nombreuses. - (2). Jn-at. C. Escarpements des coteaux, terrains argilo-calcaires. . . . . . . . . . P. lacinié. P. laciniatum DC.

Tige centrale courte, accompagnée de tiges latérales décombantes. - AC. Mémes lienx. . . . . . . . . . . . . . P. decumbens G. G.

60 - TRAGOPOGON Tournef. - Salsifis. - Pl. X.

1 - Fl., au moins celles de la circonférence, d'un violet pourpre. . . . . . . . . . . . . . . . 2

- Fl. toutes jaunes. ............ 3

2- Involucre gros, à 8-12 folioles, à fl. toutes d'un violet pourpre ; akènes fauves, plus courts que le bec. - (2). Jn-jlt. Cult. et subsp. dans les cultures. - . - . - . . .

- Involucre moyen, à 5̆-8 folioles; fl. du centre jaunes ; akènes 
extérieurs hérissés d'écailles, plus longs que le bec. - (2). Mai-jlt. R. Pelouses des coteaux calcaires. Venerque, Pechbusque. . . . . . . . . . S. à f. de safran. Chocifolius L.

3 - Pédoncules fortement renflés au sommet; iuvolucre gros, à 8-12 folioles dépassant les fleurs; akènes extérieurs à angles aigus, plus courts que le bec (f. 34). - (2). Jn-at. AR. Coteaux de la Garonne. . . . . . S. à gros pédoncules. 'T. majon Jacq.

- Pédoncules peu ou point renflés au sommet. . . . . 4 4

4 - Folioles de l'involucre égalant les fleurs d'un jaune pâle ; akènes extérieurs égalant le bec. - (2). Mai-spt. AC. Prés, champs, vignes... . . . . . S. des prés. T. proateng is L.

- Folioles de l'involucre plus courtes que les fleurs d'un beau jaune; akènes extérieurs plus longs que le bec. - (2). Mai-spt. C. Prés, lieux herbeux... . . S. d'Orient. T. oliontalis I.

\section{1 -- HYPOCHÆRIS L. - Porcelle. - Pl. X.}

- Ligules dépassant sensiblement l'involucre; akènes tous très atténués en bec ; f. hérissées. - \%. Mai-spt. C. Terties, prés, pelouses. . . . . . . P. enracinée. H. Ira dicata L.

- Ligules égalant l'involucre ; akènes de la circonférence sans bec (f. 3̋̈) ; f. glabres. - (1). Jn-at. C. Moissons, terres graveleuses. . . P. glabre. 基. glabroa L. 62 - CAT ANANCHE Vaill. - Cupidone. - Pl. X, f. 36 (akène).

Tige de ๖̌-8 dm., velue; pédoncules longs. - భ. Jn-jlt. C. Friches des coteaux du Lauragais et de la Garonne.

C. blene. C. cannalea L.

$$
63 \text { - CICHORIUM L. - Chicorée. - Pl. X. }
$$

Capitules sessiles (f. 37), par 2,3; akènes à paillettes très courtes. - भ. Jlt-spt. C. Lieux incultes. . C. sauvage. C. intybus L. On cultive le c. Endivia L.. à f. larges, cordées, et ses variétés (endive, scarole). La racine de Chicorée sert à préparer la poudre de ce nom.

$$
64 \text { - TOLPIS Gaertn. - Tolpide. - Pl. X, f. } 38 \text { (akène). }
$$

Tige de 1-3 dm. ; capitules solitaires sur de longs pédoncules. (1). Mai-jlt. AC. Lieux secs, graveleux.

$6 \check{-}$ - HEDYPNOIS Tournef. - Hedypnoïde. - Pl. X.

Pédoncules renflés-fistuleux ; involucre hérissé (f. 39, 40, akènes). 
- (1). Mai-jn.R. Berges du canal de Brienine et du canal du M. H. de Grète. HI. concerica Willd.

$$
66 \text { - HYOSERIS Juss. - Hyoséride. }
$$

Capitules pauciflores sur des pédoncules dilatés au sommet (1). Jn. A été rencontiè le long du canal du $M$..

67 - RHAGADIOLUS Tournef. - Rhagadiole. - Pl. X, f. 44.

Panicule divariquée; akènes tous lisses. - (1). Jn-jlt. AC. Moissons des coteaux tertiaires. . . R. étoilé. Re. stellatus DC.

68 - ARNOSERIS Gaertn. - Arnoséride. - Pl. X, f. 43 (akène).

Capitules petits, sur des pédoncules longuement renflés-fistuleux (f. 42). - (1). Jn-at. AG. Champs cultivés, siliceux. . . . . . A. fluette. A. Disilia L.

69 - LAMPSANA L. - Lampsane. - Pl. X, f. 44 (akène).

F. inf. lyrées, à segment terminal grand; capitules petits, glabres (f. 45). - (1). Jn-spt. GG. Haies, décombies. . . . . . . .

$$
70 \text { - SCOLYMUS L. - Scolyme. - Pl. X. }
$$

F. scabres, décurrentes (f. 46) ; capitules entourés de bractées foliacées. - \%. Jlt-at. AC. Lieux incultes, bords des chemins. Embouchure, Braqueville, Blagnac, etc.. • $\cdot$ • • • •

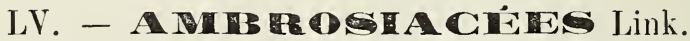

\section{XANTHIUM L. - Lampourde. - Pl. XI.}

1 - Tige munie de fortes épines ; f. blanches-tomenteuses en dessous $(f .1)$. (1). Jn-oct. C. Lieux incultes. T. . . . . . . . . . épineuse. X. Spinosini.

- Tige non épineuse ; f. vertes en dessous. . . . . . . 2

2 - Fruits de $10 \mathrm{~mm}$. de long, env., terminés par 2 becs droits; f. un peu en coeur à la base. - (1). At-spt. C. Bords de la Garonne........... L. glouteron. X, stoumarium L.

- Fruits dépassant souvent $2 \mathrm{~cm}$. de long, terminés par 2 becs arqués l'un vers l'autre et crochus (f. 2). - (1). At-spt. R. Bords de 
la Garonne et de l'Ariège.

L. à gros fruits.

hor cocion

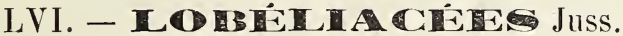

\section{LOBELIA L. - Lobélie. - Pl. XI.}

Tiges effilées ; f. caul. oblongues ; fl. brièvt pédicellées (f. :3). (2). Jn-spt. R. Bois, landes humides. Gouttevernisse, bois de Bonzom (V. Lacaze). . . . . . . . L. brûlante. L. uneng L. Plante àcre et vénéneuse.

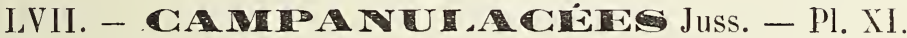

1 - Corolle à 5 divisions profondes, linéaires, d’abord rapprochées en tube puis ćtalées. . . . . . . . . . . 2

- Corolle superficicllement lobée, comparulée ou rotacéc . . 3

2 - Fl. pédicellées; anthères soudéesen tube; fl. bleues. 1 Jasione.

- il. sessiles; anthères libres. . . . . . . . 2 Phyteuma.

3 - Calice à tube allongé, linéaire-oblong ; corolle rotacée (f. 7). .

- Calice à tube court ; corolle campanuléc (f. 9). 4 Campanula.

$$
1 \text { - JASIONE. L. - Jasione. - Pl. XI. }
$$

Fl. petites, pédicellées, en tête gloluleuse involucrée (f. 4); f. ondulées, linéaires-lancéolées. - (1) ou (2). Jn-oct. G. Lieux caillouteux, siliceux. . . . . J. de montagne. Horman I.

\section{2 - PHYTEUMA L. - Raiponce. - Pl. XI.}

Souche renflée; tige simple, à f. inf. ovales, cordées ( d'un blanc jaunâtre (f. 6), en épi. - \%. Mai-jlt. G. Bois, prés.. . . R. en épi.

\section{3 - SPECULARIA Heist. - Spéculaire. - Pl. XI.}

- Corolle ouverte, aussi longue que les divisions du calice ; rameaux étalés (f. 7). - (1). Mai-jlt. CG. Cullures. . . . . . . . - . . . . S. miroir de Vénus.

- Corolle fermée, bien plus courte que les sépales; rameaux dressés. - (1). Mai-jlt. AC. Cultures. (S. hybrida A. DG., (1). Prismatocarpus confertus Moench.)..............

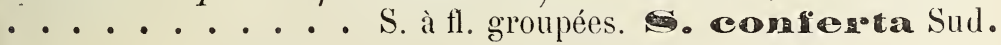

(1) Planta non hybrida; nomen ineptum. 
4 - CAMPANUl A Tournef. - Campanule. - Pl. XI.

1 - Fl. sessiles, les sup.res disposées en capitule; f. sup. res ovales-aiguës, sessiles (f. 8). - \%. Mai-spt. C. Bois secs, pelouses. • ........... G. agglomérée. C.

— Fl. pédonculées. . . . . . . . . . . 2

2 - Divisions du calice ovales ou lancéolées. . . . . 3

- Divisions du calice étroites, linéaires, glabres. . . . •

3 - F. inf. ovales-aiguës, cordées, incisées-dentées ; corolle grande, poilue ; plante de $\check{5}-10 \mathrm{dm}$., hispide ; capsule penchée. - \%. Jn-at. G. Bords des ruisseaux, lieux couverts. . . . . . . . . .

C. gantelée. C. Trachelium L.

- Ces caractères non réunis. . . . . . . . . . 4

4. - Capsule dressée ; tige de $4-10 \mathrm{dm}$. ; f. radicales oblongueslancéolées, atténuées en pétiole, les caul. étroites :

$a$ - Grappe simple, étroite, pauciflore; fl. grandes, de 3-4 cm. de diam.; plante ordint. glabre. - 2. Mai-jlt. AR. Bois des coteaux de la Garonne et de l'Ariège.

C. à f. de pêcher. C. r persoictolia L.

乙- Panicule lâche, à rameaux étalés-ascendants ; fl. médiocres (f. 9); plante + ou - pubescente. - \%. Mai-at. CG. Haies, buissons. . . . . . . C. étalée. C. patera L.

- Capsule penchée; tige de 1-2 dm. ; corolle petite, dépassant à peine le calice; plante hérissée. - (1). Jn-at. AG. Murs, lieux caillouteux. (Roncelia Erimus Dumort.)...........

C. érine. C. Le ane $\mathrm{L}$.

5 - Capsule dressée, s'ouvrant près du sommet ; panicule étroite; f. infres oblongues; tige de $4-\delta \mathrm{dm}$. - \%. Mai-spt. AG. Prés,

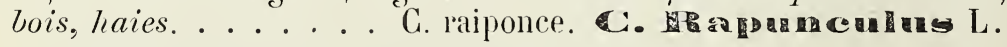

- Capsule penchée, s'ouvrant vers sa base ; fl. peu nombreuses ; f. inf res suborbiculaires-cordées, les caul. étroites ; tiges grêles, de 1-3 dm. - \%. Jn-spt. R. Lieux piereux : bords de la Garonne et de l'Ariège. . . . . . C. à f. rondes. C. Hootuandifolia L.

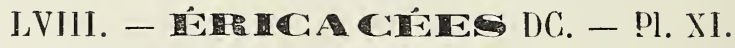

Corolle beaucouj plus courte que le calice pétalö̈de (f. 10). cailina . Corolle bien plus longue que le calice (f. 11) . . . . . 2 Erica.

$$
1 \text { - CALLUNA Salisb. - Calluna. - Pl. XI. }
$$

F. petites, opposées, imbriquées, sur 4 rangs ; fl. idd'un rose pour- 
pre (f. 10), en grappes. - h. Jlt-spt. C. Bois, bruyères. (Vulg.t bruyère). . ...... C. vulgaire. C. valgab Salisb.

\section{2 - ERICA L. - Bruyère. - Pl. XI.}

1 - Fleurs d'un vert jaunâtre, petites, axillaires ; arbuste de ö-12 dm., à rameaux glabres. - Ђ. Jlt-oct. CG. Bois secs, bruyères. . . .......... B. à balais. E. copanoia L.

- Fl. roses ou purpurines, lar ${ }^{\natural}$. blanches. . . . . . . 2

2 - Pédoncule bien plus long que la fleur ; grappes compactes ; anthères saillantes ; f. verticillées par 4-ち. - 5. Jn-spt. AR. . Bouconne, Colomiers, La Ramette. . . . . . . . . . . B. vagabonde. E. vams $\mathrm{L}$.

- Pédoncule plus court que la fleur ou l'égalant; panicule étroite ; anthères incluses (f. 11); f. ternées. - b. Jn-spt. AR. Bois et bruyères. Buzet, Fronton, Garidech. . . . . . . . . . .............. B. cendrée. cinen L.

Sous.classe III. - Corolliflores.

\section{LIX. - O}

Baie globuleuse, noire ; fl. blanches. . . . . . . . 1 Ligustrum. Capsule ovoüde-comprimée. . . . . . . 2 Syringa.

\section{1 - LIGUSTRUMI Tournef. - Troëne. - Pl. Xl}

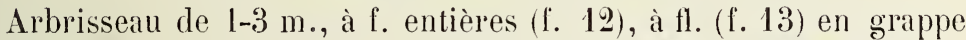
serrée. - G. Haies, buissons. . T. commun. T. vulgated.

\section{2 - SYRINGA L. - Lilas.}

F. cordiformes, ovales-acuminées ; fl. violettes ou blanches. $-\mathfrak{b}$. Av.-mai. Cultivé et subsp. (Lilac Tournef.). . . . . . . . ........... L. vulgaire. vulganois L.

LX. - H R B B

JASMINUM! L. - Jasmin. - Pl. XI.

- Fl. jaunes ; f. alternes (f.14). - Ђ. Mai-jlt. Plantẻ dans les haies.......... J. arbrisseau. . Hondeans L. 
- Fl. blanches; f. opposées, pennées. - Ђ. Mai-jlt. Cultivé. . - J. officinal. ofificinale L.

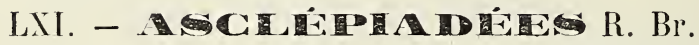

\section{VINCETOXICUM Mœnch. - Dompte-venin. - Pl. XI.}

- F. opposées, ovales-lancéolées ; fl. d'un blanc jaunâtre (f. 15๊) ; follicules fusiformes. - 4. Jn-spt. C. Bruyères, rocailles, bois secs. . . . . . . . D. officinal. . of foinale Monch.

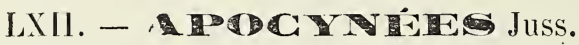

\section{VINCA L. - Pervenche. - Pl. XI.}

- F. glabres, ovales-lancéolées ; calice à lobes courts (2 $\mathrm{mm}$.), lancéolés, glabres (f. 16). - \%. Ms-mai. C. Bois, haies, buissons ............. P. à petites fl. . . . . .

- F. à bords ciliés, ovales-acuminées; calice à lobes linéaires, longs (10-15 mm.), ciliés. - భ. Ms-mai. AC. Haies, lieux couverts. . . . . . . . P. à grandes fl. ma mo

On cultive le Nerium oleander L. (Laurier-rose), à f. lancéolées, opposées ou ternées.

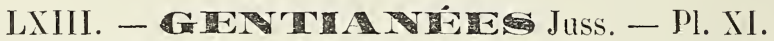

1 - Calice dialysépale ; 6-8 étamines; fl. jaunes (f. 17). 1 Chlor.

- Calice gamosépale; 4-5 étamines. . . . . . . . . ¿

2 - Style nul; corolle bleue (f. 21). . . . . . 4 Gentiana.

- Style filiforme; fl. roses ou jaunes. . . . . . . . . . 3

3 - Calice tubuleux, à 5 lobes (f. 18); anthères tordues en spirale après l'authèse; fl. roses. ........ 2 Erythruea.

- Calice campanulé, à 4 divisions (f. 19, 20); anthères non tordues. ................ 3 Cicendia.

$$
1 \text { - CHLORA L. - Chlorette. - Pl. XI. }
$$

F. ovales-triangulaires, comnées à la base (f. 17). - (1). Jn-at. C. Coteaux calcaires ou argileux . • • • • • • •

\section{2 - ERYTHR EA Rich. - Erythrée. - Pl. XI.}

- Fl. subsessiles, en cymes dichotomes; lohes de la corolle de 丂ั-6 mm. de long; f. inf. en rosette. - (2). Jn-at. G. Friches, bois, teriains argilo-calcaires. . . . . . . . . . . . . . . . . .

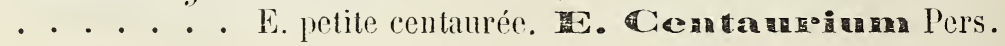


- Fl. pédonculées, en cyme + ou - étalée, sans bractées (f. 18) ; lobes de la corolle de $4 \mathrm{~mm}$. de long; f. inf. non en rosette ; tige de 5 -15 cm. - (1) ou (2). Jn-spt. AC. Lieux humides, sablonneu.x; bords de la Garonne. . . . . . . . . . .

Plantes amères, toniques, fébrifuges.

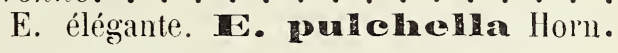

$$
3 \text { - CICENDIA Adans. - Cicendie. - Pl. XI. }
$$

- Tige dressée, de 4-10 cm., à rameaux dressés; fl. jaunes ; calice à lobes triangulaires (f. 19). - (1). Jn-spt. R. Lieux humides des terrains siliceux. Bouconne (Noulet).

C. filiforme. C. Airion Delarb.

- Tige de 2-8 cm., rameuse, à rameaux étalés ; fl. d'un blanc jaunatre ; calice à lobes profonds et étroits, linéaires (f. 20). - (1). Jn-spt. - Avec le précédent. . . C. naine. C.Pusilla Griseb.

\section{4 - GENTIANA Tournef. - Gentiane. - Pl. XI.}

Corolle grande, tubuleuse, à gorge nue, à 5 lobes entiers (f. 21). - \%. Jlt-oct. AR. Bois humides, lieux fangeux. Bouconne, La Ramette, Muret, etc.

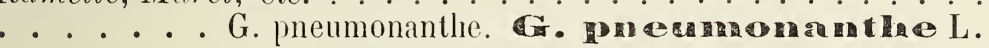

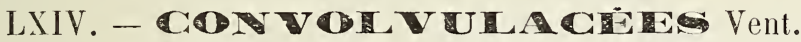

Tige feuillée; corolle campaniforme, à limbe entier, à 5 plis . . . .

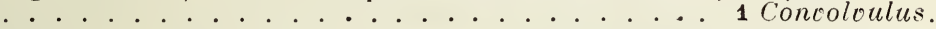
Tige sans feuilles; plante parasite; corolle o! dturcéolée. 2 Cuscuta.

$$
1 \text { - CONVOLVULUS I. - Liseron. - Pl. XI. }
$$

1 - 2 bractées aiguës cachant le calice; fl. blanche, de 气̌ $\mathrm{cm}$. de diam.; f. cordées-sagittées. - భ. Jn-oct. AG. Haies, broussailles. (Calystegia R. Br.).. . . . L. des haies. C.

- Bractées éloignées des fleurs. . . . . . . . . 2

2 - Tige volubile; 1 . sagittées ; fl. blanches ou rosées (de $2 \mathrm{~cm}$. de diam.), axillaires. - \%. Mai-spt. CC. Lieu.x cultivés, bords des chemins. . . . . . . L. des champs. C. a

- Tige non volubile; f. oblongues; fl. roses (1. 22), en cymes lâches. - \%. Ju-jlt. AR. Rives du Tarn et de l'Ariège. . . . . . . L. de Biscaye. C. cantaloioa $\mathrm{L}$.

$$
\text { 2- CUSCUTA Tournef. - Cuscute. - Pl. XI. }
$$

1 - Fl. à odeur de vanille, ayant un pédicelle 2-4 fois plus long que le calice ; corymbes lîches; tube de la corolle fermé par des 
écailles. - (I). Jlt-spt. G. Sur le Medicago sativa. ............... odorante. C. survodians Ser.

- Fl. sessiles ou subsessiles, en groupes serrés, globuleux. .

2 - Styles plus longs que l'ovaire ; lobes du calice acuminés; graines lisses. . . . . . . . . . . . . 3

— Styles plus courts que l'ovaire; étamines incluses. . . . . 4

3 - Tiges d’un jaune pâle, s'étendant en cercle : écailles séparées par un intervalle obtus plus large qu'elles-mêmes. - (1). Jlt-spt. CG. Sur Trifolium pratense et autres plantes.

C. du trèfle. C. Co

- Tiges rougeâtres, s'étendant sans ordre ; écailles séparées par un intervalle aigu et étroit (f. 23,24$)$. - (1). Jlt-spt. C. sur beaucoup de plantes. . . C. du Thym. C. Epideymm Murr.

4 - Corolle urcéolée (f. 20̈); graines brunes, écailleuses; tige souvent simple ; fl. pentamères. - I . Jn-jlt. R. Sur le lin cultivé.

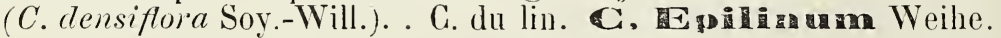

- Corolle en cloche (f. 26); graines jaunes, lisses ; fl. ord. tétratmères. - (1). Jn-at. R. Sur U. dioica et Humulus.

C. à glandes fl. C. majo jö Bauh.

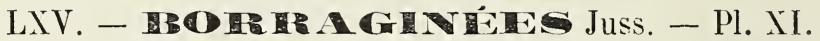

1 - Corolle munie à la gorge de 5 écailles conniventes. . . . . 2

- Corolle à gorge glabre ou velue, dépourrue d'écailles . . 10

2 - Corolle à lobes aigus, très étalés (f. 27); étamines très saillantes, rapprochées. . . . . . . . . . . 1 Borrago.

- Corolle à lobes arrondis ou émarginés . . . . . . . . . 3

3 - Tube de la corolle courbé ; carpelles entourés d'un rebord saillant (f. 29, 30). . . . . . . . . . 3 Ly:op:is.

- Tube de la corolle droit. . . . . . . . . . . . . 4

4 - Akènes couverts d'épines, adhérents à une colonne centra'c. 5

- Akènes lisses ou rugueux, sans épines. . . . . . . . . 6

5 - Fl. bleues, petites ; akènes épineux al bord seulemeut (f. 40). ............... 9 Echinospermum.

- Fl. rougeàtres; akènes épineux sur toute Ieur surface (f. 41). . 10 Cynoglossum.

6 - Corolle à 5 écailles allongées, rapprochées en cône (f. 31,32).

- Corolle à écailles courtes, obtuses ou émarginées . . . . . . y

7 - Akènes petits. de $1-2 \mathrm{~mm}$. de long ; fl. petites (f. 37, 39), en cymes effilées ............ 8 Myosotis.

- Akènes de $3-5 \mathrm{~mm}$. de long. . . . . . . . . . . . 8

8 - Akènes oroüdes (f. 43), comprimés latéralement, adhérents à un axe central; fl. petites, bleues. . . . . . 11 Asperugo.

- Akènes libres. . . . . . . . . . . . . . 9 
9 - Akènes anguleux, à base concave, entourée d'un rebord sail-

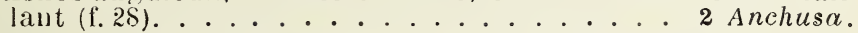

- Akènes ovoïdes, à base plane (f. 33) ; grappes feuillées. . . . . ................ 5 Lithospermum.

10 - Corolic irrégulière, presque bilabiée ; étamines inéqales, à filet long (f. 34).......... 6 Echium.

- Corolle régulière ; filet des étamines court. . . . . . . 11

1 I - Calice arant un tube plus long que les lobes; corolle en entonnoir (f. 35)............ 7 Pulmonaria.

- Calice fendu presque jusqu'à sa base . . . . . . . 12

12 - Akènes libres cntre cux ; fl. en grappes fiuillées. . . . . .

5 Lithospermum.

- Akènes adhérents par leur bord interne; fl. en épis serrés (. 44).

12 Heliotropium.

1 - BORRAGO Tournef. - Bourrache. - Pl. XI.

Fl. grandes, bleues, pédonculées (f. 27) ; sépales connivents après l'anthèse. - (1). Mai-oct. C. Depuis longtemps naturalisée dans le voisinage cles liabitations.

B. officinale. offeriendis $\mathrm{L}$.

Plante adoucissante et béchique.

\section{2 - ANCHUSA L. - Buglosse. - Pl. XI.}

Tige de 4-10 dm. ; fl. bleues ou rosées (f. 28), en panicule feuillée; tube de la corolle plus court que le calice. - (2). Mai-at. C. Champs argilo-calcaires. . . . . . B. d'Italie. . . italiog Retz.

\section{3 - LYCOPSIS L. - Lycopside. - Pl. XI.}

F. ondulées; fl. bleues, en panicule feuillée; corolle de 7-9 mm. de long (f. 29, 30, fr.). - (1). Mai-spt. CG. Champs sablonneux, graviers. . . . . . . L. des champs. I. a novensis L.

\section{4 - SYMPHYTUM Tournef. - Consonde. - Pl. XI.}

- Fl. violettes, rosées ou blanches (f. 31, 32); f. longt décurrentes. - \%. Mai-jn. Cultivé et subsp. çà et lá.

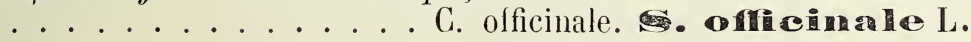

- Fl. jaunatres; f. peu décurrentes. - q. Av.-mai. C. Lieux frais, bois, prés. . . . . C. tubéreuse. C. tuberosonth L.

\section{こ - LITHOSPERMUM Tournef. - Grémil. - Pl. XI.}

1 - Fl. grandes, bleues ou violettes; akènes blancs, lisses. - $\%$. Av.-jn. GG. Bois, haies.

- Fl. petites, blanches ou d'un blanc jaunâtre. . . . . . 2 
2 - Akènes gris perle, lisses et luisants; gorge de la corolle à ŏ bosses velues. -- 2. Mai-jlt. GC. Bois, bords des ruisseaux, haies. (Herbe aux perles). . . . . G. officinal, I. Offieinale L.

- Akènes d'un gris brunâtre, fortement tuberculeux (f. 33) ; gorge de la corolle nue. - Av.-spt. GG. Cultures. . . . . . . . ............ G. des champs. R. anevense L.

\section{6 - ECHIUM Tournef. - Vipérine. - Pl. Xl.}

1 - F. radicales ovales, brusq ${ }^{t}$ contractées en pétiole; nervures latérales des f. saillantes en dessous; corolle violette, striée de blanc. - (2). Jn-at AG. Lieux incultes; plaine de la Garonne.

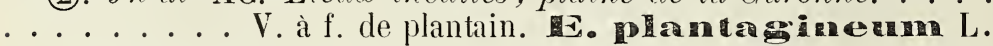

- F. radicales oblongues ou oblongues-lancéolées, à nervures latérales non saillantes. . . . . . . . . . 2

2 - F. caul. atténuées à la base; fl. roses, en pyramide grande, très poilue, à poils blancs, très étalés ; corolle petite, à tube égalant le calice. - (2). Mai-jlt. G. Lieux incultes; vallées de l'Hers et de la Garonne. . . . . . . . V. d'ltalie. E. italicume L.

- Fl. bleues; f. caul. non atténuées à la base ; panicule allongée et étroite; corolle bleue ; étamines saillantes (I. 34). - (2). Mai-spt. CC. Lieux incultes. . . . . V. vulgaire. E. valgan-e L.

- Etamines incluses; panicule Jarge; fl. plus petites. . . . . . . .

............. (E. Wierzbickii Haberl.) E. Schilferi Lang.

- Etamines saillantes ; panicule Jarge; corolle à tube plus long que le calice ; f. sup. atténuées à l.

E. tuberculatum Hoff. et Link.

\section{7 - PULMONARIA L. - Pulmonaire. - Pl. XI.}

1 - F. radicales estivales ovales, brusquement rétrécies en un pétiole ailé au sommet (f. 36); fl. rouges (f. 3̋), devenant d'un bleu violacé. - \%. Ms-mai. C. Bois, lieux couverts.

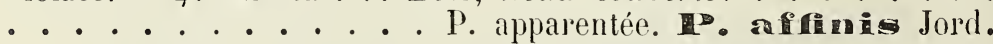

- F. radicales estivales elliptiques-lancéolées (longues de $2-3 \mathrm{dm}$.), rétrécies insensiblt en pétiole : les caul. supres. embrassantes; fl. d'abord rouges puis d'un bleu violacé. - భ. Mars-mai. AC. Bois, lieux couverts. ( $P$. vulgar is Mérat, p. p., non Clus.)........

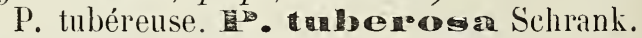

Obs. - Le P. longifolia Bast. à f. estivales lancéolées (longues de 5-6 dm.), dépassant la tige, les caul. 7-9, un peu embrassantes, existe apparemment dans les bois du Lauragais. Peut-être en est-il de même du P. azurea Bess, à f. non maculées, longues el ètroites, à fi. d'un bleu d'azur.

\section{8 - MYOSOTIS I. - Myosotis. - Pl. Xl}

1 - Calice couvert de poils appliqués; plantes des lieux humides. 
- Calice convert de poils étalés et crochus.

2 - Tige radicante, à poils + ou - étalés ; corolle bleu ciel, rar ${ }^{t}$ rosée ou blanche, de $6-8 \mathrm{~mm}$. de diam. - $\%$. Mai-spt. AC. Marais, fossés, ruisseaux. . . M. des marais. Doth.

- Tige dressée, glabrescente, à poils apprimés; fl. moins grandes, d'un bleu pâle (f. 37). - AC. Bords de l'Hers, canal du Midi. M. grêle. M. strigulosa Rehb.

3 - Corolle grande, d'un bleu d'azur, à limbe plan ; pédicelles étalés; calice fructilère fermé (f. 38). - (2) ou \&. Mai-jlt. AC. Boishu-

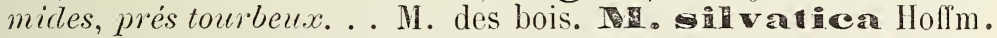

- Corolle petite (diam. 1-2 mm.), à limbe concave. . . . . 4 4

4 - Pédicelles fructifères inf'rs 2 fois env. plus longs que le calice, qui est fermé par les divisions conniventes; corolle petite, à la fin bleue, à gorge jaune. - (1) ou (2). Av.-spt. CO. IIaies, lieux incultes. . . . . M. intermédiaire r. lant.

- Pédicelles fructif. infrs plus courts que le calice ou l'éga-

¿- Calice fructilère ourert, sur des pédicelles étalés; corolle blene, très petite, à tube plus court que le calice. - (1). Av.-jn. CG. Lieux incultes, murs, talus. (M. hispida Schlecht.).

M. des collines. The collin

- Calice fructifère fermé, plus long que le pédicelle. . . . . 6

6 - Pédicelles fructifères in Prs étalés ; corolle passant dı jaune au rouge, au bleu et an violet, à tube dépassant le calice (f. 39). - (1). Av.-jn. CG. Champs cultivés et incultes, terrains siliceux.

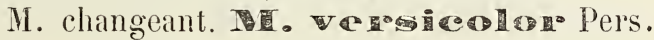

- Pédicelles fructifères infrs dressés ; corolle bleue, à tube ne dépassant pas le calice. - I. AR. Lieux sablonneux; vallée de la Garonne . . . . . . . . . M. raide. M. stricta link.

\section{9 - ECHINOSPERMUM Swariz. - Echinosperme. - Pl. XI.}

Fl, petites, en grappes étroites et feuillées; sépales très étalés (f. 40). - (1) ou (2). Jn-at. AC. Terrains caillouteux incultes.. .

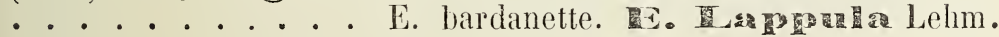

\section{0 - CYNOGLOSSUM Tournef. - Cynoglosse. - Pl. XI.}

- Corolle bleue, veinée-réticulée de rouge; carpelles sans rebord, un peu convexes en dessus (f. 41). - (I). Mai-jlt. C. Bords des chemins, décombres. . . . C. rayée. C.

- Gorolle rougeâtre, non veinée ; carpelles plans, à rebord saillant. - (2). Mai-jlt. AR. Rives de la Garonne, de l'Ariège et du

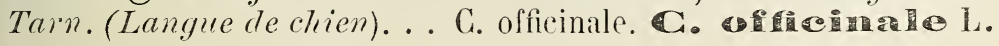


11 - ASPERUGO Tournel. - Ripetle. - Pl. X1.

Fl. axillaires, fasciculées, paraissant opposées aux feuilles; sépales accrescents (f. 42); akènes de $31 / 2 \mathrm{~mm}$. (f. 43) de long. - (I). Mai-jn. R. Pouvourville, Matabiau. . . . . . . . . ....... R. couchée. R. Hocumbens L.

\section{2 - HELIOTROPIUM Tournef. - Héliotrope. - Pl. XI.}

F. ovales, pubescentes-grisâtres ; fl. petites, blanches, en 1-3 épis terminaux (f. 44). - (1). Jn-oct. CG. Champs cultivés.. . . . . .

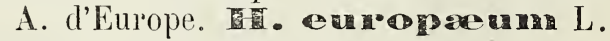
On cultive l'H peruvianum L., à fl. odorantes (H. du Pérou).

\section{LXVI. - X XII.}

1 - Capsule orö̈de, courerte d'aiquillons, s'ouvrant en 4 ralves (1.5) . . . . . . . . . . . 5 Datura.

- Capsule lisse, s'ouvrant en travers (pride). . 6 Hyoscyamus.

- Baic. . . . . . . . . . . . . . . 2

2 - Arbrisseau épincux, à ramcaux tombants; baic ellipsoïde, rouge. 1 Lycium.

- Plante herbacéc ou ligneuse-sarmenteuse, non épineuse. . 3

3 - Baie renfermée dans un calice accrescent, renfié en ressie (f. 3) . . . . . . . . . . . . . . 4 4

- Baie non renfermée dans le calice; cymes corymbiformes. . ................... 2 Solanum.

4 - Baie charnuc, à 2 losess ; corolle rotacéc. . . . . 3 Physalis.

- Baie sèche à la maturité, à 3-5 loges; corolle en cloche. . .

\section{1 - LYCIUM L. - Lyciet.}

F. lancéolées; fl. violeties; calice à 2 lèrres. - - J. Jn-spt. Cult. et subspt. dans les haies. . L. de Barbarie. 耳. W

\section{2 - SOLANUM Tournef. - Morelle. - Pl. XII.}

1 - - Tige grimpante, ligneuse a la base; fl. violettes (f. 1); baie rouge. - Ђ. Jn-spt. C. Buissons, haies, lieux frais. . . . . .

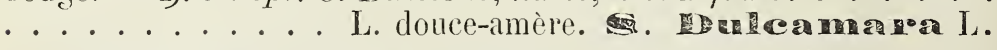

- Tige herbacée, non grimpante. . . . . . . . 2

2 - F. pennatiséquées; baie globuleuse, vert jaunàtre ou violacée. - भ. Jn-spt. Cullivé : originaire de l'Amérique du Sud. (Pomme de terre). . . M. tubéreuse. tomerom L.

- F. simples, dentées ou sinuées. . . . . . . . 3 
3 - Baie noire à la maturité, globuleuse; fl. blanches (f. 2). (1). Jn-oct. CG. Décombres, jardins, cultures. . . . . . . . . Il. noire.

- Baie rouge ; f. un peu velues, à odeur musquéc. - Mèmes lieux. AC. . . . . . . . . . . . s. miniatum Bernh.

- Baje janne orangé, passant au brun ; plante relue-grisâtre. R. Eno. de T. . . . . . . . . . . . . . s. villosum Lamk.

On cultive les $\mathbf{S}$. melongena L. (Aubergine) et $\mathbf{S}$. lycopersicum L. (Tomate).

Les f. de la douce-amère sont calmantes; les fruits de la $M$.noire sont très vénéneux.

\section{3 - PHYSALIS L. - Coqueret. - Pl. Xll.}

Rhizome traçant ; f. ovales-acuminées ; fl. blanches ; baie rouge, dans un calice devenant rouge (f. 3). - \%. Jn-spt. AR. Yignes des terrains aryilo-calcaires. Coteaux de la Garonne et de

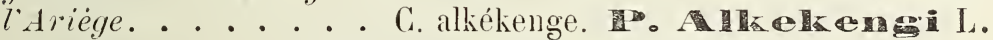

Ses baies sont diurétiques et ses feuilles émollientes.

$$
4 \text { - NICANDRA Gaertn. - Nicandra. }
$$

Glabre ; corolle bleu clair, à fond blanc. - (1). Jlt-spt. Cultivé et subspt. ; originaire du Pérou. . . . . . . . . . . . . .

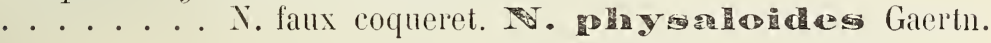

$$
\text { ə̃ - DATURA L. - Datura. - Pl. XII. }
$$

Odeur vireuse; f. grandes, ovales-lancéolées, dentées ; corolle blanche (f. 4, ̌, lr.). - (1). Jlt-spt. C. Env. de T., vallée du Tarn. (Pomme épineuse). . . D. stramoine. 西。

On cultive le. D. Tatula L., à corolle violacéc.

$$
\text { 6- HYOSCYAMUS Tournef. - Jusquiame. - Pl. XII. }
$$

Plante velue-glanduleuse, à odeur vireuse; cymes scorpioïdes; corolle jaunatre, veinée de violet (f. 6). - (1). Jn-at. G. Env. de T. ;

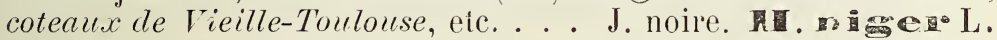

Le D. Stramonium et la Jusquiame sont des plantes très vénéneuses, employées comme calmantes; la fumée des feuilles de Datura soulag̀e lés aceès d'asthme.

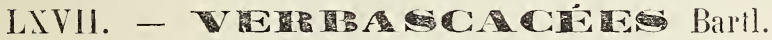

\section{VERBASCUM Tournef. - Molène. - Pl. XII.}

1 - Inflorescence glanduleuse; poils des étamines en partie violicés. . . . . . . . . . . . . . . 2 
- Inflorescence non glanduleuse, + ou - tomenteuse.

2 - Fl. solitaires, en longue grappe étroite, à pédoncule 2 fois plus long que le calice (f. 7, 8); f. glabres. - (2). Jn-spt. G. Lieux

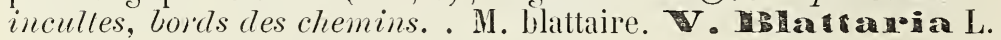

- Fl. par 1-כ̌ à l'aisselle de chaque bractée ; grappes lâches ; pédoncules plus courts que le calice ; f. pubescentes. - (2). Jn-spt. AR. Lieux incultes; Blagnac.. .

3 - F. de la tige + ou - décurrentes. . . . . . . . 4

- F. de la tige non décurrentes. . . . ... . . . . 7

4 - Toutes les étamines à filets munis de poils en partie violets ; f. inf.res sinuées ou penmatifides; panicule grande. - (2). Jlt-spt. CG. Rives de la Garome et de l'Ariège.

M. sinuée.

ए. si

- Etamines, au moins les supres, à fllets garnis de poils blancs ou jaunâtres. . .

$\check{5}$ - Stigmate plus large que long; plante à tomentum persistant, à f. presque entières; épi dense ; 3 étamines à filets velus, 2 à fileis glabres. - (2). Jn-spt. AR. Tallée de la Garomne. . . . . . ........ M. bouillon blanc. T. The

- Stigmate plus long que large, décurrent sur le style. • 6

6 - F. décurrentes jusqu'a la suivante ; corolle plane, de 3-4 $\mathrm{cm}$. de diam. - (2). Jn-spt. AG. Lieux incultes: rives de la Garonne. M. faux bouillon blane. The the

- F. à décurrence ne dépassant guère le milieu d'un entre-noeud ; fl. moins grande. - (2). Jn-spt. AC. Mêmes lieux. .

7 - F. presque toutes sessiles; poils des étamines jamais violets.

$a$-Duvet floconneux caduc, blanc ; rameaux de la panicule ouverts. - (2). Jn-spt. AC. Terrains caillouleux inculles. .

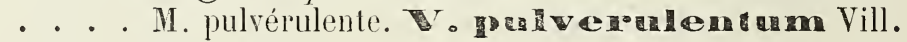

乙- Tomentum grisâtre, persistant, fin ; raneaux de la panicule redressés. - (2). Jn-spt. AC. Mêmes lieux.

- F. distinctement pétiolées, les inf. cordées; filets tous munis de poils violets; stignate plus large que haut. - (1). Jlt-spt. AR. Rives de la Garonne et de l'Ariège.

I. noire.

Lesfl. de Verbascum sont adoucissantes et lectorales; leurs f, bouillies dans du lait, sont emplovées en cataplasmes four le raitement des clous, des panaris et des hémorrhoüdes. 
LXVIII. - C C

1 - 2 étamines; corolle à 4 pétales un peu inégraux, à tube très court (f. 10) ............... 1 Veronicu.

-4 étamines didynames dont 2 stériles (f. 21) ; f. opposées. .................... 6 Gratiola.

- 4 étamines didynames fertiles.

2 - Corolle à tube allongé, à 4-5 lobes (f. 25); f. alternes $\dot{\text { Digitalis . }}$

- Corolle à 2 lèvres distinctes . . . . . . . . . . . . 3

- Corolle bossue à la base, à tubelarge, personée (f. 17) : f. entières...........................

3 - Corolle éperomuée à la base. . . . . . . . . . . . . 4

- Corolle non éperonmée à la base . . . . . . . . . . 5

4 - Corolleà goorge fermée ; éperon grêle, allongé(f. 21). 4 Linaria.

- Corolle ì gorge ouverte; éperon court (f. 19). 3 Anarrhinum.

5 - 1-2 graines dans chaque loge ; f. opposées; lèvre sup.re de la corolle comprimée (f. $2 \%$ ).......8 8 Melampyrum.

- Graines nombreuses daus chaque loge. . . . . . . . . 6

6 - Calice renflé-rentru; anthères mutiques. ........ 7

- Calice non renfié. . . . . . . . . . . . . . 8

7 - F. 1-2 fois pennatipartites ; fl. en grappes bractéolées (f. 28). .

9 Pedicularis.

- F. dentées, opposées ; fl. jaunes, cu éjis feuillés $(f .30)$. . . . .

8 - Anthères mutiques ; corolle à tube subglobuleux (f. 13) ; calice à 5 dirisions. . . . . . . . . 5 Scrofularia.

- Anthères aristées à la base de chaque loge ; calice à 4 divi-

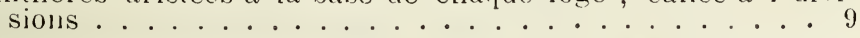

9 - Corolle blanche ou violacée, à lobes de la lèvre inférieure émargiués ou bilobés (f. 32)....... 13 Euphrasia.

- Corolle jaune ou rougeâtre, à lobes de la lèrre inf. entiers. 10

10 - Plante très visqueuse ; étamines courtes à loges plus longt aristées que les autres........ 11 Eufragia.

- Plante non visqueuse; étamines toutes également aristées (f. 31 ). 12 Odontites.

\section{1 - VERONICA Tournef. - Véronique. - Pl. Xll.}

1 - Fl. en grappes axillaires (1. 9), jamais terminales. . . . . 2

- Fl. en grappes terminales; pédicelles finctifères droits (f. 13).

— Fl. axillaires, solitaires ; pédicelles fructifères courbés (f. 150 ).

2 - Calice à $\breve{~ d i v i s i o n s, ~ l a ~ s u p ~ p r e ~ t r e ̀ s ~ p e t i t e ~ ; ~ f . ~ o p p o s e ́ e s, ~ d e n-~}$ tées, pubescentes $($ f. 9,10$)$; tiges couchées à la base. - Ұ. Mai-jlt. $\mathrm{CG}$. Coteaur secs, prés, lisières des bois. 
- Calice à 4 divisions ; tiges couchées, radicantes à la base.

3 - Pédicelles plus courts que le calice; f. ovales, dentées. - $\nsucc$. Mai-jlt. AG. Bois, pâturages.

- Pédicelles plus longs que le calice.

4 - Tiges velues ; f. ovales, à dents profondes. . . . . . 气

- Tiges à peu près glabres; f. elliptiques ou lancéolées; plante des lieux humides

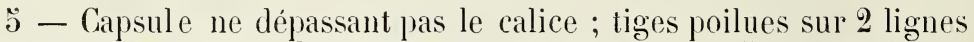
opposées; grappes ord.t opposées. - \%. Av.-jn. CG. Bois, haies, prés. . . . . . V. petit chêne. Cinamadnoys.

- Capsule plus longue que le calice ; tiges velues; grappes alternes. - q. Mai-jn. AC. Lieux frais, bois. .

6 - F. étroites, linéaires-lancéolées, entières ou presque entières, sessiles; grappes lâches, alternes. - \%. Mai-spt. AC. Lieux marécageu, mares, fossés. V. à écusson. Toutellata L.

Plante velue-glanduleuse. . . . . . o. pubescens Noulet.

- F. lancéolées, dentées, sessiles, demi-embrassantes; grappes opposées ; tige creuse, à 4 angles. - 4 ou (2). Mai-spt. C. Bords

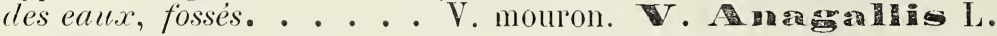

- F. ovales, obtuses, faiblt dentées, pétiolées (f. 11); grappes opposées; tige pleine, cylindrique (f. 12, fruit). - \%. Mai-oct. G. Fossés, bords des eanx..

V. cressonnière. W. Hecealiunga $\mathrm{L}$.

7 - F. caul. moyennes palmatifides, à $3,00,7$ segments ; corolle d'un bleu vif; grappes feuillées. - (1). Ms-mai. AC. Moissons,

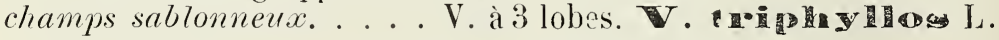

- F. caul. moyennes entières, dentées ou crénelées. . . . . . 8

8 - Tiges couchées-radicantes, puis redressées ; f. glabres, opposées, presque entières; fl. bleu pâle. - (2) ou \%. Av.oct. C. Fossés, prés, bois... V. à f. de serpolet. Y. ser

- Tiges non radicantes, + ou - dressées; grappes feuillées. 9

9 - F. florales plus courtes que les pédicelles fructifères, qui sont bien plus longs que la capsule ( $f$. 13) ; plante pubescente-glanduleuse. - (2). Av.-jn. AC. Clamps cultivés. Plaine de la Garon-

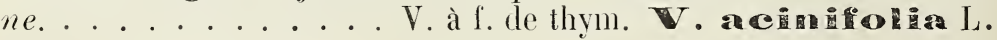

- F. florales dépassant les fleurs (f. 14) ; pédicelle fructifère plus court que le calice ; plante pubescente. - (1). $A v \cdot-j n$. CG. Lieux cultivés. . . . . . . . V. des champs. V. Tovensis L.

10 - Sépales cordiformes à la base, ciliés; f. palmatilobées, réni- 
formes, à 3-כ̆ lobes (f. 1つ̆) ; capsule glabre, subglobuleuse. - (1). Ms-mai. CG. Lieux cultivés.

— Sépales ovales ou lancéolés, peu ou point ciliés. . . . . 11

11 - Capsule à lobes divergents, pubescente (f. 16); pédicelle fructifère courbé-réfléchi, de $10 ั$-20 mm., graines concaves-convexes. - (I). Ms-mai. CG. Lieux cultives. (T'. Buxbaumii Ten.). . . .

- Capsule à lobes non divergents ; pédicelles fructifères ne dé-

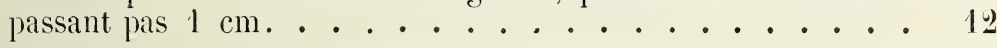

12 - 3-7 graines ovoïdes dans chaque loge; sépales obtus; fl. blanches, rosées on d'un bleu très pâle ; capsule chagrinée, glandıleuse au sommet, à style ne dépassant pas l'échancrure. - (1). Ms-oct. R. Lierx cultivés. Env. de T. .

- 7-12 graines dans chaque loge; sépales aigus ; fl. d'un bleu vif ; capsule non chagrinée, pubescente-glanduleuse silr toute sa surface, à style dépassant l'échancrure. - (2). Ms-oct. CC. Partout. ( $\mathrm{r}$. didymá Ten.). . . . V. des cultures. W Dolira Fr.

Corolle rosée, veinée de rose foncé. - Pouvourville. v. rosella Sud.

La $V$. officinale est employéc dans les affections de poitrine; elle facilite l'expectoration.

\section{2 - ANTIRRHINUM Tournef. - Muflier. - Pl. xIl.}

- Divisions du calice larg. ${ }^{\mathrm{t}}$ ovales, bien plus courtes que la corolle; fl. en grappe. - *. Jin-spt. AC. Tieux murs, coteaux de la Garome. . . . . . M. à grandes fl. A. Ho

- Divisions du calice linéaires, dépassant la corolle purpurine (f. $17,18, \mathrm{fr}$.$) ; fl. axillaires. - (1). Jn-oct. C. Champs cultivés.$

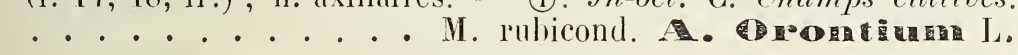

\section{3 - ANARRHINUM Desf. - Anarrhine. - Pl. X11.}

F. inf. en rosette; fl. petites, violettes (f. 19), en grappe. - (2). Jn-at. Bords du Tarn ; apporté par les eaux. . . . . . . . . . - . . A. à f. de pâquerette. A. De

\section{4 - LINARIA L. - Linaire. - Pl. XII.}

1 - F. larges, pétiolées, glabres, réniformes-orhiculaires, à ร̌-7 lobes (f. 20); fl. axillaires, d'un violet pâle, à palais jaune. - 4 . Mai-spt. AR. Vieux murs, à l'ombie. 'T'.

- F. larges, pétiolées, velues ou glanduleuses ; fl. axillaires. 2

- F. étroites, linéaires ou oblongues. . . . . . . . . 3 
2 - Pédoncules velus; 1. ovales on sulorbiculaires; corolle jaune, à lèvre supre d'un brun violet. - (I). Jn-oct. CC. Champs cultivés. . . . . . . L. bâtarde. .

- Pédoncules glabres; 1. moyennes hastées, les sup res sagittées (I. 21 ) ; fl. d'un jaune pâle, à lèvre sup re pourpre. - (1). Jn-oct. CC. Champs cultivés. . . . . L. élatine. W. Détane Mill.

3 - Corolle violacée, à palais ne fermant pas la gorge; capsule s'ouvrant au sommet par 2 ouvertures. . . . . . . . 4 4

- Corolle complètement fermée ; capsule s'ouvrant par 4-10 dents.

$4-$ F. courtes, ovales ou oblongues, épaisses ; fl. bleu violet, à base blanchatre. - 2. Av.-jlt. AR. Gravier's de la. Garonne et de l'Ariège. . . . . . L. à f. d'origan. K. on

- F. linéaires-lancéolées; fl. petites, à palais jaunâtre; plante toute poilue-glanduleuse, très rameuse. - (1). Jn-oct. CG. Terrains

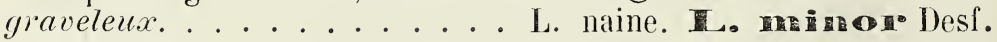

$ら$ - Fleurs blanclies, bleues ou violettes. . . . . . . 6

- Fleurs jaunes ou jaunâtres, à palais orangé. . . . . . . 7

6 - Fl. pourpre violet, à palais plus pâle ; éperon grêle, plus long que la corolle (f. 22); graines planes, ciliées. - (1). Mai-spt. C. Bruyères, champs sablonneux incultes.

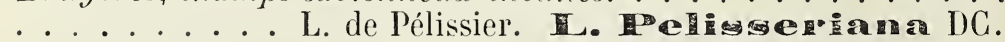

- Fl. violet pâle, striées de violet ; éperon couri; graines à 3 angles, non ciliées. - w. Jn-spt. C. Graviers, terties, terrains siliceux. . . . . . . . . I. striée. 直.

7 - Tiges étalées-diffuses, de כั-20 cm. ; grappes courtes, denses ; corolle pâle; capsule déprassant à peine le calice. - (2). Mai-spt. C. Champs cultivés, terrains argilo-calcaires. . . . . . . . .

L. couchée. 显. 3ap Desf.

- Tiges dressées, de 2-6 dm.; grappes longues ; corolle jaune soufre; capsule 2 fois plus longue que le calice. - - Jlt-spi AC.

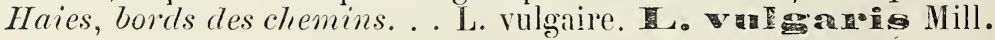

5- SCROFULARIA Tournef. - Scrofulaire. - Pl. XII.

1 - F. pennatiséquées; tige subarrondie ; étamines saillantes (I. 23). - 2. Mai-jlt. G. Plaine de la Garonne.

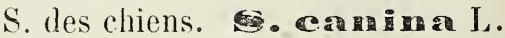

- F. ovales, dentées; tige quadrangulaire. . . . . 2

2-F. aiguës; tige et pétioles non ailés; sépales étroitement scarieux. - 4. Jn-at. AC. Ruisseaux, fossés.

S. noneuse. nodosa $\mathrm{L}$. 
- F. obtuses; tige et pétioles à angles ailés ; sépales largement scarieux. - 4. Jn-at. CC. Le long des eaux. (S. aquatica L. p. p.)............. S. de Balbis.

$$
6 \text { - GRATIOLA L. - Gratiole. - Pl. XII. }
$$

Glabre; f. opposées; fl. axillaires, roses (f. 24). - భ. Jn-at. AR. Lieux marécageux. La Ramette, Colomiers, Bouconne. . . . . . G. officinale. fir.oficiantis L.

\section{7 - DIGITALIS Tournef. - Digitale. - Pl. XII.}

- Corolle grande, ord.t purpurine. - (2). Jn-at. R. Se rencontre parfois sur les graviers de la Garonne. . . . . . . . . .

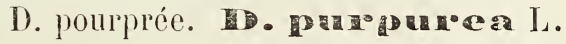

- Corolle plus petite, jaune pâle (f. 2马ั) ; tige glabre. - q ou (2).

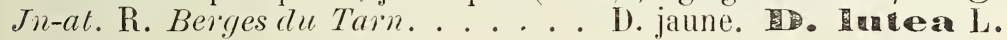

\section{8 - MELAMPYRUM Tournef. - Mélampyre. - Pl. XII.}

- Epis quadrangulaires, compacts (f. 26); corolle blanc jaunâtre ou rougeâtre. - (1). Jn-at. AC. Bois des coteanx. . . . . . .

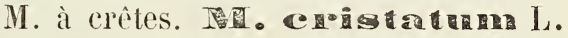

- Fl. unilatérales, en grappe très lâche, feuillée (f. 27) ; corolle jaunâtre, parfois lilacée. - I. Jn-spt. CG. Bois, prés secs. . .

\section{9 - PEDICULARIS Tournef. - Pédiculaire. - PI. XII.}

Tiges nombreuses, de 1-2 dm. ; fl. roses, en grappes étroites (f. 28, 29). - (2) ou \%. Av.-jn. AR. Bois, bruyères. Bouconne, vers Pujaudran. . . . . . P. des bois. sileatica L.

\section{0 - RHINANTHUS L. - Rhinanthe. - Pl. XII.}

- Bractées jaunâtres, dentées en scie ; corolle à tube courbé. (1). Mai-jtt. C. Prés, pâturages. R. majeur.

- Bractées vertes, à dents étroites ; corolle à tube droit (f. 30). Plante plus petite que la précédente. - (1). Mai-jn. AC. Prés secs,

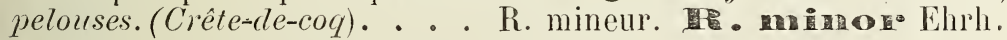

\section{1 - EUFRAGIA Griseb. - Eufragie.}

- Fl. jaunes, en épi feuillé. - (1). Mai-at. R. Prés, fossés. Bords cle l'Hers, au pont d'Aiga, chemin cle Balma (Noulet). (Trixago Stev.; Barlsia L.). . E. visqueuse. EE. viscosa Benth.

- Fl. pourprées, en épi non feuillé. - (1). Av.-mai. AR. Gra- 


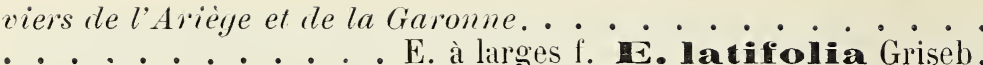

\section{2 - ODONTITES Hall. - Odontites. - Pl. XII.}

1 - Fl. jaunes ; étamines saillantes ; bractées plus courtes que les fleurs. - I). Jlt-sept. C. Friches des coteaux. . . . . . . ............ 0. jaune. Iutea Rchb.

- F. rongeâtres . . . . . . . . . . . 2

2 - Bractées plus longues que les fleurs ; f. lancéolées-acuminées. - (1). Mai-jlt. C. Champs cultivés.

0 . printanière. verna $\operatorname{Rchb}$.

- Bractées plus courtes que les fleurs (f. 31); f.moins larges ; floraison tardive. - Jlt-oct. C. Champs cultivés.

0 . tardive. O. serotina Rchb.

Rameaux allongés, les inférieurs étalés. . v. divergens (Jord.).

13 - EUPHRASIA Tournef. - Euphraise. - Pl. XII, f. 32 (fl.).

- Bractées poilues-glanduleuses ; corolle de 10-10 mm. de long ; f. caul. aiguës, denses ; tige ramense presque dès la base. - (1). Jltoct. R. Prés, pelouses; bords de la Garonne et de l'Ariège. (E. Rotskoviana Hayne)..... E. olficinale. H. oflicimalis L.

- Bractées non glanduleuses; corolle de $8-10 \mathrm{~mm}$. de long; f. glabrescentes. - (1). At-oct. AC. Pelouses sèches, bois, graviers. (E. ericetorum Jord). . . . . . E. raide. 国. Host.

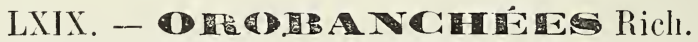

- Flcurs naissant de la souche, ayant 1 seule bractée ; calice à 4 divisions. ............. 3 Clandestina. - Fleurs en épi
terminal
Fl. à 1 bractée; calice à 2 divisions très profondes, bifides....... 2 Orobanche. Fl. à 3 bractées; calice à 4-5 divisions . . . . . 1 Phelipcea.

\section{PHELIP ÆA Tournef. - Phélipée. - Pl. XII.}

1 - Tige simple; fl. bleues; anthères velues ; calice à ô divisions. - 2. Mai-jlt. AC. Su' l'Artemisia campestris; coteaux el rives de la

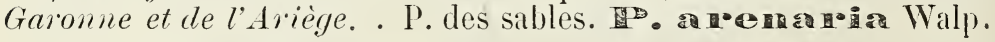

- Tige rameuse; fl. plus pelites. . . . . . . . . . . 2

2 - Stigmate blanchâtre ; corolle jaunâtre ou bleuâtre supérieurt; lèvre infre non plissée entre les lobes; filets pubescents à la base. 4. Jn-spt. AC. sur Cannabis sativa. ........... 
- Stigmate jaunâtre; corolle bleu violet au sommet; lèvre infre munie de plis velus entre ses lobes ; filets à peu près glabres (f. 33, 34). - \& Mai-jlt. AR. Sur Asperula arvensis, Galium tricorne, etc. Aufrér i, Pujaudran. . . . P. de Mutel. P. Muteli Reut.

\section{2 - OROBANCHE L. - Orobanche. -- Pl. XII.}

1 - Etamines insérées vers la lase de la corolle, au-dessous du 1 /4. inférieur du tube.................. 2 - Etamines insérées au-dessus du $1 / 4$ inf. du tube de la co-

2 - Etamines à filets glabres à la base ; stigmate jaune pâle ; corolle fauve, + ou - rougeâtre; tiges robustes (2-つ̊ dm.), renflées à la base. - q.Mai-jn. CG Sur Sarothammus scoparius et Ulex eu-

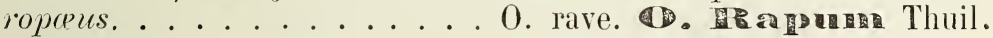

- Etamines à filets + ou - velus à la base.

3 - Stigmate jaune vif ; corolle (f. 33̈) jaunâtre à la base, à gorge couleur de sang, pourpre en dehors. Plante violacée-rougeâtre. \%. Mai-jn. AC. Sur beaucoup de Iségumineuses.

O. couleur de sang. D. chenta Bert.

Plante entiorement jaune citron. . . . . . v. citrina Coss. et G.

- Stigmate pourpre.

4 - Corolle d'un blanc jaunatre ; lève inf. à lobe médian bien plus grand que les latéraux; épi lâche. - q. Mai-jtt. A rechercher

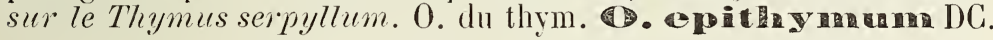

- Corolle d'un blanc rougeâtre ou violacé ; lèvre inf. à 3 lobes presque égaux; tige de 3-6 dm. - \%. Jn-jtt. Sur Galium Mollugo et Asperula gatioides. . . . . . 0. du galiet. O. gat

5 - Stigmate janne ; corolle jaunâtre, glabrescente ; sépales uninerviés, égalant le tube de la corolle. - \%. Jn-at. AC. Sur Hedera Helix. . . . . . . . 0. du lierre. Hedere Vauch.

— Stigmate violet ou pourpre. . . . . . . . . . 6

6 - Lèvre inf. à 3 lobes très inégaux, le grand à 2-3 divisions ; corolle blanche ou lilas, à tube courbé. - \%. Jn-jlt. AR. Sur Eryngium campestie. Arènes de Blagnac, Venerque.

0 . améthyste. an e loy tea Thuil.

- Lèvre inf. à lobes égaux ou peu inégaux. . . . . . . . . 7

7 - Lèvre supre presque entière ; corolle blanc jaunatre, + ou veinée de violet; filets velus à la base, glabres au sommet; tige rougeâtre; sépales dépassant le tube de la corolle. - q. Jn-jtt. AG. Sur Picris hieracioides et auties Composées.. 
- Lèvre supre entière ; corolle rougeâtre ou violacée; filets velus à la base, glanduleux au sommet; sépales 2 fois plus courts que le tube de la corolle. - \& Jn-jlt. R. Sur Teucrium Chamadrys, coteaux de la Garonne et de l'Ariège.

- . . 0. de la germandrée. W。 Schultz.

- Lèvre supre émarginée on bilobée.. . . . . . . . 8

8 - Style violacé; corolle petite, blanchâtre, + ou - teintée de violet, à tube insensiblement courbé. - \%. Jn-jlt. CG. Sur Trifolium pratense et beaucoup d'autres plantes.

0 . à petites fl. D. minno

- Style jaune ; corolle droite à la base, brusquement courbée au milieu. - \%. Jn-jlt. C. Sur Artemisia campestris et Dipsacus sil-

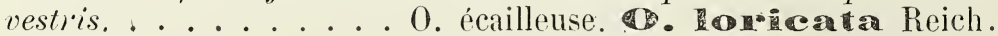

\section{3 - CLANDESTINA Tournef. - Clandestine. - Pl. XII.}

Souche écailleuse ; corolle d'un violet pourpré, de 4-ŏ cm. (f. 36). - 2. Ms-mai. C. Bords des eanx, au pied des arbres. (Lathrea Clandestina L.). . . . C. à fl. dressées. C. Hedi

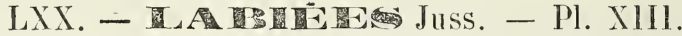

1 - Corolle à 1 seule lèvre, la supre nulle un très réduite (f. 35). . 2

- Corolle à 2 lèvres distinctes (f. 25). . . . . . . . . . . . 4 4

— Corollle à 4 lobes à peu près égaux (f. 2) . . . . . . . . . 3

2 - Lèvre à 3 lobes (f. 34) ; tube de la corolle ayant un anneau de poils................ 27 Ajugu.

- Lèvre à 5 lobes (f. 35) ; tube de la corolle sans anneau de poils.

3 - 4 étamines, toutes munies d'anthères (f. 2). . . . 1 Menthu.

- 4 étamines, dont 2 sans anthères (f. 3) . . . . 2 Lycopus.

$4-2$ étamines fertiles et 2 atrophlées. . . . . . . . . . . 5

- 4 étamines fertiles (ayaut des anthères) . . . . . . . 6

5 - Filets des étanines munis, vers leur base, d'une petite dent dirigée en bas. ...........12 Rosmarinus.

- Filets bifurqués au sommet; les 2 loges de l'anthère séparées parun long connectif. ......... 11 Salvia.

6 - Etamines incluses avec le stric dans le tube de la corolle, qui est blanche. ........... 15 Marrubium.

- Etamines + ou - saillantes hors du tuhe de la corolle. . 7

7 - Calice bilabié et muni d'une bosse ou écaille saillante à la base de la lèvre supre (f. 32. .). . ..... 25 Scutellaria.

- Calice brlabié, à lèrre supre non bossue (f. 5). . . . . . . 8

- Calice à dents à peu près égales, non déjetées en 2 lèves (f. 12 ).

S - Etamines antérieures plus longues, fléchies sur la lèvre inférienre; fl. cu épis (f. 4)........ 3 Lavandula. 
- Etamines droites, divergentes, les antérieures plus longues. . .............. 4 Thymus.

- Etamines arquées, distantes à la base, rapprochées sous la lèvre supre de la corolle . . . . . . . . . . . . 9

- Etamines parallèles, rapprochées sous la lèrre supro de la corolle, les antérieures plus longues. . . . . . . 11

9 - Calice subcylindrique, à lèvre inf. bifide; f. ovales, dentées superficiellt............... 10

- Calice évasé (f. 13), à gorge velue; corolle ì tube sans anneau de poils. ............. 9 Melissa.

10 - Inflorescence + ou - làche (f. 9) ; fl. munies de courtes bractées ne formant pas involucre.......7 Calaminthx.

- Inflorescence en verticilles sérrés; fl. munies de bractées sétacées nombreuses formant involucre. . . . 8 Clinopodium.

11 - Fl. grandes (3 cm.), en verticilles feuillés (f. 31) . 24 Melittis.

- Fl. moyenues, en épis compacts (f. 33) . . . . 26 Brunella.

12 - Elamines droites, divergentes. . . . . . . . . . 13

- Etamines parallèles, rapprochées sous la lèvre supro de la corolle (f. 14) ........... 10 Satureice.

13 - Calice glabre à la ggorge ; f linéaires-elliptiques. 6 Hyssopus.

- Calice velu à la gorge ; f. ovales (f. 7) . . . . . 5 Origanum.

11 - Etamines antérieures plus courtes que les supérieures . 15

- Etamines antérieures plus longues que les supérieures. . 16

15 - Tiges couchées-radicantes ; ière inf:e de la corolle á lobe médian cordiforme (f. 17). . . . . . . 13 Glechoma.

- Tiges drescécs ; lèvre infre de la corolle à lobe médian orbiculaire et concave (f. 18)......... 14 Nepeta.

16 - Akènes tronqués et velus au sommet; f. à 3-5 lobes profonds (f. 26). . . . . . . . . . . 21 Leonurus.

- Akènes tronqués et glabres au sommet; dents du calice non épincuses...................... 17

- Akènes + ou - arrondis au sommet. . . . . . . . 18

17 - Corolle jaune (f. 30); anthères glabres. . . 23 Galeobdolon.

- Corolle purpurine ou blanche (f. 28); anthères velues . . . . . .. . . . . . . . . . . . . 22 Lamium.

18 - Anthères à 2 loges parallèles ; tube de la corolle sars anneau de poils............... 19 Betonica.

- Anthères à 2 loges divergentes.. . . . . . . . . . . 19

19 - Authères dejetées hors de la corolle après la fécondation . . . ..................... 18 Stachys.

- Aurhères non déjetées après l’anthèse. . . . . . . . 20

20 - Lèvre supro de la corolle droite, un peu concave. l'infre à 3 lobes ; ralice campanulé, à 10 nervures; akènes à 3 angles ; plante fétide, à 11. purpurines (f. 20) . . . . 16 Ballota.

- Lère supre de la corolle courbée en casque, comprimée latéralement; calice tubuleux ; akènes ì 3 angles ; 11 grandes. .

17 Phlomis.

- Lèrre supre te la corolle concare, l'infre portant 2 plis en forme de dent a la base du lobe moyen (f. 21, 25); calice à deuts + ou - épineuses; akènes ovoüles. . . . 20 Guleopsis. 


\section{1 - MENTHA I. - Menthe. - Pl. XIII.}

1 - Gorge du calice fermée par des poils ; 1 . petites, faiblt dentées; fl. petites, en verticilles (f. 1) nombreux. - \%. Jlt-oct. CG. Fossés, lieux humides. . . . M. pouliot. M. Herlegium I.

- Gorge du calice nue. . . . . . . . . . . 2

2 - Fl. en verticilles feuillés; axe floral ordin. ${ }^{\mathrm{t}}$ terminé par des feuilles. . . . . . . . . . . . . 3

- Fl. en épis terminaux ; axe floral non terminé par des feuilles.

3 - Calice en cloche, à dents courtes; f. pétiolées, les florales presque aussi grandes que les autres; tiges diffuses. - \%. Jlt-spt. C.

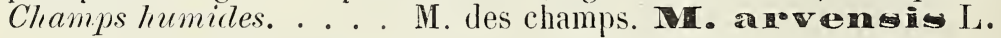

- Calice tubuleux-campanulé, à dents lancéolées-subulées ; l. décroissantes de la base au sommet. - \%. Jlt-spt. AC. Lieux humides. (M. sativa Auct.). . . . . . . . . . . . . .

M. verticillée. M. vedroilata $\mathrm{L}$.

4 - F. pétiolées, vertes. . . . . . . . . . כ

- F. sessiles ou subsessiles, blanches-tomenteuses en dessous.

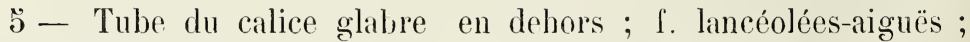
épi conique; odeur suave. - q. Jlt-at. Cultivé et subspt.......

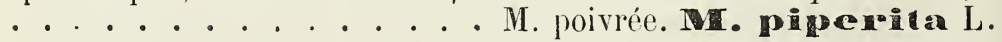

- Tube du calice velu-hérissé ; f. ovales ; épis terminaux globuleux ou ovö̈des, obtus. - Jlt-sept. C. Bords cles eaux, fossés.

M. aquatique. M. aquariea L.

6 - F. ovales-oblongues ou lancéolées, aiguës, peu ou point ridées; épis cylindriques, denses (f. 2, fl.). - భ. Jlt-spt. AR. Rives

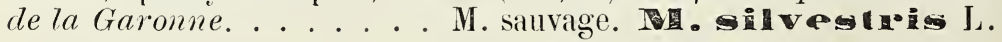

F. très blanches en dessous, lancéolées-rcuminées . . . . . . . . M. candicans Crant\%.

F. grises-pubescentes (non blanches) en dessous ; épis grêles. làches. - Balma. . . . . . . . . M. Nouletiana Timb.

- F. ovales-suborbiculaires, obtuses, ridées-bosselées ; épis aigus, compacts. - \%. Jlt-spt. C. Fossés, lieux lumides.

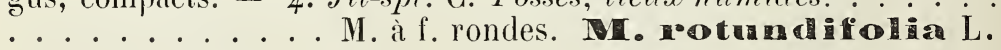

\section{2 -- LYCOPUS Tournef. - Lycope. - Pl. XIII.}

F. ovales-lancéolées, incisées-dentées ou pennatifides ; fl. blanches (f. 3). - \%. Jlt-spt. G. Bords des eaux, lieux humides. . . . 


\section{3 - LAVANDULA I. - Lavande. - Pl. XIII.}

Fl. bleues (f. 4) ; f. oblongues, étroites, retrécies à la base ; bractées linéaires. - b. Jn-jlt. R. Graviers de la Garonne et de l'Ariège. . . . . . L. à larges $\mathrm{f}$. 直. Latiliolige Vill.

\section{4 - THYMUS L. - Thym. - Pl. XIII.}

1 - Tiges ligneuses, dressées, non radicantes; tube du calice bossu à la base ; odeur agréable. - G. Jlt-spt. AR. Graviers de la Garonne et de l'Ariège. . . T. vulgaire. T. vulganois L.

— Tiges + ou - radicantes ; f. planes ; calice à tube rétréci à la base (f. ூّ)..

2 -- Rameaux pubescents tout autour; f. de $4-6 \mathrm{~mm}$. de long; épis globuleux ou oblongs. - \%. Jlt-spt. C. Lieux secs, pelouses, friches. . . . . . . T. serpolet. T. envylimm L.

- Rameaux munis de 2 ou 4 lignes de poils; f. de $1 \mathrm{~cm}$. et plus de long; épis + ou - allongés (f. こ้, calice). - Ұ. Jn-spt. CG. Lieux secs, sablonneux. . . . • • • . . . • •

Le Thym rulgaire est tonique et stimulant ; il pcut servir à combattre l'atonie du tube digestif.

$$
5 \text { - ORIGANUM Tournef. - Origan. - Pl. XIII, f. } 6 \text { (fl.). }
$$

F. pétiolées, presque entières (f. 7) ; épis rapprochés en corymbe. - 4. Jlt-spt. C. Bords des chemins, friches.

\section{0 . vulgaire. O. vingane L.}

On cultive l'O. Marjorana L. (Marjolaine), qui est sudorifique et stomachique.

\section{6 - HYSSOPUS L. - Hysope.}

Fl. bleues, en épi unilatéral. - \%. Jlt-spt. Cultivé.

Amère et tonique, stomachique et vermifuge.

$$
7 \text { - CALAMINTHA Tournef. - Calament. - Pl. XIII. }
$$

1 - Calice bossu à la base (f. 8 ) ; 4-8 fl. petites, violettes, en verticilles, sur des pédicelles simples et courts; tiges de 1-2 dm. (1). Mai-at. CC. Champs argilo-calcaires.

C. acinos. C. A cinos Clairv.

- Calice non bossu (f. 10); fl. en corymbes axillaires pédonculés.

2 - F. petites, grisitres, de 10-15 mm. de long, ì dents superfi- 
cielles; tl. de 10-12 mm. de long; calice à dents peu inégales, à poils de la gorge très visibles (f. 9, 10). - \%. Jlt-spt. GC. Bords des chemins, lieux incultes. (Petit calament).

\section{C. népéta. C. Saver av.}

- F. vertes, plus grandes que dans le $C$. Nepeta: dents du calice très inégales ( $f .11$ ) ; corolle rose clair, de 10-12 mm., à tube court, peu saillant. - \%. Jlt-spt. AC. Bords de la Garonne. (C. adscendens Jord.). . . C. à f. de menthe. C. menthiolia Host.

Fi. purpurines, plus grandes $(12-14 \mathrm{~mm}$. de long), à tube très saillant. - Bois. Pouvourville ............. v. purpurea.

\section{8 -- CLINOPODIUM L. - Clinopode. - Pl. XIII.}

Tiges mollement velues; f. ovales ; fl. purpurines (f. 12). - 2. Jlt-spt. CG. Lieux secs, incultes. (Calamintha Clino-

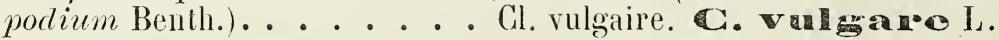

\section{9 - MELISSA L. - Mélisse. - Pl. XIII, f. 13 (calice).}

Fl. blanches ou rosées, en glomérules dépassés par les feuilles. 4. Jn-spt C. Bois, lieux couverts, frais.

. . . . . . . . M. officinale. NE. officinalis $L$.

Très aromatique; est stimulante et stomachique.

10 - SATUREIA L. - Sarriette. - Pl XIII, f. 14, (fl.).

Tige de 2-3 dm., à f. linéaires; odeur agréable. - (I). Jn-spt. AC. Gravier's de la Garonne et de l'Airiège. Cultivée comme plante assaisonnante. . . . S. des jardins. Inoretemsis L L.

\section{1 - SALVIA L. - Sauge. - Pl. XIII.}

1 - Corolle grande, ordint violette, à tube garni d'un anneau de poils; f. oblongues; plante à odeur prononcée. - \%. Mai-jlt. AC. Friches des coteaux; Lauragais, Clermont, Venerque. Souvent

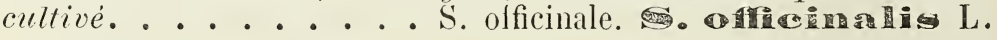

- Tube de la corolle sans anneau de poils. . . . . . . . 2

2 - Bractées grandes, ovales-orbiculaires, dépassant le calice (f. 15); ;l. d'un bleu très pále. - \%. Jlt-at. AR. Gravier's de la Garonne et de l'Ariège, etc. . . . S. sclarée.

- Bractées bien plus courtes que le calice. . . . . . . . . 3

3 - Corolle d'un beau bleu, de 20-24 mm. de long, dépassant longuement le calice; style saillant. - \%. Mai-jlt. C. Prés, lieux herbenx. . . . . . . S. des prés. protensis L.

- Corolle petite, dépassant peu le calice; style peu saillant ou 
4 - Corolle d'un bleu clair, une fois plus longue que le calice, comprimée latéralement, courbée en faux dès la base (f. 15); plante à odeur forte. - 4. Mai-at. CG. Pâturages, bords des chemins.

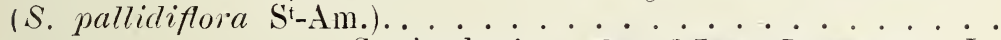

\section{S. clandestine. Cland ostina $\mathrm{L}$.}

- Corolle d'un bleu foncé, à peine plus longue que le calice, non comprimée latéralement; odeur faible. - \%. Mai-at. CG. Avec la précédente. (S. horminoides Pourr.).............

$S$. verveine. venonaca $L$.

La $S$. officinale est stimulante ; elle excite les fonctions de la peau et permet de combattre l'atonie du tube digestif.

\section{2 - ROSMARINUS L. - Romarin.}

Arbrisseau odorant, à fl. bleuâtres, à f. linéaires. - h. $M s-a v$. Cultivé et naturalisé sur les coteaux du Lauragais et de PechDavid. . . . . . . . . R. officinal. Re ofificinalis L.

Stimulant et stomachique.

13 - GLECHOMA L. - Gléchome. - Pl. XIII.

F. réniformes-crénelées; fl. violettes (f. 17); tiges radicantes. 4. Ms-mai. CG. Haies, lieux couverts. . . . . . . . . . .

G. lierre terrestre. G. hedenacea $L$.

A des propriétés béchiques et anticatarrhales ; excite l'expectora. tion.

\section{4 - NEPETA I. - Népéta. - Pl. XIII.}

F. cordiformes, pétiolées ; fl. blanches, ponchuées de rouge (f. 18) ; odeur forte. - భ. Jlt-spt. AR. Rives de l'Ariège, à Lacroix-

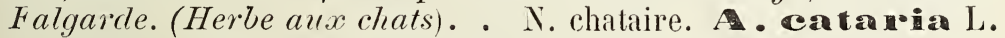

Plante amère, très ar omatique, dont l'odeur attire les chats.

$$
15 \text { - MARRUBIUM L. - Marrube. - Pl. Xlll. }
$$

$\mathrm{Pl}$. blanchâtre-tomenteuse, à odeur forte ; f. ovales-orbiculaires ; calice à 10 dents crochues (f. 19). - \%. Jn-spt. CG. Lieu.x incultes. . . . . . . . . M. vulgaire. M. valde

$$
16 \text { - BALLOTA Tournef. - Ballote. - Pl. XIII. }
$$

F. vert sombre, larg't ovales; liges de $4-8 \mathrm{dm}$. ; fl. purpurines (f. 20). - 2. Jn-at. Bords des chemins, lieux incultes.. . . . . . . . B. fétide. for foetida Lam.

17 - PHLOMIS L. - Phlomide.

Le P. Russelliana Lag., à f. grandes, cordiformes, tomenteu- 
ses en dessous, à fl. jaunes, est naturalisé au voisinage des habitations. - 2.Jn. Pechbusque, Portet. Originaire de Syrie.... .

$$
18 \text { - STACHYS L. - Epiaire. - Pl. XIII. }
$$

1 - Fl. rosées ou purpurines. . . . . . . . . . . . . . . .

— Fl. d'un blanc jaunâtre. . . . . . . . . . . 6

2 - Bractées égalant presque le calice, dont les dents sont très inégales $(f .21) \ldots \ldots \ldots \ldots$

- Bractées nulles ou dépassant à peine le pédicelle; dents du calice presque égales. . . . . . . . . . . . 4

3 - Plante verte, glanduleuse au sommet; corolle rouge brun ; f. infres ovales. - q. Jn-at. AR. Coteaux de l'Ariège. . . . . . . . E. des Alpes. alpina L.

- Plante soyeuse, blanchâtre-tomenteuse ; corolle rosée (f. 21) ; f. infres oblongues. - భ. Jlt-at. AC. Lieux incultes.

4 - F. ovales-obtuses, de $10-23 \mathrm{~mm}$. de long; corolle rosée, dépassant à peine le calice. - (1). Jlt-oct. C. Lieux cultivés, terrains siliceux. . . . . . . E. des champs. anensis $\mathrm{L}$.

- F. aiguës ou acuminées, ayant plus de $3 \mathrm{~cm}$. de long; corolle pourpre; calice glanduleux. ........... ๖

$\check{5}$ - F. cordées, ovales-acuminées, longt pétiolées; ordint 6 fl. par verticille - \%. Jlt-at. C. Lieux fiais, bois, haies. . . . . . . ............ E. des bois.

- F. oblongues-lancéolées, sessiles ou brièvement pétiolées ; 6-12 fl. par verticille. - \%. Jlt-at. C. Lieux humides; bords de la Garonne, canal du $M$. . . E. des marais.

$\times$ S. ambigua Sm. ; (S palustris $\times$ silvatica). - Ramier de Beauzelle (Noulet).

6 - F. glabrescentes, ovales; dents du calice terminées par une arête ciliée; tube de la corolle à anneau de poils transversal (f. 22). - I. Jin-spt. C. Champs cultivés, surtout argileux. . . . . . . . . . . . . . . . E. annuelle. annu L.

- F. velues, oblongues ; dents du calice terminées par une épine glabre : tube de la corolle à anneau de poils oblique. - q. Jn-spt. C. Murs, lieux incultes. . . . . . E. redressée.

\section{9 - BETONICA Tournef. - Bétoine. - Pl. XIll.}

F. ovales-oblongues (f. 23); verticilles rapprochés en épi ovoïde, +ou - interrompu; fl. purpurines. - q. Jn-spt. C. Bois, prés, pâturages....... B. officinale. B. Officinalis L. 


\section{$-155-$}

20 - GALEOPSIS Tournef. - Galéopside. - Pl. XIII.

- Tige de :3-8 dm., renflée sous les nœuds, très hispide; f. grandes, ovales-lancéolées ; calice rougeâtre, à divisions plus courtes que le tube de la corolle (f. 24). - (1). Jlt-spt. R. Rives de la Garonne et de l'Ariege. . . . . . G. tetrahit. G. Tetnathit L.

- Tige de 1-4 dm., non renflée, pubescente; f lancéolées ; 11. ord $^{\text {t }}$ purpurines (f. 20̈). - (1). Jlt-spt. C. Bords des champs, haies. . . . . . . . . G. des champs. Ga daman I.

F. étroites, presque linéaires ; plante élancée. ì rameaux étalés. dressés. - C. Champs cultivés . . . . . . . G. angustifolia. Ehr.

F. étroites; plante très rameuse dès la base, à rameaux très étalés. -C. Champs cultivés .. . . . . . . . . . . . . G. aroutica Jord.

\section{1 - LEONURUS L. - Agripaume. - Pl. XIII.}

F palmées-digitées (f. 26); fl. petites (f. 27), rosées; tige de 气̆-1つ̆ dm. - 2. Jn-spt. RR. T., près de l'Ecole vétérinaire. - Parfois cultivé et naturalisé çà et là.

\section{A. cardiaque. C. Canodiaca $\mathrm{L}$.}

\section{2 - LAMIUM Tournef. - Lamier. - Pl. XIII.}

$1-F$. sup res sessiles, embrassantes, incisées-crénelées; corolle purpurine, à tube long, droit et grêle (f. 28). - (1). Av.-oct. C. Champs cultivés. L. amplexicaule. T. annplex ceande L.

Corolle égalant ì peu près le calice. . . . v. clandestinum Rchb.

- F. toutes pétiolées. . . . . . . . . . . . . . 2

2 - Tube de la corolle sans anneau de poils ; f. ovales-triangulaires, profondt ịncisées-dentées. - (1). Ms-jn. AR. Champs cultivés. Env. de T. (L. hylridum Vill.).

- Tube de la corolle dépassant le calice et muni d'un anneau de poils.

L. découpé.

3 - Corolle de $12 \mathrm{~mm}$. env. de long, à tube droit (f. 29) ; tiges diffuses, nues aul-dessous des fl. - (1) ou (2). Ms-mai. CG. Lieux cultives, bords des chemins. L. pourpre. C. punpareum L.

- Corolle grande, à tube courbé ; f. † ou - maculées dans leur jeunesse, les supres triangulaires. - \%. Av .-oct. C. Lieux frais, fossés, haies. . . . . . . . . . . L. taché. L. macundatum L.

\section{3 - GALEOBDOLON Huds. - Galéobdolon. - Pl. XIII.}

Tiges dressées, de 3-6 dm.; f. inf. ovales-cordées; fl. grandes, jaunes (f. 30). - 2. Av.-jn. C. Bois, miseaux, lieux couverts (Lamium Galeobdolon Grantz). G. jaune. Gr. Intenm Huds. 


\section{4 - MELITTIS L. - Melitte. - Pl. XIII.}

F. grandes, ovales, pétiolées; fl. blanches, à lèvre inf. + ou maculée de rouge (f. 31). - 2. Mai-jn. AR. Bois, Bouconne . . M. à f. de mélisse. M. Mollissophyllum L.

\section{$2 \check{-}$ - SCUTELLARIA L. - Toque. - Pl. XIII.}

- Corolle bleuâtre, longue de 15 mm. env., à tube un peu courbé à la base (f. 32); f. dentées. -- \%. Jlt-spt. C. Bords de la Garonne.

T. à casque. Salon'iculata I.

- Corolle rosée, de 6-8 mm. de long, à tube droit, à f. entières ou à 1-2 dents. - 2. Jlt-spt. C. Lieux marécageux, terrains siliceux. . . . . . . . . . . . . T. naine. minon L.

\section{6 - BRUNELLA Tournef. - Brunelle. - Pl. XIII.}

1 - Fl. grandes, de $2 \mathrm{~cm}$. au moins de long, bleu violacé, en épi dépourvu de f. à sa base; filet des étamines longues terminé en dent courte. - 4. Jn-at. G. Lieux herbeux, bois.

B. à grandes fl. RB.

- Fl. ne dépassant guère $13 \mathrm{~mm}$.; épi ayant 1 paire de f. à sa base ; étamines longues à filet terminé en pointe allongée. . . . 2

2 - Fl. violettes, rart blanches; f. ord ${ }^{t}$ entières (f. 33); plante peu velue; pointe des étamines droite. - \%. Jn-oct. CG. Lieux herbeux. . . . . . . . . B. vulgaire. PB. vulgan-is L.

3 - Fl. d'un blane jaunattre; f. ord pennatifides ou pennatipartites; plante velue; pointe des étamines arquée. - \%. Jn-at. C. Lieux secs, pelouses, terrains argilo-calcaires. ........

Le B. hyssopifolia Lam., à f'. entières, sessiles, étroites, à fl. violettes, a été rencontré entre Revel et Vaudreille (Barthés), où il n'est. sans doute que subspontané.

\section{7 - AJUGA L. - Bugle. - Pl. XlII.}

1 - Fl. jaunes ; f. tripartites, à segments linéaires. - (1). Jnspt. C. Champs cultivés, terrains argilo-calcaires.. . . . . . . . B. faux pin. A. Clnamaepitys schreb.

- Fl. bleues, roses ou blanches. . . . . . . . . . . . 2

2 - Tiges velues-laineuses tout antour, sans rejets couchés; f. radicales souvent détruites à la floraison. - - *. Mai-jlt. R. Rives du Tain. . . . . . . . B. de Genève. Gomevensis $\mathrm{l}$.

- Tiges velues sur 2 faces opposées; souche à rejets feuillés, couchés, + ou -- radicants; f. radicales en rosette (f. 34, fl.). \%. Mai-jn. CG. Lieur.r herbeur. B. rampante. hoptans L. 


\section{8 - TEUCRIUM L. - Germandrée. - Pl. XIII.}

1 - Calice bilabié ; fl. jaunes, solitaires à l'aisselle des bractées (f. 3̋̈), en grappe terminale étroite; f. cordées et réticulées-ridées. - \%. Jlt-spt. CG. Haies, bois. . . . . . . . . . . - Calice à divisions presque égales. . . . . . . . . 2

2 - Fl. solitaires ou par 2-3 à l'aisselle des bractées ou des f. 3

— Fl. en glomérules serrés; plantes aromatiques. . . . . . ร

3 - F. pétiolées, 1-2 fois pennatipartites, à segments étroits ; fl. purpurines. - ID. Jlt-spt. C. Champs piemeux des terrains calcaires ou argileux. . . . . . . . . G. botride. T. Bormy L.

- F. dentées ou crénelées; fl. solitaires ou par 2 à l'aisselle des - f. $\sup ^{\mathrm{res}}$.

4 - Tiges herbacées ; f. sessiles; fl. violacées ; calice velu-laineux, sans anneau de poils à la gorge. - \%. Jlt-spt. R. Prés humides. De Blagnac à Beauzelle, Croix-Daurade, Grenade (Noulet). G. scordium. T. Sconodium L.

- Tiges ligneuses; f. atténuées en pétiole court; fl. purpurines (1. 36) ; calice + ou - rougeâtre, muni d'un anneau de poils à la gorge. - 4. Jn-spt. CC. Escarpements des coteaux, lieux pier-

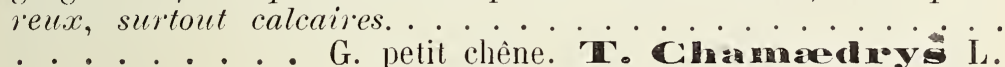

$\check{\jmath}$ - F. entières, vertes et luisantes en dessus, tomenteuses en dessous, à bords roulés; corolle d'un blanc jaunâtre. - q. Jn-spt.

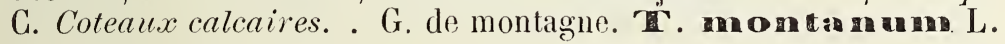

- F. crénelées, tomenteuses sur les 2 faces; fl. blanches ou purpurines. - 4. $\dot{J}_{n-a t}$. AR. Coteaux calcaires du Lauragais ; graviers de l'Ariège. . . . . G. blanc de neige. 'T. Poliom L.

Le T. Chamcerdrys est amer et fébrifuge; on l'emploie comme stimulant dans les dyspepisies.

\section{LXXI - VEHERTACHES Juss.}

\section{VERBENA Tournef. - Verveine. - Pl. XIII.}

F. incisées-dentées ou pennatifides; fl. lilas, en épis lâches (f. 37). - \%. Jn-oct. (G. Bords des chemins, pelouses. . . . . . 


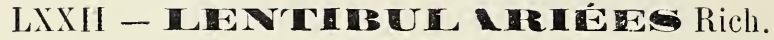

\section{UTRICULARIA L. - Utriculaire. - Pl. XIII.}

F. munies de vésicules (f. 38) ; corolle jaune, à lèvre supre égalant le palais. - Jn-spt. R. Eaux stagnantes, le long de la Gaironne:Bouconne....... U. vulgaire. U. valgan-is L.

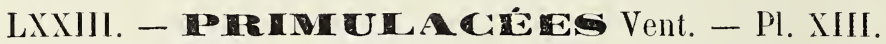

1 - Capsule globuleuse, s'olivrant en travers (f. 42 bis) ; plantes glabres. . . . . . . . . . . . . . 2

- Capsule s'ouvrant par des valves . . . . . . . . . . 3

2 - Corolle blanche ou rosée, très petite (diam. 1-2 mm.), plus courte que le calice (f. 43) . . . . . 4 Centun iulus.

- Corolle dépassant le calice ; f. opposées, entières (f. 41, 42). . .

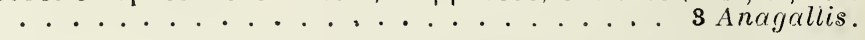

3 - Capsule soudée au tube du calice; f. caul. alternes, obovales

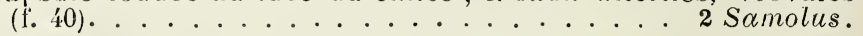

- Capsule non soudée avec le tube du calice. . . . . . . . 4

\{ - Tige feuillée; fl.jaunes ; f. entières, opposées ou verticillées. .

- F. toutes radicales, ridées-réticulées, + ou - dentées

............... 5 Primula.

1 - LYSIMACHIA Tournef. - Lysimaque. -- Pl. XIII.

1 - Fl. (f. 39) nombreuses, en panicule terminale ; f. par 2-4, ovales-lancéolées; tige de $ّ-10 \mathrm{dm}$. - \%. Jn-spt. C. Borls cles eaux. . . . . . . . . I. vulgaire. 直。 y

— Fl. solitaires, axillaires ; tiges de 1-o̊ dm., couchées, radicantes ; f. glabres, opposées. . . . . . . . . . . 2

2 - Sépales ovales-aigus, cordés; pédoncule ne dépassant pas la feuille; capsule à 5̆ valves. - Ұ. Jn-at. AC. Fossés, lieux humides. L. nummulaire. L. Nommulanoia L.

- Sépales linéaires-subulés ; pédoncule fin, dépassant la f. ; capsule à 2 valves. - \%. Jn-at. AR. Bois humides et couverts. Ve-

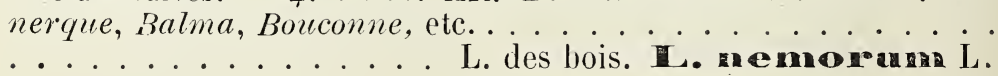

\section{2 - SAMOLUS Tournef. - Samole. - Pl. XIII.}

Glabre; fl. petites, blanches, en grappe terminale (f. 40). - $\%$. Jlt-at. CG. Fossés, lieux humides, terrain argilo-calcaire. 
3 - ANAGALliS Tournef. - Mouron. - Pl. XIII.

4 - F. pétiolées, petites, suborbiculaires; tiges filiformes, radicantes, de b-15 cm. (f. 4.1); corolle rose. - \%. Jn-at. AC. Prés humides, lieux tourbeux; terrains siliceux. . . . . . . . . 11. délicat. A. tenella $L$.

- F. sessiles, ovales-lancéolées; tiges de 1-3 dm. . . . . 2

2 - Fl. rouges ou carnées ; pétales ciliés-glanduleux, dépassant les sépales (f. 42, 42 bis, fr.). - (1). Mai-spt. CC. Cultures.. .

- Fl. bleties ; pétales non ciliés-glanduleux, égalant les sépales. - (1). Mai-spt. AC. Avec le précédent. . . . . . . . .

\section{4 - Centunculus L. - Cenienille. - Pl. Xill.}

Tige grêle, de 1-6 cm.; f. supres alternes, ovales (f. 43). - (1). Jnspt. AR. Terrains siliceux humides, au moins en hiver; fossés, sentiers. . . . . . . . . . C. naine. C. minimus L.

\section{5 - PRIMULA Tournef. - Primevère. - Pl. XIIII.}

1 - Pédicelles radicaux ( rart $^{t}$ sur une hampe centrale); calice velu sur les ançles; corolle jaune soufre, grande $(3 \mathrm{~cm}$. de diam.), à limbe plan, à gorge plissée. - 4. Mais-mai. R. Rives du Tarn. (P. grandiftora Lam.). . . P. Pulgaire. T. vulganois Huds.

- Pédicelles en ombelle sur une hampe commune. . . . . 2

2 - Corolle petite $(8-12 \mathrm{~mm}$. de diam.), jaune vif, à limbe concave, à gorge plissée ; calice blanchâtre, renflé, ouvert. - \%. MSmai. C. Press, bois. . . . P. officinale. H. officinalis Jacq.

- Corolle de 12-20 mm. de diam., d'un jaune pále, à limbe presque plan, à gorge non plissée (f. 44); calice vert sur les angles, non renflé. - \%. Av.-mai. AC. Bois fiais, lieux couverts. St-Geniès, etc. . . . . . . . . P. élevée. elsodion. Jacq.

\section{LXXIV. - GLOHUCARTER Camb.}

\section{GLOBULARIA Tournef. - Globulaire. - Pl. XIII.}

Tiges simples, dressées, de $5030 \mathrm{~cm}$. ; f. glabres (f. 45) ; fl. bleues, rart blanches (f. 46). - 4. Mai-jn. AC. Pelouses des coteaux, bois, terrains calcaires. (G. Willkommii Nym.). . . . . . . . .

G. vulgaire. G. vulgaris DC. 


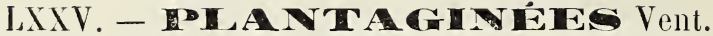

\section{Plantago Tournef. - Plantain. - Pl. XIII.}

1 - Tige rameuse et feuillée ; f. linéaires ; épis serrés, courts. 2

- Tige nulle; pédoncules radicaux ; épis + ou - allongés. 3

2 - Plante ligneuse, très rameuse ; bractées dépassant à peine les fleurs. - 4. Jn-jtt. C. Coteaux. P. des chiens. P. Cymops L.

- Plante herbacée ; bractées infres plus longues que les fleurs (f. 47). - (1). Jn-at. R. Sables des bords du Tarn.

- . . . . . P. des sables. P. anenaria W. et K.

3 - F. pennatifides, à segments étroits; tulıe de la corolle velu ; capsule à 4 loges monospermes. - (1) ou (2). Av.-oct. C. Bords des chemins, lieux secs, sablonneux. . . . . . . . . . . .

P. corne de cerf. P. Comonopus L.

- F. entières ou dentées. . . . . . . . . 4

4 - F. lancéolées ou linéaires, plus de 6 fois plus longues que larges. . . . . . . . . . . . . . 气

- F. ovales ou n'étant pas 4 fois plus longues que larges.. • 6

5 - Tube de la corolle velu ; f. linéaires, coriaces, planes ; épi cylindrique ; racine longue, pivotante. - \%. Jlt-at. AC. Pelouses des coteaux calcaires du Lauragais, rives de la Garonne. . . .

P. serpentin. Serpentina Vill.

- Tube de la corolle glabre (1. 48, 49) ; 1. lancéolées, minces ; épi ovoüde ou oblong (f. こั0), de $1-3 \mathrm{~cm}$. - భ. Mai-oct. CG. Prés, pelouses. . . . . . P. lancéolé. P. Iancedara L.

Robuste; épi de $4.8 \mathrm{~cm}$. de long. . . . . . . v. Timbali (Jord.).

Plante couverte de longs poils soreux. . v. eriophora Hoffm. et Lk.

6 - F. presque sessiles, pubescentes sur les 2 faces, à vures, bien plus courtes que la hampe ; épi de 2-6 cm. ; corolle blanche. - 4. Mai-spt. CG. Prés, bords des chemins, terrains argilo-calcaires. . . . . . P. moyen. media L.

- F. pétiolées, glabrescentes, à ち, 7, 9-11 nervures, égalant la hampe.

7 - F. ovales-obtuses, peu dentées ; hampes dressées ; épis allongés, cylindriques. - q. Jlt-oct. CC. Pelouses, prés, bords des chemins. ........... P. à grandes f. H. major- L.

- F. dentées ou sinuées: hampes étalées-arquées ; épis souvent arqués. - \%. Jn-at. AC. Lieux incultes, bords des chemins, terrains sablonneux. P. intermédiaire. P. in ten'media Gilib. 
Sous-classe IV. - Monochlamydèes.

\section{LXYVI. - AMATEATACRES R. Br. - Pl. Yll.}

1 - F. linéaires-subulées, sessiles (f.53); akène. . 3 Polycnemum.

- F. ovales-rhomboïdales, pétiolées . . . . . . . . 2

2 - Fruit s'ouvrant trausversalement (pyxide, f. 51). 1 Amarantus.

- Fruit indéhiscent (akène) ; périgone à 5 divisions. 2 Euxolus.

\section{1 - AMARANTUS Tournef. - Amarante. - Pl. XIII.}

1 - Bractées non piquantes, de la longueur du périgone à 3 divisions (f. 气̆l) ; tige glabre; fl. cn glomérules axillaires; 3 étamines. - (1). Jlt-oct. C. Décombres, lieux cultivés.

.............. sauvage. A silvestmis Desf.

- Bractées raides, piquantes, plus longues que le périgone. 2

2 - Fl. en glomérules axillaires ; 3 étamines ; 3 divisions au périgone ; planie blanchâtre, à f. écliancrées au sommet. - (1). Jn-spt. C. Champs cultivés et incultes. Plaines de la Garonne et de l'Ariège. . . . . . . . A. blanche. A. allogss I.

- Fl. en panicule compacte non feuillée ; périgone à こ̆ divisions, 5 étamines; hractées 2 fois plus longues que le périgone. - (I). Jlt-spt. CG. Champs cultivés, clécombres. • . . . . . • • ....... A. réfléchie A. e drofioxis $\mathrm{L}$.

\section{2 - EUXOLUS Rafin. - Euxolus. - Il. XIII.}

- Tige glabre ; f. souvent échancrées au sommet; fruit presque aussi large que long. - (1). Jlt-spt. CC. Lieux cultivés, javrlins. (Amarantus ascendens Lois.). . . . . . . . . . .

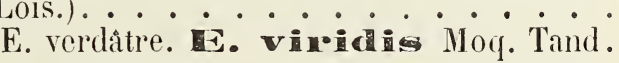

- Tige pubescente dans le haut; f. entières (f. こّ) ; fruit presque 2 fois plus long que large. - \%. Jn-oct. C. Lieux incultes, bords des chemins, le long des murs. (Amarantus L.). . . . . . . .............. défléchi. W. deflexus Raf.

\section{3 - POLYCNEMUM L. - Polycnème. - Pl. XIII.}

Tiges de ö-12 cm., ćtalées ou couchées ; bractées égalant à peine le périgone. - (I). Jn-spt. AC. Champs sablonnelx. . . . . .

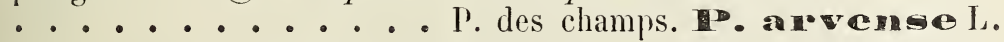

Plus robuste ; bractées dépassant le périgone(f. 53). P. majus A. Br. 


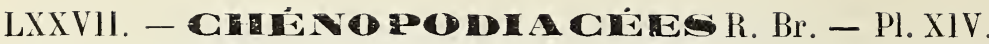

1 - Plante dioïque; fl. mâles à $4-5$ sépales ; fl. femelles tubuleuses, à 4-6 divisions, les 2 internes enveloppant le fruit; 4 strles longs............. 5 Spinacia.

- Fl. hermaphrodites ou plantes monö̈ques ou polygames. . 2

2 - Fruit enveloppé par 2 valves herbacées (f. 6) ; fl. en glomérules disposés en épis ou en panicule...... 6 Atriplex.

- Fruit entouré de 3-5 sépales libres ou soudés. . . . . . 3

3 - Périgone charnu et rouge vif à la maturité (f. 2); 2 styles . . . ................ 3 Blitum.

- Périgone restant herbacé et ne se soudant pas avec le fruit

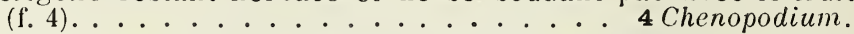

- Périgone devenant coriace, à divisions se soudant pour envelopper le fruit............... 4

4 - F. entières; périgone soudé avec le fruit. . . . . . 2 Beta.

- F. pennatiséquées (f. 1) ; périgone non soudé avec le fruit. . .

\section{1 - ROUBIEVA Moq. - Roubiéva. - Pl. XIV.}

Tiges couchées ; f. à divisions sublinéaires (f. 1); odeur agréable. - भ. At-oct. R. T., Ramiè du Château.

\section{R. multifide. Is mulinda Moq.}

\section{2- BETA Tournef. - Bette.}

Racine charnue, très grosse. - (1) ou (2). Jlt-spt. Cultivée. . . .

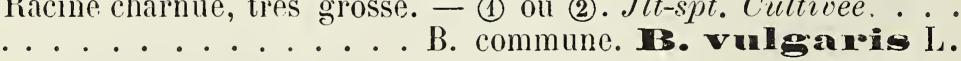
F. à nervure médiane très épaisse, charnue (Poirée). . B. cycla L.

\section{3- BLITUM Tournef. - Blite. - Pl. XIV.}

F. triangulaires, pétiolées, dentées ; épi feuillé jusqu'au sommet (f. 2). - (1). Jlt-spt. R. Décombres. T. Introduit.

B. effilée. 1B. virogatumi $\mathrm{L}$.

\section{4 - CHENOPODIUM Tournef. - Ansérine. - Pl. XIV.}

1 - Plante pubescente-glanduleuse, à odeur aromatique ; f. ver-

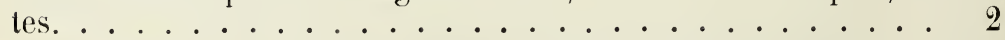

- Plante ni pubescente ni glanduleuse, à odeur nulle ou fétide.

2 - F. lancéolées, sinuées-dentées; panicule garnie de feuilles dépassant longuement les glomérules. - (1). Jn-oct. AR. Voisinage cles habitations. Cultivé et naturalisé. 
- F. pennatifides, à lobes obtus; panicule presque dépourvue de f. - (1). Jlt-oct. C. Rives de la Garonne.

\section{A. botride. C. Botroy L.}

3 - F. entières, ovales, arrondies ; plante fétide, blanchàtrefarineuse ; tige couchée. - (1). Jlt-oct. CG. Décombres, le long des murs. . . . . . . . A. fétide. C. U⿴囗十 anara L.

- F. entières, ovales ou oblongues (f. 3) ; plante verte, non fétide (f. 4, fr.); glomérules en épis ou cymes axillaires. - (1). Jlt-oct. AC. Lieux cultivés.

\section{. . . . A. polysperme. C. polyspenomun L.}

- F. + ou - dentées ou lobées, rart presque entières, mais alors fleurs blanchàtres-farineuses..

$4-\mathrm{F}$ : cordées, vertes sur les 2 faces, à 3,4 dents fortes de chaque côté ; graine horizontale. - (1). Jlt-sept. R. Lieux cultivés. Palaminy (Duteyeul). (C. hybridum L.). .

\section{A. anguleuse. C. angulosum Lamk.}

- F. non cordées à la base, + ou - charnues, souvent farineuses.

こ - Graines à bord caréné, aigu.

- Graines à bord épais, luisantes, horizontales.

6 - F. ovales-rhomboïdales, peu ou point farineuses, à dents fortes ; panicule feuillée, à rameaux étalés ; graine terıe. - I. Jltspt. C. Lieitx incultes, décombres.

\section{A. des murs. C.}

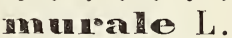

- F. ordin blanches-farineuses en dessous, ovales-rhomboïdales ; panicule à épis dressés, nus ; graines luisantes. - (1). Jlt-spt. CC. Lieux cultivés, boids des rivières. . A. blanche. C. album I.

- F. rertes sur Ies 2 faces, les supres entières ; glomérules espacés. panicule étalée...................... viride L.

- F. un peu farineuses. lancéolées, entières. C.lanceolatum Willd.

7 - F. glauques-farineuses, ovales-rhomboïdes, presque hastées ; glonérules très farineux. - (I). Jlt-oct. C. Champs cultivés, décombres. . . . . A. à f. d'obier. C. Opulifollume Schrad.

- F. triangulaires, en coin à la base, à dents fortes, peu farineuses en dessous; glomérules verdâtres, en panicule effilée. -- (1). Jlt-spt. AG. Décombres, jardins.

C. intermédiaire. C. intermedium Mert. et Koch.

Le $C$. ambrosioides est une plante stomachique et sudorifique ; ou la prend en guise de thé.

\section{5 - SPINACIA Tournef. - Epinard.}

- F. sagittées ; fruit à 2-4́ épines robustes, divergentes. - (1). (Epinard dhiver). . . . . E. épineux. Spinoss Mœnch. 
- F. ovales-oblongues ; fruit non épineux. - (1). (Epinard de Hollande, gros épinard.). . E. inerme. S. inermis Monch.

Plantes cultivées dans les jardins potagers.

6 - ATRIPLEX Tournef. - Arroche. - Pl. XIV.

1 - Plante ligneuse, de 1-2 m.; f. ovales, argentées; valves fructilères entières. - Ђ. Spt.oct. R. Planté en haies. .......

A. halime. A. Talimus L.

- Plante herbacée, annuelle, à périgone argenté, coriace à la maturité. turité.

- Plante herbacée, annuelle, à périgone vert et herbacé à la ma-

2-F. rhomboüdales, non hastées; grappes làches, feuillées ; valves du fruit ovales-triangulaires. - (1). Jlt-spt. AG. Décombres, lieux incultes Le haut Lauragais; rives de l'Ariège.

A. rosée. H. Hosea $\mathrm{L}$.

- F. triangulaires-lastées, + ou - profondément dentées ; grappes denses, nues; valves du fruit hastées. - (1). Jlt-spt. R. A èté trouvé à $T$. . . . . A. lacinièe. A. Tacin iata $\mathrm{L}$.

3 - F. de la tige allongées, lancéolées ou linéaires, les inf. presque hastées, les autres entières ; valves de fruit rhomboïdales (f. 气, 6). (I). At-oct.G. Lieux cullivés, bords des chemins. . . . . . . . .

- F. de la tige hastées-triangulaires. . . . . . . . 4

4 - Valves fructifères triangulaires, $f$ on -denticulées à base, tronquées ou émarginées; plante verte. - (1). At-oct. C. Décombres, haies, fossés. ......... A. hastée. hastata L.

- Valves fructifères ovales-orbiculaires, entières, ayant $1 \mathrm{~cm}$. de large; f. d'un vert glauque. - (1). At-spt. AR. Cultivé et subspontané.(Bonne clame). . . A. des jardins A. Inortensis L.

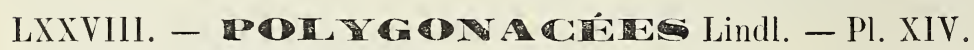

- Divisions du périgone sur 2 rangs, les internes plus grandes, saccroissant en forme de valres (f. 9); stigmates multifides. . . .

- Divisions du póricone sur i scul rang, presque égales (f. 11); stigmates en tête arrondic .........2 Polygonum.

\section{1 - PUMEX L. - Patience. - Pl. XIV.}

1 - F. hastées ou sagittées (f. 7 ); plante à saveur acide. . . 2 - F. alténuées à la hase ou cordćes ; plante à saveur non acide. 
2 - F. glauques, ovales-hastées, pétiolées; fl. polygames, en panicule non feuillée. - 4. Mai-jlt. AR. Graviers de l'Ariège; descendue des Pyrénées. . . . . P. à écussons. Te scutatus L.

- F. vertes, ovales-oblongues. . . . . . . . . 3

3 - Valves fructifères ovales, sans écailles, égalant à peine le fruit ; tiges grêles, de $1-4 \mathrm{dm} . \cdots$ - \%. Mai-spt. CC. Terres sablonneuses, muis. . . . P. petite oseille. Me. A cetosella L.

- Valves fructifères suborbiculaires-cordées, munies à la base d'une écaille réfléchie et débordant le fruit ; tige de 4-10 dm. - \&. Mai-jlt. CC. Vignes, bois, prés. P. oseille. cerosa L.

- F. étroites, les caul. linéaires ; panicule grande. - Lieux humides, prés, cunal du M. . . . . . . v. stenophyllus (Timb. et Jeanb.).

- Tige et f. de couleur pourpre : saveur nou acille ; floraison en ms-ao. - St.Jean, St.Geniès, La Ramette. . v. cincalis (Timb. et Jb.).

4 - Valves fructifères fortement dentées......... כ

- Valves fructifères entières un peu denticulées à la base. . 6

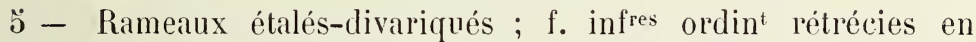
forme de violon; verticilles espacés, les infrs munis d'une feuille courte. - (2). Jn-spt. CG. Bords des chemins, lieux incultes. . . . P. élégante. pule per L.

- Rameaux ascendants ; panicule large ; 1. infres ovales-cordées ; valves fructifères triangulaires-oblongues. - q. Jn-spt. (". Lieux frais, bords des chemins.

6 - Valves fructifères ovales-orbiculaires, cordées, ordint l'extérieure seule pourvue d'un granule ovoïde; f. ondulées-crispées. \%. Jlt-spt. CC. Lieux frais, prés, fossés.

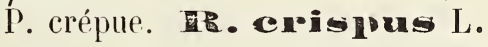

- Valves fructifères triangulaires ou lancéolées. . . . . 7

7 - Valves fructifères lancéolées-oblongues, l'extérieure seule munie d'un granule saillant; f. infres oblongues-lancéolées ; verticilles écartés, presque tous dépourvus de f. - భ. Jlt-at. C. Bois frais, saussaies.. . . P. des bois. He memonosus Schrad.

- Valves tructifères munies chacune d'un granule saillant (f. 9).

8 - F. de moins de $4 \mathrm{dm}$. de long; rameaux élalés-ascendants ; verticilles presque tous munis de feuilles (f. 8, 9, fruit); tige de 5$10 \mathrm{dm}$. - 4. Jlt-spt. G. Lieux humides, bords des chemins, bois.

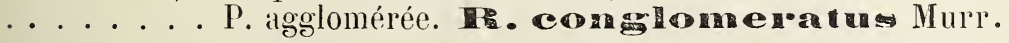

- F. infres de 4-10 dm., décurrentes sur un long pétiole ; verticilles rapprochés en panicule fournie et peu ou point leuillée ; tige de 1-2 m. - 2. Jlt-at. R. Bords des eaux, canal du M., vers Castanet. . . . P. à grandes $f$. Ta. In ydholapathum Huds. 
2 - POLYGONUM Tournef. - Renouće. - Pl. XIV.

1 - F. sagittées; tiges volubiles (f. 10). . . . . . . . 2

- F. sagittées; tiges non volubiles. . . . . . . . . . 3

- F. non sagittées; épis terminaux. . . . . . . . . 4 $2-4$.

- F. non sagittées ; fl. presque toutes axillaires, solitaires ou par

2 - Tiges cylindriques, de 1-2 m.; f. cordées-sagittées ; périgone ailé-membraneux; akènes luisants (f. 10). - (1). Jlt-spt. AC. Bords de la Garonne et de l'Ariège.

- Tiges anguleuses, de 2-8 dm. : périgone peu ou point ailé ; akènes ternes. - (1). Jn-spt. C. Champs cultivés, jardins, haies. . . . . . . . R. liseron. Convolvulus L.

3 - Fl. blanches ou rosées (f. 11), en corymbes terminaux ; akènes lisses (f. 12). - (1). Jn-al. R. Graviers de la Garonne, subsp. . . . . . . R. sarrasin. Fagopyrume L.

- Fl. d'un blanc verdâtre, en grappes axillaires et terminales; akènes rugueux. - Ju-at. R. Graviers de la Garonne : subsp... . . . . . . . R. de Tartarie. Tata tenm L.

4 - Vivace; souche rampante; f. oblongues ou lancéolées, arrondies ou un peu cordées à la base ; épis compacts. - \%. Jlt-spt. G. Marais, fossés, rivières. R. amphibie: amphibium L.

- Annuelle ; racine périgone glanduleux. . . . . . fibreuse périgone non glanduleux ; saveur herbacée......... 6

气 - Saveur herbacée ; épis oblongs-cylindriques, compacts, à fl. ord d $^{t}$ d'un blanc verdâtre; akènes luisants, concaves sur les 2 faces, de $3 \mathrm{~mm}$. de long. - (1). Jlt-spt. C. Lieux humides, bords des eaux. . . . R. à f. de patience. H. Hą̧athifolium L.

Tige à nouds très renflés ; épis linéaires. un peu lâches ; akènes de $2 \mathrm{~mm}$. de long. - Mêmes lieux que le précédent. . . . . . . . .

. . . . . . . . . . . R. noueuse. P. nodosum Pers.

- Saveur poivrée, accre; fl. d'un blanc verdâtre, en épis grêles, lîches, ordint pendants; akènes ternes, rugueux, les uns à 3 angles, les autres plans-convexes. - Jlt-oct. CG. Lieux llumides, fossés.

R. poivre d'eau. Tydnopiper. L.

6 - Epis oblongs-cylindriques, compacts, à fl. ord.t rosées (f. 13); akènes lisses, luisants, les uns à 3 angles, les autres lenticulaires- aplanis. - (1). Jlt-oct. CC. Lieux humides, fossés, bords des eaux. . . . . . . R. persicaire. Persicaria L.

- Epis filiformes, interrompus; akènes luisants ; gaines des f. ciliées.. 
7 - Fl. blanches ou rosées, en épis dressés ou penchés ; port du P. Hydropiper; akènes de 2 sortes. - I . Jlt-spt. C. Fossés, lieux inondés en hiver. . . . R à saveur douce. mite Schrank.

- Fl. d'un rose vineux, en épis très grêles, dressés à la maturité ; f. étroitement lancéolées; akènes de $2 \mathrm{~mm}$. de long. - (1). Jlt-at. AC. Fossés, plaine de la Garonne

R. fluette. mimus Huds.

8 - Tige droite; rameaux floraux presque nus, filiformes; f. elliptiques-lancéolées ; épis grêles, effilés, très interrompus, non feuillés au sommet. - (1). Jn-at. AR. Cultures de la plaine de la Gavonne, Ondes, Castelnau-d'Estretefonds.

R. de Bellardi. Bollandio All.

- Tige souvent étalée ; rameaux floraux feuillés jusqu'au sommet ; f. ovales ou lancéolées. - (1). Jlt-oct. CG. Lieux incultes. . .

R. des oiseaux, avicalaro L.

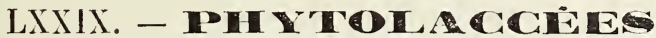

\section{PHYTOLACCA L. - Phytolaque. - Pl. XIV.}

Tige de 1-2 m. ; f. ovales-entières; fl. (f. 14) en grappes. - \% Jlt-spt. Originaire de l'Amérique septent. Naturalisé çà et lá. . . P. à 10 étamines. Docandroa $\mathrm{L}$.

Les baies (Raisins d'Amérique) sont violemment purgatives.

\section{LXXX. - TH YOE ERES Juss. - Pl. XIV.}

- Fruit charnu, drupacé ; arbuste à périgone caduc, à style très court (f. 15).................... 1 Daphne.

- Fruit sec, enveloppé par le périgone persistant; plante herbacée (f. 16). . . . . . . . . . . 2 Lygia.

\section{1 - DAPHNE L. - Daphné. - Pl. XIV.}

F. persistantes, en rosette au sommet des rameaux ; fl. jaune verdâtre (f. 15); fruit noir. - Ђ. Fév.-av. AR. Bois du Lauragais, Drémil, Cintegabelle. . . . D. lauréole. Houneolla L.

\section{2 - LYGIA Fasan. - Lygia. - Pl. XIV.}

Tige dressée, de 2-ŏ dm. ; fl. verdâtres, axillaires ; f. linéaireslancéolées (f. 16). - (I). Jlt.-spt. C. Champs argilo-calcaires. (Passerind annua Wikstr.).

L. passerine. K. Passenina Fasan. 


\section{LXXXI. - LA UIRINIES DC.}

\section{LAURUS L. - Laurier.}

Arbre à f. coriaces, persistantes ; fl. blanchâtres ; fruit bacciforme. - h. Av.-mai. Cultivé et sulsp. clans quelques haies.

L. d'Apollon. L. nobilis L.

\section{LXXXII. - ANTTALACHESR. Br. - Pl. XIV.}

- Arbrisseau diö̈que f fruit rouge, globuleux, un peu charnu. . . .

$\ldots \ldots \ldots$ Osyris.

- Plantes herbacées ; fruit sec, couronné par le périgone persistant (f. 19) . . . . . . . . . . . 2 Thesium.

$$
1 \text { - OSYRIS L. - Osyris. - Pl. XIV. }
$$

F. linéaires (f. 17), persistantes ; fl. jaunåtres (f. 18). - h. Maijlt. AC. Escarpements des coteaux. . . 0. blanc. O. alba L.

$$
2 \text { - THESIUM L. - Thésion. - Pl. XIV. }
$$

Tiges couchées ou ascendantes; f. linéaires, à 1 nervire (f. 19); fl. d'un vert jaunâtre, à 3 lractées (f. 20). - \%. Jn-spt. C. Bois, pelouses des coteanx argilo-calcaires. . . . . . . . T. couché. T. humifusum $\mathrm{DC}$.

\section{LXXXIII. - ARESTOLOCHIRES Juss.}

\section{ARISTOLOCHIA Tournef. - Aristoloche. - Pl. XIV.}

- Souche traçante; fl. jaunattres, en fascicules axillaires. - 4. Mai-jlt. AC. Vignes, haies; vallée du Tarin; env. de Toulouse. . ........... A. clématite. A. Clematis L.

-- Souche tuberculeuse; fl. solitaires, à languette brunâtre (f. 21). - 4. Av.-jlt. C. Lieux herbeux, humides. . . . . . . . . . .

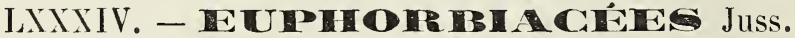

- Arbuste à $f$. persistantes ; monoïque ; capsule à 3 loges . . . . .

- Herbe diö̈que, sans suc laiteux ; capsule à 2 coques (rart 3 );

f. opposées. . . . . . . . . . . . . . 2 2 Mercurialis.

- Herbe monö̈que, à suc laiteux ; capsule stipitéc, à 3 coques

................... 3 Euphorbia. 
1 - BUXUS Tournef. - Buis.

F. opposées, entières; fl. jaune verdâtre. - 2. Ms-Av. Naturalisé. . . . B. toujours vert. Ho ennpervileens $\mathrm{L}$.

\section{2 - MERCURIALIS Tournel. - Mercuriale. - Pl. XIV.}

- Rhizome rampant ; tige simple ; fl. femelles longt pédonculées. - భ. Ms-jn. AC. Bois, lieux couverts. . . . . . . . . .

- Racine grêle, pivotante; tige ræ:meuse ; fl. femelles subsessiles (f. 22, mâle;23, femelle). - (1). Jn-nov. CC. Champs, vignes. . .

\section{3 - EUPHORBIA L. - Euphorbe. - Pl. XIV.}

1 - F. opposées, sessiles, les sup res oblongues-lancéolées ; ordint 4 rayons à l'ombelle; plante glauque de $4-12 \mathrm{dm}$. - (1). Jn-jlt. Cultivé et subspontané. . . . E. épurge. E. Ha tay-i L.

- F. opposées, petites, suborbiculaires (f. 24); fl. solitaires; tiges grêles, couchées. - (1). Jn-spt. R. Jai.dins. T. . . . . . •

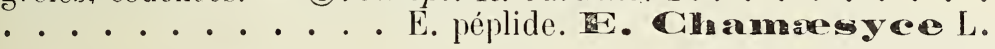

- F. éparses. . . . . . . . . . . . . 2

2 - Divisions glanduleuses du périgone arrondies, entières (f. 2气̈). 3

- Divisions glanduleuses du périgone échancrées en croissant (f. 26).

3 -Graines alvéolées ; f. obovales-spatulées, dentées supé $1^{t}$; ombelles à つ̆ rayons ; capsule lisse. - (1). Mai-oct. CG. Lieux culti-

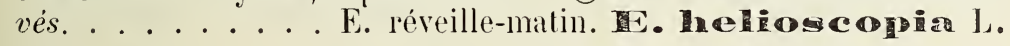

- Graines lisses. . . . . . . . . . . . 4

4 - Capsule à 3 sillons superficiels ou peu profonds. . . . .

- Capsule à 3 sillons profonds. . . . . . . . . . . 8

$\check{5}-$ Ombelle à rayons nombreux; f. petites, linćairss-oblongues, dressées, entières, glauques; capsule à dos parsemé de petiles papilles. - 4. Mai-jlt. R. Rives du Tarn. . . . . . . . . .

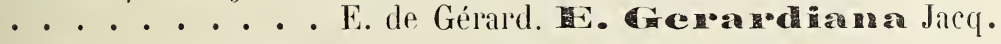

— Ombelle à 3-כ̆ rayons ; f. finement denticulées. . . . . 6

6 - F. ovales ou oblongues, de moins de $3 \mathrm{~cm}$. de long; capsule à tubercules saillants. - భ. Mai-jlt. CC. Prés, pâturages, haies. .

E. verruqueux. E. veromeos Lamk.

- F. oblongues-lancéolées, dépassant 3 cm. 
7 - Ammuelle ; l. étalées ou renversées, glabres ou à poils épars en dessous; capsule glabre, tuberculeuse (f. 2ั). - (I). Jlt-spt. AG. Lieux lumides, liaies, fossés.

E. à larges f. iv. pilapingila $\mathrm{L}$.

- Vivace; f. dressées-étalées, mollement velues, obtuses ; capsule velue ; plante robuste. - \%. Jn-jlt. C. Bois, haies.

. . . . . . . . . E. poilu. E. pilosa L.

8-Robuste, de 6-10 dnı.; ombelle à rayons nombreux; f. entières, oblongues; eapsule tuberculeuse. - ४. Jn-jlt. R. Bois. Tenerque, aux Maurices (Noulet).

E. d'Irlande. IE. myberoma L.

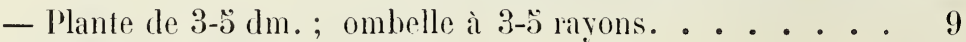

9 - Glandes du périgone d'abord jaunes puis d'un beau pourpre; capsule à tubercules obtus; 1. pubescentes. - \&. Mai-jn. C.

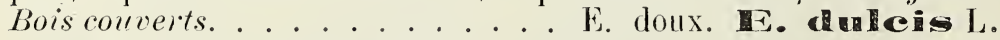

- Glandes du périgone jaunes; capsule couverte de tubercules cylindriques ; f. glabres. - (1) ou (2). Mai-spt. AC. Fossés, Lords des champs, graviers de la Garome. E. raide.

10 - Bractéees soudées 2 à 2 en une sorte de plateau orbieulaire ;

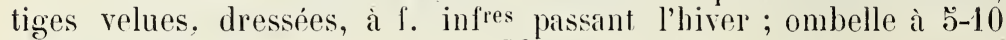
rayons (f. 26, fl.). - \%. Av.-jn. CG. Bois, broussailles. . . . . . . . . . . . E. à l. d'amandier. F. am godaloides L.

- Bractées libres. 11

11 - Graines lisses.

- Graines marquées de fossettes ou de sillons.

- Graines tuberculeuses, ovoïdes-tétragones; tige de ð̌-20 cmı., rameuse ; f. sessiles, linéaires ; ord 3 rayons à l'ombelle. - (1). $J n$ spt. CG. Lieux cultivés. . . . . . . . E. exigu. E. exigua I.

12 - F. linéaires, de $1-3 \mathrm{~mm}$. de large, celles des rameaux stériles très rapprochées; ombelle à rayons nombreux. - \&. Av.-mai. CC. Lieux sablonneur, tertres, rives de la Garomne.

F. petit eyprès. Eí. C.

- F. oblongues-lancéolées, vertes; plante de 3-8 dm., sans rameaux stérıles sous l'ombelle. - \%. Mai-jlt. R. Rives rlu Ta’n. . .

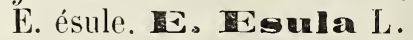

13 - Glandes du périgone à pointes courtes ; f. oblongues, glauques; graines sillonnées en travers. -. (1). Jlt-oct. C. Champs cullivés des coteaux calcaives ou argileux.

E. en laux. E. Icata $\mathrm{L}$.

- Glandes du périgone à pointes très longues ; f. ovales-arrondies, rétrécies en pétiole ; graines creusées d'un côté de petites fossettes et de l'autre de rainures. - (1). Jn-oct. C. Lieux cultivés, jardins. . . . . . E. des vignes. E. Peplus L. 


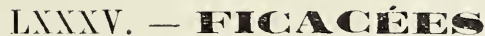

FICUS Tournef. - Figuier.

Arbrisseau à suc laiteux; monoïque. - ந. Jn-spt. Cultivé et subsp.. . . . . . . . F. commun. F. Canoica L.

\section{LXXYVI. - MOHR A CIVENA}

\section{MORUS Tournef. - Murier.}

- Fruits blancs ou rosés ; chatons femelles pédonculés. - Ł. Mai-at. Cultivé. . . . . . . M. blanc. a a ba L.

- Fruits noirs ; chatons femelles subsessiles. - §. Mai-at. Cul-

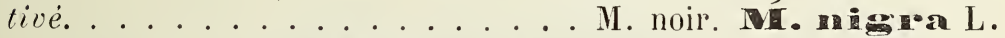

Le Broussonnetia papyrifera Duham. (Murier à propier) est cultiré dans les pares et naturilisé çà et lá ; il est originaire de la Chine.

\section{LXXXVII. - URE'THCACRES Endl. - PI. XIV.}

- F. opposées, dentées, hérissées de poils piquants ; monoüque ou diö̈que . . . . . . . . . . . . 1 Urtica.

- F. alternes, entiè rès, à poils non piquants ; fl. lolyames. • .

\section{1 - URTICA Tournel. - Ortie. - Pl. XIV.}

1 - Monoïque ; f. ovales-aiguës, tronquées ou subcordées à la base, à dents profondes; fl. mâles (f. 27) en grappes, les femelles en chatons 'globuleux pédonculés (f. 28). - \%. Av.-oct. AR. Le

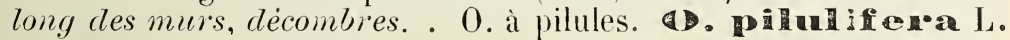

- Dioïque ou monoïque, mais alors fl. femelles en lgrappes axil-

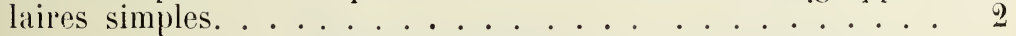

2 - Diö̈que ; f. cordées à la base ; fl. en grappes axillaires paniculées, ordt plus longues que le pétiole, les fructifères longues et pendantes. - \%. Jlt-oct. GC. Lieux incultes. . . . . . . . . . 0 . diö́que. U. dicica $\mathrm{L}$.

- Monoïque; plante annuelle, à f. non cordiformes. . . . . . 3

3 -- Grappes géminées, les inf. lemelles, plus courtes que le pétiole, les supres mâles; 2 stipules à chaque noeud; f. grandes, ovales-aiguës, à dents aiguës. - (1). Av.-mai. R. A été trouvé clans les cours de l'Arsenal, à T. .

- Grappes ord.t plus courtes que le pétiole, contenant des fl. 
mâles el des fl. femelles ; 1 stipules à chaque noud; 1. ovales ou oblongues, arrondies ou en coin à la base, à dents obtuses. - (1). Jn-oct. C. Le long des murs. . . . . O. brûlante. O. uneans L.

\section{2 - PARIETARIA Tomrnef. - Pariétaire. - Pl. XIV.}

Herbes pubescentes, à f. pétiolées, à fl. en glomérules axillaires (f. 29). - 4. Jlt-oct. G. Vieux murs, décombres.

P. officinale. P. officinalis $\mathrm{L}$.

- Tige rameuse, à ramcaux étalés ; f. orales-lancéolées, atténuées à la base ; fl. hermaphrodites â périgone sallongeant après l'anthèse.

- Tiges simples ou à rameaux courts el dressés ; f. lancéolées, atténuées aux 2 bouts ; pérignone ne s`allongeant pas. . • . . . … P. erecta Mert et Koch: Plantes un peu émollientes et diurétiquës.

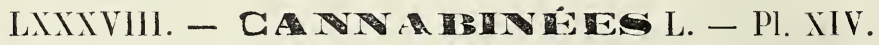

- Tige volubile ; fl. femclles en còne jédonculé (f. 30). 1 Humulus.

- Tige non volubile ; fl. femelles en glomérules sessiles.... . . 2 Cannrbis.

\section{1 - HUMULUS L. - Houblon. - Pl. XIV, f. 30 (fr.).}

F. palmatilobées, à 3-ŏ lobes ; fl. jaunâtres. - \%. Jlt-spt. AC. Buissons, haies, bords de la Garonne. . . . . . . . . . . . . H. grimpant. 基。 Lupulas L.

\section{2 - CANNABIS Tournef. - Chanvre.}

F. palnatiséquées, à ö-7 segments étroits; akène gris (chénevis). - (1). In-spt. Cultive. Originaire de la région caspienne. . . . . ................ C. cultivé. C. ativá L.

\section{LXXXIX. - UMA ARES Mirb.}

\section{ULMUS Tournef. - Orme. - Pl. XIV.}

1 - Fruits long pédonculés, ovales ou suborhiculaires, ciliés aux bords. - Ђ. Mars-mai. Planté...............

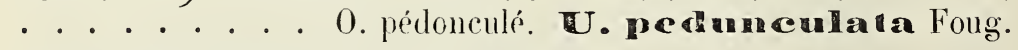

- Fruits presque sessiles et glabres. . . . . . • . . 2

2 - Graine placéc sous l'échancrure et vers le sonmet du fruit, qui est elliptique (1.31). - 5. Ms-av. G. Bois, hords des chemins.

Rameaux à écorce boursouflée-subéreuse. . . . v. suberos $\alpha$ Koch. 
- Graine placée vers le milieu du fruit; f. grandes, doublt dentées. - Ђ. Ms-av. Planté.............. ........ 0. de montagne. U. montana With.

\section{NG. - PLATA TAERS Lestib.}

\section{PLATANUS L. - Platane.}

- F. en coeur à la base, devenantglabres. - h. Av.-mai. Planté. C. . . . . . . . . . . P. d'orient. Ho onoientalis L.

- F. cunéiformes à la base, pubescentes en dessous. - b. $A v$.mai. Planté rarement .............. ....... P. d'occident. cecidentalis $\mathrm{L}$.

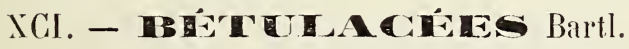

\section{ALNUS Tournef. - Aulne. - Pl. XIV, f. 32 (fr.).}

F. suborbiculaires, gluantes dans leur jeunesse, poilues en dessous à la base des nerỵures secondaires. - h. M Ms-av. CC. Bords des earx. . . . . . . . . . glutineux. A. chutinosa Gaertn.

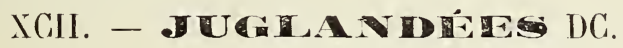

\section{JUGLANS L. - Noyer.}

F. glabres, ì 7-9 folioles ovales-aiguës. - h. Av.-mai : fr. spt. Cultive. Originaire de l'Orient. . . . . . . . . . Nogia L.

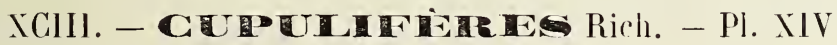

1 - Involucre fructifère épais, épineux, s'ourrant en 4 valves. . 2

- Involucre fructifère non éfincux, ne s'ourrant pas. . . . 3

2 - Chatons mâles subglobuleux. pédonculés, pendants ; fruit à 3 angles aigus (f. 33j (fâ̂nes)........ i Fagus.

- Chatons mâles filiformes, dressés ; fruits ovoüdes-comprimés (châtaiqnes). . . . . . . . 2. 2 Castanea.

3 - Involucre fructifère en forme de cupule hémisphérique (f. 35) entourant la base du fruit (gland); fl. mâles cu chatous interrompus............ . . 3 Quereus.

- Involucre fructifère foliacé ; fl. màles en chatons continus. 4

4 - Involucre fructifère à 3 lobes incigaux, le médian embrassant à demi l'akène (f. 36); fi. femelles engrappes. 4 Carpinus.

- Involucre fructifere tubuleux (f. 3\%). cnveloppant l'akène (noisette); 1l. femelles en chatous ovoüdes, écailleux. 5 Corylus. 


\section{1 - FAGUS Tournef. - Iêtre. - Pl XIV, I. 33.}

Arlure à f. ovales, sinuées-dentées, à écorce lisse. - h. Av--mai. R. dans la plaine. . . . . . H. des forèts. F. sillvatica L.

\section{2-CASTANEA Tournef. - Chataignier.}

Arbre à f. oblongues-lancéolées, dentées-cuspidées. - h. Mai-jn. Cultivé, terrains siliceux. . . . . C. cultivé. C. sativa Scop.

$$
\text { 3-QUERCUS Tournef. - Chène. - Pl. XIV. }
$$

$1-$ F. coriaces, persistantes, toujours vertes. . . . . . 2

- F. non coriaces, caduques, devenant jaunes en hiver quand elles ne tombent qu'au printemps. . . . . . . . . . 3

2 - Ecorce lisse, non subéreuse; ;. épineuses, tomenteuses en dessous. - h. An.-mai. R. Clermont, à Marconat (Noulet). . . . C. yeuse. $\mathbb{Q}$, I I $\mathrm{X}$ L.

- Ecorce subéreuse, crevassée ; f. pubescentes en dessous. - h. Av.-mai. AR. Bois. Bouconne, Colomiers. . . . . . . . . . . C.-liège $Q$. ubor $\mathrm{L}$.

3 - F. velues ou tomenteuses en dessous.

- F. glabres ou un peu pubescentes en dessous dans leur jeu-

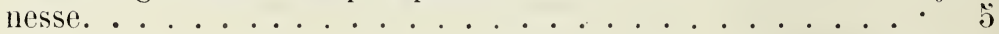

4 - Cupule hérissée d'écailles linéaires recourbées au sommel; f. à lobes profonds, aigus. - h. Av.-mai. Planté dans les parcs.

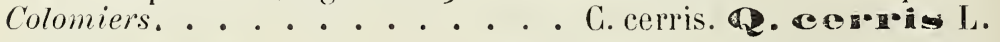

- Capsule garnie d'écailles imbriquées et apprimées ; fruits petits, sessiles ou presque sessiles; jeunes rameaux tomenteux. - $\mathfrak{b}$. Av.-mai. C. Bois. (Chêne noir).

气 - Fruits sessiles ou très brièvement pédonculés, par 2-3; i. pétiolées, les jeunes pubescentes ; rameaux étalés (f. 34, fll.). - h. Mai. C. Bois (Chêne noir).

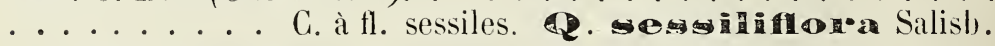

- Fruits longt pédonculés, par 1-4 (f. 30) ; f. glabres, subsessiles ; rameaux retombants. - 5. Mai. G. Bois. (Chềne blanc). . . . . . ......... C. pédonculé. $\mathbb{Q}$, podunculata Elırh

4-CARPINUS Tournef. - Charme. - Pl. XIV, f. 36 (fr.).

F. ovales-allongées, dentées, à nervures saillantes. - h. Av.mai. AG. Bois ......... G. commun. C. Betulus L. 
$\check{5}$ - CORYLUS Tournef. - Coudrier. - Pl. XIV, f. 37 (fr.).

Arbrisseau à f. ovales-cordées, pubescentes, à rameaux flexibles. - Ђ. Jv.-fëv. C. Bois, haies. (Noisetier).

C. aveline.

C. Avellaria L.

\section{XCIV. - SLICLER Rich. - Pl. XIV.}

8-30 étamines; chatons à écailles incisées ou laciniées (f. 38) . . . . . . . . . . . . . . . . . . . . . 1 Populus. $2-5$ étamines; chatons à écailles entières (f. 39, 40). . . . 2 Salix.

\section{1 - POPULUS Tournef. - Peuplier.}

1 - Jemines pousses pubescentes ou tomenteuses; écailles des chatons velues ciliées ; 8 étamines. . . . • . . . . . . 2

- Jeunes pousses et écailles des chatons glabres; 12 étamines ou plus.

2 - F. en corur à la base, ovales ou suborbiculaires, blanchestomenteuses en dessous ; écailles des chatons crémelées. - Ђ. Msav. AC. Cultivé et naturalisé. . . . P. blanc. a Da I.

- F. adultes glahres ou un peu pubescentes en dessous, suborbiculaires, longt pétiolées et très moliles; écailles des chatons incisées-digitées (1. 38). - Ђ. AC. Bois lumides.

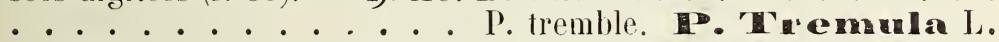

3 - Rameaux dressés-lastigiés ; arbre en pyramide étroite. - $\mathfrak{~}$. Ms av. Planté. C. (P. d'Italie).

- Rameaux étalés. . . . . . . . . . . 4 4

4 - F. très glabres, ord plus longues que larges. - h. Ms-av. Planté. CC. . . . . . . . P. noir.

- F. pubescentes aux bords, plus larges que longues, ovalescordées. - Ђ. Mars-av. Planté. (Caroline).

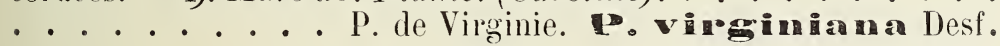

\section{2 - SALIX Tournef. - Saule.}

1 - Ecailles des chatons eutièrement jaunâtres ou roussâtres. 2

- Ecailles des chatons brunes ou noires au moins supérienrement. .............. ๖

2-Rameaux pendants; f. glalıres, étroit lancéolées; capsule sessile. - - . Av.-mai. Planté au bord des eaux (pieds femelles). (S. pleureur). . . . . . S. de Babylone. Saldylomica L.

- Rameaux dressés ou étalés. 
3 - Ecailles caduques avant la maturité des capsules; f. blanchâtres-soyeuses en dessous ; 2 étamines ; capsule glabre, subsessile ; arbre assez élevé. - b. Av.-mai. C. Bords des eaux.

S. blanc. alba L.

Jeunes rameaux jaunes ou d'un jaune rougeâtre. - Cultivé .....

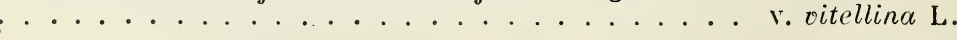

- Ecailles persistantes. . . . . . . . . . 4

$4-3$ étamines; f. glabres sur les 2 faces, vertes en dessous, rar ${ }^{\mathrm{t}}$ glauques ( 5 . amygdalina $\mathrm{L}$.) ; écailles glabres au sommet; capsule glabre, à pédicelle $2-3$ fois plus long que les glandes. - - . Av.-mai. C. Bords cles rivières . . S. à Z étamines. tromanda $L$.

- 2 étamines; f. blanchâtres-tomenteuses en dessous; capsule presque sessile. - ந. Ms-av. AC. Bords des rivières. . . . . . . ........... . . . drapé: S. incama Schrank.

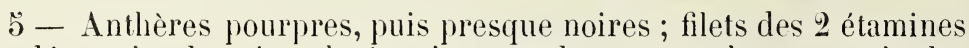
soudés et simulant 1 seule étamine; 1. glauques en dessous ; stipules

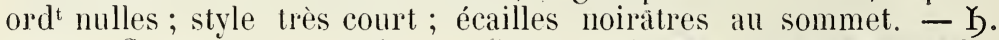
Ms-av. C. Bords desivières. S. pourpré. S. phlompea L.

- Anthères toujours jaunes. . . . . . . . . 6

6 - Chatons subsessiles, naissant avec les feuilles ; celles-ci étroites, blanches-soyeuses en dessous ; 2 étamines à filets libres; capsule sessile; style aussi long que les stigmates. - ந. Ms-av. AR. Rives du Tarn.. Souvent cultive....

S. des vanniers.

8. viminalis L.

- Chatons naissant avant les leuilles; capsule pédonculée ( $f_{\text {. }}$ $40)$; f. ovales ou oblongues.

7 - Bois de 2 e année très lisse sous l'écorce ; bourgeons şlabres ; f. de $4-5 \mathrm{~cm}$. de large, à pointe courbée, blanchâtres-tomenteuses en dessous. - Ђ. Ms-av. AC. Bois humides, bords des eaux. . . • S. Marceau. cappea L.

- Bois de 2 année muni sous l'écorce de lignes longitudinales saillantes; bourgeons pubescents ; 1 . obovales ou oblongues-lancéolées, à pointe droite (f. 39, fl. mâle; f. 40, capsule). - Ђ. Ms-av. AC. Bois humides, bords des ruisseaux. . . . . . . . .

S. cendré. sì. cinon I.

\section{Classe II - MONOCOTYLÉDONES}

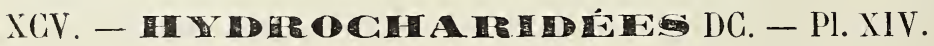

F. toutes radicales, molles, obtuses, linéaires (f. 41). 1 Vallizneria. Tige à f. verticillées par 3 , oblongues. . . . . . . . 2 Eloder. 
1 - VALLISNERIA Micheli. - Vallisnérie. - Pl. XIV.

Plante submergée; fl. mâles en capitules ovoïdes; fl. femelles solitaires sur un long pédoncule contourné en hélice (f. 41). - \%. Jlt-oct. C. Eaux tranquilles, canaux. . . . . . . . . . . .

\section{2- ELODEA Rich. - Elodée. - Pl. XIV, f. 42.}

Plante submergée ; fl. solitaires, à spathe tubuleuse. - q. Jn-at. C. Eaux courantes ou stagnantes. Canaux; flaques, à Braqueville. Tiès envahissante.

E. du Canada. F. Camadonsis Rich.

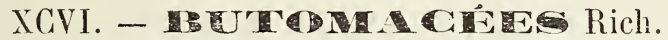

\section{BUTOMUS Tournef. - Bulome.}

Aquatique; f. toutes radicales, linéaires, triquètres; fl. roses, en ombelle. - q. Jn-at. AR. Cá et là, canal du Midi, Portet, ete. .

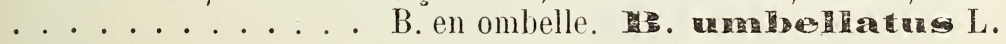

\section{XGVII. - LE C Rich. - Pl. XIV.}

1 - F. aériennes sagittées (f. 43) ; plante monoïque; étamines nombrcuses. .............. 1 Scagittaria.

- F. aériennes non sagittées; fl. hermaphrodites. . . . . 2

2 - Carpelles libres, nombreux; ordint 6, 12 étamines. 2 Alisma.

- Carpelles soudés jar leur base, divergents en étoile ; 6 étami. nes :.............. 3 Damasonium.

1 - SAGITTARIA I. - Sagittaire. - PI. XIV, f. 43 (f.).

F. submergées linéaires: fl. infres femelles, en grappe étroite. \%. Jn-at. AR. Bords des eaux stagnantes. Ondes, Grenade, Canal

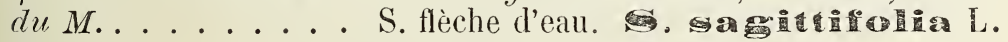

$$
2 \text { - ALISMA L. - Alisma. - Pl. XIV. }
$$

- Fl. petites (f. 44), de $5 \mathrm{~mm}$. de diam. environ, blanches ou rosées, en panicule grande; f. ovales-lancéolées, arrondies ou un peu cordées à la base; carpelles sur un seul rang (f. 45). - \%. Jn-spt. CG. Bords des eaux. . . . . A. plantain d'eau. .

F. lancéolées, longt rétrécies en pétio'e. . v. lanceolatum (With.).

- Fl. plus grandes, ord en ombelle terminale; f. lancéoléeslinéaires; carpelles en tête globuleuse. - q. Mai-spt. R. Maréca- 
ges, bords des eaux. Canal du M., Plaisance. A. renoncule. A thandoides $\mathrm{L}$.

3 - DAMASONIUM Tournef. - Damasonie. - Pl. XIV, f. 46.

F. oblongues, arrondies ou cordées à la base (f. 46); fl. rosées, en ombelle ou en 2-3 verticilles espacés. - \%. Mai-spt. AC. Fossés, étangs. Plaine de la Garonne.

D. étoilé. D. stellatum Rich.

\section{XGVIII. - COICITICA CRES Juss.}

COLCHICUM Tournef. - Colchique. - Pl XIV.

Bulbe plein ; f. lancéolées; 1-4 fl. lilacées (f. 47, fl. ; 48, fr.). - 4 . At-oct. G. Piés humides.

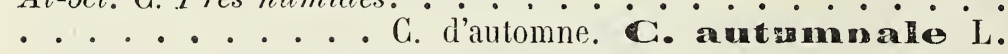

Plante irritante ct très vénéneuse.

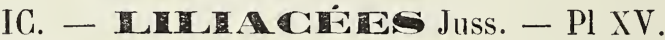

1 - 3 stigmates ou un stigmate à 3 lobes ; périgone à divisions

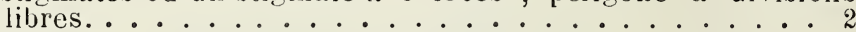

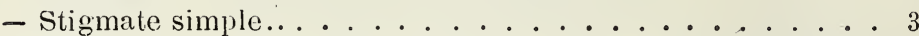

2 - Style nul ; tige uniflore, longt nue au sommet; périgone en eloche (f. 1)................ 1 Tulipa.

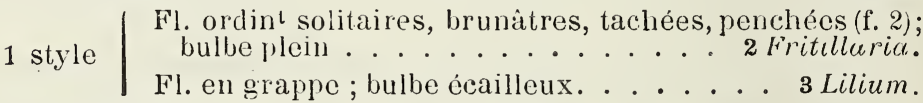

3 - Périgone à divisions libres ou soudées seulement vers leur base (f. 5). .................... . . 4

- Périgone â divisions soudéc $\mathrm{s}$ en tube au moins dans leur moitié inférieure (f. 8) ; fl. en grappe. . . . . . . . . . 9

4 - Fl. en ombelle, renfermées d'abord dans une spathe. 5 Allium.

- Fl. en grappe ou en corymbe............ . 5

5 - Filets des étamines tous ou plusieurs sensiblement élargis à la base ; fl. blanches oü jaunatres. . . . . . . . . . 6

- Filets des élamines peu ou point élargis à la base (quelquefois élargis, mais alors fl. bleues). . . . . . . . . . 7

6 - Partie élargie de la base des filets velue, voùtéc, recouvrant l'ovaire. . . ........... 11 Asphodelus.

- Filets des étamines élargis jusqu'au sommet (f. 5)

6 Ornithogulum.

7 - Souche fibreuse ; fl. blanches, à divisions étalées (f. 9) . . . . .

10 Phalangium.

- Souche bulbeuse; fl bleues ou jaunes . . . . . . . . 8

8 - Anthères fixées par leur base; fl. jaunàtres (f. 6), en ombelle. 
- Anthères fixées par le dos ; fl. bleues, en grappe . . 4 Scilla.

9 - Filets des élamines dilatés à la base (f. 7) . . . 8 Bellevallia.

- Filets des étamines filiformes (f. 8). ...... 9 Muscari.

$$
1 \text { - TULIPA L. - Tulipe. - Pl. XV. }
$$

- Fl. jaunes; étamines à filets barbus. - $4 . A v$. R. Champs, vignes. Bas Lauragais, env. de T., au Mival, a St-Simon (Noulet). - . . . . . . . . T sauvage. T. sil trestris L.

- Fl. blanches ou rosées, avec une large bande rouge sur le dos des divisions du périgone (f. 1). - $\%$. Av. RR. Existait autrefois autour de Toulouse, dans les vignes; se rencontre sur les coteaux de la rive droite du Tam. . . . . . . . . . . . . . . . ......... . . T. de l'Ecluse. Tr. Clusiana Vent.

\section{2 - FRITILLARIA L. - Fritillaire. - Pl. XV, f. 2.}

F. linéaires, alternes. - \%. Av. C. Près humides, surtout dans les terrains calcaires. . . . F. pintade. F. Nereagris L.

$$
3 \text { - LILIUM I. - Lis. }
$$

On cultive le L. candidum L., à fl. grandes, blanches.

$$
4 \text { - SCILLA L. - Scille. - Pl. XV. }
$$

1 -- Fleurs numies de bractées membraneuses ; 1. lancéoléesoblongues (f. 3, fl.). - \%. AR. Lieux ombragés, bois frais. Venerque, Bouconne, T., château de Labastide (Noulet).

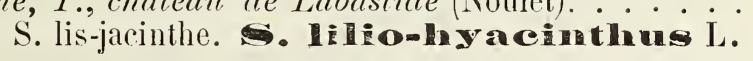

— Fl. dépourvues de bratées ; f. étroites. . . . . . . v

2 - Ordint 2 feuilles presque aussi longues que la tige. - 4 . Ms-av. R. Broussailles, haies, lieux frais. Bouconne, vers Brax.

- 3-气̆ feuilles filiformes bien plus courtes que la tige ; fl. paraissant avant les feuilles. - భ. Jlt-spt. AC. Coteaux secs, bois découverts, graviers de l'Ariège, vallée du Touch.

-. . . . . . . S. d'automne. S. antuminais $\mathrm{L}_{\text {. }}$

$$
\check{\jmath} \text { - ALLIUM L. - Ail. - Pl. XV. }
$$

1 - Fl. grandes, d'un beau rose (f. 4), en ombelle lâche, à spathe univalve ; filets simples; f. planes ; bulbe accompagné de bulbilles. - 4. Av.-mai. R. Vignes. Blagnac, Lalande, Auterive. . . •.

- Ces calactères non réunis. 
2 - Etamines toutes à filets simples; fl. nombreuses, sans bulbilles, depassées par la spathe ; pédoncules très inégaux ; fl. livides ou d'un rose pâle. - 2. Jlt-at. AC. Champs, vignes. . . . . .

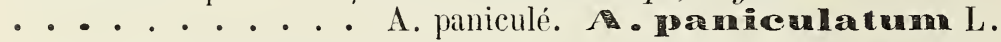

Pédoncules peu inégaux; fl, pâles, à carène verdâtre. A. pallens L.

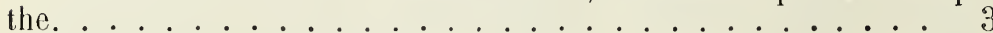

3 - F. planes, non fistuleuses ; ombelle ample, à 30-80 fl. rosées, à carène plus foncée. - \%. Jn-jlt. C. Champs ; vignes. . . . . . - A. à fl. nombreuses. polyanthum Rœm et Schult.

- F. fistuleuses, demi-cylindriques. . . . . . . . 4

4 - Fleurs non accompagnées de bulbilles, d'un beau rouge, en ombelle globuleuse, à pédoncules peu inégaux ; spathe bivalve. 4. Jn-jlt. C. Champs, vignes. . . . . . . . . . . . •

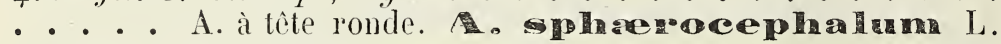

- Fl. entremêlées de bulbilles, d'un lilas sale, en ombelle petite, globuleuse ; spathe univale. - 4. Jn-jlt. CG. Lieux cultivés.

On culvive l'A. sativum I. (Ail), l'A. Porrum L. (Porreau), l'A. Cepa L. (Oignon), l'A. fistulosum L. (Cibcule), l'A.ascalonicum L. (Echalotte) et l'A. Schœnoprasum L. (Civette). - L'odeur des plantes de ce genre se communique au lait des vaches qui en mangent.

;6 - ORNITHOGALUM L. - Ornithogale. - Pl. XV.

1 - Fl. jaunâtres, en grappe spiciforme allongée, au sommet d'une hampe robuste, droite. - భ. Mai-jn. C. Prés, bois. Vallée

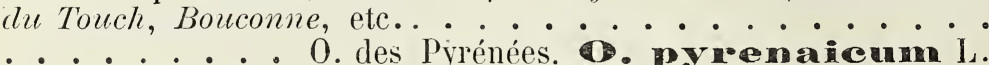

- Fleurs blanches, en corvmbe.......... 2

2 - Pédicelles fructifères dressés ou peu étalés. - \%. Mai-jn. AC. Champs cultivés. . O. en ombelle. O. umberllatum L.

- Pédicelles fructifères longs, d'abord ascendants puis étalés à

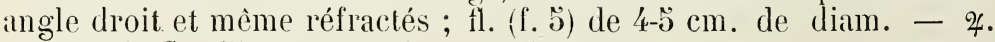
Av.-mai. C. Champs argilo-calcaires. • • • • • • • •

$$
7 \text { - GAGEA Salisb. - Gagée. - Pl. XV, f. } 6 \text { (fl.). }
$$

Ord 2 feuilles linéaires; ombelle à 2 bractées ; pédoncules pubescents. - \%. Av. Champs cultivés des terrains argilo-calcaires. A rechercher. Existe dans le Tarn et dans l'Ariège et viaisemblablement aussi dans le Lauragais.

G. des clamps.

G. ancensis Sch. 


\section{8 - BELLEVALIA Lap. - Bellevalie. - Pl. XV.}

F. longues, étroites ; fl. d'un blanc sale (f. 7), en grappe conique. - 2. Av.-mai. AC. Prés humides. Vallées du Touch, du Girou, de l'Hers, de la Saune, à Ste-Foix, Préserville (M. Marty).

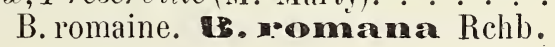

\section{9 - MUSCARI Tournef. - Muscari. - Pl. XV.}

1 - F. largement linéaires ; grappe très longue, surmontée d'une toufle de fl. stériles pédicellées, d'un beau bleu; fl. inférieures d'un brun livide. - \%. Ms-av. CC. Champs cultivés.

- F. + ou - cylindriques, joncilormes; fl. supres subsessiles. 2

2 - F. cylindriques, à sillon très étroit; grappe courte, dense, à fl. petites, bleues; capsule échancrée en cœur au sommet. - \%. Ms-av. CG. Lieux cultivés .

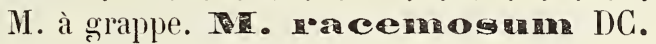

- F. demi-cylindriques, de 2-4 mm. de large ; capsule non échancrée au sommet (f. 8, fl.) - \&. Av.-mai. R. Champs cultivés. Avignonet (Timbal). . . . . M. négligé. M. neglectum Guss.

\section{0 - PHALANGIUM Tournef. - Phalangère. - Pl. XV.}

Fl. (f. 9) en grappe simple; capsule aiguë. - భ. Mai-jn. C. Bois,

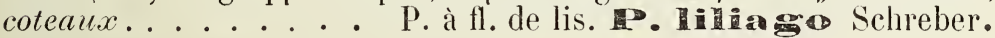

\section{1 - ASPHODELUS L. - Asphodèle. - Pl. XV.}

Souche tuberculeuse ; tige simple ou peu ramifiée; fl. blanches (f. 10), en grappe dense. - q. Mai-jn. C. Bois.

A. blanc. A. a Ibus Mill.

On cultive la Jacinthe d'Orient (Hyacinthus orientalis L.), à fl. odorantes et de couleur variée, et le Lis jaune(Hemercallis flava L.), à fl. d'un jaume pâle.

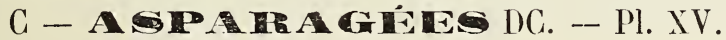

1 - Arbuste à rameaux aplatis (cladodes, f. 11), épincux, simulant cles feuilles ovales-aiguës; diöque...... 1 Ruscus.

- Plante herbacée ou ligneuse, mais sars rameaux aplatis. . 2

2 - Ramuscules filiformes, (pris somvent pour des f.), fasciculés à l'aisselle de f. en forme d'écaille; dioüque... 2 Asparagus.

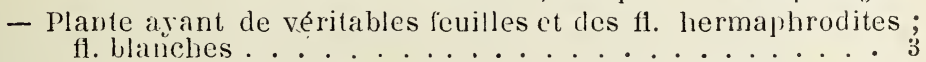

3 - Périgone à divisions soudées cn un long tube cylindrique (f. 13) 3 Polygonatum.

- Périgone à divisions soudées en cloche subglobuleuse (f. 14). . 4 Convallaria. 


\section{1 - RUSCUS L. - Fragon. -- Pl. XV, f. 11.}

Tige dressée, rameuse ; baie globuleuse, rouge. - h. Ms-av. C. Bois, broussailles . . . . F. piquant. aculeatus L.

$$
2 \text { - ASPARAGUS L. - Asperge. - Pl. XV. }
$$

- Tige lisse, à rameaux allongés; baie rouge. - \%. Ju-jlt. Cultivé et subsp.. . . . . . A. officinale. . officinalis L.

- Tige ligneuse, très rameuse, tortlieuse, à ramuscules piquants (f. 12) ; baie noire. - h. Jin-at. AG. Coteaux de la Garonne et de l'Ariège. . . . . . . . A. à f. aiguës. A. acutifollius L.

\section{3 - POLYGONATUM Desf. - Sceat-de-Salomon. - Pl. XV.}

- Pédoncules portant 1-2 fl. de $2 \mathrm{~cm}$. de long (f. 13); filets des étamines glabres. - 4. Mai-jn. AC. Bois. Bouconne, La Ramette. (P. vulgare Dest.). . . . . . P. officinal. OfDeinalo All.

- Pédoncules portant $2-6$ fl. de $12-10 \mathrm{~mm}$. de long ; filets des étamines velus. - 2. Mai-jn. AR. Bois. Bouconne. . . . . . . . . . . . . . . . . S. multiflore. mo enltiflorenn All.

\section{4 - CONVALLARIA L. - Muguet. - Pl. XV, f. 14 (fl.).}

2-3 f. radicales; hampe nue ; grappe unilatérale; laie rouge. - \%. Mai-jn. R. Bois, lieux firais. Bouconne. . . . . . . . . .

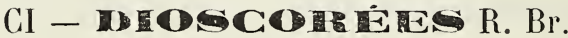

TAMUS L. - Tamier. - Pl. XV, f. 15.

Tige grimpante, f. ovales, cordiformes ; fl. verdattres. - \& Msav. IC. Bois, haies. . . . T. commun. T. commann is L.

Les jeunes pousses se mangent en guise d'asperges.

\section{CII. - TIR A AEES R. Br. - Pl. XV.}

1 - Stigmates pétaloïdes ; périgone à divisions externes étalées, les internes dressées (f. 16) . . . . . . . 1 Iris.

- Stigmates non pétaloïdes. . . . . . . . . . . . 2

2 - Périgone presque bilabié, à tube court; stigmates dilatés au sommet (f. 17). . . ......... 2 Gladiolus.

- Périgone régulier, à tube long; stigmate en coupe. 3 Crocus. 


\section{$-183-$ \\ 1 - IRIS L. - Iris. - Pl. XV.}

1 - Fl. jaunes, 2-3 dans la mème spathe; divisions internes 2 fois plus courtes que les stigmates. - 2. Mai-jn. C. Lieux humides, bord des eaux. . . . 1. des marais. T. Psendacon'us $\mathrm{L}$.

- Fl. bleues ou pourpres. . . . . . . . . . 2

2 - Fl. bleues, grandes, à tube long, à divisions externes harbues, plus pâles. - \%. Ms-av. Cultivé et subspt. Escarpements descoteaux de l'Ariège ; vieux mur's, ramier de Blagnac.

l. d'Allemagne. I. genomanica $L$.

- Fleurs d'un bleu violacé, à tube court, à divisions externes non barbues. .................... 3

$3-\mathrm{F}$. en glaive, un peu plus courtes que les tiges fleuries; fl. livides en dessous, à divisions internes dépassant les stigmates (f. 16); plante fétide. - \%. Mai-jlt. AG. Bois, lieux couverts.

I. fétide. 面. foetidissima $\mathrm{i}$.

- F. linéaires, beaucoup plus longues que les tiges fleuries; 2 fleurs, à divisions internes plus courtes que les stigmates. - \%. Jnjlt. AG. Bois, lieux couverts. I. graminéc. H. gioaminea L.

\section{2 -- GLADIOLUS L. - Glaïeul. - Pl. XV, f. 17.}

5̆-10 fl. purpurines, en grappe unilatérale. - \%. Mai-jlt. GG. Moissons. . . . . G. des moissons. G. sed etunt Gawl.

\section{3 - CROCUS L. - Safran.}

Fl. violettes ; stigmates orangés, aussi longs que le périgone. 4. Spt.nov. Cultivé et parfois subsp. . …… ............... S. cultivé C. sativus $\mathrm{L}$.

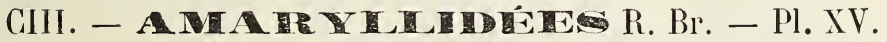

Périgone muni, à la gorge, d'une couronne pétaloïde (f. 18) . . . .

Périgone à gorge dépourvue de couronne pétaloüde (f. 19).

\section{1 - NARCISSUS L. - Narcisse. - Pl. XV.}

1-Fl. blanches ou d'un blanc jaunâtre, à couronne jaune foncé.

- Fl. jaunes, à couronne allongée, campanulée, plus foncée que le périgone ; f. élargies. . . . . . . . . . . . . 3 - Fl. jaunes, à couronne courte et en coupe ; 2-5 dans la spathe ; 
f. linéaires, joncilormes. - భ. Ms-av. R. Cultivé et subsp. . . . N. Jonquille. Jonquilla L.

2 - Hampe à 1-3 fleurs blanc crême, à couronne courte, à odeur suave. - భ. Av. Cultivé et subsp.

•. • • . . . . N. à 2 fleurs. N. biflorions Curt.

- Hampe à 3-10 fl. ; f. glaucescentes. - Ms-av. Cultivé et subsp............... N. tazette. Tazetta L.

3 - Couronne moitié plus courte que les divisions du périgone ; fl. solitaire, pâle. - \%. Av.-mai. Cultivé et subsp.

N. incomparable. N. incomparoabilis Mill.

- Couronne égalant le périgone, à bords ondulés-frangés; fl. penchée, solitaire (f. 18). - ४. Av.-mai. AR. Prés, bois. Bouconne, Tournefeuille. . . . . . . . . . . . . .

Fleur double, grande; couronne à 6 lobes crénelés. - Cultivé et subsp. . . . . . . . . ..... i major Curt.

\section{2- GALANTHUS L. - Galanthine. - Pl. XV.}

- Fl. blanche, penchée (f. 19); 2 f. opposées. - భ. Fév.-ms. AC. Prés, bois ; bords de l'Hers, Launaguet, Castelginest.

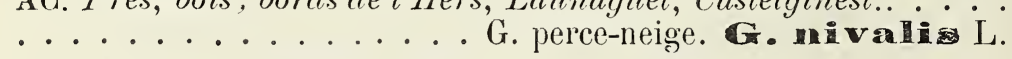

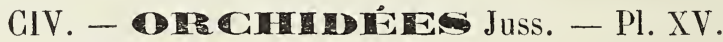

1 - Feuilles réduites ì des écailles violacées ; labelle entier; éperon filiforme (f. 34). ........... 10 Limodoron.

- Plante feuilléc. . . . . . . . . . . . . 2

2 - Labelle prolongé en éperon à sa base (f. 24); souche à 1,2 tnbercules; ovaire contournée. . . . . . . . . 3

- Labelle non prolongé en éperon (f. 21) . . . . . . . . . 8

3 - Labelle linéaire, entier, allongé ; fl. blanchâtres (f. 33) . . . . .

- Labelle à 3 lobes $+o u$ - profonds. . . . . . . . . . 4

4 - Labelle à lobes très longs, contournés en spirale; fl. verdàtres ou rosées (f.23)............... 3 Satyrium.

- Labelle à lobes non tordus en spirale. . . . . . . . . . . 5

5 - Rétinacles nus ; tubercules palmés . . . . . . . 6

- Rétinacles renfermés dans une bursicule . . . . . . . . 7

6 - Fl. d'un vert jaunâtre, à éperon très court, globuleux (f. 32). . .............. 8 Cacloglossum.

- Fl. rosées, purpurines ou blanchâtres ; éperon très long (f. 31).

7 Gymnadenia.

7 - Bursicule à 2 loges; rétinacles distincts (f. 25-28). . 5 Orchis.

- Bursicule à 1 loge; rétinacles soudés ; tubercules entiers; épi dense, court (f'.2 . . . . . . 4 Anacamptis. 
8 - Souche fibreuse. . . . . . . . . . . . . 9

- Souche tuberculeuse. . . . . . . . . . . 11

9 - Tige à 2 larges feuilles opposées (quelquefois 3) ; fl. jaune verdâtre (f. 3i). .............. 13 Listera.

- Tige à plusieurs f. alternes ; périgone à divisions presque égales. . . . . . . . . . . . . . 10

10 - Ovaire sessile, tordu ; labelle trilobé ; fl. grandes, blanches ou roses (f. 35). ........... 11 Cephalanthera.

- Ovaire non tordu, porté par un pédoncule tordu ; fl. vertes ou violacées (f. 36) .............. 12 Epipactis.

11 - Epi contourné en spirale et compact; fl. petites, blanches (f. 38) ................. 14 Spiranthes.

- Epi non contourné. . . . . . . . . . . 12

12 - Ovaire tordu ; labelle à 4 divisions linéaires (f. 22). 2 Aceras.

- Ovaire non tordu . . . . . . . . . . . . 13

13 - Périgone à divisions externes étalées (f. 29, 30) . . . 6 Ophrys.

- Périgone à divisions externes rapprochées en casque (f. 21) • .

\section{1 - SERAPIAS L. - Sérapias. - Pl. XV.}

1 - Bractées plus courtes que les fl.; les 2 divisions internes du périgone lancéolées ; labelle (ordint glabre) muni à sa base d'une seule gibbosité. - Ұ. Mai-jn. AC. Prés, bruyères, bois clairs. Bouconne, la Ramette. . . S. à languette. Ling $\mathrm{L}$.

- Bractées égalant ou dépassant les fleurs; les 2 divisions internes du périgone ovales ou arrondies à la base, brusquement acuminées (f. 20); labelle velu, d'un rouge vineux. . . . . . . . 2

2 - Labelle beaucoup plus long que large, à lobe médian lancéolé, 2-3 fois plus long que large. - \%. Jn. AR. Bois, bruyères. Bouconne, La Ramette.

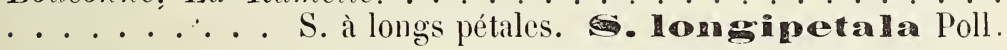

- Labelle aussi large que long, à lobe médian cordiforme, subtriangulaire (f. 21). - \%. Jn. AR. Bois, bruyères. Bouconne, Balma, Pechlusque, La Ramette.

S. en cour.

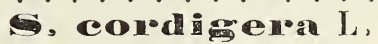

2- ACERAS R. Br. - Acéras. - Pl. XV.

Fl. jaunatres, en épi grêle ; labelle imitant un homme pendu (f. 22). - 4. Mai-jn. AC. Bois, prés secs, terrains argilo-calcaires. -. . A. homme pendu. A. Alleoporinora R. Br.

$$
3 \text { - SATYRIUM. - Satyrion. - Pl. XV. }
$$

Plante à odeur de bouc ; épi long ; éperon court (f. 23). — Ұ. Mai-jlt. AC. Friches, lisières des bois (Loroglossum Rich.) . • • . . . . . . S. à odeur de bouc. S. Hnirgocinum L. 
4 - ANACAMPTIS Rich. - Anacamptis. - Pl. XV.

Fl. d'un rose vif, en épi pyramidal; éperon linéaire, arqué (f. 24). - 2. Jn-jlt. AC. Bois, prés secs. (Orchis L.). . . . .

A. pyramidal. pyomidalis Rich.

$$
\text { 丂 - ORCHIS I. - Orehis. - PI. XV. }
$$

1 - Labelle très large, cunéiforme, à extrémité arrondie et denticulée ; fl. roses ou violacées; tulıercules entiers. - \%. Mai-jn. R. Prés, bois, friches des coteaux. A été trouvé à Bouconne, vers Léguevin, et à Portet : Avignonet.

....... . 0. papilionacé. O. papilionacea $\mathrm{L}$.

- Labelle à 3 ou 4 lobes. . . . . . . . . . . . . . . . . . 2

2 - Divisions supres et latérales du périgone rapprochées et voútées en forme de casque ; tubercules entiers. . . . . . 3

- Divisions supres ou latérales étalées, uon connirentes. . 8

3 - Divisions supres en casque aigu; labelle à 4 divisions, les 2 médianes séparées par une pointe.

- Divisions sup ${ }^{\text {res }}$ en casque obtus ou globuleux ; labelle à 3 ou 4 lobes, sans pointe au milieu. . . . . . . . . . . 6

4 - Casque d'un pourpre noir, court ; labelle blanchatre ou rosé, maculé, à 4 lobes, les latéraux linéaires, rapprochés des médians qui sont beaucoup plus larges (f. 25\%) ; bractées 8-10 fois plus courtes que l'ovaire. - 2. Mai-jn. C. Bois, prés, coteaux argilo-calcaires. (O. fusca Jacq.). . . O. pourpré. @Dumperea Huds.

- Casque d'un rose cendré ; labelle à lobes presque égaux en largeur

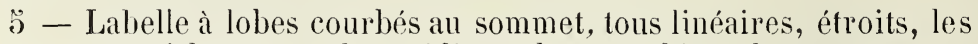
latéraux aussi longs que les médians; bractées bien plus courtes que l'ovaire. - 4. Mai-jn. AC. Prés, coteaux argilo-calcaires.. . . . . 0. singe. B. imia Lamk.

- Labelle à lobes plans, les latéraux linéaires, allongés, écartés des médians qui sont 1, 2 fois plus larges qu'eux et beaucoup plus courts. - \%. Mai-jn. R. Pres, pelouses des coteaux. Lacroix-Falgarde, vallons de Pechbusque. O. militaire. D. millitan-is L.

- Labelle à lobes oblongs, plans, les latéraux presque aussi larges mais bien plus courts que les médians; bractées atteignant ou dépassant un peu le milieu de l'ovaire. - 2. Mai-jn. AC. Piés, bois. Lacroix-Falgarde, La Ramette, Tournefeuille, Lanta, Seillome (M. Marty). . . . . 0. tridenté. B. Eod Ondata Scop.

6 - Labelle à 3 lobes, le médian entier ; fl. d'un rouge terne, à odeur de punaise; f. linéaires, aiguës. - \%. Mai-jn. AC. Prés, pe- 
louses. . . . . . . 0. punaise. O. cononolnone L.

Fl. à odeur de vanille. - Friches, bords de la Garonne..

— Labelle à 3-4 lobes, le médian échancré. . . . . . . . . 7

7 - Eperon beaucoup plus court que l'ovaire (1-2 mm.) ; fl. petites (f. 26), en épi serré, brunâtre an sommet ; labelle blanchâtre. \%. Mai-jn. AC. Bois, prés; vallées du Touch, de l'Aussonnelle. .

0 . brulé. D. ustulara L.

- Eperon presque aussi long que l'ovaire ; fl. moyennes (f. 27), en épi pauciflore, non noirâtre. - \%. Av.-mai. CG. Bois, prés. . .

8 - Fl. de couleur uniforme ou non rayées ni piquetées; tubercules entiers. ................ 9

- Fl. rayées ou piquetées de couleurs diffẻrentes ou plus foncées; tubercules palmés.

9 - Bractées à 3-ŏ nervures ; f. pliées, non tachées ; épi lâche, à fl. grandes, d'un pourpre foncé ; éperon horizontal, plus court que l'ovaire. - \%. Mai-jn. C. Prés humides.

0. à fl. lîches. Haxillon Lam.

- Bractées à 1 nervure, au moins aussi longues que l'ovaire; l. souvent tachées; épi allongé ; éperon rohuste, aussi long que l'ovaire ou plus long (I. 28). - భ. Av.-mai. AC. Bois, biuyères.. . . . . .

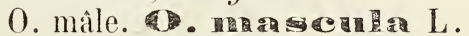

10 - Bractées presque toutes plus longues que les fleurs, qui sont rose carné, à divisions latérales externes déjetées en arrière ; f. vert gai, non maculées. - \%. Mai-jn. C. Prës humides. Vallées de l'Hers, du Girou, etc. . . . O. incarnat. O.

- Bractées souvent plus courtes que les fleurs d'un blanc lilas ; f. maculées de brun en travers. - \%. Jn. C. Bois, bruyères, prés. . . O. taché. ma aceata L.

\section{HYBRIDES SIGNALĖS ET A RECHERCHER}

$\times$ o. Gennarii Reichb. ; O. Morio $\times$ papilionacea Timb. - Prairie communale de Portet (Timbal).

$\times$ o. Debeauxii G. Camus; O. papilionacea $\times$ Morio Timb. et Marçais. - Collines d'Avignonet (Marçais). - An O. papilionacea var. ?

$\times$ o. hybrida Bœnngh. ; O. purpurea $\times$ militaris G.G. - Pech-D $\alpha-$ vid; prés, à Lacroix-Fulgurde (Timbal).

$\times$ O.Grenieri G. Camus; O. Simia $\times$ militaris Timb. - Prés, à Lacroix-Falgarde ('Timbal).

$\times$ o. Lacazei G. Camus ; Satrrium hircinum $\times 0$. Simia Timb. Prés, environs de Muret(Lacaze). - Vraisemblablement O. Simia var.

$\times$ o. parvifolia Chaub. ; O. coriophora $\times$ laxiflora Larambergue. Prés, le long du Touch, au-dessus de St-Martin(Noulet).

$\times$ o. alata Fleury; O. Morio $\times$ laxiflora Reut. - A rechercher là oi croissent les parents. 
Obs. - Il ne faut pas pertre de vue que quelques espèces d'Orchidées (O. Morio, purpurea, Serapias Lingua, etc.) sont susceptibles, même lorsqu'elles croissent isolément, de variations nomhreuses, Contrairement à l'opinion de Noulet. qui dit avoir observé une foule d'hybrides d'orchidées. j'estime que les produits adultérins sont extrêmement rares. Toutes les formes ci-dessus ont disparu des localités où elles avaient été rencontrées, et l'origine hybride de quelques-unes me paraît des plus douteuses.

\section{6 - OPHRYS L. -- Ophrys. - Pl. XV.}

1 - Divisions externes (sépales) du périgone d’un vert jaunâtre ou blanchâtre. .................... 2

- Divisions externes roses ou d'un blanc rosé. . . . . . . כ

2 - Labelle d'un beau jaune, surtout sur les bords, qui sont glabres, brusquement rétréci à la base. - \%. Av.-mai. R. Pelouses sèches des coteaux calcaires. Venerque, Pouvourville; Ste-Foix, bords de la Saune, Avignonet. . . . O. jaune. D. Iutea Cav.

- Labelle brun violet ou vert jaunatre. . . . . . . . . 3

3 - Labelle rétréci en coin à la base, à lobe médian brunâtre velouté, liilobulé (f. 29). - q. Mai. C. Prés secs.

- Labelle non rétréci en coin à la base. . . . . . . . . 4

4 - Labelle petit, orbiculaire, vert jaunâtre, pâlissant, velu sur les bords, glabre au centre. - 2. Ms-av. AR. Pelouses des coteaux argilo-calcaires de la Garonne et de l'A riège. (O. pseudospeculum

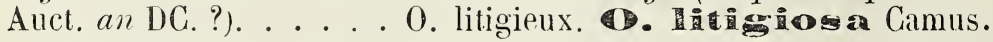

-- Labielle plus grand, ovale, brun foncé, à la fin livide; floraison plus tardive. - 2. Mai-jn. C. Bois, prés, pelouses. ... . . . . .

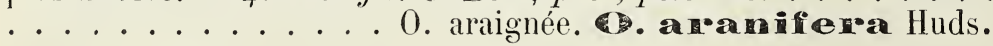

s - Labelle large, convexe, brun velouté, à lohe médian beaucoup plus grand que les latéraux, terminé par un appendice replié et caché en dessous ; gynostème à bec long. - \%. Mai-jn. C. Prés,

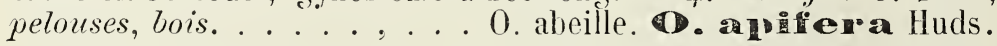

- Labelle à lobe médian subcylindrique, à appendice courbé en haut ou en avant (f. 30); gynostème à bec court. - \%. Ms-av. C. Pelouses, bois. ........ o. oiseau O.

\section{7 - GYMNADENIA R. Br. - Gymnadénie. - Pl. XV.}

Epi cylindrique, à bractées la plupart dépassant l'ovaire ; labelle à 3 lobes; éperon (f 31 ) plus long que l'ovaire. - 4. Jn-jtt. AR. Bois. Bonconne. (Oicliis L.). . . . . . . . . . . ....... G. à long éperon dir conopsea R. Br. 
8- CELOGLOSSUM Hartm. - Caloglosse. - Pl. XV.

Epi lâche ; labelle pendant, linéaire, à 2 lobes séparés par une dent (f. 32). - 4. Jn-jlt. AR. Prés humides, bois. Bouconne, bords du Touch. C. aux env. de Lanta (M. Marty). (Orchis viridis All.). . . . . . . . . C. vert. C. vinoide Hartm.

\section{9 - PLATANTHERA Richard. - Platanthère. - Pl. XV.}

- Eperon aigu, réfléchi ; fl. blanches, odorantes; anthères à loges rapprochées et parallèles (f. 33). - \%. Mai-jn. AC. Bois, bruyères, prés. (Orchis G. G.). . . . . . . . P. à 2 f. Wo bi follia Rchb.

- Eperon obtus, horizontal ; fl. d'un hlane verdattre, inodores; anthères à loges divergentes à la base. - q. Mai-jn. AC. Bois, lieux couverts. (Orchis montana Schmidt).

P. à fl. jaunâtres. Chlorantha Cust.

\section{0 - LIMODORUM Rich. - Limodore. - Pl. XV.}

Plante violacée ; fl. grandes (f. 34), en épi long. - \%. Mai-jlt. R. A été rencontré sur les rives de l'Ariège.

L. à f. avortées. 直. abonetivoum Swartz.

\section{1 - CEPHal anthera Rich. - Céphalanthère. - PI. XV.}

1 - Fl. rose lilacé (f. 3̋̈) ; bractées plus longues que l'ovaire ; labelle acuminé ; ovaire pubescent. - q. Jn-jlt. $\mathrm{R}$ Rives de l'Ariè-

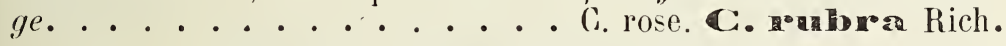

- Fl. blanches; ovaire glabre; labelle court, obtus. . . . . 2

2 - Bractées beaucoup plus courtes que l'ovaire ; divisions exter. nes du périgone aiguës ; f. étroites, linéaires-lancéolées. - \%. Av.$j n$. R. Bords des bois, coteaux rocailleux de la Garonne; Portet, à Clairfont. . . . . . C. à f. en glaive. C. ensifiolia Rich.

- Bractées égalant ou dépassant l'ovaire ; divisions externes obtuses; f. ovales ou ovales-lancéolées. - \%. Mai-jn. R. Bois des terrains calcaires ou argileux. Fenouillet, Clermont, Corronsac ; parc du Dr Vitrac, à Lanta (M. Marty).

\section{2 - EPIPACTIS Rich. - Epipactis. - Pl. XV.}

- Fl. d'un pourpre foncé; bractées toutes plus courtes que les fl. ou les infres à peine plus longues. - 2. Jn-jlt. R. Bois, saussaies de l'Ariege et de la Garonne. . E. rouge. a a - Fl. gris verdattre en dehors, rougeâtres en dedans (f. 36); 
bractées infres bien plus longues que les fl. - \%. Jlt-at. AC. Saussaies des bords de la Garonne et de l'Ariège.

E. à larges f.

$$
\text { 13. - LISTERA R. Br. - Listera. - Pl. XV, f. } 37 .
$$

Grappe longue, grêle; bractées courtes. - \%. Mai-jn. AR. šaussaies de la Garome et de l'Ariège. . L. ovale. I. ovata R. Br.

\section{4 - SPIRANTHES Rich. - Spiranthe. - Pl. XV, f. 38.}

Tige munie de bractées engaînantes; f. radicales en rosette latérale. - 4. At-oct. C. Pelouses sëches des terrains argilo-calcaires. ......... S. d'automne. soumanalis Rich.

\section{GV. - RO'}

Fl. hermaphrodites, en épi ; périgone i 4 divisions; $1,2,4$ étamines. 1 Potamogeton.

Monoïrque; fl. axillaires, solitaires ; périgone nul ; 1 étamine . . . . 2 Zannichellia.

\section{1 - POTAMOgETON Tournef. - Potamot. - Pl. XV.}

1 - F. (au moins les supres) ovales, oblongues ou lancéolées. . 2 - F. toutes très étroites, linéaires. . . . . . . 6

2 - F. pétiolées, les sup ${ }^{\text {res }}$ flotlantes, + ou - coriaces, arrondies à la base, diflérentes des l. submergées; akènes gros, verdattres, à carène obtuse. - \%. Jlt-spt. G. Eaux stagnantes. . . . . . • •

- F. toutes submergées et de même forme, minces. . . . . 3

3 - F. entières, non crispées, alternes, sauf les florales. . . . 4

- F. denticulées, un peu embrassantes. . . . . . . . ๖

4 - F. longuement lancéolées, aiguës ou mucronées, de 2-6 cm. de large, épi de 4-6 cm. de long. - భ. Jn-at. C. Eaux couranteset stagnantes. . . . . . . . . P. luisant. Heren L.

- F. ovales-obtuses, embrassantes, de 15 -30 mm. de large (f. 39) ; épi de $1-3 \mathrm{~cm}$. de long. - צ. Jn-at. AC. Eaux courantes.

๖- F. alternes, oblongues, ondulées-crispées ; épi làche, de 10$15 \mathrm{~mm}$. de long; akènes à bec long. - భ. Jn-spt. C. Eaux courantes el stagnantes. . . . . . P. crispé. F. ciopan L.

- F. toutes opposées, ćlargies-embrassantes (f. 40) ; épi ovoïdeglobuleux; akènes mucronés. - \%. Jn-at. CC. Canaux, rivières, ètangs. . . . . . . . P. dense. P. densus L. 
6 - F. non engaînantes, larges de $1 \mathrm{~mm}$. - \%. Jn-at. C. Fossés, mares, canaux. . . . . . . . F. fluet. P. pusilleus L.

- F. à base longt tubuleuse-engainante, les sup res formant pinceau quand on les sort de l'eau. - భ. Jn-at. C. Eaux courantes et stagnantes. . . . . . . P. pectiné. P. pectinatum L.

\section{2 - ZANNICHELLIA Michx. - Zannichellie. - Pl. XV.}

Tiges filiformes, rameuses ; f. linéaires; stipules membraneuses. — భ. Jn-spt. Eaux stagnantes ou courantes. . . . . . . . . . Z. des marais. Z. pa $\mathbf{l}$ utio $\mathrm{t}$ L.

Style court; stigmate en bouclier ; akènes brièvement pédicellés (f. 41 ) - AC. . . . . . . . . . z. repens Boenngh.

\section{CVI. - N A Cínes Link.}

\section{CAULINIA Willd. - Caulinie. - Pl. XV.}

Tiges diffuses, rameuses-dichotomes ; f. étroites $(1 / 2 \mathrm{~mm}$. de large), dentées (f. 42); fl. sessiles, en glomérules ; 2 styles. - \&. Jlt-spt. AC. Eaux courantes. Canal de Brienne, la Garonne. (Nä̈as minor All.). . . . . . C. lragile. C. i gogilis Willd.

\section{CVII. - LEER CIAES Dumort.}

\section{LEMNA L. - Lentille d'eau. - Pl. XV.}

1 - Frondes planes, suborbiculaires, de 巳̃ mm. de large (f. 43), brun rougeâtre en dessous et portant un faisceau de fibres radicales. - (1). Mai-jn. R. Eaux stagnantes; bords de la Garonne, Ondes, Braqueville. . . I. à plusieurs racines. T. polynolniza $\mathrm{L}$.

- Frondes rertes ou blanchâtres en dessous, ayant 1 seule fibre radicale .................... 2

2 - Frondes hémisphériques et blanchâtres en dessous, de $2 \mathrm{~mm}$. de large; fruit à 2-7 graines. - (1). Av.-jn. AR. Fossés, aux Minimes (Timbal). . . . . . . . L. gonflée. L. cullolba L.

- Frondes planes sur les 2 faces, vertes ; fruit monosperme, indéhiscent.

3 - Frondes transparentes, elliptiques-lancéolées, de 2-3 mm. de large, atténuées en pétiole, réunies 3 à 3 (f. 44). - (1). Av-jn. G. Eaux vives et tranquilles.. . L. à 3 pointes. H, tris ahea L.

- Frondes ovales ou suborbiculaires, larges de $2 \mathrm{~mm}$. - (1). Av.-jn. CG. Eaux stagnantes. . . . . L. naine. C. minor- L. 


\section{CVIII. - ARTOHDLES Juss.}

\section{ARUM Tournef. - Gouet. - Pl. XVI, f. 1.}

F. hastées-sagittées, veinées de blanc, poussant avant l'hiver; spadice à massue jaune. - \%. Av.-mai. CG.Lieux couverts, haies, broussailles. . . . . . . G. d'Italie. A. ittalieum Mill.

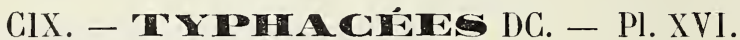

Fl. en épis brunâtres, cylindriques, compacts (f. 2); f. engaînantes; tige de 1-2 m.. . . . . . . . . . . . . . 1 Typha.

Fl. en capitules globuleux écartés, les supres mâles (f. 3). . . . . . .

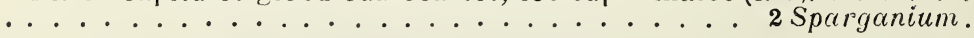

\section{1 - TYPHA Tournef. - Massette. - Pl. XVI.}

- F. planes, glaucescentes ; épi mâle et épi femelle contigus, ce dernier brun nois', à soies blanchâtres. - భ. Jn-jlt. AC. Mares, étangs. . . . . . . . M. à larges f. T. Matifolia L.

- F. plus étroites, un peu en gouttière vers leur base, vertes ; épis distants (f. 2), le femelle roux, à soies un peu roussâtres. — $\nsucc$. Jn-jlt. - AR. Eaux stagnantes. Env. cle $T$.

M. à f. étroites. T. angusisifólia $\mathrm{L}$.

\section{2 - SPARGANIUM Tournef. - Rubanier. - Pl. XVI.}

Capitules en panicule-étalée (f. 3) ; fruit sessile, brusq ${ }^{t}$ resserré au sommet. - భ. Jn-at. C. Bords des eaux, fossés.. . . . . . . . . R. rameux.

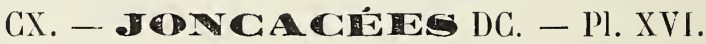

Capsule à 3 loges, à graines nombreuses ; f. glabres, + ou - cylindriques, parfois réduites à des gaînes. . . . . . 1 Juñ;us.

Capsule à 1 loge, à 3 graines (f. 10); f. planes, ordint poilues . . . .

\section{JUNCUS Tournef. - Jone. - Pl. XVI.}

1 - Inflorescence latérale, en cyme dépassée par une lıractée qui continue la tige ; f. réduites à des gaìnes radicales. . . . . . 2

- Inflorescence terminale ; des feuilles caulinaires ou radicales.

2 - Tiges vertes, striées, à moelle continue ; inflorescence compacte, brunttre ; 3 étamines ; gaînes radicales roussattres, non lui- 
santes. - भ. Jn-at. C. Lieux humides, fossés.

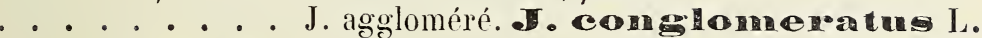

- Tiges vertes, non striées, à moelle continue; inflorescence lâche, verdâtre, à rameaux diffus; 3 étamines. - \%. Jn-at. CG. Lieux humides. . . . . . . . . J. ample. F. efrusus L.

- Tiges glauques, striées, à moelle interrompue; inflorescence lâche, verdâtre ; 6 étamines ; gaînes luisantes, d'un pourpre noir. 2. Jn-jlt. AC. Lieux lumides, canaux. .

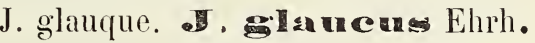

3 - F. toutes radicales, courtes ; tiges filiformes, de $2-8 \mathrm{~cm}$; 3-8 fl. brunes en glomérule ord ${ }^{t}$ solitaire et dépassé par une bractée foliacée (f. 4). - (1). Mai-jn. R. Fossés lumides. Gienade, bois de la Marianne (Noulet). . . J. en tête. can to tons Weig. — Tige plante annuelle, à souche grêle, fibreuse; tige de $1-3$ leuillée ; plante vivace, à souche rampante.

4 - Capsule oblongue, (de 4 mm. sur 2) ; gaine des l. non auriculée (f. 5, 6). - I). Jn-spt. CG. Lieux lumides, salles des rivières.........J. Jes crapauds. Dafoun L.

- Capsule subglobuleuse, obtuse, de $2 \mathrm{~mm}$. de long ; gaine des f. auriculée. - (1). Jn-sept. C. Lieux humides, sentiers cles bois.

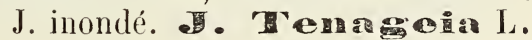

$\check{\zeta}-\mathrm{F}$. cloisonnées, paraissant noueuses sous la pression des doigts; fl. par 4-12, en glomérules.

- F. non cloisonnées, sans noeuds apparents ; fl. solitaires ou par 2-3 ; tiges dressées, comprimées ; divisions du périgone obtuses; capsule subglobuleuse, bien plus longue que le périgone. - 4 . Jn-at. AG. Lieux humides.

J. comprimé. ocom Jacq.

6 - Tige filiforme, souvent couchée, + ou - radicante, de 1-3 dm., parfois flottante ; cyme lâche ; capsule obtuse, dépassant un peu le périgone. - 4. Jn-spt. AR. Mares, lieux humides. Bou-

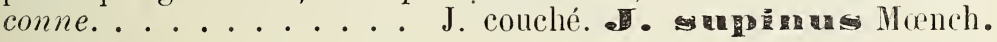

- Tige assez forte, ascendante ; capsule + ou - aiguë. . . . 7

7 - Fleurs d'un blanc verdâtre, à divisions toutes obtuses; rameaux étalés-divariqués. - \%. Jn-at. C. Lieux humides, bords des

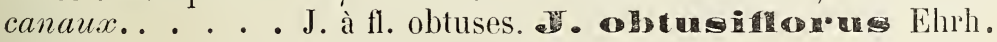

- Fl. brunâtres ; divisions extérieures du périgone aiguës. • 8

8 - Divisions du périgone toútes égales, non recourbées au sommet $(f .7,8)$; tiges de 1-6 dm., couchées, ascendantes ou presque dressées, souvent radicantes. - \%. Jn-at. CG. Lieux lumides .

..... J. à fruits brillants. J. Iame pecanders Ehrh. 
- Divisions du périgone inégales, les internes plus longues et à pointe étalée ou recourbée; tige de 4-8 dm., dressée. - 4. Jn-at. AC. Bords des eaux. J. des forêts. sil onateus Reichard.

\section{2 - LUZULA DC. - Luzule. - Pl. XVı.}

1 - Cyme formée de fl. solitaires; f. larges de $3 \mathrm{~mm}$. au plus ; capsule ovoüde-aiguë; pédoncules fructilères dressés. - భ. Av.-mai.

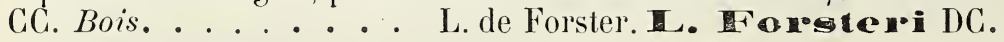

- Cyme formée de glomérules ou d'épis . . . . . . . 2

2 - Cyme lâche, très décomposée, à glomérules de 2-4 fl. ; tige de 4-6 dm. ; f. grandes, linéaires-lancéolées. - భ. Av.-jn. C. Bois, lieux couverts et lumides. . L. à larges f. 直. Maxima DC.

-... Cyme formée d'épis multiflores compacts ; f. linéaires. • . 3

3 - Racine rampante ; tiges de 1-2 dm., presque solitaires; 3-气̆ épis étalés ou penchés; anthères bien plus longues que les filets (f. 9, 10). — \%. Av.-mai. CC. Bois, prés secs.... . . . . . .

- Racine fibreuse ; tiges de $150-40 \mathrm{~mm}$., en toulles ; 4-10 épis (f. 11) dressés ; anthères égalant les filets. - భ. Mai-jn. C. Bois, bruyères. . . . . . . L. multiflore. L. me undirilona Lej.

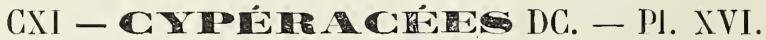

1 - Fl. unisexućes ; akène renformé dans un utricule simulant in péricarpe $\{$ f. 34, 35)............ 5 Carex.

- Fl. hermaphrodites............... 2

2 - Akènes très longuement déjassés par un faisceau de soies blanches (f. 14)..........2 Er iophorum.

- Akènes nus, ou soies plus courtesque les écailles. . . . . 3

3 - Epillets à écailles imbriquécs sur 2 rangs olposés, groupés en corymbe ou en capitule (f. 12). . . . . . . 1 Cyperus.

- Epillets à écailles imbriquées sur plusieurs rangs . . . . . 4

4 - Style renflé en bulbe à la base ; tige nue, portaut un seul épillet (f. 17). ........... 4 Eleocharis.

- Style non renflé à la base ; tige portantplusieurs éf)illets (f. 16).

3 Scirpus.

1 - CYPERUS Tournef. - Sonchet. - Pl. XVI.

1 - Souche rampante, horizontale ; tige de $6-10 \mathrm{dm}$.; f. de 4-10 mm. de large; épillets lrun rougeâtre, rapprochés en éventail sur des pédoncules inégaux, en ombelle composée ; ombellules à pédoncules tous dressés ; involncre à 3-ŏ l. dressées. - \%. Mai-spt. CC. Lieux humides, bords des eaux. . . . S. long. C. Homgug L.

Epillets bruns; les 2 péctoncules inf. des ombellules étalés à angle 
droit ; involucre à $3-4$ feuilles dont 2 très longues, réfléchies. - Jlt-at. R. Canal du Midi, au Béarnais (Timbal). . . . . . c. badius Desf.

-- Souche fibreuse; tiges de $ّ$-3ٌ $\mathrm{mm}$., annuelles. . . . . . 2

2 - Epillets brunâtres (f. 12); 3 stigmates (f. 13); akènes obovoüdes-trigones, rétrécis à la hase. - (1). Jn-spt. AC. Lieux humides, sablonneux. . . . . . . . S. brun. C. Insess L.

- Epillets jaunâtres ; 2 stigmates; akènes obovales-orbiculaires, comprimés. - (1). Jn-spt. AC. Lieux lumides, sablonneux. . . . S. jaunatre. flavescens $\mathrm{L}$.

\section{2 - ERIOPHORUM L. - Linaigrette. - Pl. XVI.}

Plusieurs capitules pédonculés, à pédoncules glabres, rudes ( $f$. 14). - Ұ: Mai-jn. R. Marais. Bouconne.

L. à larges f. E. Iatifolium Hoppe.

\section{3 - SCIRPUS Tournef. - Scirpe. - Pl. XVI.}

1 - Tige cylindrique ou un peu comırimée. . . . . . 2 2

— Tige à 3 laces sur toute sa longueur. . . . . . . .

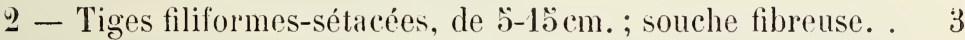

- Tiges assez grosses, non filiformes, de $\breve{5}-20 \mathrm{dm}$. ; souche rampante. .

3 - Akènes striés en long; 1-3 épillets dépassés par une bractée qui continue la tige (f. 10). - (1) ou \%. Jn-at. AC. Lieux sa-

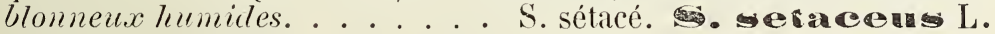

- Akènes lisses ; épillets souvent solitaires, peu ou point dépassés par la bractée. - (1) ou \%. Jn-at. AR. Marais de la Garonne, à Ondes. . . . . . . . . S. de Savi. a vi Seb. et M.

4 - Tige molle, compressible, cylindrique, de 1-2m.; fl. en épis ovoïdes, bruns. - q. Jn-at. AC. Mares, bords des eaux, le long de la Garonne. . . . . . . . S. des étangs. Ia caustrois I.

- Tige ferme, dure, de $5-14 \mathrm{dm}$., munie à la base de f. canaliculées; fl. en capitules globuleux. - \%. Jlt-at. C. Prés humides, bords des eaux. . . . . . S jonc. Kanoselnoenus L.

$\check{5}-$ Epillets loruns, de $1-4 \mathrm{~cm}$. de long, en glomérules, les uns sessiles les autres pédonculés (f. 16). - ฯ \% Jt-spt. AC. Marais, fossés, bords des eaux. Rives de la Garonne.

$S$. maritime. manoirimus $\mathrm{L}$.

- Epillets vert brunâtre, de 3-6 mm. de long, en panicule ombelliforme décomposée ; involucre à $3-\breve{b}$ bractées loliacées. - q. Maijlt. R. Lieux lumides, boids des eaux. Braqueville. 


\section{4 - ELEOCHARIS R. Br. - Eléocharis. - Pl. XVI.}

- Souche rampante ; 2 stigmates ; les 2 écailles infres embrassant chacune la moitié de la base de l'épillet (f. 17); akènes jaunâtres (f. 18, fl.). - ¥. Jn-at. CC. Lieu.x marécageux, fossés. .

E. des marais. E. palug tois R. Br.

- Souche fibreuse ; 3 stigmates ; l'écaille infre de l'épillet embrassant toute la base de celui-ci (f. 19); akènes brunâtres. - *. Jn-at. R. Bords des eaux. Canal du Midi, en amont des Demoiselles.

E. multicaule. E. multicaulis Sm.

L'E. acicularis R. Br., à tiges nombreuses, capillaires, de $3.12 \mathrm{~cm}$, portant un éri terminal petit. ovoïde, à 3 stigmates, croît aux bords du Tarn et est à rechercher aux bırds de la Garome. - Jn-at. Annuel.

5 - CAREX Mich. - Carex. - Pl. XVI.

1 - Tige terminće par un seul épi composé d'épillets (f. 20) unisexués ou à fl. les unes mâles, les autres lemelles ; 2 stigmates. 2

- Tige portant plusieurs épis distincts, unisexués, les mâles au sommet, les femelles axillaires (f. 3̋ั) . . . . . . 10

2-Rhizome horizontal, longuement traçant. . . . . . . 3

- Souche courte, ordin ${ }^{t}$ gazomnante, verticale ou oblique, rart ${ }^{\text {tun }}$ peu rampante $(6)$.

3 - Epillets nombreux, ovoüdes, formant un épi compact, allongé, les intermédiaires mâles, les autres femelles. - q. Mai-jn. R. Marais. Ondes, bords de la Garonne. . . . . . . . . . .

C. distique. C. A

- 3-6 épillets, mâles au sommet, rapprochés en épi ovoüde (f. 20); tige grêle, à f. de $1-2 \mathrm{~mm}$. de large ; utricules couverts de nervures. —. Mai-jn. C. Piés lumides, fossés, marécages . . . . . . . C. divisé. C. divió Huds.

4 - Epillets à fl. mâles au sommel, femelles à la base . . . .

- Epillets à fl. fenelles au sommet, mâles à la base. . . . 9

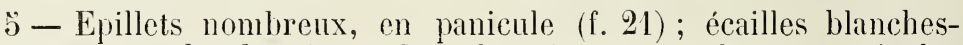
scarieuses aux bords; tiges à 3 angles aigus et scabres; utricules un peu éialés. - 4. Mai-jn. AC. Prés tourbeux, bords des eaux. .

— Epillets en épi étroit. . . . . . . . . . . . 6

6 - Utricules dressés à la maturité, luisants, munis d'un bec fort: écailles à bordure blanche ; tige grôle, de 3-6 dm., scabre au sommet seul $;$ f. très étroites ; souche courte, un peu rampante, non gazonnante. - q. Mai-jn. AC. Bords des eaux. Canal du M. . . . ........ C. arrondi. C. Iomotiuseula Good. 
- Utricules étalés-divergents à la maturité ; souche gazonnante.

7 - Tige robuste $(3-8 \mathrm{dm}$.), à 3 angles aiğus, à faces concaves, à f. planes ; épillets nombreux (f. 22); écailles à nervure verte, excurrente (f. 23). - \%. Mai-ju. CG. Fossés, lieux humides. . . . . .

- • • • . . . . C. des renards. C. velpina L.

- Tige grêle, à laces planes ou convexes. . . . . . 8

8 - 4-8 épillets rapprochés en épi oblong, + ou - dense ; écailles roussâtres. - 4. Mai-jn. C. Bois humides, fossés, prés. . . . . . . . . . . . . C. rude C. mhnorea L.

— 4-כ̃ épillets infrs très espacés, les supérieurs rapprochés (f. 24); utricules (I. 2‡) peu étalés ; écailles blanchâtres. - Ұ. Mai-jn. C. Prés humides, bois. . . . . C. écarté. C: livulsa Good.

9 - Epillets verdâtres, les inférieurs très écartés, munis chacun d'ıne longue bractée foliacée dépassant la tige. - \%. Mai-jn. C. Lieux humides et couverts. . . . . C. espacé. C. emota L.

- Epillets brun roux, rapprochés en épi court, à bractées courtes ; utricules à bords membraneux. - భ. Mai-jn. R. Marécages, fossés. Braqueville, Tournefeuille.

10 - 2 stigmates (f. 26 , épi femelle); souche filseuse, gazonnante ; tige scabre ; İ.à gaìne fibrilleuse ; 1-2 épis mâles; utricules à bec court (f. 27). - q. Mai-jn. R. Bords des eaux. St-Martin-du-T.

C. raide. Cinera Good.

- 3 stigmates.

11 - Utricules pubescents ou tomenteux sur les faces. . . . 12

- Utricules à faces glabres (rart un peu pubescents, mais alors sans bec ; f. glauques). . . . . . . . . . 15

12 - F. poilues particult sur les gaines; 2-3 épis mâles fauves, à écailles velues ; 2-3 épis femelles espacés, vert pâle, à écailles aristées. - \%. Mai-jlt. CG. Prés, lieux sablonneux lumides. . . .

C. velu. C. Hinera $\mathrm{L}$.

Epi mâle glabrescent; f. et gaines glabrescentes. v. hirtiformis Pers.

- F. glabres ; 1 seul épi mâle.

13 - Souche fibreuse, gazonnante ; f. aussi longues que les tiges; épi mâle obovale, jaunâtre ; $2-3$ épis femelles, l'infr un peu pédonculé. - Y. Av.-jn. C. Bois, lieux couverts. Lauragais, Venerque.

- Souche rampante.

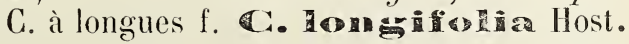

14 - F. inf. réduites à des gaines brun rougeâtre; épi mâle sublinėaire ; utricules subglobuleux ; bractée infre étalée. - $\%$. 
Mai-jn. AG. Lieux humides, bois, prés.

C. tomenteux. C. comentosa $\mathrm{L}$.

- Tige nue jusque près de la base ; épi mâle en massue (f. 28) ; utricules 2 fois plus longs que larges (f. 29); bractées infres dressées, à gaine membraneuse. - 4. Av.-jn. CG. Lieu.x herbeux. (C. procox Jacq.) . . . . . . . . . C. printanier. C. verona Chaix.

15. Utricules sans bec ou à bec très court et tronqué (f. 30). . 16

— Utricules prolongés en bec. . . . . . . . . 18

16 - 2-3 épis mâles au moins en partie. Souche stolonifère; 1 . glauques; épis femelles cylindriques, pédonculés ; écailles noirátres. - \%. Mai-jn. CG. Prés, bois humides, coteaux argileux. .

C. glanque. C. Slanca Murr.

- 1 seul épi mâle, fauve ou verdâtre. . . . . . . . 17

17 - Souche fibreuse ; f. pubescentes; bractées à peine engaìnantes ; 2-3 épis femelles vert pâle, denses (f. 30). - \%. Mai-jn. AC. Bois, prés tumides. . . C. pâle. C. pallescens L.

- Souche rampante ; bractées à longue gaine ; 3-ŏ épis femelles linéaires, verdâtres, penchés, à fleur's lâches; utricules atténués au sommet, à bec nul ou peu apparent. - 4. Ju-jll. R. Bois frais, Venerque, Balma, Bouconne.

18 - Utricules obovoïdes, renflés, brusq terminés en un bec court, cylindrique (f. 31); Ґ. glauques; épi mâle brun ; 1-3 épis femelles espacés, un peu làches (f. 32); tige de 2-4 dm., lisse. - $\%$. Mai-jn. AC. Prés, pâturages lumides. .

C. panic. C.

- Utricules à bec + ou - allongé et + ou - comprimé. . 19

19 - Epi mâle solitaire. . . . . . . . . . . . . . 20

— Plusieurs épis màles ; souche rampante . . . . . . . . 26

20 - Epis femelles peu ou point pédonculés, dressés. . . . . 2!

- Epis femelles longuement pédonculés et penchés à la maturité. .........................

21 - Epis femelles pâles, jaunâtres, ordint rapprochés; utricules divergents à la maturité; souche gazonnante. . . . . . . . . 22

- Epis femelles brunâtres, écartés ; fruits dressés à la maturité.

22 - Utricules renflés, jaunes à la maturité, très étalés, à bec rude, long, un peu courbé et réfléchi ; bractées à la fin réfléchies. 4. Mai-jlt. AR. Prés hunides. Tallées du Tarn et de l'Hers. . . 
- Epis femelles plus retits, les supróaglomérés sous le mâle: utricules plus petits, à bec droit. - Mai-at. Lieux humides. (A recher'eher).

C. Ederi Ehrh.

23 - Epis femelles ovoïdes-oblongs ; écailles ovales-aiguës; souche rampante ; écailles de l'épi mâle blanches-scarieuses aux bords. - 4. Mai-jn. R. Marais de Commères, près de Grizolles; Ondes.

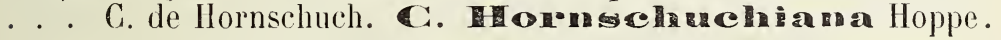

- Epis femelles oblongs-cylindriques; écailles ovales-mucronées ; utricules verdâtres, striés ou ponctués de brun ; souche fibreuse. 4. Mai-jn. AC. Prés lumides. . . C. distant. C. Alistans L.

24 -.. Utricules atténués en bec court dépassant l'écaille brune ; tige de 7-12 dm., trigone : f. de $1 \mathrm{~cm}$. de large ; 3-6 épis femelles ayant ord ${ }^{t}$ plus d'un dm. de long. - \%. Mai-jn. C. Lieux lummides, ruisseaux. (C. maxima Scop.).

C. pendant. C. De di nads.

- Utricules à bec allongé; épis femelles n'alteignant pas $1 \mathrm{dm}$. de long. . . . . . . . . . . . . . . . 2.

20 - Tige lisse (saul au sommet); f. de $3-6 \mathrm{~mm}$. de large ; épis femelles linéaires, à fl. lâches (f. 33), à écailles blanc verdâtre, lancéolées, un peu plus courtes que l'utricule (f. 34). - \%. Mai-jn.

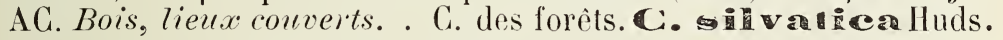

- Tige très rude sur les angles, de $4-8 \mathrm{dm}$. f f. de $6-10 \mathrm{~mm}$ de de large; épis femelles denses, rapprochés de l'épi mâle ; écailles linéaires, vertes, égalant les utricules verdâtres. - \%. Mai-jlt. AG. Fossés, bords des eailx.

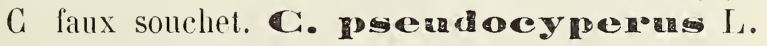

26 - Epis mâles grêles, jannátres, linéaires ; tige scabre, de 3-ŏ dm. ; 1 . vertes, de 4-6 mm. de large ; 2-3 épis femelles denses, à écailles brun pâle (f. 3ä); utricules jaunâtres, enflés (f. 36). — భ. Mai-jlt. AC. Prés humides, bords des eaux, canaux.

C. en vessie. C.

- Epis mâles robustes, d'un brun noir ; f. glaticescentes; utri-

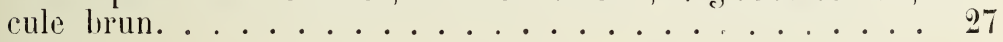

27 - Ecailles infres des épis mâles obtuses ; utricule comprimé, de $4 \mathrm{~mm}$. de long. - 4. Mai-jn. C. Bords des canau.x, fossés. . C. des marais. C. Ipatedosa Good.

- Ecailles des épis máles acuminées-aristées (f. 37) ; utricule (f. 38) à faces convexes, de 气̆ mm. de long. - \& Mai-jn. C. Bords des eaux, marais, canaux. . C. des rives. C.

\section{GXII. - G}

1 - Fl. unisexuées, les mâles en épillets formant une panicule terminale, les fernelles en épis axillaires. . . . . 1 Ze.

- Fl. hermaphrodites, parfois accompagnées de fl. unisexuées ou arortées. 
2 - Fl. en tête courte, arrondie et hérissée de pointes coriaces (Pl. XVIII, f. 4).......... 32 Echinaria.

- Epillets disposés en grappe ; glume supérieure grande, convexe, hérissée de petites pointes crochues (PI. XVII, f. 5). . .

7 Tragus.

- Fl. en épi ou en panicule, glabres ou velues, mais sans pointes crochues................ . . . .

3 - Fl. en épis linéaires rassemblés au sommet de la tige ct comme digites (PI. XVII, f. 8)............ 4

- Fl. non comme ci-dessus. ............. . 6

4 - Epis velus, soyeux, munis de longues arêtes ; épillets géminés, l'un sessile, l'autre pédicellé (P1. XVII, f. 1). . 2 Andropogon.

- Epis glabres ou peu velus. . . . . . . . . . 5

5 - Epillets et caryopses comprimés latéralement; racine ram-

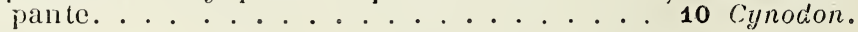

- Epillets el caryopses comprimés par le doș (Pl. XVII, f. 4). . .

6 - Ejpllets nou insérés dans des excavations du rachis, disposés en épi ou en panicule. . . . . . . . . . . . . 7

- Epillets sessiles, en épi, insérés dans des excavations du rachis (Pl. XVIII, f. 33); stigmates sessiles. . . . . . . 43

7 - Epillets sessiles, disposés en éji ou très brièyt pédicellés et formant une panicule étroite simulant un épi. . . . . 8

- Epillets ordint manifestement pédicellés, disposés en panicule diffuse................ . . 18

8 - Epi unilatéral, grêle ; glumes tronquées, dépassant la fleur ; tiges de 2-10 cml, filiformes (P1. XVII, f. 16). . 16 Mibora.

- Epi ovoïde ou presque cylindrique; tiges non filiformes. . . 9

9 - Epillets à 1 seule fl. fertile. . . . . . . . . . . . 10

- Epillets ayant au moins 2 fl. fertiles. . . . . . . . 15

10 - Epillets munis d'un involucre unilatéral formé de soies raides et scabres (I1. XVII, f. 2); glumes mutiques.. . 3 Setaria.

- Epillets défourrus de soies scabres. . . . . . . . 11

11 - 1 seule glumelle, munie d'une arête rers la base ; épi compact; glumes égales (PI. XVII, f. 14, 15). . . . . 15 Alopecurus.

- 2 glumelles; souche fibreuse. . . . . . . . . . 12

12 - Íl. fertile accompagnée de 2 fl. rudimentaires réduites chacune à une glumelle aristée (Pl. XVIl, f. 9); glumes inégalos. . .

11 Anthoxunthum.

- Fl. fertile non accompagnée de fl. réduites à une glumelle aristée................. . 13

13 - Glumes égales, munies chacume d'une longue arête ; épi barbu (Pl. XVII, f. 2s)...........24 Polypogon.

- Glumes égales, plus longues que les fl. aiguës ou mucronées. ........................ 11

- Glumes inégales, acuminées, ayant à leur base un renflement blanchâtre ; épi atténué aux 2 bouts (PI. XVII, f. 26).

23 Gastridium.

14 - Glumes acuminées, à carène ailée ; épi oroïde (Pl. XVII, f. 11) ou + ou - cylindrique; 2 styles très longs. . 13 Phalaris.

- Glumes mucronées, à carène non ailée ; épi cylindrique. compact (PI. XVII, f. 12); 2 styles courts. . . . . 14 Phleum. 
15 - Epillets fertiles accompagnés d'épillets stériles formés le pailleltes fortt mucronées ou aristées" (PI. XVII, f. 18, 19).

17 C'ynosurus.

- Epillets tous fertiles ou à quelques fl. stériles non comme ci-

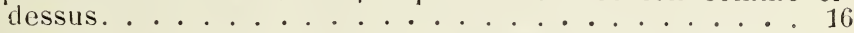

16 - Glumelle infre portant de longs poils soyeux (PI. XVIII, f. 7). . ............. . 35 Meliea.

- Glumelles glabres ou glabrescentes.

17 - Glumelle inf. terminće par une arête au moins aussi longue qu'elle (Pl. XVIII, f. 11); grappe unilatérale. . 38 Vulpia.

- Glumelle inf. mutique ou à arête courte ; épi rameux ; glumes carénées (Pl. XVIII, f. 5). ........ 33 Kickerix.

18 - Epillets à 1 seule fleur, ferlile. . . . . . . . . . . 19

- Epillets à 2 fleurs, l'une fertile, l'autre stérile, màle. . . . 22́

- Epillets à 2 ou plusieurs fl. fertiles . . . . . . . . . 27

19 - Glúmes nulles ; panicule lâche, à épillets comprimés par le côté (Pl. XVII,f. 7) ; glumelles égales, mutiques. 9 Leersia.

- 2 glumes; glumelles ilégales. . . . . . . . . . . . 20

20 - Glumelles entourées à leur base de poils soyeux qui les dépassent, l'infre aristée. (PI. XVII, f. 21); panicule grande, assez ample...........20 Calamagrostis.

- Glumeiles glabres ou à poils bien plus courts qu'elles.

21

21 - Epillets géminés ou terués, le central sessile, hermaphrodite, aristé, le ou les latéraux pédicellés et mâles; glumes velues. (ऐ!. XVII, f. 6).......... 8 Sorghum.

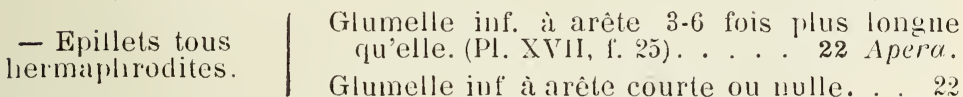

22 - Glumelle infre un peu velue à sa base ; panicule allongće ; clume infre dépassant la fleur ; épillets de 2 rim. de long.

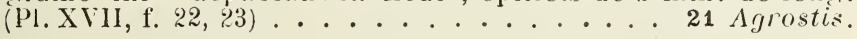

- Glumelle infre glabre, luisarte. . . . . . . . . . 23

23 - Panicule dense. resserrée avant et après la floraison ; glumes carénées (Pl. XVII, f. 10). . . . . 12 Baldingera.

- Panicule très lâche; glumes convexes sur le dos (P). XVII, f. 30$)$............... 25 Milium.

24 - Epillets hérissés ; f. glabres et saus ligule ; épis unilatéraux, format une pauicule raide (P1. XVH, f. 3).. 5 Echinochloa.

- Epillets glabres | mutiques............... . 25

ou glabrescents, aristés (les mâles); épillets à 2 fleurs. . . 26

25 - Panicule unilatérale, composée de 15-30 épillets; glumes riolacées (Pl. XVIlI, f. 8)......... 35 Melica.

- Panicule làche, à plus de 30 épillets, à 11 verdâtres; stigmates violets. . .......... 4 Panicum.

26 - Arêtes incluses ou déprassant peu l'épillet; glumes presque égales (PI. XVII, f. 34, 35)......... 28 Holeus.

- Arêtes tordues-genouillées. dépassant longuement l'épillet; glumes très inégales (Pl. XVIII, f. 1)... 29 Arrhenaterum.

27 - Fl. entourées de longs poils soyeux; panicule ample ; épillets à $2.7 \mathrm{fl} \ldots \ldots . \ldots 28$ 
- Fl. entourées de poils courts ou dépourvues de poils à leur

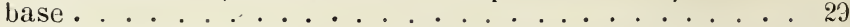

28 - Glumes inégales, plus courtes que les fl. ; glumelle inf. entière (Pl. XVII, f. 20). ......... 18 Phragmites.

- Glumes égales, aussi longues que les fl. ; glumelle inf. tridentée. ............... 19 Arundo.

29 - Glumelle inf. aristée. . . . . . . . . . . . 30

- Glumelle inf. mutique.............. . . 37

30 - Glumelle inf à sommet à arête genouillée. . . . . 31 + ou - échancré $\mid$ à alête droite......... 34

- Glumelle inf. à sommet entier, à arête courte (rarement plus

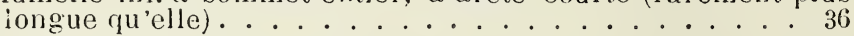

31 - Glumes à peu près égales. . . . . . . . . . . . . . . . . . . . . . . . 32

- Glumes manifestementinégales . . . . . . . . . 33

32 - Caryopse sillonné ; glumelle inf. bifide au sommet; épillets à 2 fl. sessiles (Pl. XVII, f. 31). . . . . . . 26 Air $\alpha$.

- Caryopse non sillonné ; glumelle inf. tronquée-dentée au sommet; épillets à $1 \mathrm{fl}$. sessile l'autre pédicellée. (PI. XVII. f. $32,33) . \ldots . . . .27$ Deschampsia.

33 - Caryopse velı, presque fusiforme, à face interue sillonnée (P1. XVIII, 1. 2). . . . . . . . . 30 Aven.

- Caryopse glabre, oblong, à face interne non sillonnéc (PI.XVIII, f. 3)................ 31 Trisetum.

34 - Glumes égalant l'épillet, qui a 4, 6 fl. (Pl. XVIIl, f. 6); caryopse ovale............. 34 Danthonire.

- Glumes plus courtes que l'épillet. . . . . . . . . 35

35 - Epillets condensés en glomérules compacts (Pl. XVIII, f. 10), unilatéraux, de $3-7$ fi........ 37 Dactylis.

- Epillets non condensés en glomérules, de 3-20 fl. (Pl. XVIII, f:14). ................. . 40 Bromus.

36 - Epillets en glomérules compacts, unilatéraux ; glumelle inf. carénée (Pl. XVIII, f. 10)....... 37 Dactylis.

- Epillets + ou - espacés ; glumelle inf. unn carénée, a dos arlondi, aiguë ou aristée (Pl. XVII!, f. 12, 13).. 39 Festuca.

37 - Glumes égalant l'épillet, (pui a 4, 6 fl. (Pl. XVIIJ, f. 6).

- Glumes plus courtes que l'épillet . . . . . . . . 39

38 - Glumelle inf. à dos arrolidi, non caréné . . . . . . . . 39

- Glumelle inf. à dos carénć . . . . . . . . . . . . 41

39 - Glumclle inf. très aiguë au sommet, souveut aristée. (Pl. XVIII, f. 12,13$)$; plantes vivaces . . . . . . . 39 Festuca.

- Glumelle inf. obtuse ou tronquéc au sommet . . . . . . . 40

40 - Glumes éqales ; épillets très mobiles, de 5-15 fl. distiques (Pl. XVIII, f 19;. . . . . . . . . . 43 Briza.

- Glumes inégales. $\mid \begin{array}{r}\text { Epillets à } 2 \mathrm{fl} \text { fertiles et à une fl. supre sté- } \\ \text { rile (Pl. XVIII, f. 9). . . . } \mathbf{3 6} \text { Molinia. } \\ \text { Epillets à 3-11 fl.;plantes glabres. des bords } \\ \text { des caux(Pl. XVIII, f. 16,17).. } 41 \text { Glyceria. }\end{array}$

41 - Ligule remplacée par des poils ; épillets comprimés latéralement (Pl. XVIII, f. 20), en pauicule très rameuse. 
- Ligule membraneuse . . . . . . . . . . . . . 4?

42 - Plante aquatique ; épillets biflores; glumelles presque égales, à 3 nervures (PI. XVIII, f. 25, 26).. . . . . . 46 Catabrosa.

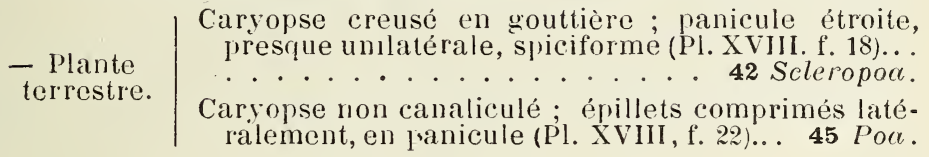

43 - Un seul épillet à cbaque excavation du rachis . . . . . . 4'

- 3 épillets uniflores à chaque excavation du rachis ; glumes et glumelle inf. aristées (Pl. XVIII, f. 2T). . . . 47 Hordeum.

44 - Epillets uniflores (fl. supre rudimentaire) ; épi cylindriquesubulé (Pl. XVIII, f. 34, 35), à axe fragile.. . . 56 Lepturus.

- Epillets à plusicurs fleurs . . . . . . . . . . 45

45 - Epillets à 1 seule glume (sauf le terminal); épi distique (PI. XVIII, f. 33). . ........... 55 Lolium.

- Epillets tous ì 2 glumes . . . . . . . . . . . . 46

46 - Epi compact. peu ou poist comprimé, subcylindrique. . . . 47

- Epi comprimé, distique ou unilatéral. . . . . . . . . 48

47 - Epillets à 2 fl. fertiles et une incomplète. . . . . 48 Secale.

- Epillets à 3-5 fi.; glumes ovales, ventrues. . . . . . . 48

48 - Glumes à 1 ou 2 carènes; glumelle inf mutique ou à 1 scule arête. ............... 49 Triticum.

- Glumes arrondies sur le dos, non carénées, à 1 ou plusicurs arêtes divergentes; glumelle inf.' à $2-3$ dents nues ou aristées. (Pl. XVIII, f. 28). . . . . . . . . 50 Egilops.

49 - Glumelle iıf. munie d'une arête genouillée (Pl. XVIII, f. 32).. ................. 54 Gaudinir.

- Glumelle inf. à arête droite ou nulle . . . . . . . . . 50

50 - Epillets sessiles, à 5-10 fl.; glumes presque égales (Pl. XVIII, f. 29). . . . . . . . . . 51 Agropyrum.

- Epillets brièvement pédonculés; glumes très inégales. . . 51

51 - Glumelie supre à sommet arrondi ; épi lâche, dıstique (Pl. XVIII, f. 30). ......... 51 Brachypodium.

- Glumelle supre à sommet bidenté ; épi grêle, distique ou unilatéral (Pl. XVIII, f. 31)......... 53 Nardurtıs.

\section{1 - ZEA L. - Maïs.}

On cultive le Z. mays L., originaire du Paraguay.

\section{2 - ANDROPOGON L. - Barbon. - Pl. XVII, l. 1 (épillet).}

丂ૅ-12 épis digités; racine traçante; f. en gouttière. - \%. Jlt-spt.

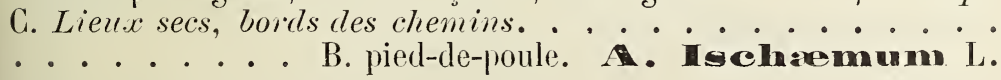

$$
3 \text { - SETARIA P. B. - Sétaire. - Pl. XVII. }
$$

1 - Soies non accrochantes, vertes ou violacées; glumelles pres- 
que lisses. - (I). Mt-spt. C. Lieux cultives.

S. verte. vinom P. B.

- Soies non accrochanles, d’un jaune poussitre (f. 2); glunclles ridées en travers. - (1). Jt-spt. AG. Lieux cultives.

- Soies accrochantes, vertes ou violacées; glumelles presque lisses. - (1). Jlt-spt. C. Lieux cultivés. . . . . . . . . . . .

S. verticillée. veroticillata P. B.

On cultive les $\mathbf{S}$. italica P. B., à inflorescence arquée-pencliée. à épillets munis de poils couts (Millet des oiseaux), et $\mathbf{S}$. germanica P. B., à inflorescence dressée, à épillets brunâtres, munis de lonğs poils (Mohor).

\section{4 - PANICUM L. - Panic.}

Pédicelles longs; épillets assez gros, mutiques; tige de $\breve{-10} \mathrm{dm}$. - (1). Jlt-at. (Mil, millet). Cultivé daus les Pyrénées; se rencontre aux bords de la Garome. Originaire de l'Inde.

P. millet. H. miliaceun $\mathrm{L}$.

ॐ - ECHINOCHLOA P. B. - Echinochloa. - Pl. XVII, f. 3.

Plusieurs épis unilatéraux; épillets + 011 - aristés; tige coudée, de 4-8 dm. - I). Jlt-spt. IC. Lieux cultivés, bords des eanr. (Panicum L.). . . . . . E. pied-de-coq. E. Chos-Gralli L.

$$
6 \text { - DIGITARIA Scop. - Digitaire. - Pl. XVII. }
$$

1-2 $\left(\operatorname{rat}^{4} 1,3\right)$ épis à fl. solitaires el alternativement disposées des deux còtés de l'épi. - \&. Jn-spt. C. Bords des eaux; banquettes du canal du Midi, rives du Tarn. (Paspalum Sw.; Panicum G.

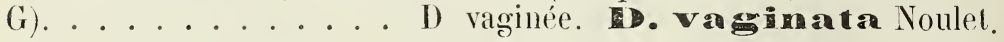

— $2-8$ épis, à fl. géminées.............. 2

2 - Tiges étalées; f. et gaines glabres; 2 -4 épis à épillets ovaleselliptiques (f.4); glume supre égalant la glumelle. - I). Jlt-oct. AC. Lieux cultivés, terres sablomeuses. (I). filiformis Kol.)

D. glabre. 甚

- Tiges redressées ; f. et gaines velues ; 6-8 épis + ou - violacés, à épillels lancéolés-oblongs ; glume suppre de moitié plus courte que la ghumelle. - (1). Jlt-oct. C. Champs cultivés, décombies. . . . . . . . . . . D. sanguine. 策。

\section{7 - TRAGUS Haller. - Bardanette. - Pl. XVII.}

Tiges de 10\%-30 cm., + ou - couchées ; grappe cylindrique, rougeâtre (f. ö, épillels). - I. Jn-at. R. Alluvions ile la Grarome. B. c'll grilppe. 'T. Hoacemosa Hall. 


\section{8 - SORGHUM Pers. - Sorgho. - Pl. XVll.}

Epillets la plupart mutiques (f. 6 ) ; tige de $8-100 \mathrm{dm}$. -- \%. Jloct. AR. Rives de la Garonne. . . . . . . . . . . ......... S. d'Alep. Inalopenso Pers.

On cullive les $\mathbf{S}$. vulgare Pers. (Millet a baluis) et $\mathbf{S}$. saccharatum Pers, à tige sucrée

$$
9 \text { - LEERSIA Sw. - Léersie. - P'. XVII, f. т. }
$$

Souche stolonifère; noeuds velus ; f. sup. engainant la pauicule au début. - 4. At-spt. AC. Bords des eaux. Canal du Midi, rives de la Garonne. . . . L. faux riz. C. on·izoides Sw.

$$
10 \text { - CYNODON Rich. - Chiendent. - Pl. XVII, f. } 8 .
$$

Rhizome rampant; tiges couchées-ascendantes ; f. glauques. - $\psi$. Jlt-at. GG. Terrains sablomneu.x. . . C. Dactylon Rich.

\section{1 - ANTHOXANThUM L. - Flouve. - Pl. XVII, f. 9 (épillet).}

Epi oblong; souche fibreuse. -- q. Mai-jn. CC. Piés, bois. . . ......... Fl odorante. Adoratume L.

12 - BALDINGERA Fl. der Wett. - Baldingère. - Pl. XVI1, f. 10 (épillet).

Tige de 8-12 dm. ; f. larges de $1 \mathrm{~cm}$. env. ; panicule violacée ou verdâtre. - \%. Jn-jlt. C. Bords des eaux: canal du M. (Phalaris L.). . . . B. faux roseau. andundiuace Dumort.

$$
13 \text { - PHALARIS L. - Phalaris. - Pl. XVII. }
$$

1 - Carène à aile prolongée en une pointe lancéolée; épi oblong, à peine dégagé de la gaine de la f. sup re - \%. Jn-jlt. AR. Lieux cultivés. Le long de l'Her's : St-Martin-de-Lasbordes, au-delà de Périole (Baillet). . . . . . P. grêle. P. paracaxa L.

- Carène à aile non prolongée en pointe ; panicule développée hors de la gaine supre. . . . . . . . . . . 2

2 - Epi gros, ovoüde (f. 11); aile de la carène large. - (1). Maijlt. AR. Cliamps cultivés : env. de T. : parfois cultivé. . . . . . . . . . . P. des Canaries conanonsis L.

- Epi eylindrique ; aile de la carène très étroite, occupant toute la glume. - (1). Ju-at. R. Chaumes. Aufièri, Croix-Daurade. (Noulet). . . . . . . . . P. ténu. Temuis Host. 


\section{4 - PHLEUM L. - Fléole. - Pl. XVII.}

1 - Glumes obovées-cunéiformes, munies d'une carène dorsale glabre. - (1). Av.-mai. R. Lieu.x secs, champs, murs. Env. de T. . . . . . . . . . . F. rude. tos perom Jacy.

- Glumes à carène dorsale ciliée. . . . . . . . . . 2

2 -Glumes rétrécies au sommet, tronquées très obliquement. \%. Jn-jlt. C. Pelouses sèches des coteaux argilo-calcaires : coteaux de la Garonne. . . . F. de Bohmer. P. Hedn nenei Wibel.

- Glumes tronquées à angle droit (f. 13) ; tige non renflée en bulhe à la base; épi de 12-18 cm. - 2. Jn-jlt. C. Prés, pelouses.

............. des prés. pratense L.

Tige un peu bulbeuse ; épi de $5-8 \mathrm{~cm}$. - Bois, fossés. C.

$\ldots \ldots \ldots \ldots \ldots \ldots \ldots$. . . . . . . . . . .

Tige bulbeuse et géniculée à la base ; épi de 1-3 cm. (f. 12). - Lieux secs . . . . . . . . . . . . . . . . v. nodosum Gaud.

\section{3 -- ALOPECURUS L. - Vulpin. - Pl. XVII.}

1 - Tige couchée, puis genouillée-ascendante, souvent radicante; épi velu. - q. Mai-spt. AC. Fossés, bords des eau.r.

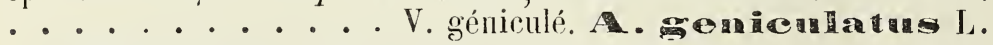

- Tige dressée ou ascendante, non radicante. . . . . . 2

2 - Tige renflée-bullıeuse à la base ; épi grềle; f. supres à gaine très peu renflée; glumes à peine soudées à la base. - q. Mai-jn. R. Prés humides. Bords de l'Her's, à Tournefeuille; du Touch, au pont d'Ä̈ga. . . . . . . V. luulbeux. D. Dullbosus L.

- Tige non renflée en bulbe. . . . . . . . . . . 3

$3-\mathrm{F}$. supres â gaine cylindrique; glumes soudées jusqu'ì leur milieu ; épi glabrescent. - I. Mai-jlt. CG. Champ.s cultives. . V. des champs. A gogrestis I.

- F. supres à gaine renflée; glunes soudées dans leur 13 inf. (f. 15) ; épi velu (f. 14). - \%. Mai-jlt. CG. Champs cultivés. . . ........... V. des prés. A. pratensi $\mathrm{L}$.

\section{6 - MIBORA Adans. - Mibora. - Pl. XVII.}

- F. toutes radicales; épillets de $2 \mathrm{~mm}$. (f. 16, 17). - (1). Fév.av. C. Terres graveleuses. (M. minima Desv, ; Chamagrost is minima Borkh ). . . . . . M. printanière. M. verna P. de B.

\section{7 - CYNOSURUS I. - Cunosure. - PI XVII.}

- Epi ovoïde; ghlumelles à arète de $1 \mathrm{~cm}$. de long (I. 18). - (1).

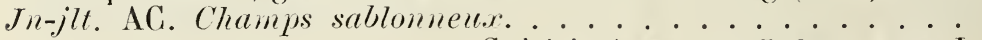


- Epi cylindrique ; glumelles simplement mucronées (f. 19). 4. Jn-jlt. CG. Prés, pelouses, bois.

C. à crêtes. C. coistatus $\mathrm{I}$.

18 - PHRAgMITES Trin. - Roseau. - Pl. XVII, f. 20 (épillet).

Rhizome rampant; tige de $1-2 \mathrm{~m}$. ; f. de $1 \mathrm{~cm}$. de large ou plus ; panicule violacée. - \%. Jlt-spt. C. Bords des eaux. (Roseau à balais). . . . . . R. commun. Commm is Trin.

\section{9 - ARUNDO L. - Roseau.}

Tige de 3-כ̌ m. ; f. de 2-4 cm. de large. - భ. At-spt. AG. Naturalise sur les coteaux de la Garonne. Ne fleurit que très rarement. . . . . . . R. à quenouilles. A. Ronax L.

20 - CALAMAgROSTIS Adans. - Calamagrostide. - Pl. XVII.

Tige de 6-12 dm., à f. scabres; glumelle inf. munie d'une arète dorsale (f. 21). - \%. Jn-at. R. Lieux humides. Bouconne. . . . C. commune. C. Epigoios Roth.

\section{1 - AgROSTIS L. - Agrostide. - Pl. XVII.}

1 -Glumelles égales; f. planes ; ligule courte, tronquée; panicule compacte, à rameaux garnis d'épillets jusqu'à leur hase. - z. Jn-at. R. Canal du M., entre les écluses Bayard et Matabiau... . . . . . . A verticillée. . verticillata Vill.

- Glumelles inégales, la sup petite ou nulle. . . . . . . 2

2 - Ligule courte, tronquée; f. planes ; panicule toujours lâche, + ou - violacée (f. 22, 23, épillet). - \%. Sn-spt. CC. Bords des

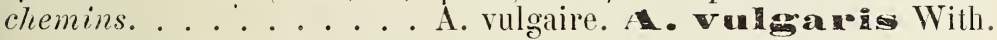

- Jigule oblongue ; panicule resserrée après la floraison. . 3

3 - F. planes; glumes presque égales : 2 glumelles. - $\%$. Jn-at. CG. Prés, champs, bords des chemins. A. blanche. alba L.

- F. radicales enroulées-filiformes; glumes inégales; 1 glumelle. - 4. Jn-at. AR. Lieux lumides, fossés, bois. - Bouconne, T. A. des chiens. A. Canna $\mathrm{I}$.

Le sporolobus tenacissimus P. B. est naturalisé sur les rives du Tarn, à Mézens (Marcais, in $h b$. Sudre). On le reconnaîtra à ses épillets très petits (1 mm. de long), en panicule étroite (f. 24), à glumes très iné. gales, l'inf. plus courte que la fleur, et à ses ligules presque nulles.

\section{2 - APERA Adans. - Apéra. - Pl. XVII.}

Panicule étroite, effilée (f. 20̈) ; anthères ovoïdes; tiges de 15̆-30 cm. - (1). Jn-jlt. R. Lieux sablomneux. De Portet $\dot{a}$ Braque- 
ville (Noulet) ; ramier de Beauselle. (Agrostis L.)

A. interrompue. $A$. intenomia $P . B$.

23 - GASTRIDIUM P. B. - Gastridie. - Pl. XVII.

Tiges de $1-4 \mathrm{dm}$; épis atténués aux 2 bouts, d'un vert blanchâtre (f. 26 , fragm. d'épi ; 1. 27, épillet). - (1). Jn-spt. C. Terves siliceuses ou argilo-siliceuses, après la moisson.

$\mathrm{G}$. ventrue. G. Hendigenam Gaud.

\section{4 - POLYPOGON Desf. - Polypogon. - Pl. XVII.}

Epi vert blanchâtre (f. 28 ); arêtes des glumes de $5 \mathrm{~mm}$. de long (f. 29). - *. Jn-jlt. R. Lieux humides. Env. de T. . . . . . . . . ...... P. de Montpellier. H. monspellicinse Dest.

$$
\text { 2ö - MILIUM Tournef. - Millet. - Pl. XVII. }
$$

Tige de 6-10 dm., lisse ; f. planes ; épillets de $3 \mathrm{~mm}$. de long (1. 30). - 4. Mai-jlt. G. Bois des collines. . . . . . . . . .

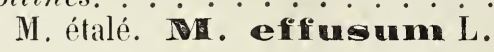

$$
26 \text { - AIRA L. - Canche. - Pl. XVII. }
$$

- Tiges nombreuses ; épillets fasciculés, ventrus à la base ; panicule très fournie, peu étalée. - (1). Jn-at. C. Lieux secs, ter.es graveleuses. . C. à plusieurs tiges. M. malticulnós Dum.

- Tiges ord solitaires ; épillets écartés; panicule dilluse, lâche (f. 31). - (1). Av.-jtt. CG. Lieux secs, bois, pelouses. . . . . . . . C. caryophyllée. A. canyophyiea $L$.

\section{7 - DESCHAMPSIA P. B. - Deschampsie. - Pl. XVII.}

- Arête de la glumelle à peu près droite, incluse ou égalant à peine les glumes (f. 33); ligule allongée. - భ. Jn-jlt. C. Bois humides, saussaies. . . D. gazonnante. D. carespitosa P. B.

Fl. plus petites, violacées. . . . . . . v. parviflora (Thuill).

- Arête de la glumelle coudée, presque 2 fois plus longue qu'elle (I. 32) ; ligule courte, tronquée. - 4. Jn-jlt. AR. Bois, terains

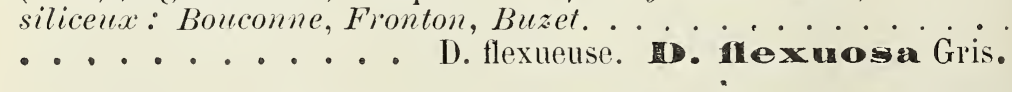

$$
28 \text { - HOLCUS L. - Houlque. - Pl. XVII. }
$$

- Arête incluse (f. 34, fragm. de panicule), arquée en crochet; fl. suppe glabre; plante mollemeut velue, à souche courte. - \%. Jnat. CC. Prés, bois. ........ I. laineuse. H. lanatus L.

- Arête exserte, coudée ; fl. supre barbue à la hase (f. 30̃); sou- 
che rampante, stolonifère. - भ. Jn-at. AR. Prés secs, bois, haies. Bouconne, La Ramette, Balma. . . H. molle. Hilnollis L.

\section{9 - ARRHENATERUM P. B. - Arrhénatère. - Pl. XVIII.}

Plante glabre, de 6-12 dm., à souche rampante, non renflée-bulbeuse (f. 1, épillet). - 4. Mai-jlt. CC. Piés, haies, bois. (Avena elatior L.). ......... A. élevé. A. elatiuss M. et K.

Souche bulbeuse; nœuds de la tige pubescents. - A rechereher. .

$$
30 \text { - AVEnA Tournel. - Avoine. - Pl. XVIII. }
$$

1 - Epillets dressés; f. et gaines infres velues; fl. rougeâtres ; axe de l'épillet velu. - 4. Mai-jn. AC. Lieux secs, bois, prés.

.......... A. pubescente. A. pubescems L.

- Epillets penchés ou pendants. . . . . . . . . 2

2 - Glumelle glabre ou à peine poilue à sa base; fl. non articulées sur le rachis et ne se détachant pas à la maturité; épillets presque tous à 2 fleurs dont une au moins mutique.. . . . . . . 3

- Glumelle très poilue dans sa moitić inf. ; fl., au moins l'inf., très articulées sur le rachis, et caduques........... 4

3 - Panicule étalée de tous côtés; pédoncules par 4-8. - (1). Jnjlt. Cultivé. . . . . . . A. cultivée. sativa L.

- Panicule unilatérale, resserrée; arêtes droites. - (I). Jn-jlt. Cultivée. (Avoine de Hongrie). .... A. Oromialis L.

4 - La fl. infro seule articulée sur le rachis; glumelle à poils roux; panicule étroite, unilatérale; axe de l'épillet velu dans sa moitié sup ${ }^{\mathrm{re}}$ - (1). Jn-jlt. C. dans les blés.

..... . . A. de Ludovic. A. Ludoviciana Dur.

- Toutes les fl. articulées sur le rachis ; axe de l'épillet entièrement velu.

5 - Panicule unilatérale; glumelle inf. chargée à la base de longs poils blanchâtres (1.2). - (1). Jn-at. C. Piairies arlificielles, tertres, cultures. . . . . A. barbue. A. Da Iorat Brot.

- Panicule étalée en tous sens; glumelle infre chargée de longs poils fauves ou roussâtres. - (1). Jn-jtt. C. Moissons, cultures. . .

A. folle. A. fatua L.

\section{1 - TRISETUM Pers. - Trisète. - Pl. XVIII.}

Souche stolonifère; tige de 4-10 dm. ; panicule devenant jaunâtre (f. 3, épillet). - ४. Jn-jlt. CG. Talus, prẻs, pelouses. (Avena L ). . . . . . . T. jaunâtre. T. flavescens P. B. 
32 - ECHINARIA I)sf. - Echinaire. - Pl. XVIII (f. 4).

Tiges de $6.12 \mathrm{~cm}$. , nues au sommet. - (1). Mai-jlt. RR. Lieux pierreux des terrains calcaires. A été rencontré à Pech-David. . E. en tête. Capitata Desf.

\section{3 - KELERIA Pers. - Kolérie. - Pl. XVIII.}

1 - Glumelle inf. aristée ; tiges de 1-3 dm., dépourvues de pousses stériles; épi verdâtre, compact (f. 5). - (1). Mai-jlt. C. Lieux secs, bords des chemins. . . K. fléole. Iz. phleoides Pers.

- Glumelle infre non aristée ; tiges munies à leur base de pousses stériles.

2 - Souche recouverte par les gaìnes desséchées et indivises des f. ancieones; f. planes, la plupart radicales; glumes à carène non ciliée; épi interrompu. - \%. Jn-at. C. Pelouses sèches des coteaux. . . . . . . . K. à crêtes. 值. Coristata Pers.

- Souche recouverte par les gaines des f. anciennes et déchirées en filaments entrecroisés; f. radicales filiformes; glumes ciliées sur la carène. - 2. Mai-jlt. AC. Coteaux, pelouses des bords de la Garome et de l'Ariege. K. du Valais. Tr. Valesiaca Gaud.

\section{4 - DANTHONIA DC. - Danthonie. - Pl. XVIII.}

Epillets peu nombreux, ovoüdes-oblongs, de $7-9 \mathrm{~mm}$. de long (f. 6); tige de 1-4 dm. - \%. Jn-at. AC. Bois, piés, bruyères. (Tiriodia decumbens P. B.). . . . . D. inclinée. T. decunelbens DC.

$$
33 \text { - MELICA L. - Mélique. - Pl. XVIII. }
$$

- Glumelle inf. longt ciliée (f. 7) ; pédoncules rameux, dressés, en épi allongé, velu-blanchâtre. - \%. Mai-jlt. Lieux secs, escarpements des coteaux. . . . . . . . . M. ciliée. M. cilia ta L.

F. glauques, planes; tiges lisses au sommet ; épi lobé, interrompu à la base. - AC . . . . . . . . . . . . . v. Magnolii (G. et G.)

- Glumelle inf. glabre ; f. vertes ; panicule lâche (f. 8), sans poils soyeux. - Mai-jn. CG. Bois courverts.

M. uniflore. Anniflona Retz.

$$
36 \text { - MOLINIA Schrank. - Molinie. - Pl. XVIII, f. } 9 .
$$

Tige de 4-10 dm., longt nue au sommet, à 1 seul noud près de la sonche; panicule grande. - \%. Jn-at. CG. Bois, friches, lieux firais. M. bleue. Corenter Mcench.

$$
37 \text { - DACTYLIS I. - Dactyle. - Pl. XVIII, f. } 10 .
$$

F. planes ; épillets de $5-6 \mathrm{~mm}$. de long; souche gazonnante. $-\mathcal{q}$. Eté.CG. Friches, prés, bois. I). aggloméré. D. golomentata I. 
38 - VULPIA Gmel. - Vulpie. - Pl. IVIII.

1 - Glumelle inf. longt ciliée ; glume inf. nulle ou très courte ; axe de l'épillet velı. - (1). Mai-jn. AR. Murs, bords des champs. T., Corniche des quais et aux Minimes.

. . . . . . . . V. ciliée V. cilia ta Link.

- Glumelle inf. non ciliée. . . . . . . . 2

2 - Glume supre aristée, l'inf. uulle ou peu distincte; f. cnroulées ; épi dense, de 2-7 cm.; épillets glabres. - (1). Mai-jn. RR. Rives de la Garonne, au-dessous de Braqueville (Noulet).(I. bromoides GG.). . V. membraneuse. membran acoa Link.

- Glumes non aristées, l'inf. très visible.

3 - Glume inf. égalant le 1/3 ou le 1 / de la supre (f. 11) ; panicule allongée, rapprochée de la f. sup. et souvent embrassée par elle. - I. Mai-jlt. CG. Lieux cultivés. (I'. pseudo-myuros Rehb.).. . V. queue-de-rat. V.

- Glume inf. égalant la 12 de la supre ; panicule courte, éloignée des 1. - (1). Mai-jlt. C. Terres sablonneuses, bords des champs... . V. queue-d'écureuil. coinmoides Roth.

\section{9 - FESTUCA L. - Fétuque. - Pl. XVIII.}

1 - Toutes les f. enroulées-sétacées; souche fibreuse; panicule étroite, presque unilatérale; glumelle aristée. - ₹. Mai-jn. CG. Lieux arides, firches des coteaux.

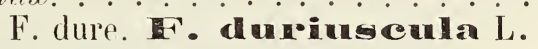

F. très glauques. - Bords de l'Ariège et de la Garonne . . . . .

- F. radicales enroulées-sétacées, les caul. planes. . . . 2

- Toutes les f. planes. . . . . . . . . . 3

2 - Souche rampante; épillets à ŏ-10 fl. : glumelle inf. à arête

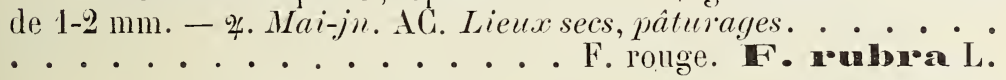

- Souche fibreuse ; épillets à 4-ŏ fl.; glumelle inf. à arête de 2-4 mm. - \%. Mai-jtt. C. Bois.

- . . . F. à f. variées Hoterophyila Lam.

3 - Gaines des f. inf. renflées en bulbe allongé ; panicule d'un jaune brunâtre, à épillets larges, à 3-ŏ fl (f. 12); tiges de 8-12 dm.

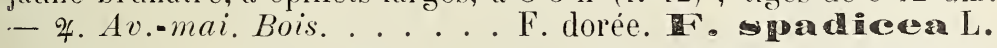

Panicule penchée. lâche, à rameaux rudes, par 2, 3. - C. Bouconne, Colomiers, Venerque. . . . . . . . . . F. spectabilis Jan.

- Gaines des f. inf. non renflées en bulbe; panicule verte ou violacée . 
4 - Glumelle inf. à arête égalant env. 2 fois sa longueur (f. 13); tige de 6-10 dm., glabre ainsi que les gaines ; panicule lâche, penchée. - Ұ. Jn-at.AR. Bois couverts des collines. Venerque, Balma, St-Geniès. . . . . . . F. géante. F. gigantea Vill.

- Glumelle inf. à arête courte ou nulle. . . . . . . ร

5 - Rameaux infrs portant tous 4-17 épillets à 4-6 fl.; plante robuste, à souche fibreuse. - \%. Jn-jlt. C. Bords des eaux, prés humides . . . . . . F. roseau. F. anomdinacea Schreb.

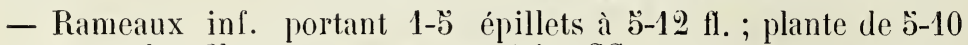
dm., à souche fibreuse. - \%. Mai-jlt. CC. Lieux herbeux, prés. (F. pratensis Huds.). . . . . F. Élevée. F. elation- L.

\section{0 - BROMUS L. - Brome. - PI. XVIII.}

1 - Glumelle infre fusiforme, earénée sur le dos, du moins au sommet. . . . . . . . . . . . . 2

- Glumelle inf. uı peu ventrue, arrondie sur le dos, même au sommet.

2 - Plante vivace ; arète plus courte que la glumelle. . . . 3

- Plante annuelle; arête plus longue que la glumelle; épillets élargis au sommet. . . . . . . . . . . 4

3 - Epillets peuchés, à $6-9 \mathrm{fl}$. ; panicule très lâche ; f. planes, de ๖ั-12 mm. de lar'ge, à gaînes hérissées; tige de 10-12 dm. - \%. Jn$j t t$. AC. Bois couverts des collines. B. rude. BB. asper- Murt.

- Epillets dressés, à らૅ-8 fl.; panicule raide; f. radicales étroites. — q. Mai-jlt. C. Coteaux, prés secs. . . . . . . . . . . . B. dressé. Hs. edectus Huds.

4 - Panicule serrée et penchée d'un côté ; glumelle inf. égalant sou arête; épillets pubescents. - (1). Mai-jn. C. Lieux stèriles, graviers, murs. ...... B. des toits. H. tectomm L.

- Panicule droite ou dilluse; glumelle inf. plus courte que son arête...................... ら

כ - Panicule serrée, à épillets dressés ; glumelle inf. longue d'env. $15 \mathrm{~mm}$.; arête de $2 \mathrm{~cm}$. - (1). Jn-jlt. CC. Bords cles champs, murs, tertves. B. de Madrid. M. Madritensis L.

- Panicule lâche ; épillels aỵant au moins ò cm. de long. • • 6

6 - Tige glabre ; ; panicule làche et diffuse ; épillets glabres, rıdes, pendants; glumelle inf. longue de $150-18 \mathrm{~mm}$. - (1). Mai-at. CG. Murs, haies, champs cultivés. B. stérile. D. oleilis L.

- Tige pubescente; f. velues; arêtes de $3 \mathrm{~cm}$. de long au moins; glumelle inf. de $2 \mathrm{~cm}$. env. (f. 14); panicule dense et dressée (B. ambigens Jord.) ou liche à pédoncules penchés (B. Borrei 


\section{$-213-$}

Jord.). - (1). Mai-jn. CG. Lieu.c incultes, haies, murs.

B. élevé. Mo. maximas Desf́.

7 - Epillets linéaires-lancéolées, glabres ; arête égalant la glumelle; panicule très lâche, à la fin penchée. - (1). Jn-at. C.C. Champs, pelouses. . . . . B. des champs. B a nevonsis L.

— Epillets élargis, ovoïdes ou oblongs. . . . . . . . 8

8 - Glume sup. aussi longue que l'inf.; arĉte plus courte que la glumelle; panicule lîche, devenant penchéc, à épillets ord ${ }^{t}$ glabres. - (1). Mai-jlt. AC. Moissons.

B. des seigles. is secalinus $\mathrm{L}$.

- Glume sup. plus courte que l'inl'e. . . . . . . . . 9

9 - Epillets mollement pubescents; panicule oblongue, dressée et resserrée après la floraison. - (2). Mai-jn. CG. Bords des chemins, champs. . . . . . . . . B. mollet. Ho mollis L.

- Epillets glabres ou à peu près. . . . . . . . . . 10

10 -- Glumelle inf. à bord insensiblement arqué, longue de 7 mm. ; panicule étroite, dressée, resserrée après la floraison. - (1). Mai-jlt. C. Prés, bords des champs. (B. pratensis Auct.) . . . . .

B. à grappe. F. Tracemiosus L.

- Glumelle inf. à bord formant vers le 1/3 sup. un angle obtus, longue de $9 \mathrm{~mm}$. (f. 15) ; panicule lâche, penchée à la maturité. (1). Mai-jlt. C. Piés, champs. . . . . . . . . . . .

B. controversé. commentatens Schrad.

\section{1 - GLYCERIA R. Br. - Glycérie. - Pl. XVIII.}

1 - Tiges très robustes, dressées, de 1-2 m. ; f. larges, les radicales fasciculées; épillets petits, de つั mm., à วั-10 fl. (f. 16); pédoncules longs; panicule ample. - \%. Jlt-at. AC. Canal du M. (G. aquatica Wahl.). G. remarquable. G. spectaloilis M. et K.

- Tiges flasques, couchées-radicantes, souvent nageantes; épillets longs de $10-15 \mathrm{~mm} \ldots \ldots \ldots \ldots 2$

2. - Glumelle inf. à 7 nervures, presque aiguë ; rameaux inl. de la panicule dressés pendant l'anthèse, ordint géminés, un seul à plusieurs épillets ; panicule unilatérale. - q. Jn-at. C. Eaux, fossés, canaux. . . . . . Gl. flottante. Goritams R. Br,

- Glumelle inf. arrondie au sommet (f. 17) ; rameaux inl. de la

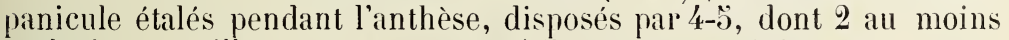
à plusieurs épillets. - ४. Jn-at. AC. Avec le précédent. . • . G. plissée. Holicara Fr.

42 - SCLEROPOA Griseb. - Scléropoa. - Pl. XVIII, f. 18.

Plante glabre, de $5-20 \mathrm{~cm}$, à tiges élalées puis ascendantes. - (1). 
Jn-jlt. GC. Jieux secs, friches des collines. (Poa L., Festuca Kunth.). S. rigide. 5 . no ida Griseb.

$$
43 \text { - BRIZA L. - Brize. - Pl. XVIII. }
$$

- Ligule courte, tronquée; souche rampante; fl. de $3-4 \mathrm{~mm}$. de long. - భ. Jn-jlt. GG Prés, pelouses, bois.

B. moyenne. he edia L.

- Ligule allongée, aiguë; souche fibreuse ; fl. de 2-3 mm. (f. 19).

(1). Mai-jlt. AC. Champs sablonnewx, moissons.

B. mineure. 且, ming $0^{\circ} \mathrm{L}$.

\section{4 - ERAGROSTIS P. B. - Eragrostide. - Pl. XVIII.}

- Epillets lancéolés, à ŏ-2ŏ fl. étroitement imbriquées (f. 20) ; épillets court pédicellés. - (1). Ju-at. AC. Cultures, teres sablonneuses. . . . . E. à gros épis. megastaclnya Link.

- Epillets linéaires-étroits, de 4-ŏ mm. de long sur 1 de large, violacés, à ő-10 fl. distiques; 1. glabres. - (1). Jn-spt. CG. Champs sablonneux. . . . . . . . E. poilue. E. pillosa P. B.

$$
40 ั \text { - POA L. - Paturin. - Pl. XVIII. }
$$

1 - Rameaux de la panicule raides, épais, garnis de fleurs jusqu’à leur base ; tiges de 6-10 cm., étalées ; panicule unilatérale (f. 21). (1). Mai-jn. R. Pelouses, le long clu canal cu M., au Béarnais et aux Minimes, (Sclerochloa P. B.). P. dur. Scop.

- Rameaux de la panicule nus à leur base. . . . . . . 2

2 - Tiges renflées en bulbe à leur base ; souche gazonnante; ligule allongée ; panicule ovoüde, à fl. souvent trausformées en bulbilles foliacés (v. vivipara). - \%. Av.-jn. CG. Mus, pelouses. .

- Tiges non bulbeuses. . . . . . . . . . . . 3

3 - Ligule de $3-4 \mathrm{~mm}$. de long (f. 23). . . . . . . . . . 4

- Ligule courte (1 mm. au plus), tronquée (f. 24). . . . . .

4 - Annuclle; panicule à rameaux étalés à angle droit ; tiges de ว̆-2ò cm., ascendantes. - (1). Toute l'année. Partout.

- Vivace ; panicule à rameaux étalés-dressés, les inf. par 4-6 (f. 22 ) ; souche fibreuse ; tige de 4-9 dm., rude, ansi que les gaines (f. 23, ligule). - ४. Mai-jlt. CG. Frés, pâturages.

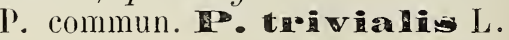

5 - Souche filıreuse, à peine rampante; f. supre à gaine plus courte que le limbe ; rameaux in res de la panicule par 3- 
jlt. AC. Bois, piés. . . . P. des bois. Hemoralis L.

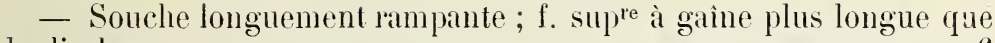
le limbe.

6 - Tiges cylindriques (sauf à la base) ; panicule étalée ; épillets à 3-כ̆ fl. velues (f. 24, ligule). — \%. Mai-jlt. CG. Prés, pelouses.

P. des prés. Po pratensis $L$.

- Tiges fortement comprimées; panicule étroite, presque unilatérale; épillets à 4-8 fl. - ‥ Jn-at. AC.Prés secs, murs, vignes, terrains argilo-calcaires

\section{P. comprimé. H. comno esosa L.}

46 - CAtabrosa P. B. - Catabrose. - Pl. XViII, 1. 25,26 (épillet).

- Rhizome stolonifère ; f. courtes et larges. - भ. Mai-jlt. AC. Eaux stagnantes. . . . C. aquatique. C. aquatica P. B.

\section{7 - HORDEUM L. - Orge. - Pl. XVIII.}

- Glumes inégales, celles de l'épillet médian ciliées ; gaînes glabres ; arète de la glumelle infre dépassant longt les glumes (f. 27). (I). Mai-at. CG. Bords des chemins, lieux incultes

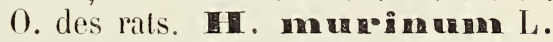

- Glumes égales, non ciliées ; gaines inf. mollement velues; arête de la glumelle inf. dépassant peu les glumes. - \%. Jn-jt. AC. Prés, pâturages. . O. faux seigle. secalinmm Schreb.

On cultive les $\mathbf{H}$. vulgare L. (Orge currée) à épillets sur 6 rangs, dont 4 plus sitillants, $\mathrm{H}$. hexastichum $\mathrm{L}(O . \dot{\alpha} 6$ rangs), H. distichum $\mathrm{L}$. (Puumelle), à épillet médian seul fertile et à épi long de $8-12 \mathrm{~cm}$. et H. Zeocriton Lo $(O$. en éventail $)$, à épis courts $(4-6 \mathrm{~cm}$.), à arêtes étalées.

$$
48 \text { - SECALE L. - Seigle. }
$$

Glaucescente; glumelle inf. à carène ciliée. - (1) ou (2). Mai-jtt. Cullivé ............ cenale L.

\section{9 - TRITICUM L. - Froment.}

On cultive le r, sativum L., à glumes carénées seulement au sommet. à glumelle inf. mucronée (T. hybernum L., bladette) $0 u$ + ou - aristé (T. æstivum L., Blé fin) et le 'T. tun L. (Blé barbu), à glımes carénées de la base au sommet.

$$
50 \text { - ÆGILOPS L. - Egilope. - Pl. XVIII. }
$$

2-3 épillets rapprochés ; glumes à 3, 4 arêtes divergentes (f. 28). - (1). Mai-jn. CG. Coteaux, murs, bords des chemins. . . • 
5ั1 - AGROPYRUM P. B. - Agropyre. - Pl. XVIII.

1 - Souche fibreuse ; fl. longuem ent aristées (f. 29); f. rudes sur les 2 faces. -- \%. Jn-at. R. Haies, buissons. Bouconne, la Ramette.

A. des chiens. A. caninum Rom. et Sch.

- Souche rampante . . . . . . . . . . . 2

$2-\mathrm{F}$. ordint vertes, à nervures fines; glumelle inf. aiguë, + ou - aristée. - 4. Jn-spt. C. Lieux incultes, sablonneux. . . . . . ........... A. rampant. A repens P. B.

- F. glauques, à nervures très saillantes, à pointe enroulée ; glumelle inf. obtuse. - \%. Jn-spt. CC. Lieux incultes, champs sablonneux. . . . . A. champêtre. A. canupestres G. G.

52 - BRACHYPODIUM P. B. - Bracliypode. - Pl. XVIII.

1 - Souche rampante. . . . . . . . . . . . 2

- Souche fibreuse ; f. planes . . . . . . . . . . . . . 3

$2-3,6$ épillets dressés, en épi court ; f. distiques, très étroites; glumelle sup. à arête courte. - \%. Jn-spt. R. Friches, bois secs. Haut Lauragais, Avignonet (Timbal)

B. rameux. IR. ramosum R. et Sch.

- Epillets nombreux, en épi allongé ; glumelle sup. à arête longue. - q. Jn-spt. CG. Lieux secs, coteaux, tertres .

B. penné. $\mathbf{B}$. pinnarum P. B.

$3-2,3$ épillets à $10-20$ fl. (f. 30) ; tige de 5-20 cm. - (1). Maijlt. AC. Coteaux argilo-calcaires. . . . . . . . . . . B. à 2 épis. H. distachyon P. B.

- Epillets nombreux, à ő-10 fl. ; tige de 4-9 dm. - \& Jlt-oct. CC. Bois, lieux couverts.

B. des forêts. Rs. silvaticum Rơm. et Sch.

53 - NARDURUS Rchb. - Nardure. - Pl. XVIII.

- Epi distique ; glumelle inf. subobtuse ; tiges de 1-6 dm. - (1). Mai-jlt. AC. Bois, sol sablonneux. Tallée du Tarn, Fronton. (Festuca Poa Kunt.) N. de Lachenal. R. Lachenalii Godr.

- Epi unilatéral (f 31); glumelle inf. aiguë, + ou - aristée. (1). Mai-jlt AC. Vignes, lieux secs, graveleux. (Festuca tenuiflora Schrad.) . . . . . . . . . N. délicat. N. tonellus Rchb.

54 - GAUDINIA P. B. - Gaudinie. - Pl. XVIII, f. 32.

Tiges de 3-6 dm. : f. velues, planes. - \%. Jn-jlt C. Lieux herbeux. . . . . . . . G. fragile. G. freagillis P. B. 


\section{วัว - LOLIUM L. - Irraie. - Pl. XVIII.}

1 - Souche vivace, cespiteuse, émettant des fascicules de feuilles; plante des prés ou des lieux herbeux. . . . . . . . . 2

- Souche annuelle, dépourvue de faisceaux de feuilles; plante des champs cultivés. . . . . . . . . . . . 3

2 - Glumelle inf. mutique ; épillets à $3-10 \mathrm{fl}$; f. souvent pliéescanaliculées dans leur jeunesse. - \%. Ji-oct. CG. Prés, pelouses. . I. vivace. Le

- Glumelle inf. aristée ; épillets à ő-1ŏ fl. ; f. enroulées par les bords dans leur jeunesse. - q. Jn-jlt. Cultivé en gazons ou bordures et en prairies artificielles (Ray-giass.)

3-Glumes 2-3 fois plus courtes que l'épillet, à 10-2气 fl. + ou aristées. - (1). Jn-jlt. Prairies artificielles, terrains argilo-calcaires. . . . . . 1. multiflore. H.

- Glumes égalant l'épillet ou un pen plus courtes. . . . . 4

4 - Epillets fructifères petits, lancéolées ; glumelles membraneuses. - Mai-jn. C. Champs cultivés. (L. rigidum Gaud.) . . . .

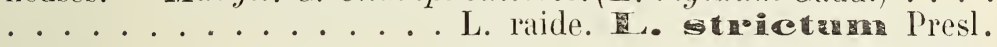

- Epillets fructifères gros, elliptiques ; glumelles cartilagineuses

5 - Fl. courtes ( $4 \mathrm{~mm}$.), non aristées (ordint) ; épi court ; tiges grêles, de 3-气 dm., croissant dans les linières. - (1). Mai-jn. AC. Champs, cultures. (L. linicola Sond.).

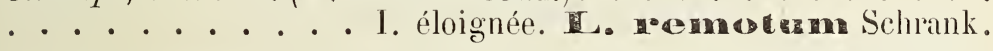

- Fl. de 8-10 mm. de long, en épi allongé; plante roluste, des moissons ................. 6

6 - Fl. aristées ; arète droite, égalant la glumelle; glumes égalant ou dépassant l'épillet. - (I. Jn-jlt. G. Moissons.

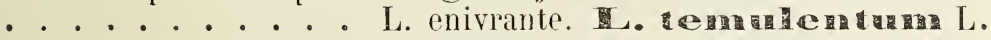

- Fl. mutiques ou munies d'une soie molle, caduque (f. 33). (1). Jn-jlt. Avec le précédent, mais moins C. . . . . . . .

$$
\text { ว6 - LEPTURUS R. Br. - Lepture. - Pl. XVIII. }
$$

Tige de 2-4 dm.; épi grêle, dressé (f. 34); épillets latéraux à 1 seule glume (f. 3ö). - I . Jn-jlt. AR. Pelouses, bords des chemins. Balma, St-Lys, Muret, T., Pinsaguel (Duffort).

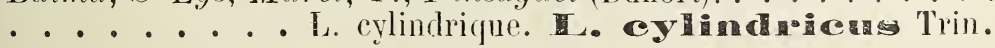




\section{Sous-embranchernent II. - Gymnospermes.}

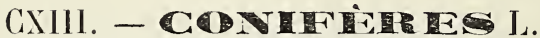

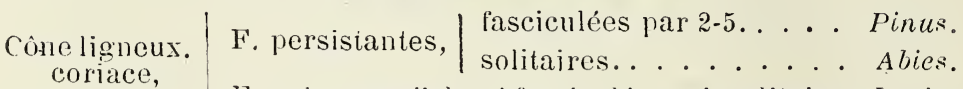
F. caduques, d'abord fasciculées puis solitaires. Larix. Fruit charnu, noir glauque; f. verticillées par 3. . . Juniperus. bacciforme rouge; f. éparses .......... Taxus.

\section{JUNIPERUS Tournel. - Genévrier. - Pl. XIX.}

Diöque; f. piquantes; fruit d'abord vert puis noir glauque (f. 1). - ந. Av.-mai. AC. Firiches des coteaux, bois.

G. commun.

On plante les $\mathbf{P}$. silvestriš L. (Pin commun), P. pinea L. (P. pignon), P. Pinaster Soland (P. maritime), P. Cedrus L. (Cèdre) et quelques autres; les Abies excelsa DC. (Epicea) et pectinata DC. (Sapin); le Larix europæa DC. (Mélèze); le cupressus sempervirens L. (Cyprès), plusieurs espèces de Thuya el lo Taxus baccata L. (If). Ces plantes ne sont pas spontances daus notre régiou.

\section{Embranchement II. CRYPTOGAMES VASCULAIKES}

CXIV. - N Juss. - PI. XIX.

1 - Sporanges soudés entre eux, disposés en épi linéaire (f. 2). . ...................... Ophioglossum.

- Sporanges placés à la face inf. des frondes (f. 5). . . . . . 2

2 - Face inf. des frondes couverte d'écailles (f. 4). . 2 Ceterach.

- Face inf. des frondes à écailles nulles ou rares.. . . . . . 3

3 - Sores orbiculaires, dépourvus d'indusic (f. 5). 3 Polypodium.

- Sores recouverts d'une membrane ou indusie (f. 10). . . . . 4

4 - Frondes simples, cordées à la base; sores linéaires (f. 14) . . .

- Froudes profondément divisées. . . . . . . . . . . . . 5 
5 - Sores situés sur les bords des segments de la fronde et recouverts par le bord replić de ces segments (f. 15, 16) . . . 6

- Sores sur la surface des frondes, loin des bords, et munis d'une indusie distincte (f. 10). . . . . . . . . . .

6 - Sores formant aux bords des segments des frondes une ligne continue qui borde les segments (f. 15). . . . . 8 Pteris.

- Sores n'occupant que le sommet des segments, en ligne interrompue (f. 16). . . . . . . . 9 Adianthum.

7 - Sores allongés, linéaires ou oblongs (f. 11,12,13). . . . . . .

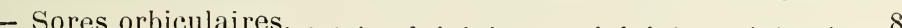

8 - Indusie fixée par son centre (f.6) . . . . 4 Aspidium.

- Indusie fixée par son centre et par un pli qui la rend réniforme $(\mathrm{f} .8,9,10) \ldots \ldots . . . .55$ Polystichum.

\section{1 - OPHIOGLOSSUM Tournef. - Ophioglosse. - Pl. XIX.}

Fronde entière, ovale-lancéolée (f. 2, 3). - భ. Mai-at. R. Lieux marécageux. Entre Pouvourville et Tieille-Toulouse, Aufréri, Pressac (Noulet); env. de Lanta (M. Marty)...........

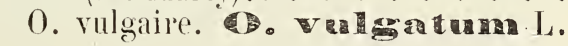

\section{2 - CETERACH C. Bauh. - Cétérach. - Pl. XIX.}

Frondes de $\breve{5}-15 \mathrm{~cm}$. , pennatipartites, à lobes arrondis (f. 4). - 4 . Jn-oct. AC. Vieux muis.. . . . . . . . . . . . . . . . .

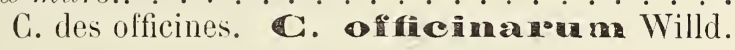

\section{3- POLYPODIUM Tournef. - Polypode. -- Pl. XIX.}

Fronde pematipartite, à segments linéaires-lancéolés (f. ๖̈). - q. Toute l'anmée. C. Murs, rochers, haies.

P. vulgaire. valgane L.

\section{4-ASPIDIUM R. Br. - Aspidie. - Pl. XIX.}

Frondes lipennatiséquées, à folioles fort ${ }^{t}$ auriculées (I. 6) ; pétiole

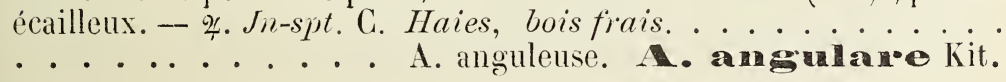

$$
\check{\jmath} \text { - POLYSTICHUM Roth. - Polystic. - Pl. XIX. }
$$

- Pétiole sans écailles ; fronde pennatiséquée, à segments pennatipartites (f. 7 ); sores petits, en lignes également distantes des bords et de la nervure médiane (f. 8). - \%. Jn-spt. R. Marécages. Bords de la Garonne, près: de Menerie; entre Blagnac et Beauzelle (Noulet). . . P. à bords roulés. To Theli

- Pétiole écailleux; fronde pennatiséquée, à segments pematipartites (f. 9$)$; sores gros ( $1 \mathrm{~mm} .1 / 2$ de diam.), rapprochés de lit 
nervure médiane (f. 10). - \%. Jn-oct, AR. Bois humides. Boucunne, Balma, St-Martin-de-Lasbordes.

........ P. fougère mâle. F. Filix mas Roth.

\section{6 - ASPLENIUM L. - Doradille. - Pl. XIX.}

1 - Fronde pennatiséquée, à folioles ovales ou orbiculaires (f.

11); pétiole noirâtre - \%. Jn-spt. C. Murs, haies, puits. • . ·.

- Fronde 2-3 fois pennatiséquée. . . . . . . . . . 2

2 - Pétiole brun noirâtre; frondes triangulaires-lancéolées, à segments incisés-dentés (I. 12). - \%. Mai-spt. C. Lieux couverts, haies, rochers, vieux murs.

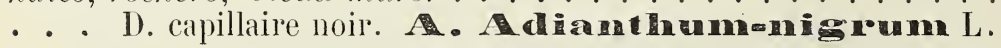

-- Pétiole vert; fronde ovale-triangulaire, à segments courtement obovés-cunéiformes (f. 13). - \%. Mai-spt. R. Vieux muss. T., Tournefeuille, pont de Cagueloule. Portet, à Canti. . . . . .

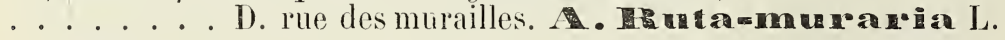

\section{7 - SCOLOPENDRIUM Sm. - Scolopendre. - Pl. XIX.}

Fronde oblongue-lancéolée, à peu près entière (f. 14). - \%. Jnspt. AC. Puits, rockers ombragés. (S. officinale Sm.). . . . . ......... S. vulgaire. valgaro Symons.

$$
8 \text { - PTERIS L. - Ptéride. - Pl. XIX, f. } 10 .
$$

Fronde 2-3 fois pennatiséquée, ovale-triangulaire, à pétiole très long, nu. - భ. Jlt-spt. CG. Clamps argilo-siliceux ou sablonneux

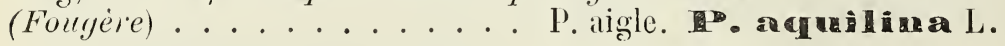

\section{9 - AdIANTHUM L. - Capillaire. - Pl. XIX.}

Pétiole nu, noir ; fronde mince, à folioles cunéiformes (f. 16). 4. Ju-spt. AR. Puits, rocher's et murs humides. Rives de la Garonne, en aval de T., Cornebarieu, bords du Touch..

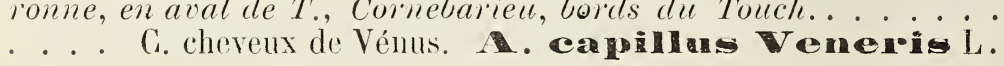

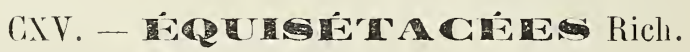

EQUISETUM Tournel. - Prile. - H. XIX.

1 - Tiges de 2 sortes, les lertiles simples, roussatres, paraissant avant les stériles et se détruisant après lit sporose $(f .17,18) . .2$

- Tiges toutes semblables, vertes. . . . . . . . 3 
2 - Gaines des tiges à 20-30 dents ; tiges stériles blanchâtres, de o-12 dm. - 9. Mars-av. C. Lieux humides des terrains argilocalcaires. (E. Telmateya Erhr.). . . . . . . . . . . . . P. élevée. T: maximum Lam.

- Gaines des tiges à 8-12 dents ; tiges stériles vertes, de 3-6 dm. - 4. Ms-av. C. Cllamps sablonneux. . . . . . . . . . P. des champs. areverise $\mathrm{L}$.

3 - Tige simple ou presque simple, à gaines cylindriques, noires

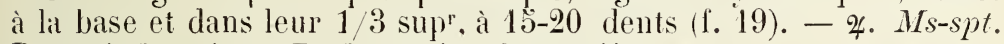
R. Bois humides. Pech-David, St-Geniès. . . . . . . . . .

P. d'hiver. Inyomalo L.

- Tige rameuse ; gaines élargies en coupe (f. 21). . . . 4

4 - Tiges fertiles se flétrissant en hiver, à 6-8 sillons; épi court, cylindracé, obtus (f. 20). - భ. Mai-jn. C. Lieux marécageux, bords des canaux. . . . . . P. des marais. De

- Tiges toutes lertiles, vertes, scabres (f. 21), très rameuses, persistant pendant l'hiver; épi ovoïde, mucroné (f. 22). - Ұ. Ju-spt. C. Lieux sablonneux, plaine de la Garonne. (E. ramosum DC.). P. rameuse. T. Hamosisgimmm Desf.

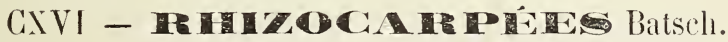

\section{AZOLLA Lam. - Azolle. - Pl. MIX, f. 23.}

Plante nageante, de 1-o̊ cm., à frondes ovales, imbriquées, devenant rouges. - (1). Av.-spt. C. Eaux stagnantes, fossés : se multiplie rapidement et forme un épais tapis à la surface des eaux. Env. de T., Lamarque, Braqueville. D'origine américaine. . . . .......... A. lougère. A. Hilculoides Lam. 



\section{ADDITIONS ET CORREGTIONS ${ }^{(1)}$}

Page 18, ligne 2\%, après (Timbal), ajouter : Ramier de Beauselle.

Page 22, à la fin du g. RANUNCULUS, ajouter :

Le $\mathbf{R}$. caucasicus M. Bieb, qui diffère du $R$. acer L. par ses fleurs plus grandes, ses tiges poilues-hérissées, ses feuilles moins protonment découpées et très velues, est adventice cu Bécurñis, à Toulouse. - Mai-jn.

Page 2 (clé des Crucifères), compléter ainsi le $n^{\circ} 12$ :

- F. entières, glauques et glabres ; fl inodores, blanc jaunâtre. . .................... 9 bis. Conringia 1.223.

Page 26 (clé des Crucifères), compléter ainsi le no 23 :

- Silicule comprimée, à 2 lobes orbiculaires, échancrée au sommet, de $21 / 2 \times 1 \quad 1 / 2 \mathrm{~mm} . \ldots \ldots \ldots \ldots$. . . . 17 bis. Senebiera p. 223.

Page 29, après le g. ALLIARIA, ajoutei :

9 bis - CONRINGIA Adans. - Conringie.

F. caulinaires cordées-amplexicaules, siliques de $8-12 \mathrm{~cm}$. de long. - (1). RR. Mai-jn. Cultures. T., champs du Béarnais. (Erysimum perfoliatum Grantz). . . . . . . . . . . ....... C. d'Orient. C. oxiontallis Andrz.

Page 31 , au bas de la page, ajouter :

$$
17 \text { bis - SENEBIERA I)C. - Sénébière. }
$$

F. pennatipartites; fl. très petites; grappes opposées aux $f$. ; pédicelles filiformes. - (1). Av.-at. RR. Originaire d'Amérique; naturalisée a T., aux Minimes, rue Chaussas. (S.didyma Pers.). .

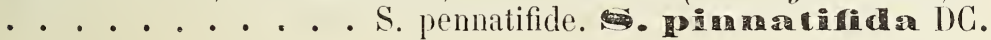

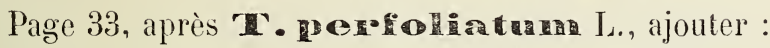

F. entières, obtuses ; tige dressée; grappes allongées. - Av.-mai. Coteaux de Lacroix-Falgarde et de Goyrans. . . T. erraticum Jord.

Page 34, à la fin du g. ALYSSUM, ajouter :

L'A. incanum L. (Berterou incance DC.), ì pétales bifiles, blancs, à silicules elliptiques, poilues, plus courtes que les pédoncu:es, est subspontané à Grenade, sables de l'ile Miquelis, et ì Ondes, dans les iles de l'Hers (M. Fages). - Eté. Bisannuel ou vivace.

(1) - Ces additions sont relatives à quelques espèces omișes et à d'autres dont j'ai constaté l'existence dans la région toulousaine pendant l'impression de la Florule. - H. S. 
Page 36, à la fin dlug. RESEDA, ajouter :

Le R. alba L, à fl. blanches, à capsule munie de 4 dents, à feuilles pennatiséquées, à segments nombreux, est adventice au Béarnais, $\dot{\alpha}$ Toulouse. - Mai-jn.

Page 37, compléter ainsi le g. HELIANTHEMUM :

- F. toutes stipulées; tiges herbacées ; pétales jaunes, plus courts que les sépales ou les égalant. . . . . . . . . . 2

2 - Bractées foliacées, égalant ou dépassant les fl.; pédicelles bien plus courts que les sépales; capsule de $1 \mathrm{~cm}$. de long. - (1). Mai-jn. R. Collines calcaires d'Avignonet. (H. niloticum Pers.). .

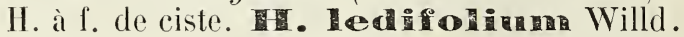

- Bractées réduites, égalant à peine les pédicelles, qui dépassent ordint les sépales ; capsule de $4-\breve{~ m m}$. de long. - (1). Av--jn. P. Collines calcaires d'Avignonet. . . . . . . . . . . .

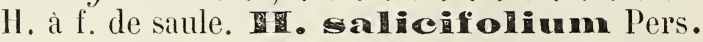

Page 40, après o llica v. rosella, ajouter :

Calices à nervures purpurines ; pétales tachés de pourpre. - $T$., au Béarnais . . . . . . . . . . . s. quinquevulnera L.

Page 40, à la fin du g. SILENE, ajouter :

Le S. dichotoma Ehrh., qui se distingue du S. gallica L. par sa capsule beaucouj, plus longue que son support, est adventice au ramier de Bauzic, ¿̀ Grenade (M. Fages).

Page 5̆, à la fin dı g. ONONIS, ajouter :

L’o. biflora Desf., plante de la région méditerranéenne, à f. trifoliées, à pédoncules biflıres, aristés, dépassant les f... à fl. jaunes, veinées de rose, à gousse cylindrique, dépassant longt le calice, est adventice au Béarnais, ì T. - Annuel. Mai.

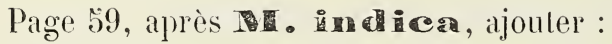

- Fl. jaunes, de 2-3 $\mathrm{mm}$. de long, inodores, à pétales inégaux ; gousse subglobuleuse, de $3-4 \mathrm{~mm}$. de long. munie de côtes concentriques. - Av.-mai. R. T., Champs, piess, entre l'Embouchure et le Béarnais (C.). . . . . . II. sillonné. Desfor.

Page 60, au g. MELILOTUS, compléter ainsi le $n^{0} \mathbf{2}$ :

- Pétales inégaux (ailes plus courtes que la carène, qui égale l'étendard de $7-9 \mathrm{~mm}$. de long) ; folioles larg't ovales-cunéiformes ; gousses de $气 \mathrm{~mm}$. de long, à côtes concentriques. - (1). Mai-jn. RR. Ramier de Beauselle: T., au Béarnais. Originaire de la région méditeranéenne. . . M. ennemi. I . infesta Guss.

\section{Page 61 , après T. olegans, ajouter :}

Tiges fistuleuses; fi. plus grandes, de $8.9 \mathrm{~mm}$. de long, au licu de 6-7. - T., au Béarnais . . . . . . . . . . . T. fistulosum Gilib.

- Caractères du T. elegans, mais calices à dents égales, plus 
courtes que le tube; fl. toujours dressées (non renversées) ; gousse resserrée au milieu. - (1). Mai-jn. RR. Piés du Béarnais, à T. .

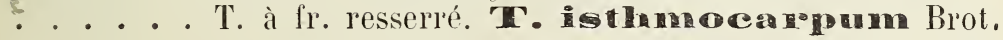

- Caractères dı T. elegans, mais dents du calice recourbées après l'anthèse, fl. blanches ou faiblt rosées; gousse sessile, bosselée, crénelée au bord infr. - (1). Mai-jn. R. T'., au Béarnais. . ......... T. noirâtre. T. nignescens Viv.

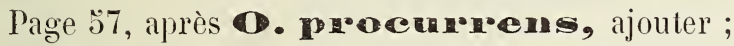

- Fl. roses, petites ( $8 \mathrm{~mm}$. de long), dépassant pen ou point le calice, en grappes terminales feuillées; tiges non radicantes, de 5̆$20 \mathrm{~cm}$. à 1. 3-foliées ; plante velue-glanduleuse, à pédoncules uniflores, articulés. - (1). Jn. R. Coteaux calcaives d'Avignonet.

B. renversée. D. Ha

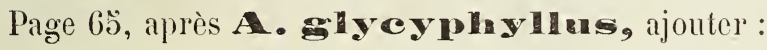

- Fl. petites, 6-8 mm. de long, jaune verdâtre; 17-2つ folioles oblongues, velues en dessous ; gousse pubescente, de $3 \mathrm{~cm}$. de long, courlée en hamecon. - (1). Mai-jn. R. T., champs cultivés, au Béarnais. . . . . A. en hamecon. A. Tanosos L.

Page 66, après V. dasycarpa, ajouter :

Grappes de $2.6 \mathrm{fl}$. de $1 \%-18 \mathrm{~mm}$. de long, d'un violet bleuitre ; 7-9 paires de folioles oblongues, échancrées au sommet; gousse de $4 \mathrm{~cm}$. de long env. et de 9-10 mm. de large. - Mai-jn. R. Prairies artificielles. T., au Béarnais.......... V. Pseudocracca Pert.

Page 66, après I. Tissolita, ajouter :

- F. infres réduites au pétiole foliacé ovale ou oblong, les supres à 2-4 folioles ovales ou suborbiculaires; pédoncules portant !-2 fl. d'un jaune pâle'; gousse à 2 ailes membiraneuses. - (1. Mai-jn. R. Prairies artificielles. T., au Béarnais. . . • . . . . . . .

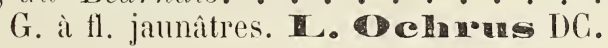

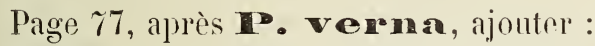

- Tiges non radicantes, dressées, de 3-כ̆ dm. ; f. très velues, à 7 folioles ; carpelles mûrs plissés-rugueux. - q. Mai-ju. . . . . . •

Folioles oblongues, grandes, profondt dentées sur tout leur contour ; stipules à $2-3$ sęments étroits ; pétales jaune pâle, ne dépassant pas le calice. - RR. Coteaux dominant le village de LacroixFalgarde, au-dessus de l'église (Marçais) et ver's le sud.

P. dressée. $P$. recta $L$.

Page 91, au no 33, après segments des f. linéaires, ajouter ;

$\alpha$ - Racine non bulbiforme; base des styles conique. 26 Ptychotis.

$b$ - Racine bulbiformo ; base des styles déprimée, discoïde . . . . 25 bis Bulbocastanum ए, 226. 
Page 95̆, après tonuisoimum, ajouter :

- Involucre à 3-5̆ folioles largt lancéolées, plus longues que les rayons (2-4) de l'ombelle; f́. linéaires-acuminées; plante de $5-20 \mathrm{~cm}$. - II. Jn-jlt. R. Coteaux calcaires avignonet. (B. aristatum G. G.). . . . . . B. opaque. FE. opacum lange.

Page 95, avant PTYCHOTIS, ajouter :

\section{5 bis. - BULBOCASTANUM Adans.}

Involucre et involucelles à $\breve{-}-8$ folioles ; fruit ovoïde-oblong ; ombelles à 10-15̆ rayons inégaux. - \%. Mai-jn. R. T., prairies artificielles, au Béarnais. (Bunium Bulbocastanum L., Carum

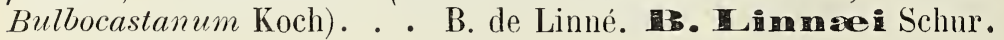

Page 103, ligne 7 : au lieu de trompé, lire tronqué.

Page 114, avant C. segenem, ajouter : T., au Béarnais.

Page 118, après C. Lemuilloms, ajouter ;

- Capitules ovoïdes-oblongs, un pen plus gros, solitaires ou par 2-4 sur des pédoncules nus an sommet; akènes visqueux. - (2). Jnjlt. R. T., champs incultes, au Béarnais. . . . . . . . . .

Page 120, à la fin du g. CENTAUREA, ajonter :

Le C. collina L., qui se distingue du C. Sccibiosa par ses feuilles pubescentes-crépues, ses fleurs jaunes. ses involucres dont les folioles sont bordées de cils raides, le terminal épineux, presque aussi long que la foliole, croit sur les coteaux calcaires digvignonet. Vioace. Jn-spt. - On le distinguera aisément du C. solstitialis, qui a aussi les ficurs jaunes. à ses f́. caulinaires non décurrentes.

Page 133, à la fin dı g. CONVOLVULUS, ajouter :

- Tige non volubile; f. oblongues ; fl. axillaires, solitaires, bleues aux bords, blanches et jaunes dans le fond. - (1) Jn. T., champs cultivés, au Béarnais (Adventice). . . . . . . . ............... L. tricolore C. theolon L.

Le Dichondra sericea Sw. Prod., 54, (D. repens Forst. var. sericed Choisy), plante grêle, à tiges jadicantes, à f. petites, réuiformes, entières. longt pétiolées, pubescentes-soreuses cu cessous, à fi. très petites (3 mm. environ), à corolle 5-lobce, d'un blanc verdâtre et clabre, à fruit, formé de 2 capsules monospermes et très velues, est naturalisé sur les pelouses dru Jardin des Plantes, ¿̀ T. - Vivace. Mai-jn. Originaire d'Amérique ou d'Australasie.

Page 143, ligne 3, au lieu de V. Meredifolia lire $\mathbf{V}$. hederoriolion.

Page 144, à la fin dug. LINARIA, ajouter :

Le L. triphylla Mill., plante glabre et glaurque, à f. ovales, sessiles, les inférieures ternées; à fl. grandes, jaunes, à éperon violet. est adventice au Béarnais, ¿'Toulouse. - Mai-jn. - Le L. commutata Bernh., qui existait autrefois autour de La Ramette, semble avoir disparu depuis longtemps de cette localité. 
Page 1כ̆1, ligne 4, ajouter : Coteaux d'Avignonet (CG).

Page 160, à la fin du g. PLANTAGO, ajouter :

Le P. lagopus L., à f. lancéolées, à épi oblong, très velu, est adventice au Béarnais, à Toulouse. - Annuel. Mai-jn.

Page 170, après E. Es

- F. glauques, distinctement dentées, les supres ovales-oblongues, élargies à la base et un peu embrassintes; ombelles jaunâtres, à $\breve{~}$ rayons épais. Faciès de E. verrucosa. - భ. Mai-jn. R. Collines et champs calcaires, à Avignonet. . E. denté.

Page 180, après D. pyzenaicunth, ajouter :

- Fl. blanches avec une bande verte sur le dos, en longue grappe aiguë an sommet d'une tige de $3-4 \mathrm{dm}$.; f. de $1 \mathrm{~cm}$. de large env. - 2. Mai-jn. R. Champs cultivés. T', au Béarnais; Avignonet $(\mathrm{C})$. . . O de Narbonne. Hanolnemse L. 

PI. I. - Renoncées, Berbérées, Papavées, Fumarées.
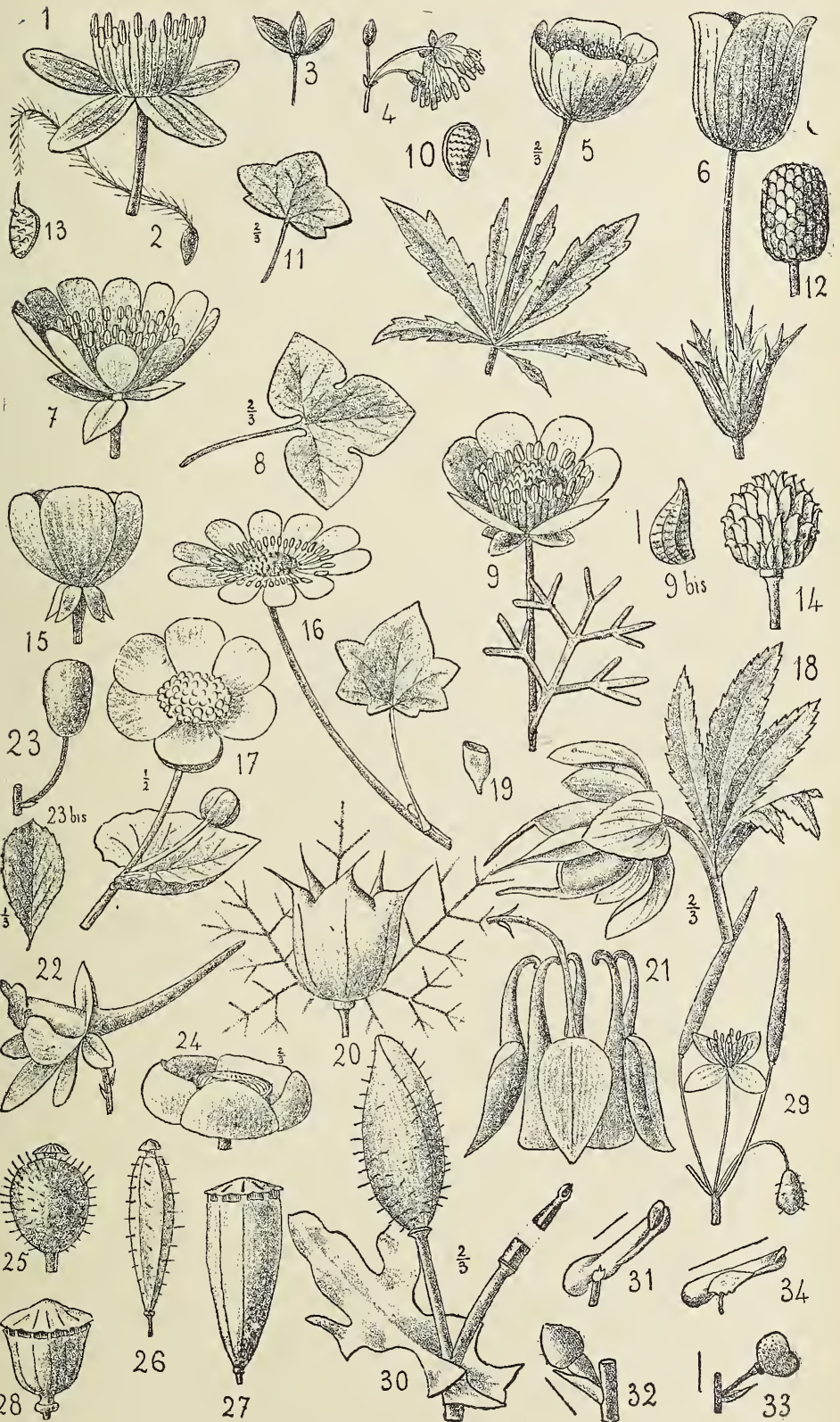


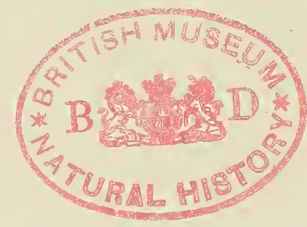


Pl. II. - Crucifères, Résédacées.

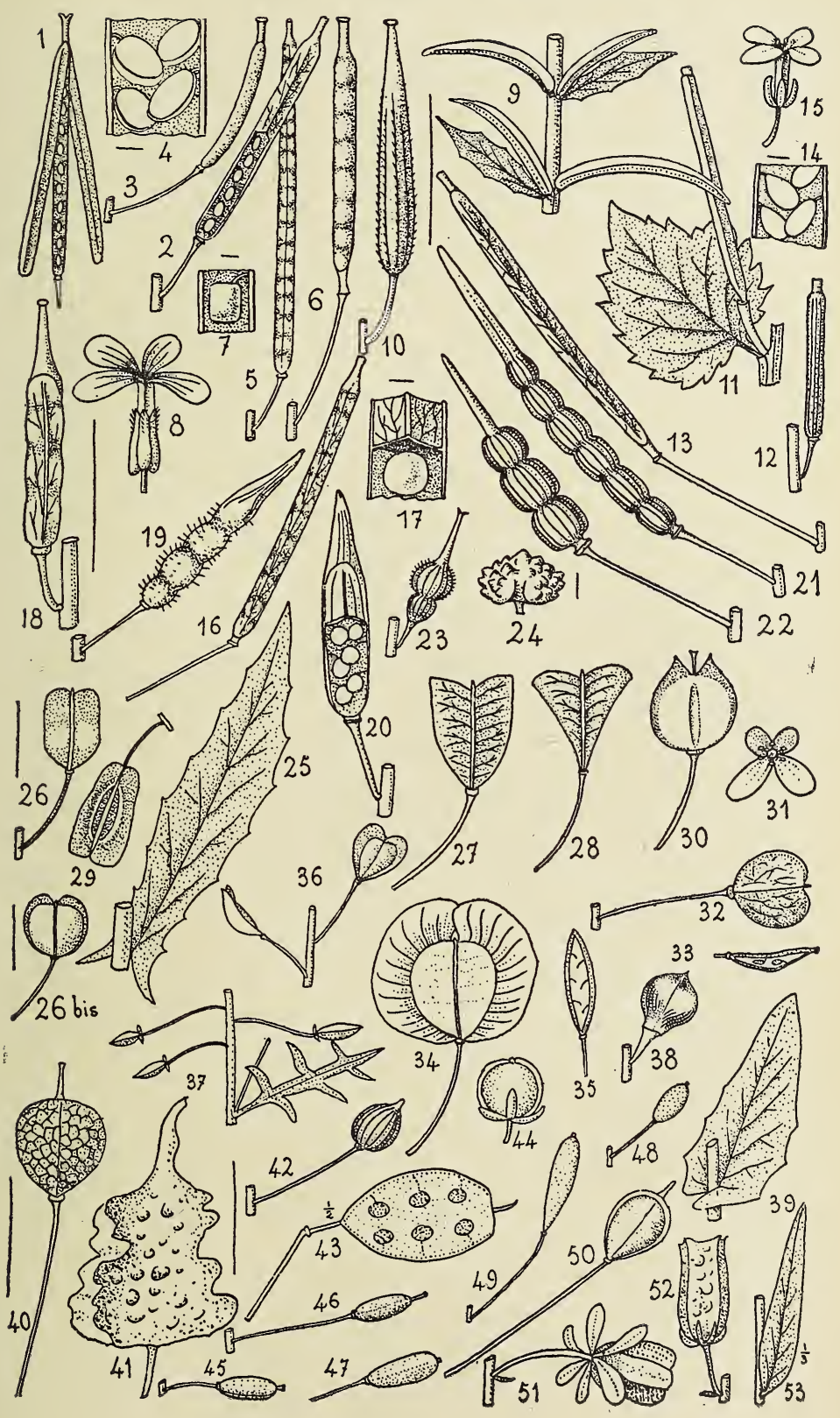




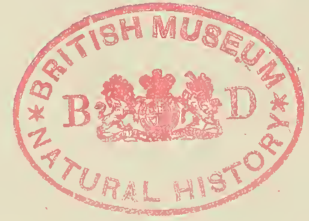


Pl. III. - Cistacées, Violacées, Caryophyllées.
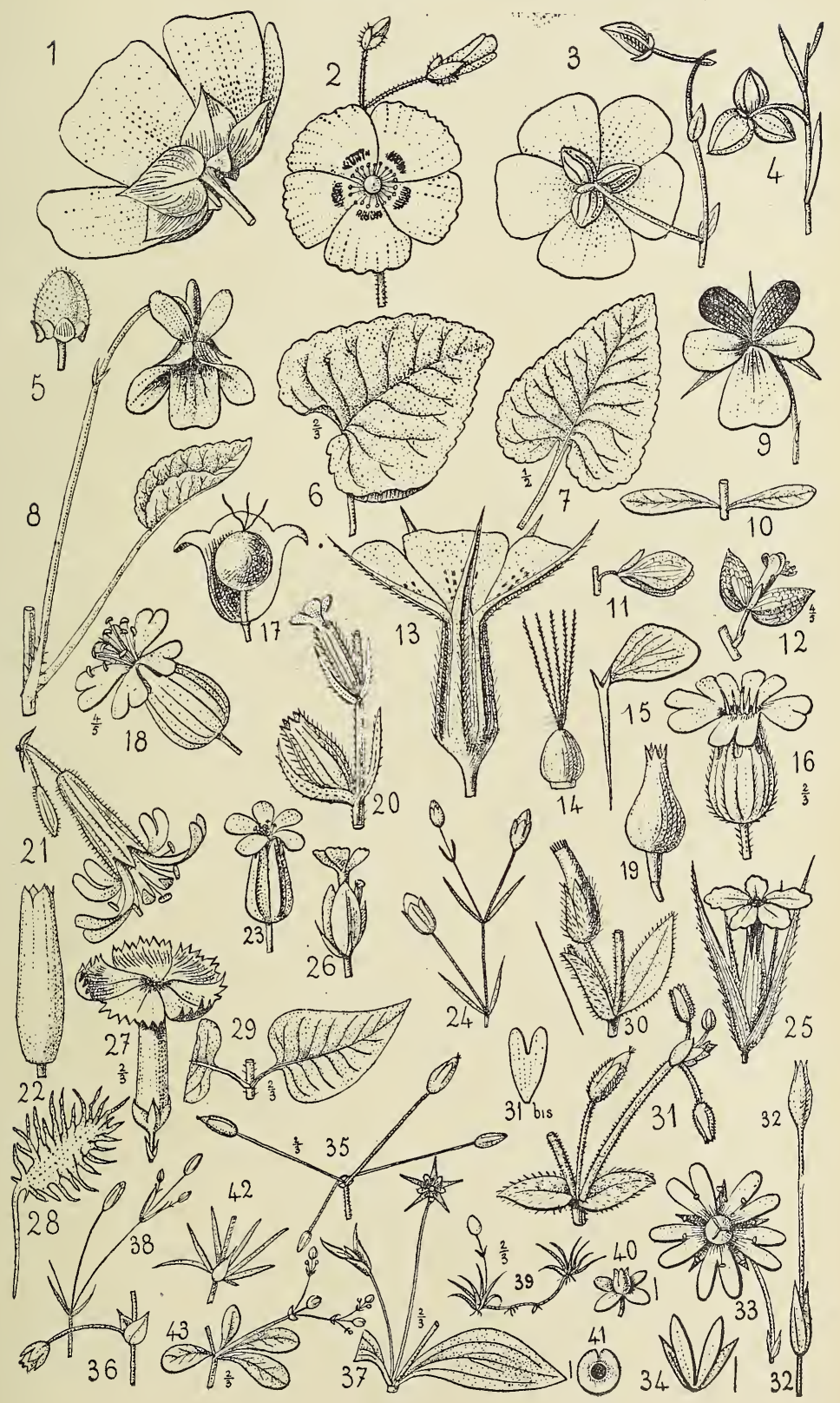


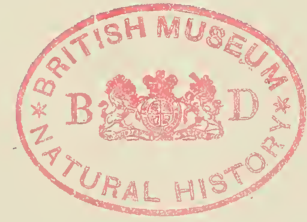


Pl. IV. - Hypéricies, Malvées, Géranées, Rhamées, ete.

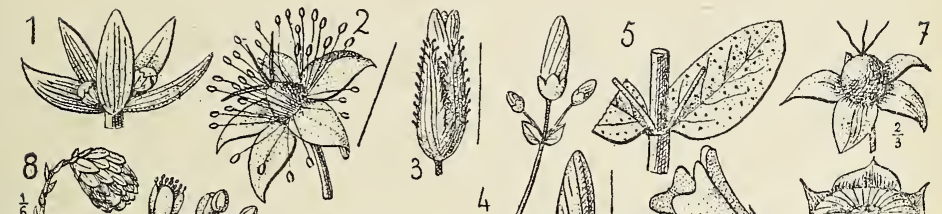

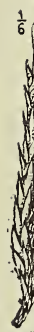

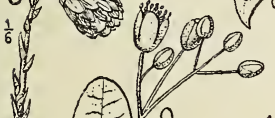

$=19$

(1)

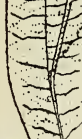
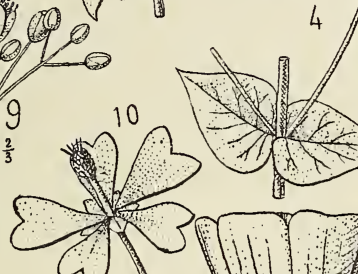

A

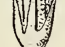

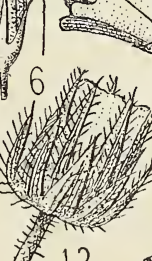
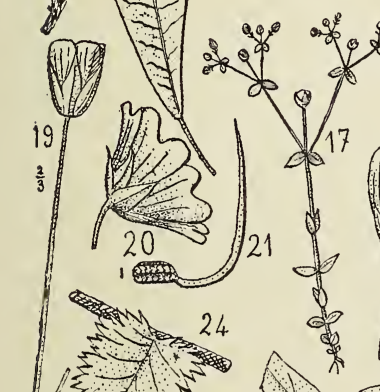

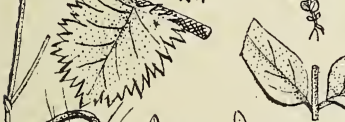
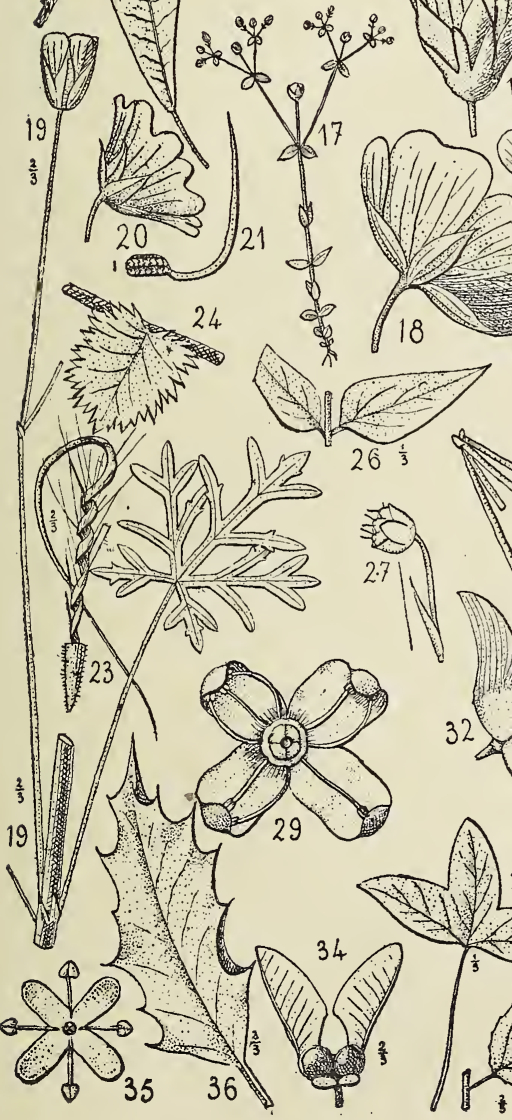

1.

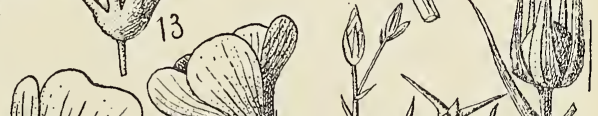

$\rightarrow 12$

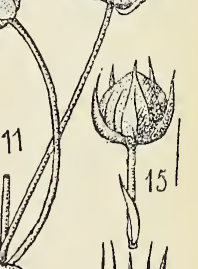

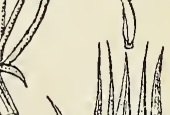
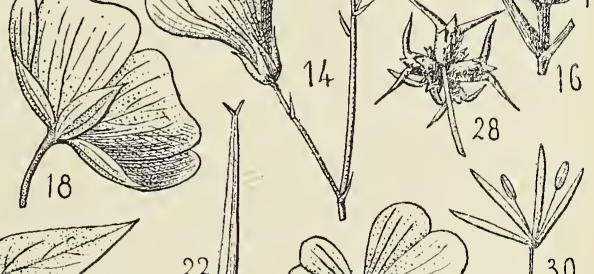

12 Y Y 14

22
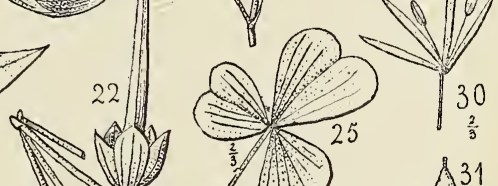


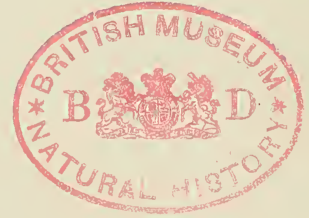


PI. V. - Légumineuses.
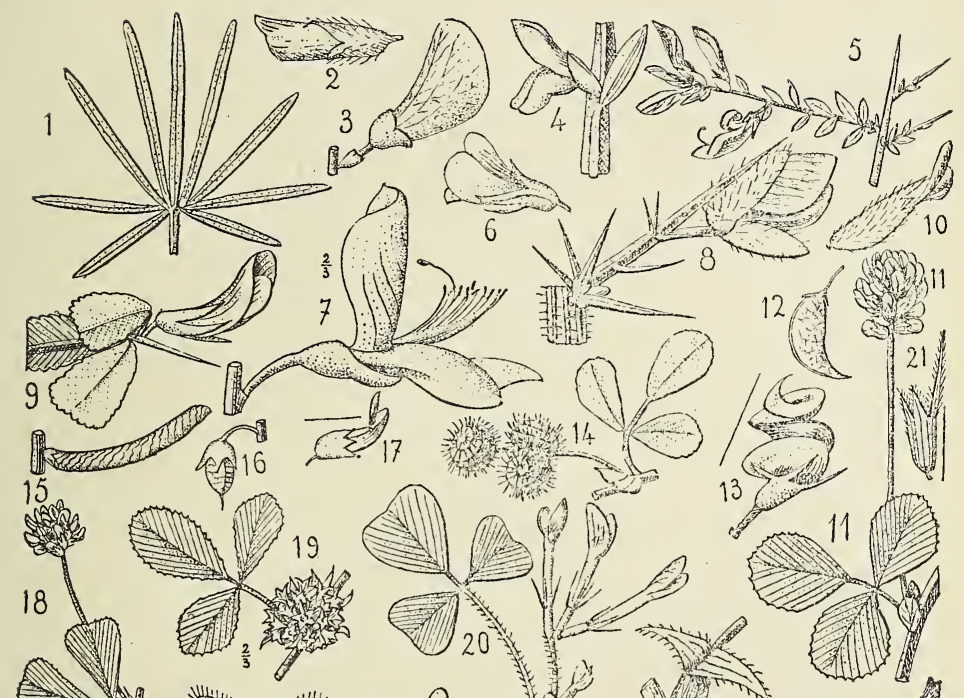

Q
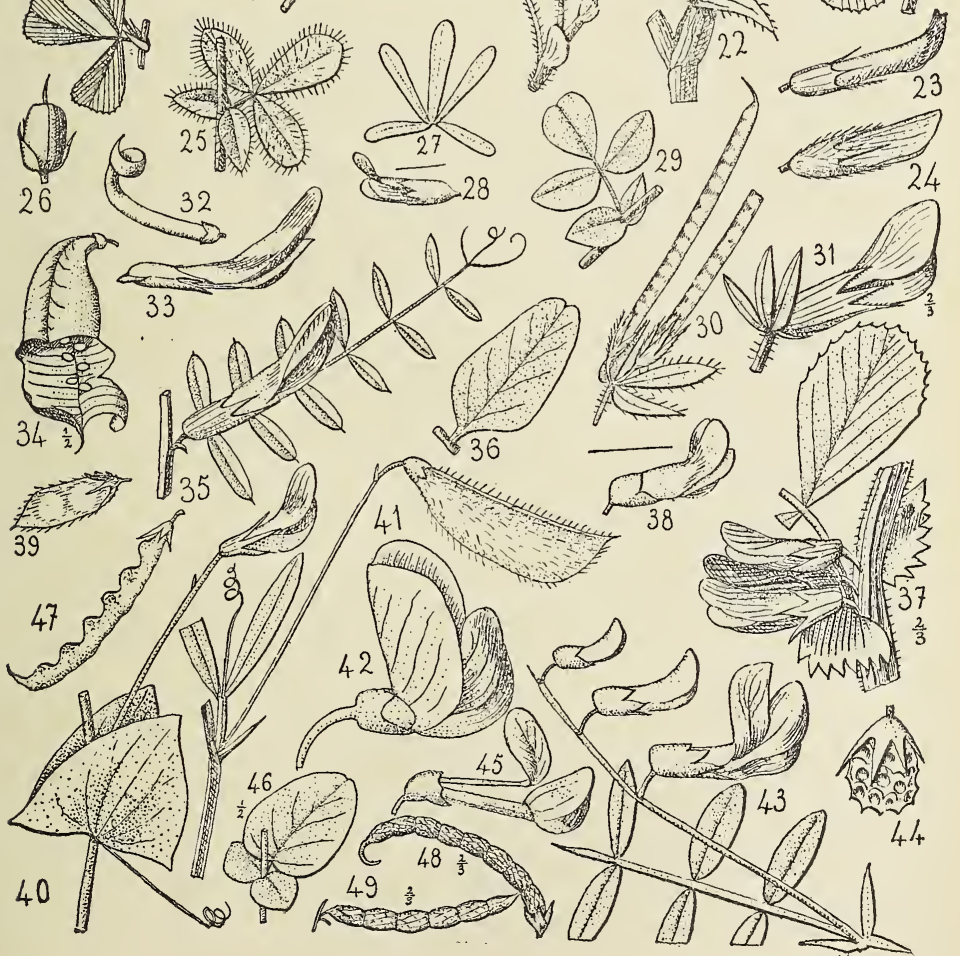


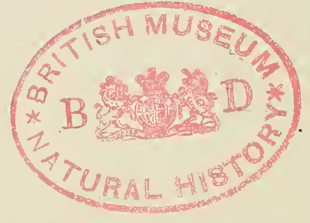


Pl. VI. - Rosacées, Cucurbitées, Saxifrées, Crassulées, etc...

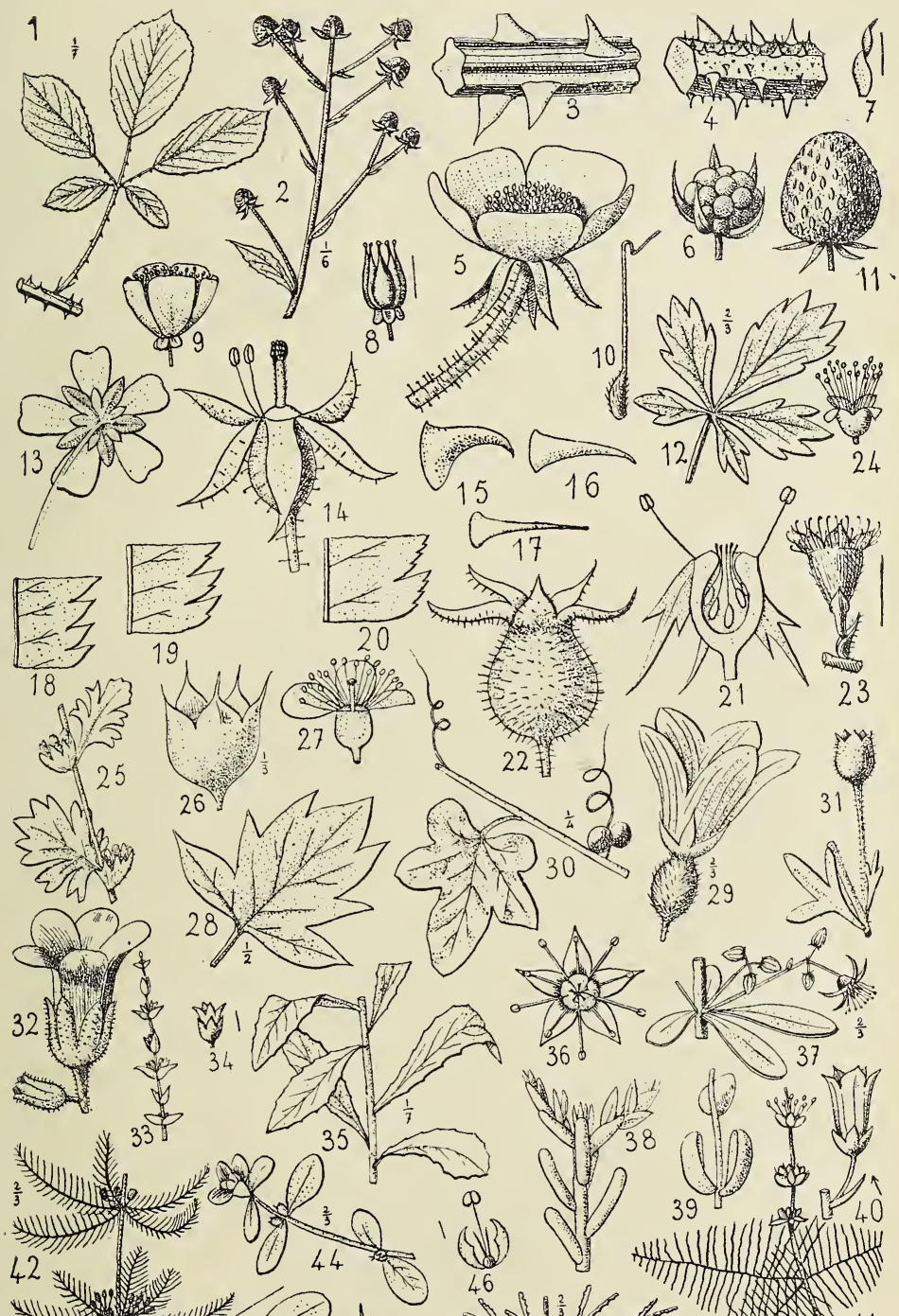

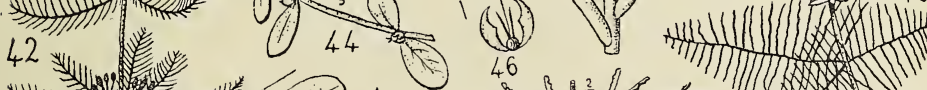
. 


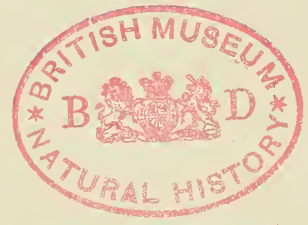


Pl. VII. - Onagrées, Paronychées, Ombellilères.

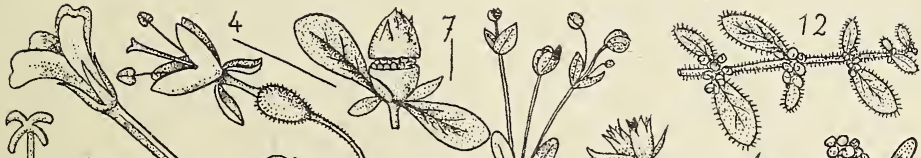
$1 \mathrm{~T}^{100}$ 1. 1.

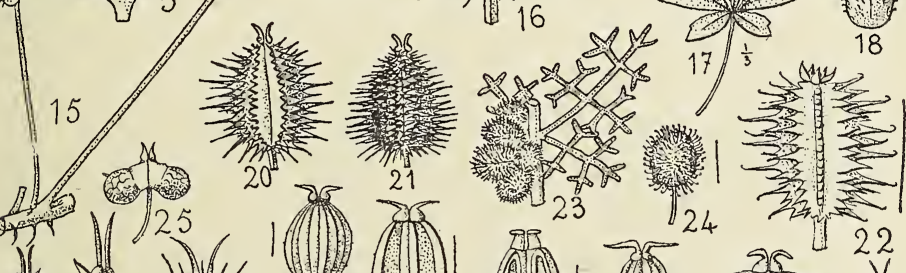
(1) $26 \quad \begin{array}{lllll}27 & 28 & 30\end{array}$

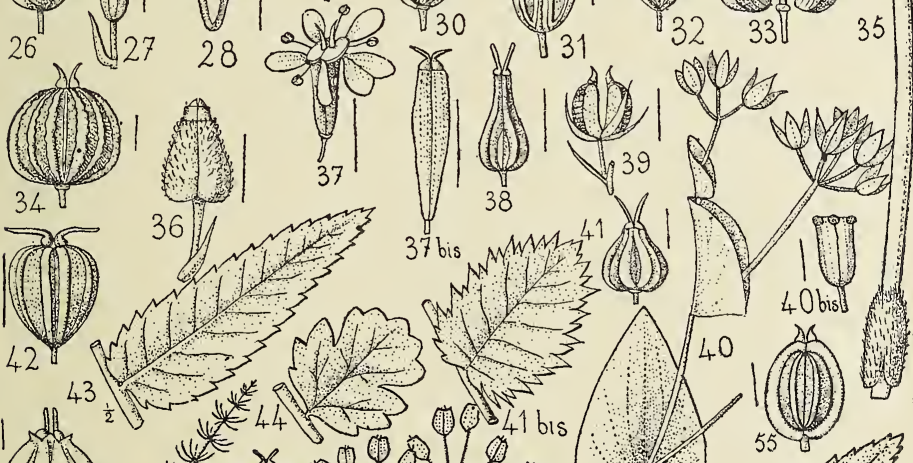
(15) 


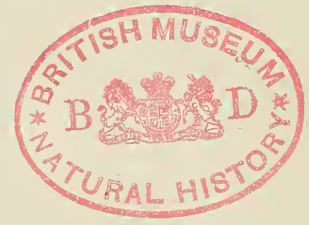


Pl. VIII. -- Caprilées, Rubiacées, Valérianées, Dipsacées.
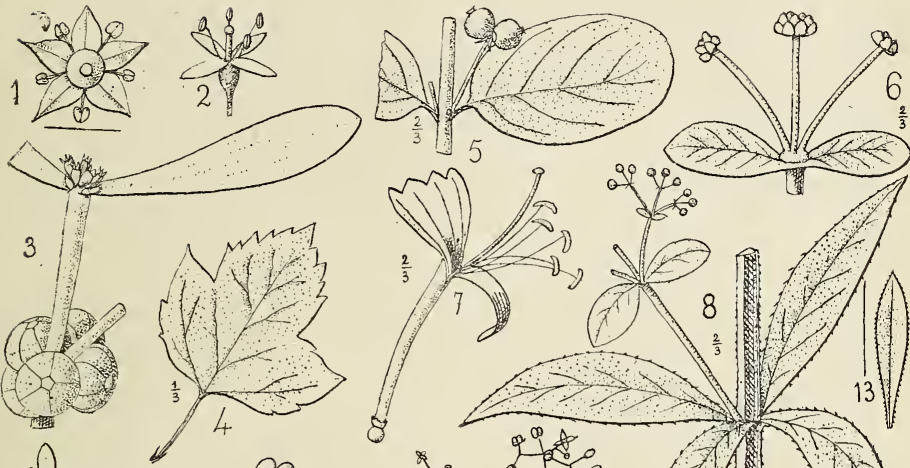

की की

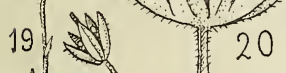

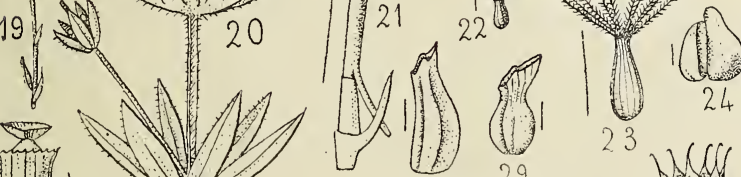

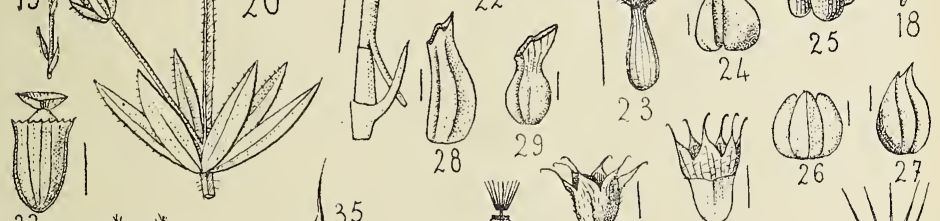

33

35

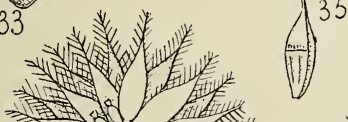
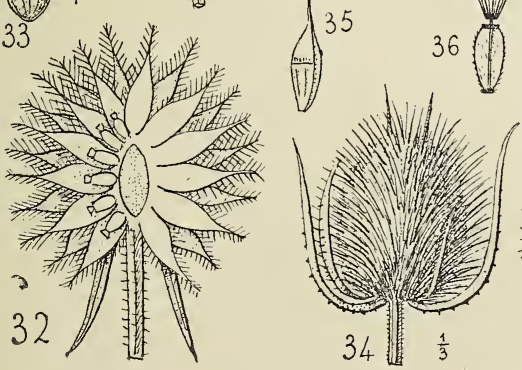

तive

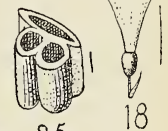

vit vêt

$\underbrace{27}_{39}$
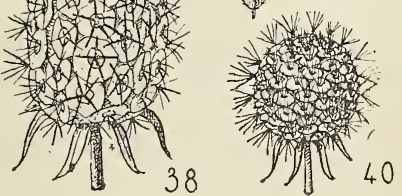


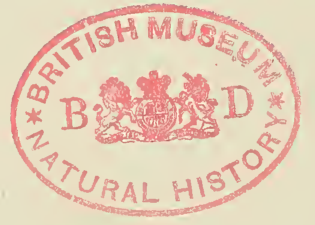


P1. IX. - Composées (Corvmbif. et Cynarocép. p. p.).

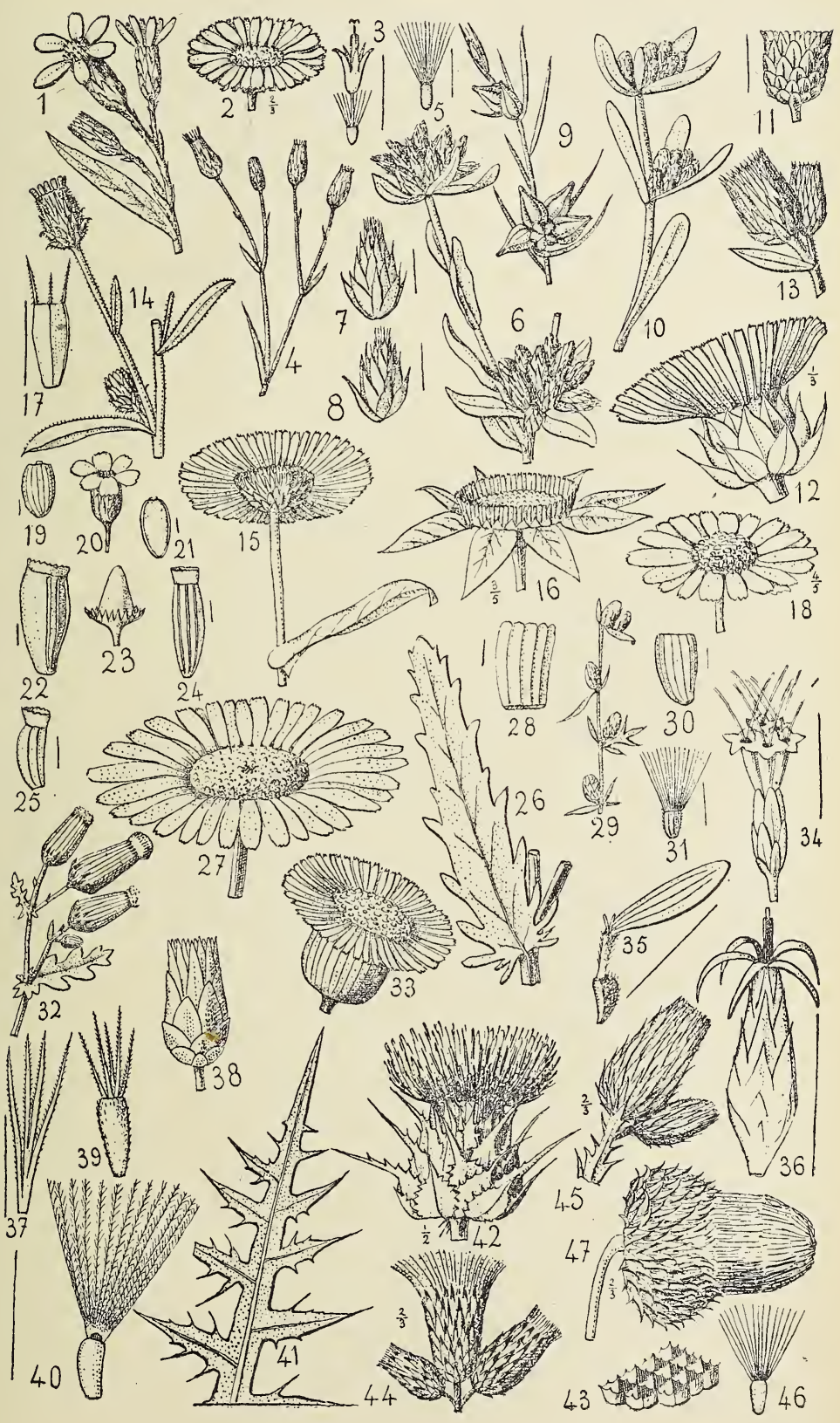




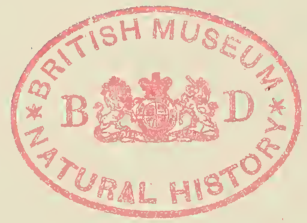




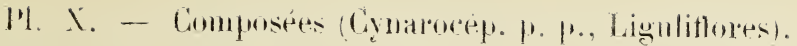
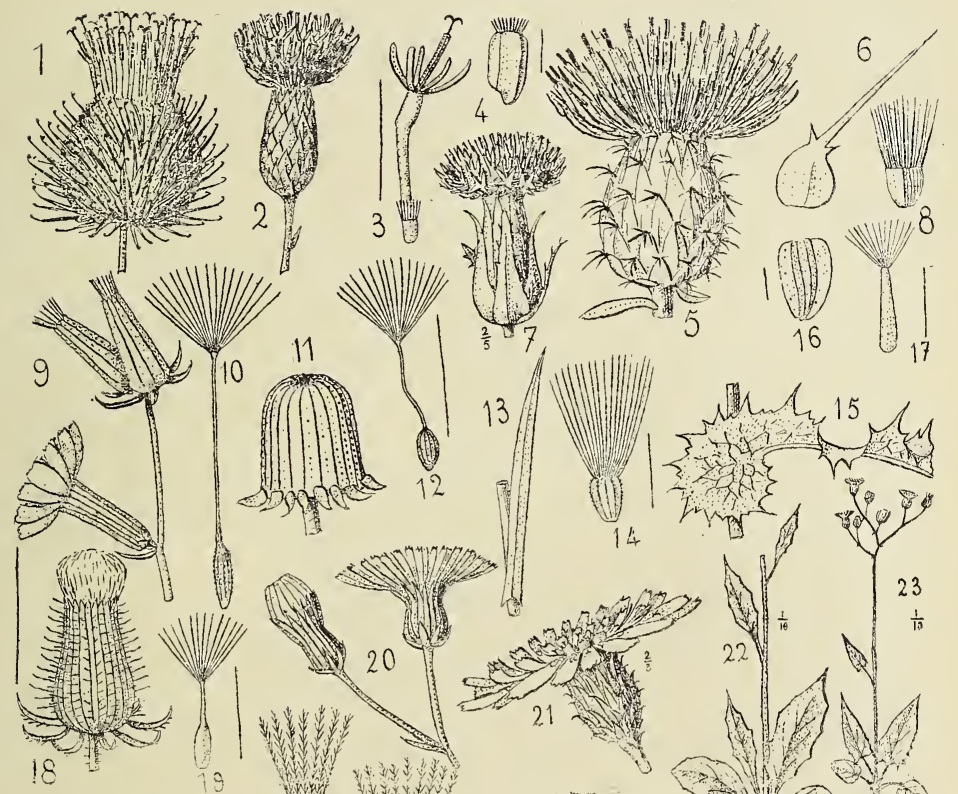

15

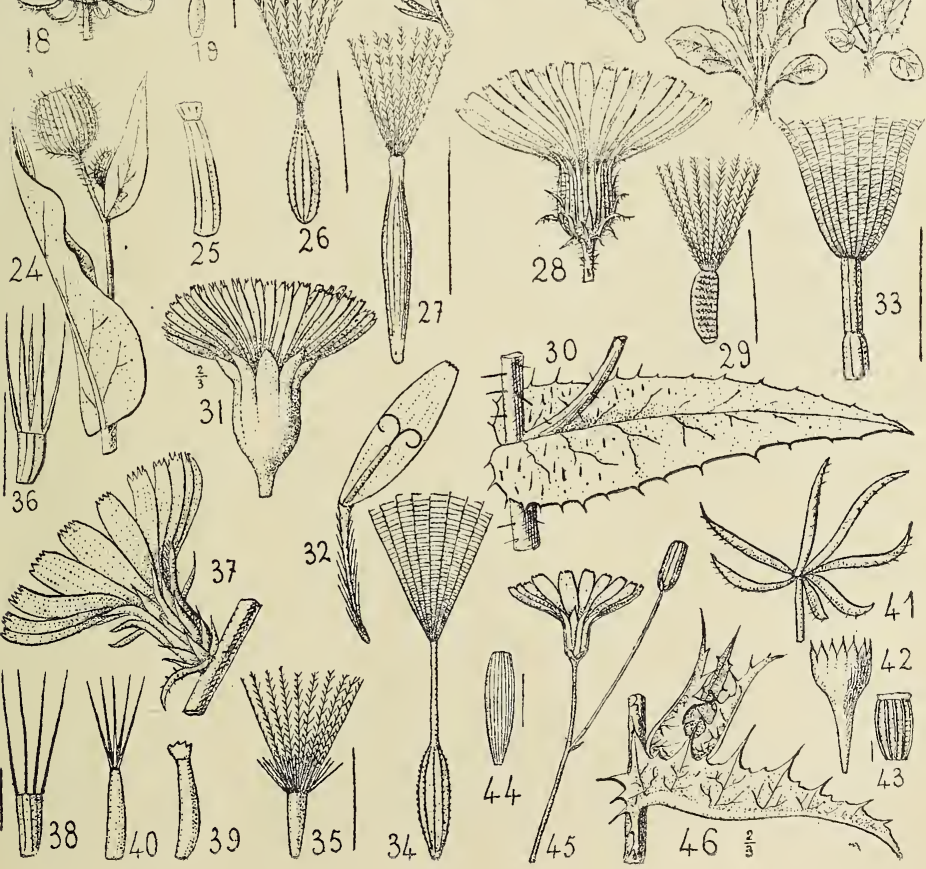




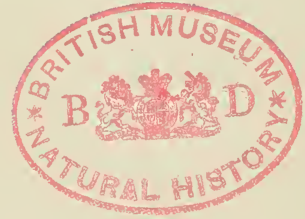


Pl. Xl. - Ambrosées, Campanées, Gentianếes, Borragées, etc.

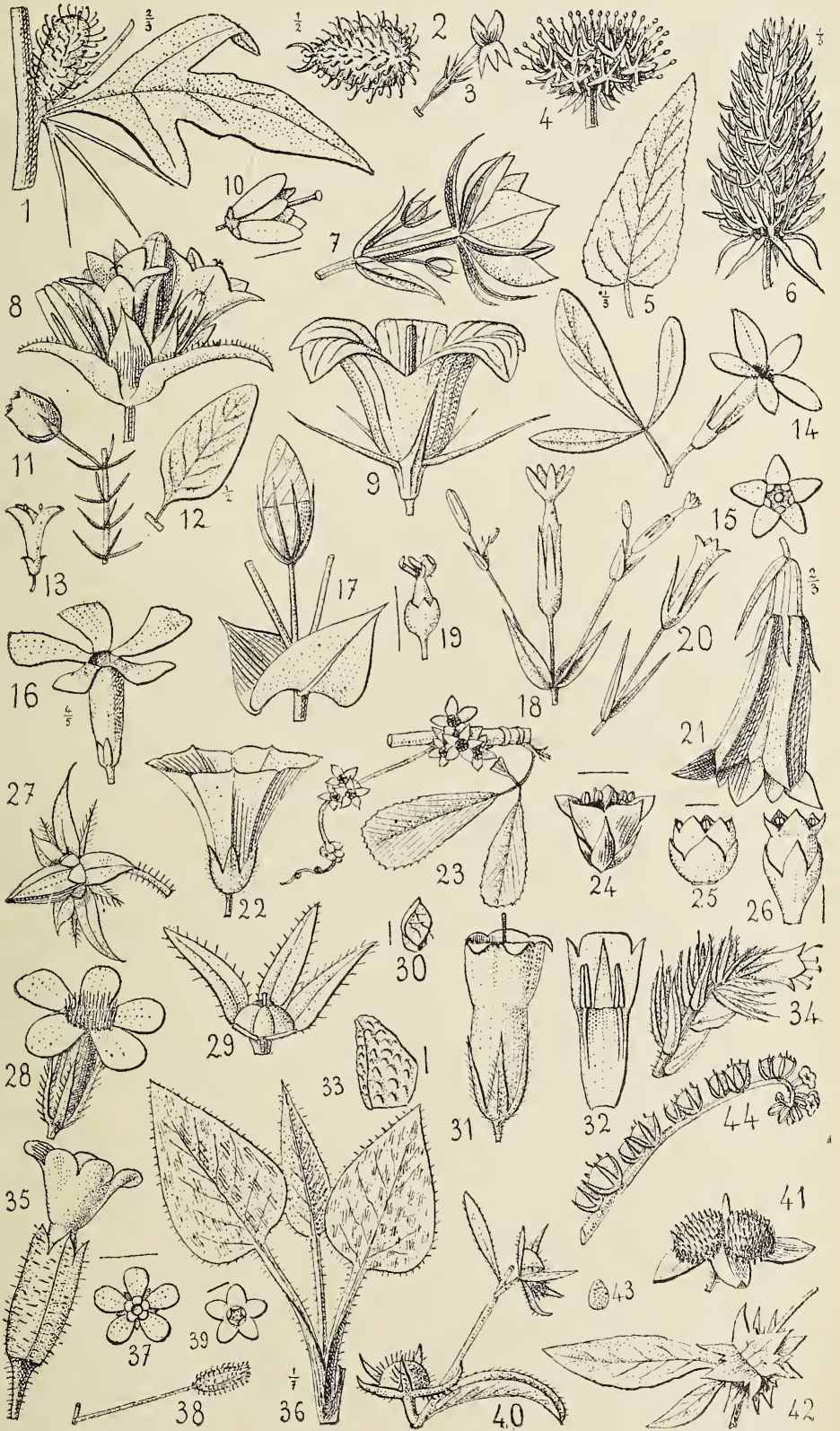




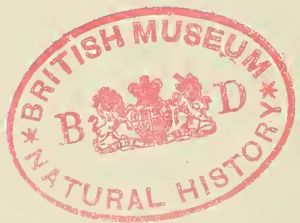


Pl. XIl. - Solanées, Verbées, Scrofulées, Orobtécs.
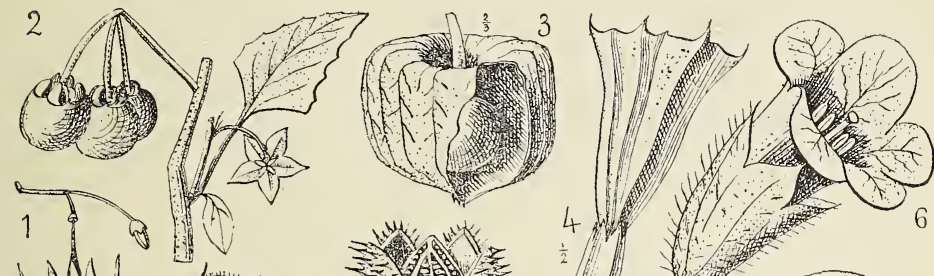

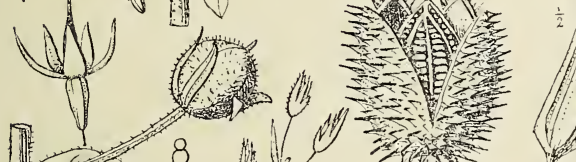
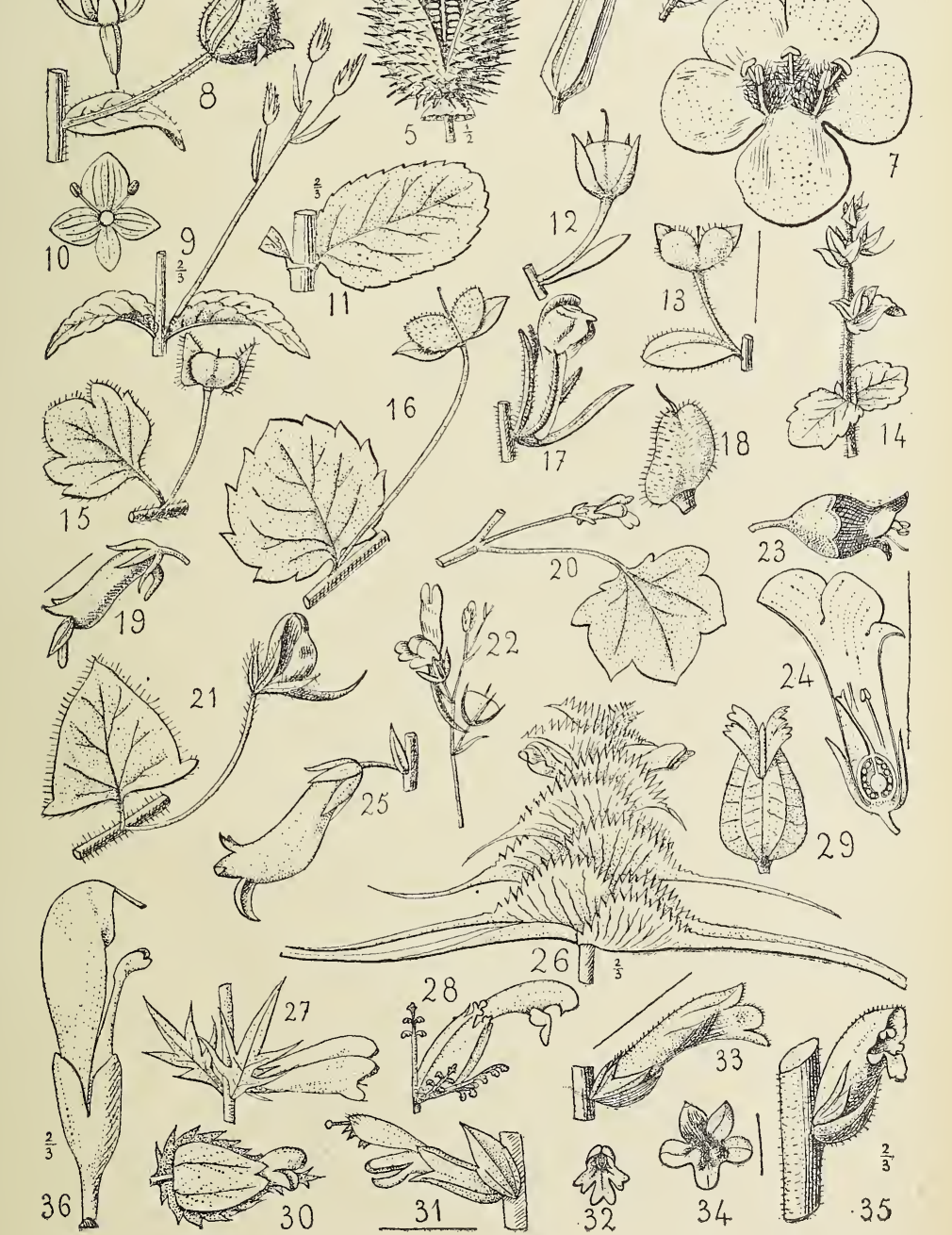

Pl. XIIl. - Labiées, Primulés, Glohuter, Plantagées, Amareses.
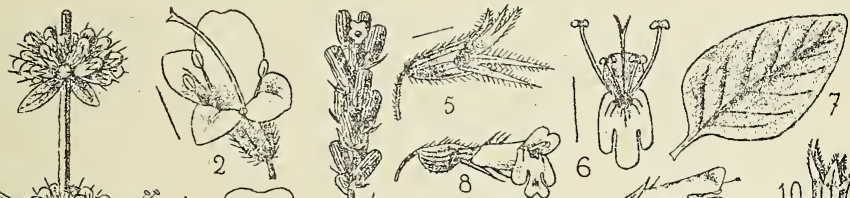

ation 10 素 (1) 413

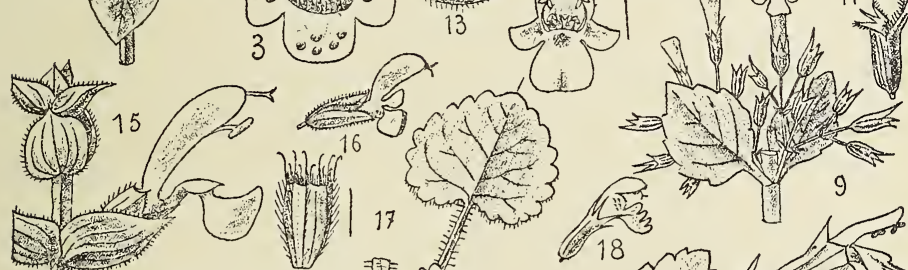

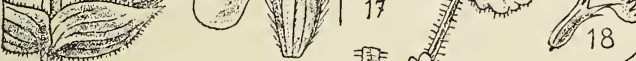
$\frac{21}{21} 0{ }_{22}$ $25-23$

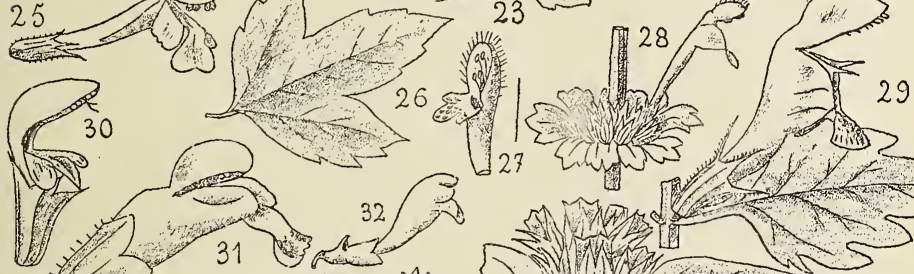

$\rightarrow \operatorname{lom}_{34}^{35}=1$ th
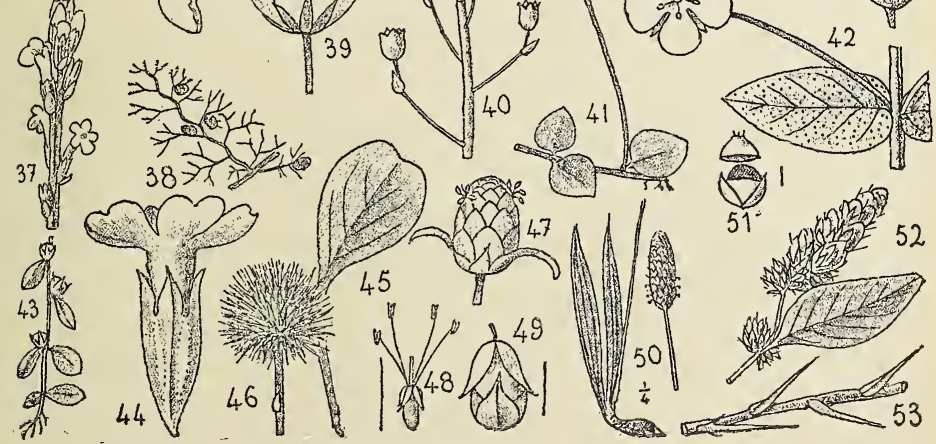


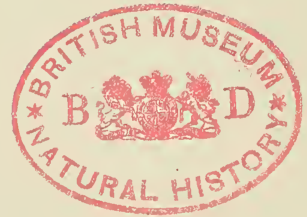


Pl. XIV. - Monochlamydées, Hydrochées, Alimacées, Colchées.
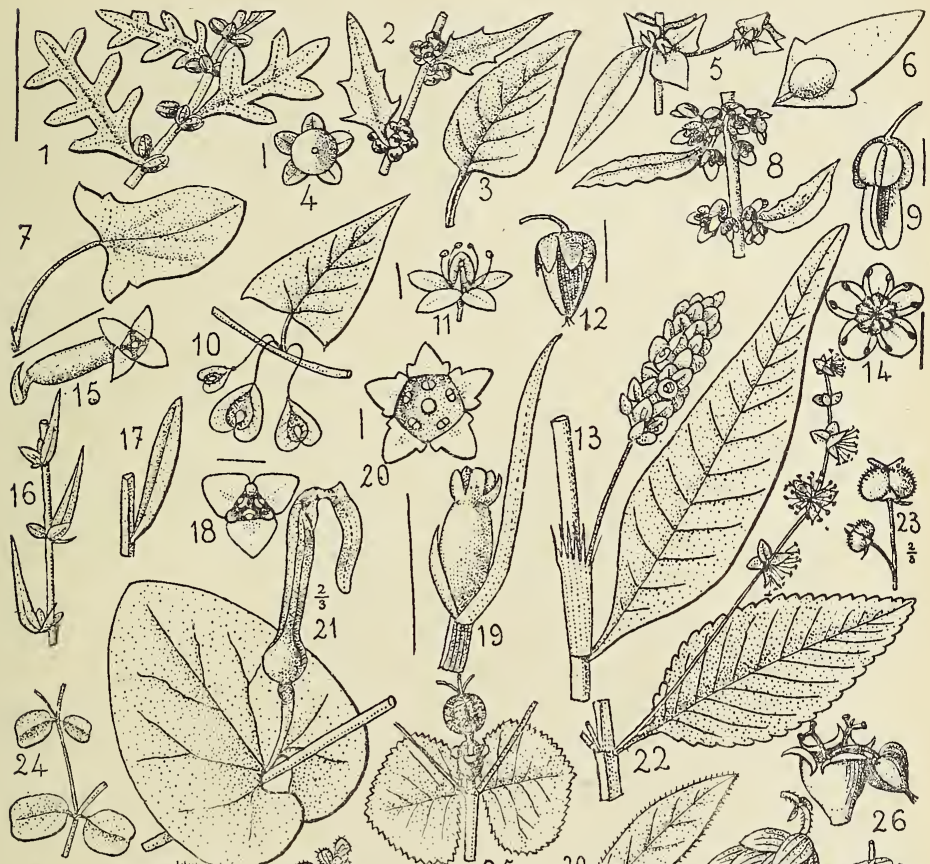
420 (1) 26 (3) o , $N$ (1)
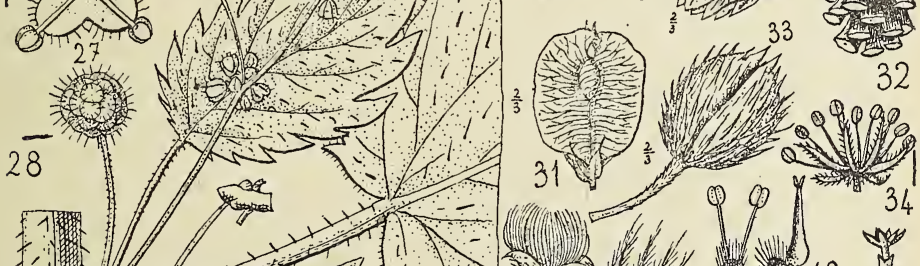

1. 1.1

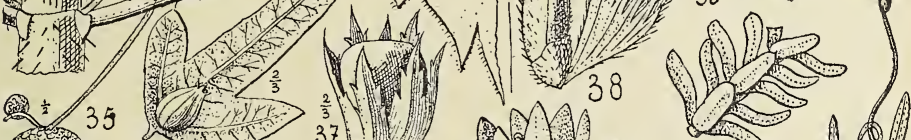
(36) 


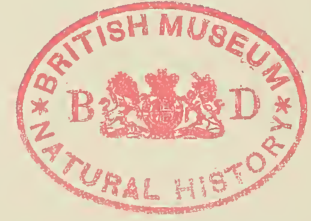


Pl. XV. - Liliacées, Asparées, Iriaces, Amaryles, Orchidées, etc...
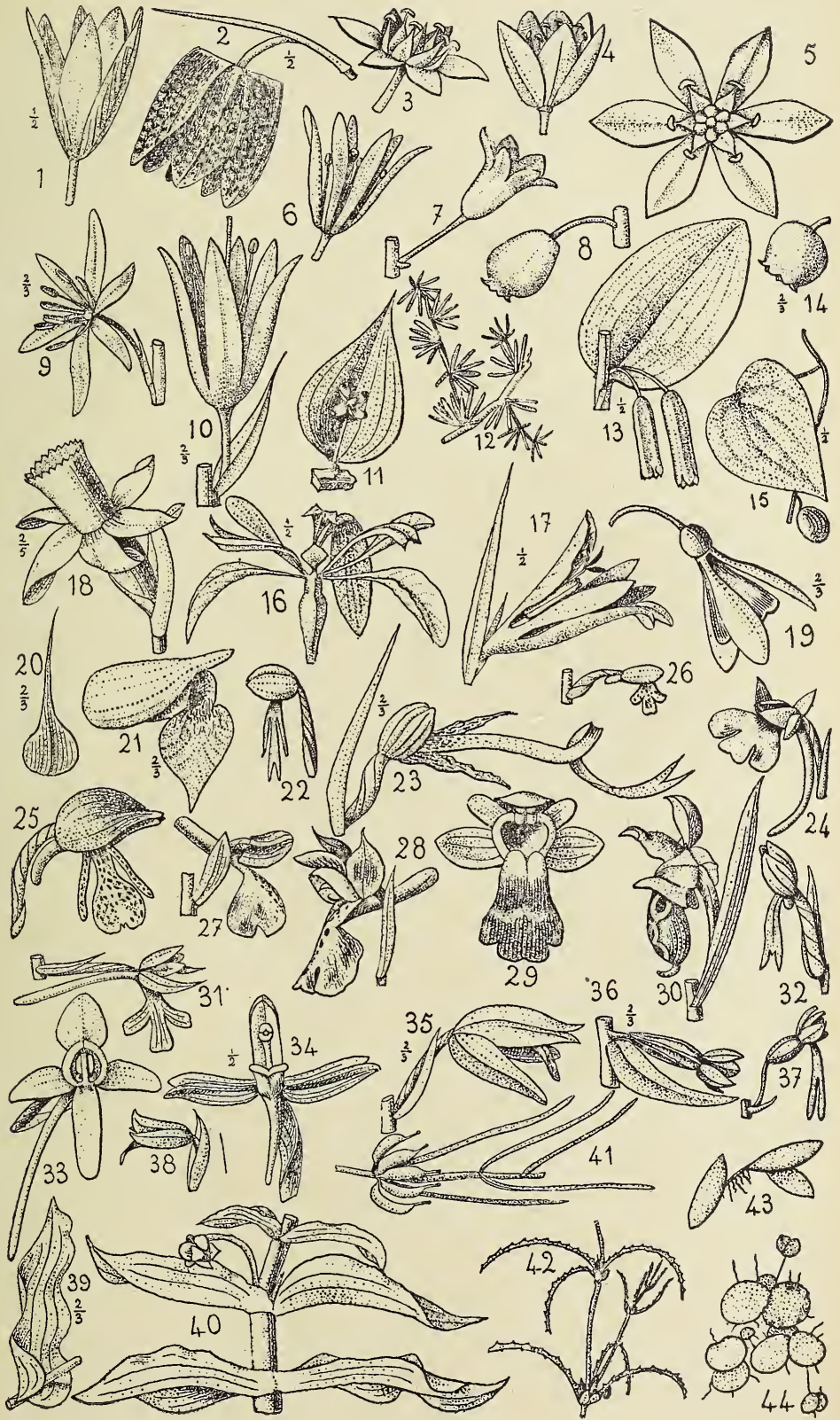


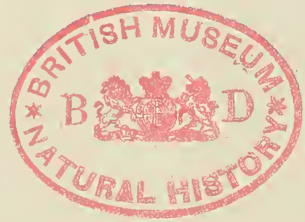


PI. XV1. - Typhées, Joncacées, Cypéracées.

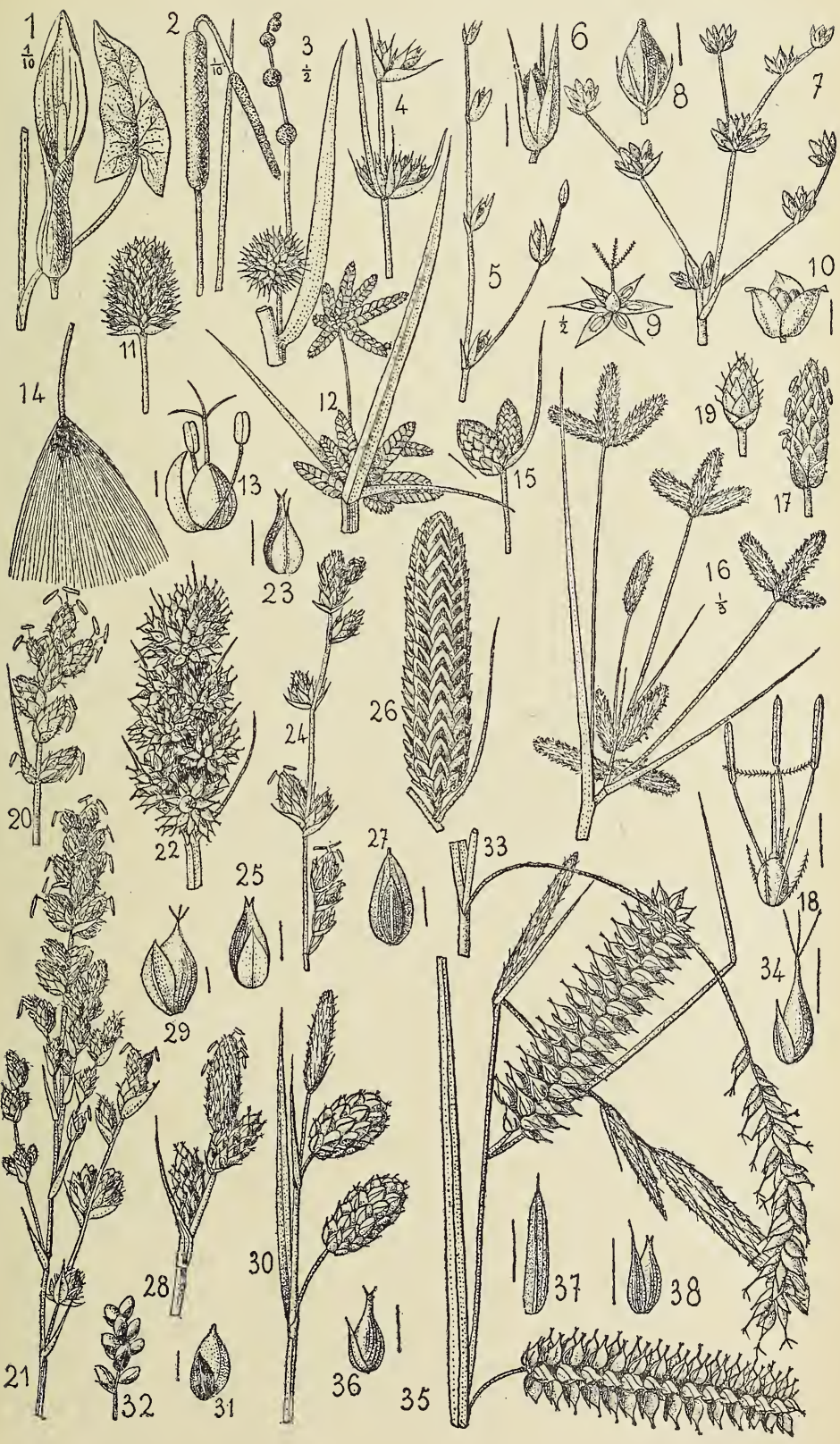




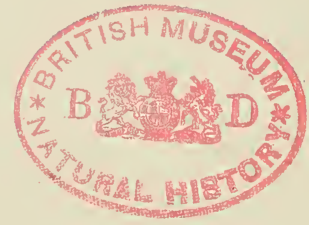


Pl. XVII. - Graminćes.

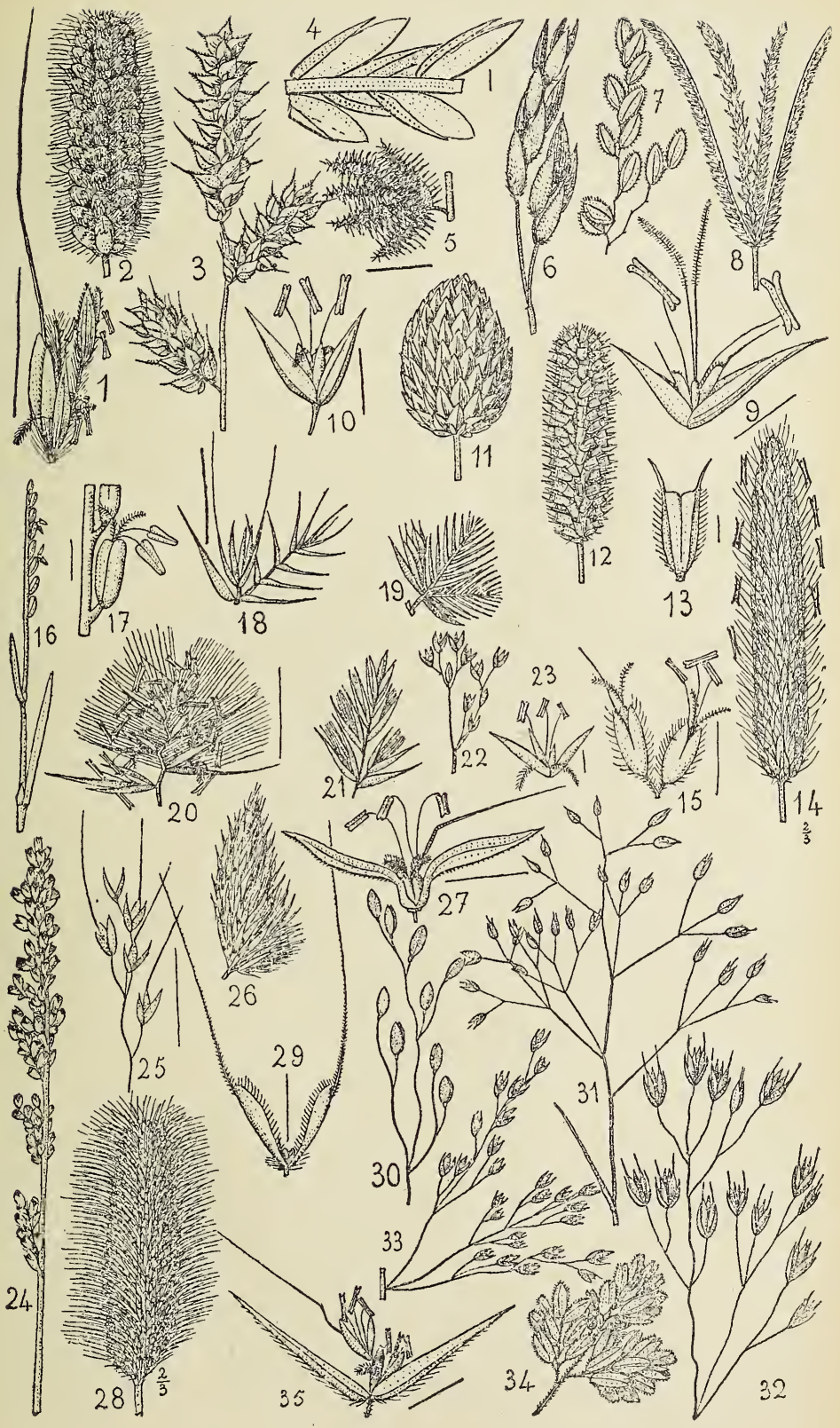




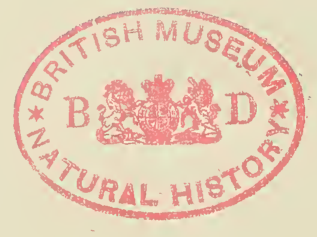


Pl. IVIII. - Graminées.

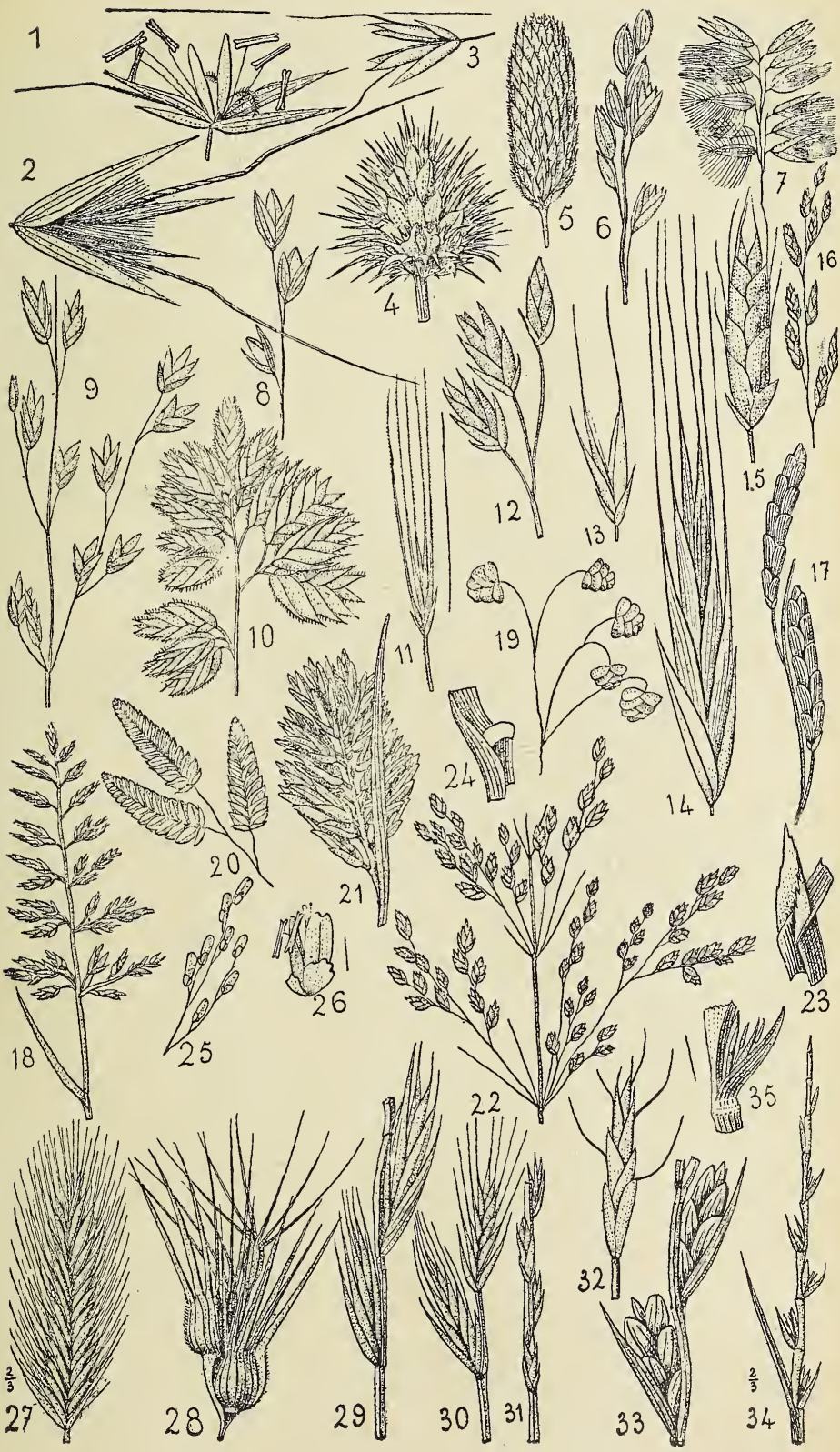




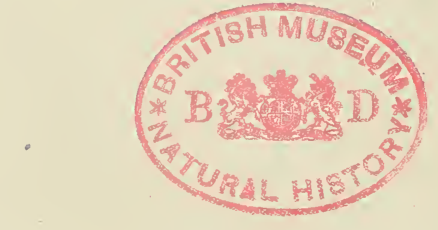


Pl. XIX. - Gymmospermes, Cryptogames.

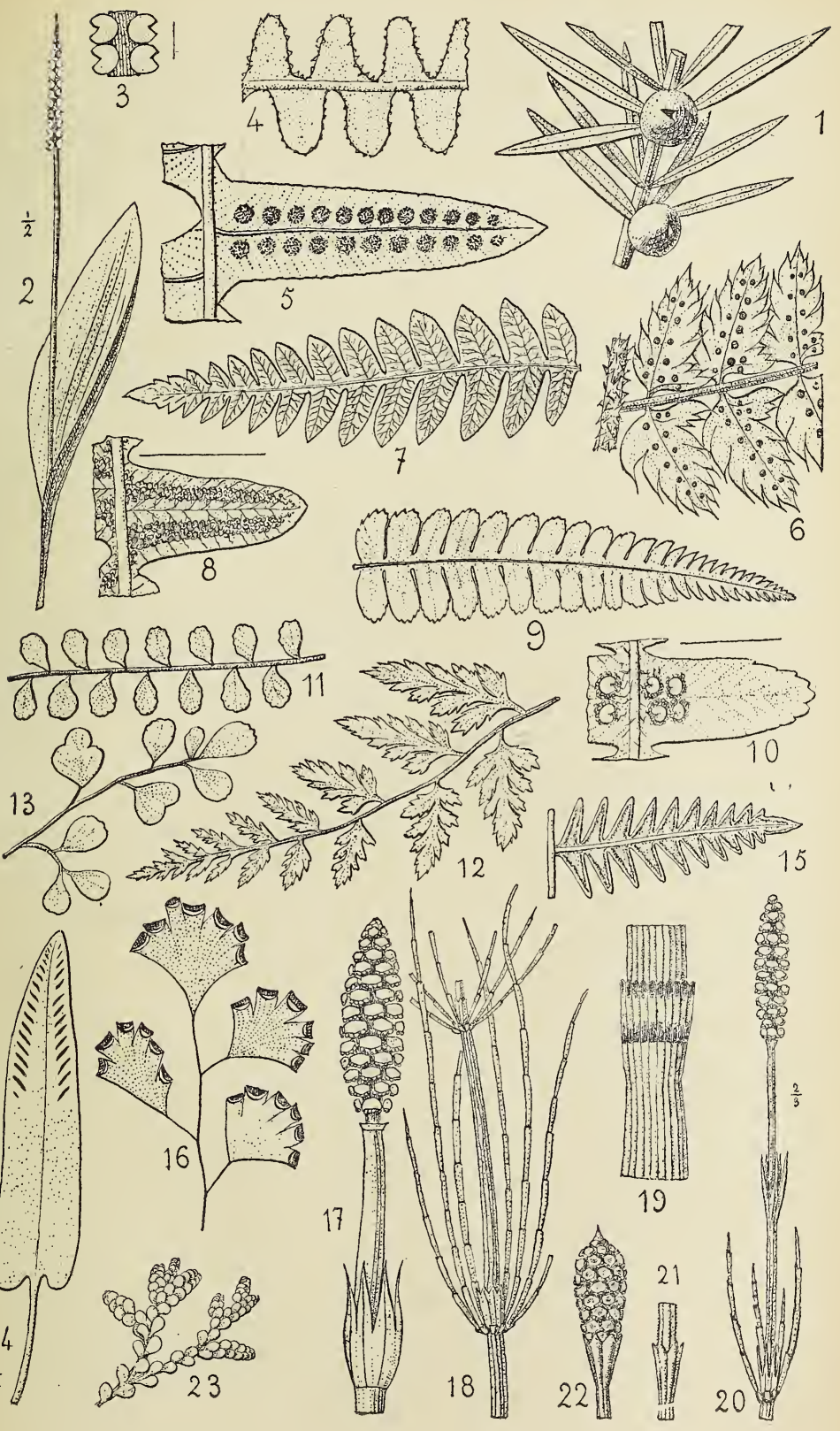




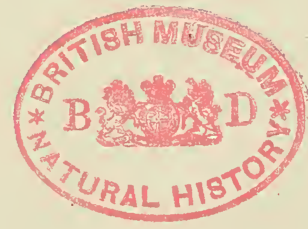




\section{VOGABULAIRE}

DES TERMES DE BOTANIQUE EMPLOYÉS DANS CETTE FLORUL:

Acaule. Dépourvue de tige.

Accrescent. Qui s'accroit après la floraison.

Aciculaire. En forme d'aiguille.

Acumen, acuminé. Pointe; terminé insensiblement en pointe.

Aigrette. Faisceau de poils terminant certains fruits.

Aile. Membrane mince qui borde certains organes.

Aisselle. Angle formé par l'insertion d'une feuille.

Akène. Fruit sec, ne s'ouvrant pas, ayant le péricarpe distinct de la graine.

Amplexicaule, F. dont la base embrasse la tige.

Anastomosé. Se dit dles nervures disposées en réseau.

Anthèse. Le moment de la floraison.

Apétale. Fl. sans pétaies.

Apiculé. Terminé en pointe courte.

Aphylle. Dépourvu de feuilles.

Apprimé. Appliqué sur.

Aristé. Pourvu d'une arête.

Ascendant: D’ahord horizontal puis relevé.

Auriculé. Muni d'oreillettes.

Axillaire. Placé à l'aisselle d'une f.

Bacciforme. En forme de baie.

Baie. liruit charnu à plusieurs graines (groseille).

Bec. Pointe terminale d'un fruit.

Bi. Deux - bifide, fendu en 2 ; biflore, à 2 fl.; bilabic, à 2 lèvres, etc.

Bractée. F. modifiée se trouvant à la base d'une fleur.

Bractéole. Petite bractée.

Caduc. Tombant de bonne heure.

Calice. Enveloppe extérieure d'une fl .

Calicule. Groupe de hractées rapprochées du calice.

Capillaire. Fin comme un cheveu. 
Capitule. Groupe de fl. sessiles rapprochées en tête serrée au sommet d'un pédoncule.

Capsule. Fruit sec s'ouvrant par des valves ou des trous.

Carène. Réunion des 2 pétales inf. d'une fl. papilionacée.

Caréné. Muni d'un angle aigu, en forme de carène.

Carpelle. Nom donné aux pièces qui constituent le pistil (PI. XX. f. 1,c).

Caryopse. Fr. sec, ne s'ouvrant pas, ayant le péricarpe soudé à la graine (avoine, Pl. XX, f. 9).

Caulinaire. Situé sur la tige.

Cespiteux. Formant gazon par les f. et les tiges rapprochées.

Concolore. De couleur uniforme.

Contracté. Resserré.

Connivent. Rapproclié par le sommet.

Cordiforme, cordé. Echancré en cour à la base.

Corymbe. Groupe de fleurs pédonculèes naissant à des points diftérents, mais atteignant à peu près le même niveau.

Crénelé. A bords présentant des dents arrondies.

Cunéiforme. En forme de coin.

Cuspidé. Terminé en pointe courte, aiguë et brusque.

Décombant. Qui s'élève d'abord, puis retombe.

Décurrent. Qui se prolonge au-dessous de son point d'insertion.

Déhiscent. Qui s'ouvre à maturité.

Dialypétale. Corolie à pétales bien distincts jusqu'à leur base, (Pl. XX, f. 1).

Dialysépale. Calice à pétales libres.

Dichotome. Qui se divise et se subdivise en 2.

Didynames. (Etamines) 2 grandes et 2 plus courtes.

Diffus. Etalé làchement, sans ordre.

Digité. Formé de parties insérées à un même point.

Diö̈que. A fl. máles (à étamines) et femelles (à pistil) portées par des pieds différents (chanvre, saule, pl. XX, f. 7).

Discolore. De 2 couleurs différentes.

Distique. Disposé sur 2 rangs opposés.

Divariqué. A parties s'écartant sous rles angles très ouverts.

Drupe. Fruit charnu à noyau (cerise).

Eglanduleux. Dépourvu de glandes.

Emarginé. Echancré.

Engaînant. Disposé en gaine ou étui autour d'un organe. 
Eperon. Prolongement tubuleux porté par une fleur.

Epillet. Petit épi.

Etendard. Pétale supérieur des fl. papilionacées (légumineuses).

Falciforme. En forme de petite faux.

Fasciculé. Réuni en faisceau.

Fastigié. A ramea ix rapprochés et dressés.

Fibrilleux. Formés de petits filaments très ténus.

Filet. Support de l'anthère (étamine).

Fififorme. En forme de fil.

Fistuleux. Cylindrique et creux.

Foliacé. Ayant l'apparence d'une f .

Follicule. Fr. sec, à une loge, s'ouvrant par une seule fente.

Fronde. F. des fougères.

Frutescent. Qui ressemble à un arbrisseau par sa consistance

Gaine. Partie de certaines feuilles embrassant la tige.

Gazonnant. En touffe serrée, formant gazon.

Géminé. Disposé 2 à 2 , par paire.

Genouillé ou géniculé. Coudé en genou.

Glabre. Sans poils.

Glabrescent. Presque glabre.

Glanduleux. Couvert de glandes ou petites vésicules ordint pédonculées, secrétant un liquide particulier.

Glauque. Convert d'une poussière blanchàtre ou bleuàtre.

Glaucescent Presque glauque.

Glomérule. Groupe de fleurs presque sessiles.

Glume. Ecaille située à la base d'un épillet, chez les Graminées.

Glumelle. Ecaille entourant les organes reproducteurs chez les Graminées.

Gynostème. Organe provenant de la soudure des filets des étamines avec le style chez les Orchidées.

Hampe. Pédoncule naissant de la sonche, dépourvu de feuilles.

Hasté. Ayant, à la base, 2 lobes aigus et divergents.

Hermaphrodite. Fl. ayant des étamines et un pistil (Pl. XX, f 1). Hispide. Couvert le poils raides.

Imbriqué. Se recouvrant comme les tuiles d'un toit.

Imparipennée. F. pennée ayant un nombre impair de folioles. Indéhiscent. Qui ne s'ouvre pas à maturité.

Inerme. Sans aiguillons. 
Infère. Se dit de l'ovaire situé au-dessous du point d’insertion des étamines et adhérent au tube du calice (Garance, Pl. XX, f. 4).

Inflorescence. Disposition des fl. sur la plante.

Involucelle. Petit involucre des ombellules dans les ombellifères.

Involucre. Réunion de bractées à la base d'une ombelle ou d'un capitule.

Labelle. Pétale élargi en forme de tablier chez les Orchidées

Labié. Muni de lèvres.

Lacinié. Découpé en segments longs et étroits.

Lame. Partie élargie d'un pétale.

Lancéolé. Allongé et atténué aux 2 bouts.

Ligulée. Corolle gamopétale irrégulière formée d'une partie inpro tubuleuse et d'une partie plane (Pissenlit).

Limbs Partie élargie d'une feuille

Linéaire. Etroit et allongé, à bords à peu près parallèles.

Lyré. Pennatifide ou pennatipartite, à segment terminal très développé.

Mono. Un seul. Monochlamydé à une seule enveloppe florale, moncsperme, à une seule graine. etc...

Monoïque. Plante dont un mème individu porte des fl. màles et des fl. femelles (noyer, noisetier, Pl. XX, f. 6).

Mucroné. Brusquement terminé en pointe (mucron) courte.

Multi.... Beaucoup de...

Mutique. Dépourvu de pointe ou d'arête.

Nectarifère. Qui porte des nectaires, organes glanđuleux secrétant un liquide sucré (nectar).

Oblong. 3-4 fois plus long que large.

Obovale. En forme d'ouf dont le gros bout est en haut.

Obtus. A sommet arrondi.

Ombelle. Groupe de fl. dont les pédoncules naissent au même point.

Onglet. Partie étroite d'un pétale.

Opposé. Se dit de deux organes qui naissent à la même hauteur, en face l'un de l'autre.

Orbiculaire. En forme de cercle.

Oreillette. Dilatation présentée par la base d’une feuille.

Ovaire. Partie inférieure d'un carpelle (pistil) et renfermant les ovules (P. XX, f. 50).

Ovule. Petit corps renfermé dans l'ovaire el donnant naissance à la graine après la fécondation. 
Paillettes. Productions minces, allongées, écailleuses, qui, chez quelques composées, sont mèlées aux $\mathrm{fl}$.

Palmati... Désigne une $\mathrm{f}$. palmée. Palmatilobés, divisée en lobes larges, n'atteignant pas le milieu du limbe: palmatifide, à divisions atteignant à peu près le milieu du limbe; palmatipartite, à divisions atteignant presque le pétiole: palmatiséquée, à divisions atteignant le pétiole et étant complètement distinctes (P1. $\mathrm{XX}, \mathrm{f} .12$ ).

Palmée. F. dont les nervures principales partent d'un même point, situé sur le bord du limbe (vigne, PI. XX, f. 12, i).

Panicule. Groupe de fleurs pédonculées dont les pédoncules infrs sont plus allongés que les autres (avoine).

Papilionacée. Corolle à š pétales inégaux, un supérieur (itendard), 2 latéraux (ailes) et 2 infrs,+ ou - soudés (carène).

Paripennée. F. composée-pennée, ayant un nombre pair de folioles.

Pauciflore. A fleurs pell nombreuses.

Pectiné. Disposé comme les dents d'un peigne.

Pennati .. S'applique à une f. pennée (Voir palmati....) qui a une seule nervure principale d'où partent, de part et d'autre, des nervures secondaires (pommicr, PI. XX, f. 12).

Pentamère. Fleur dont les parties sont au nombre de 5 .

Perfoliée. F. embrassante, comme traversée par la tige.

Péricarpo. La partie du fruit qui enveloppe la graine.

Pétaloïde. Qui ressemble à un pétale.

Pétiole. Partie rétrécie (queue) d'une feuille.

Pistil. Organe femelle de la fl.; il est formé de carpelles comprenant chacun un ovaire, un style et un stigmate (PI. XX, f. $5,0, s, t)$.

Polygame. Qui porte des fl. màles, des fl. femelles et des fl. hermaphrodites

Polysperme. A plusieurs graines.

Procombant. Qui s'incline vers le sol.

Pubescent. Couvert de poils courts et làches.

Radical. Qui naì de la racine ou de la souche.

Radicant. Qui émet des racines.

Réceptacle. Sommet élargi du pédoncule, portant parfois un grand nombre de fleurs (Composées).

Réticulé. En réseau.

Ronciné. F. pennatificle ou partite à segments aigus et dirigés ver's le bas.

Rotacé. Plan, étalé en roue. 
Sagitté. En de forme de fer de flèche.

Samare. Fruit sec à péricarpe dilaté en aile (orms).

Scabre. Rude au toucher.

Sessile. Sans support.

Sétacé. Fin et raide comme une soie.

Sétiforme. En forme de soies de porc.

Silique, silicule. Fruit sec, à 2 loges, s'ouvrant par 2 valves.

Sinué. A bord flexueux, à angles peu profonds.

Sore. Croupe de sporanges chez les Fougères.

Spathe. Membrane enveloppant quelques inflorescences (Allium).

Spatulé. Arrondi au sommet, très atténué à la base.

Stigmate. Extrémité d'un carpelle, terminant le style ( Pl. XX, f. $̋, t)$.

Stipité. Muni d'un support particulier.

Stipules Appendices foliacés se trouvant à la base du pétiole (rosicr).

Stolon. Rejet rampant et radicant.

Style. Prolongement de l'ovaire portant le stigmate (PI. XX, f. 5̈, s). Sub... Presque. - Subbiserie, presque en 2 séries ; subsessile, presque sessile, etc.

Supère. Ovaire placé au-dessus du point d'insertion des étaminẹs (Coquelicot, ficaire, PI. XX, f. 1).

Ternés. Réunis par 3.

Tétradynames. (Etamines) 4 grandes, 2 petites.

Tomenteux. Couvert d'une pubescence serrée, cotonneuse. Tri... Trois.

Turion. Tige de $\mathbf{A}^{\text {re }}$ année chez les liubus. Ne porte que des f. ; portera des fl. l'année suivante.

Utricule. Enveloppe du fruit chez les Carex. Vésicule remplie d'air chez quelques plantes aquatiques.

Uni. Un, Uniflore, à $1 \mathrm{fl}$; uniloculaire, à 1 loge; uniscxué, à 1 seul sexe.

Urcéolé. En forme d'urne.

Verticille. Ensemble d'organes insérés à la même hauteur.

Vivace. Qui vit plusieurs années. 


\section{TABLE ALPHABÉTIQUE}

\section{DES GENRES ET DES ORDRES}

Abies ......... 218| Andropogon.... 203| Baldingera ..... 20ð

Acer .......... 52

Aceras ........ 180

Acérinées ... ...

Achillea....... 113

Adianthum..... 220

Adonis........ 19

Egilops........ 9130

Esculus........ 52

Echusa ........ 93

Agrimonia ..... 80

Agropyrum...... 216

Agrostemma..... 39

Agrostis. ....... 207

Ailanthus . .... 54

Aira........... 208

Ajuga ......... \อั6

Alchimilla...... 81

Alisma........ 177

Aussmacées...... 177

Alliaria .. ..... 29

Allium ........ 189

Alnus .......... 173

Alopecurus .... 206

Alsine....... . 4/k

ALSINÉE.......... 41

Althra ......... 47

Alyssum ... 3', 223

AMarantacées ... 161

Amarantus ..... 161

Amaryllidées . . . 183

AMbrosiacées . . 128

Ammi ........ . 96

AMPÉLIDÉES ...... כั2

Ampelopsis...... 52

AmygdaléEs...... 69

Amygdalus ..... $\quad 70$

Anacampseros... 84

Anacamptis .... 186

Anagallis.

Anarrhinum.....

Anchusa........ .
Androsæmum... 46

Andryala. ..... 125

Anemone....... 18

Anethum...... 97

Angelica........ 97

Anthemis....... 112

Anthoxanthum . . 2000

Anthriseus ...... 9'

Anthyllis...... อิ8

Antirrhinum.... 14:3

Apera......... 207

Apium ......... 96

Apocréées ..... 132

Aquilegia...... 92

Arabis......... 28

Araliacées....... 97

Arctium....... 118

Arenaria ........ 4 4't

Argyrolobium ... 57

Aristolochia .... 168

\. IISTOLOChí́es . . 168

Armeniaca ..... 70

Arö̈dées ......... 192

Arrhenaterum. . 209

Artemisia ...... 114

Arum ......... 192

Arundo ......... 207

Ascléptadées. . . . 132

Asparagées ..... 181

Asparagus...... 182

Asperugo...... 138

Asperula ..... . 101

Asphodelus.... 181

Aspidium....... 219

Asplenium ..... 220

Asteriscus.. . ... 112

Astragalus... .. 63

Atriplex....... 164

Avena.......... 209
Arnoseris........ 128

133 Azolla.......... $22_{2}$ Callitriche..... 85

Ballota ........ 1503

Barbarea...... 27

Barkhausia..... 122

Bartsiu........ 1405

Batrachium .... 19

Bellevalia...... 181

Bellis. . ....... 109

Berbéridées..... 23

Berberis...... . 23

Berula......... 98

Beta......... 162

Betonica...... $15 \%$

Betulacées..... 173

Bidens........ 112

Bifora......... 99

Blitum ........... 162

Bonjeania...... 62

Borraginées ..... 134

Borrago....... 138

Brachypodium... 216

Brassica....... 30

Briza.......... 214

Bromus ......... 212

Broussonnetia... 171

Birunella........ 156

Bryona........ 83

Bulbocastanum.. 226

Bunias ......... 34.

Buphtalmum. ... 112

Bupleurum..... 9 9

Butomacées. .... 177

Butomus...... 177

Buxus....... 169

Cactées... ..... 80

Cactus ......... 8 8̈

Calamagrostis ... 207

Calamintha.... . 151

Calendula ...... 11 ö

Calepina...... 3/4 


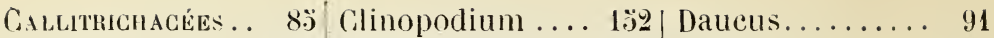

Calluna....... 130 Coeloglossum.... 189 Delphinium..... 23

Caltha......... 22 Colchicacées. ... 178

Calystegia....... 133 Colchicum..... 178

Camelina...... 33 Colutea ....... 6. $6^{\prime}$

Campanula...... 130 Composées ....... 103̈

Campanulacées... 1 129 Conifèies...... 218

Cannabinées .... 172 Conium ........ 94

Cannabis....... 172

Caprifoliacées...

Capsella .........

Cardamine ......

Cardaria........

Carduncellus ....

Carduus.........

Carex .... . ... 190

Carlina........ 11

Carpinus ....... 17

Carum ..........

Caryophyllées . .

Conopodium.....

98 Conrıngia ..... . 223

32 Convallaria..... 182

28 Convolvulacées. 133

32 Convolvulus. 133, 226

120 Conyza....... 110

118 Coriandrum .. .. 92

96 Coriaria........ ๖े

116 Coriariées....... כ̆

Cornacées.......

9:i Cornus..........

38 Coronilla........

Castanea ....... 17t

Catabrosa ...... 219̆

Catananche... . 127

Caucalis.........

Caulinia........ 19

Célastrinées..... כ

Centaurea .. 119, 22

Centranthus . ... 10

Centunculus.... .

Cephalanthera... 189

Cerastium.......

Cerasus .........

Círatophyllacées

Ceratophyllum ..

Cercis

42 Crucianella......

70 Cructa Ères........

86 (incubalus. ...

86 Cucumis ........

รัวั

Ceterach ........ 219

Chærophyllum.... 9

Chamagrostis.... 206

Cheiranthus ..... 27

Chelidonium ... . 2

Chénopodacées .. 16

Chenopodium ... 162

Chlora .......... 132

Chondrilla.. .... 120

Chrysanthemum.

Chrysocoma......

Cicendia .........

Cicer.

Cucurbita ......

Dianthus ... ... \&

Dichondra...... 226

Deschampsia .... 208

Digitalis........ 1/锠

Digitaria..... . . 20

Dioscorées ... 182

Diplotaxis ...... 29

Coronopus .... 32

Corrigiola .......

Conlus ......... 17

Dipsacées...... 103

Dipsacus ....... 103

Doronicum ..... 11'

Doryenium . ... 63

Draba ......... 3

ofl Ecballium...... 82

Echinaria.......210

98 Echinops...... 116

98 Echinochloa.... 204

68 Echinospermum. 137

32 Echium ........ 136

83 Elatine........ 45

7. Elatinées ... ... 40

109 Eleocharis...... 196

8 8̈ Elodea......... 177

8' Epilobium.. ... 87

8.3 Epipactis....... 189

81 EQuisét acées..... 220

122 Equisetum .. ... 220

183 Eragros is ..... 21't

101 Erica.......... 131

20 Ericácées....... 130

39 Erigeron ....... 109

83 Eriophorum ... 19ว

8.) Erodium ...... 50 0

82 Erophila....... 33

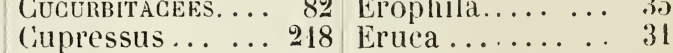

Cupularia ...... 111 Erucastrum..... 30

Cupulifères.. ... 173 Ervum......... 65

Cuscuta....... 133 Eryngium...... 91

Cydonia........ 82 Erysimum ....... 222

Cynara........ 116 Erythræa....... 132

Crnarocéphales. . 116 Eufragia......... l't $^{\prime}$

120 Cynodon ........ 203 Eupatorium ..... 130̈

114 Cynoglossum.... 137 Euphorbia ..... 169

109 Cynosorus...... 206 Euphorbiacées. .. 168

133 Cypéracées ..... 194 Euphrasia .. . . 146

6't Cyperus........ 194 Euxolus........ 161

Cichorium....... 127

Circæa........ 87

Cirsium ....... 117

Cistinées. ...... 35

Cistus......... 36

Cilandestina ..... 148

Glematis ........

Cytisus........ 56

Dactylis

210

Damasonium .... 178

Danthonia.... , 210

Daphne........ 167

18 Datura ........ 139 Ficacées....... 171

Faba.......... 66

Fagus .......... 174

Festuca.........2 211

Ficaria....... 22 
Ficus ........ 171 Hippocastanées...

Filago........ 110 Hippocrepis ....

ficeniculum..... 93

Fougéres....... 218

Fragaria...... 76

Fraxinées....... כ̆l

Fraxinus ....... รั?

Fritillaria ...... 179

Fumana....... 37

Fumaria....... 24

Fumariacées ..... 24

Gagea .......... 180

Galanthus ...... 116

Galeobdolon..... 1 อัวั

Galeopsis... .... Iรว

Galium......... 108

Gastridium...... 208

Gaudinia....... 216

Genista........ วั6

Gentiana ....... 133

Gentranées ...... 132

Géraniacées..... 49

Geranium ...... 49

Geum......... 76

Gladiclus....... 183

Glaucium....... 2'

Glechoma ....... 153

Gleditsclıia ...... อ๊

Globularia... ... 1 อั9

Globulariées .... 159

Glyceria.........

Gnaphalium......

Gramisées .......

Gratiola......... 14̌

Grossulariées....

Gymnadenia..... 188

Gypsophila..... 4

Haloragées .....

Hedera

Hedypnois...... 127

Helianthemum.36, 224

Helianthus ..... 112

Helichrysum .... 110

Heliotropium.... 138

Helleborus ..... 22

Helminthia ..... 126

Helosciadium.... 96

Hemerocallis .... 18!

Hepatica ........

Heracleum ... . .

Herniaria

Hesperis.

Hieracium . . . . . .
97

hippuridées.....

Ilippuris........

llirschfeldia .....

Holeus .......... 20

Inolosteum........

Hordeum....... 21

Humulus....... 172

Hutchinsia......

Hlvacinthus. ... 181

HYydochaRIDÉEs . . 176

Hydrocotyle.... 91

Hyoscyamus. ... 139

Hyoseris ...... 128

Hypéricinées .... . 40

Hypericum ..... 4.

Hypochoeris .... 127

Hypopitys...... 46

Hyssopus. ..... 15̆1

Iberis .........

33

33

Ilicinées........ כ3

Inula......... 111

Ir acées ........ 182

Iris ............ 183

lsatis......... 33

Jasione........ 129

JASMINÉES...... 131

Jasminum...... 131

Jovcacées ...... 192

JUGLANDÉE.... 173

Juglans.. . . . . 173

Juncus ......... 192

Juniperus... . ... 218

Kentrophyllum . .

120

$\begin{array}{lll}\text { Knautia ........ } & 104 \\ \text { Koeleria ... } & \ldots & . .210\end{array}$

Labiées......... 148

Lactuca.......... 121

Lagenaria....... 83

Lamium......... 150

Lappa ........... 118

Lampsana ........ 128

L.rix............ 218

Lathyrus ... 66, 228

19 Lathrea . . ..... 148

97 Laurinées. . .... 168

88

28

123
2 Légumineuses .... כั4

Lemna.......... 191

马̈ Lemnackes ....... 191

ö Lens.......... 64

9 Lentibulakiées . . 158

Leontodon...... 120

Leonurus........ โวั้

Lepidium....... 32

Lepturus ....... 217

Leucanthemum. . 113

Ligulif LORES . . . 120

Ligustrum. . ... 131

Lilac .......... 131

Liliacées . .... 178

l.ilium......... 179

Limodorum..... 189

Linaria........ 143

Linacées........ 48

Linosyris ........ 109

Linum ......... 48

Listera ......... 190

Lithospermum... 13ă

Lobelia........ 129

Lobélacées..... 129

Lolium ......... 217

Lonicera ...... 97

Loranthacées .... 98

Coroglossum ..... 18

Lotus........ . 63

Lunaria......... 34

Lupinus........ ร็

Luzula.......... 19'

Lychnis ...... 39

Lycium..... ... 138

lycopsis.... ... 13ã

Lycopus....... 150

Lygia.......... 167

Lysimachia ..... 158

Ly'ThRacées....... 86

Lythrum........ 86

Malachium ..... 42

Malus .......... 82

Malva ......... 47

Matvacées...... 47

Marrubium..... 153

Matricaria...... 113

Medicago....... 58

Vielampyrum.... 14:̈

Melandryum... . 39

Nelica......... 210

Melilotus... 59, 294

Melissa........ 152

Melittis........ 150

Mentha......... 150 
Mercurialis ..... 169| Osyris......... 168| Porturacées.... 88

Mespilus ..... 81 Oxalidées....... 40 Potamogeton ... 190

Mibora ......... 206 Oxalis.......... §0 POTAMoGÉTonÉEs.. 190

Milium ...... . 208 Potentilla... 76, 225

Moehringia ..... 44. Paliurus... .... 5ี3 Poterium....... 81

Ionchia....... 43 Pallenis........ 111 Primula....... 159

Molinia....... . 36 Panicum ....... 204 Primulacées.... 158

Monotropa...... 46 Papaver........ 23 Prismatocarpus.. 129

Monotropacées... 46 Papavéracées.... 23 Prunus........ 69

Montia....... 88 Parietaria ...... 172 Psoralea....... 62

Moracées...... 171 Paronychiacées .. 88 Pteris .. ....... 220

Morus........ 171 Paspalum...... 204 Pterotheca. .... 122

Muscari ....... 181 Passerina...... 167 I'tychotis....... 90̆

Myagrum...... 34 Pastinaca...... 97 Pulicaria....... 111

Myosotis....... 136 Pedicularis... .. 1450 Pulmonaria.. .. 136

Myricaria..... . 87 Peplis........ 86 Pyrethrum..... 114

Myriophyllum ... 85

NAÏACÉES...... 191

Naïas ......... 191

Narcissus...... 183

Nardosmia...... 115

Nardurus......2 216

Nasturtium......

Nepeta...........

Nerium........ 132

Neslea.. .......

Nicandra ... . . . 139

Nigella ..........

Nuphar......... .

Nyinphra ..... .

NYMPHEACÉES . . . .

Odontites....... 146

OEnanthe... ... 93

OEnothera ...... 87

Oléacées ........ 151

OMbellifÈres.... 89

Onagrariées ..... 86

Onobrychis..... 68

Ononis . 57, 224, 220

Onopordon...... 117

Ophioglossum . . 219

Ophrys ........ 188

ORchidées....... 184

Orchis......... 186

Origanum ...... 151

Orlaya......... 92

Ormenis........ 112

Ornithogalum 180, 227

Ornithopus ..... 69

Ornus......... รั।

Orobanche...... 147

Ororanchées. .... 146

Orobus..........

Persica ....... 70

Petasites ....... 115

Petroselinum .... $\quad 96$

Peucedanum.... 97

Phalangium ..... 18

Phalaris........ 205

Phaseolus ....... 53

Plıelipæa....... 146

Phleum . . ..... 206

Phlomis ... ... 153

Phragmites.... . 207

Physalis........ 139

Pliytolacea ..... 167

Phytolaccées .... 177

Picris ......... 126

Pimpinella ...... 98

Pinus .......... 218

Pirus......... 82

Pisum.......... 68

Plantago ...... 160

Plantaginées.... 160

Puatanacées .... 173

Platanthera..... 189

Platanus....... 173

Poa .......... 214

Podospermum... 126

Polycarpon...... 40

Polycnemum .... 161

Polygala........ 38

P'OLYGalacées .... 38

Polygonatum .... 182

Polygonacées.... 164

Polygonum...... 166

Polypodium ..... 219

Polypogon....... 208

Polystichum.... . 219

Pomacées . .... 81

Populus ....... 176

68 Portulaca........
Quercus ....... 174

Radiola......... 48

Ranunculus .... 49

Raphanistı um.... 31

Raphianus...... 31

Rapistrum.... . 31

Renonculacées .. 17

Reseda .... 36, 223

Rí́sédacéEs ...... 36

Rhagadiolus ..... 188

RHamnées....... ¿

Rhamnus....... 54

Rhinanthus..... 14:

RHuzocarpées .... 221

Rhus .......... ร3

Ribes........... 83

Robinia ........ 64

Roncelia........ 130

Roripa ........ $3 \ddot{3}$

Rosa .......... 30

Piosacées ....... 69

Rosinées....... 70

Rosmarinus ..... 153

Roubieva...... 162

Rubia .... . . ... 99

Rubiacées....... 99

Rubus........ 71

liumex ......... 164

liuscus........ 182

Ruta ......... ö1

Rutacées ....... כ̋

Sagina ........ 44

Sagittaria ..... 177

SALICINÉES ...... 17\%

Salix ......... 17

Salvia......... 1002 


\begin{tabular}{|c|c|c|}
\hline Sambucus...... 98 & Sonchus.. & Trisetum \\
\hline Samolus......... 1508 & Sorbus... & Triticum. \\
\hline nicula $\ldots .$. & Sorghum ..... & Trixago... \\
\hline GUISORBÉES.... 80 & Sparganium. . & Tulipa... \\
\hline TALACÉES ..... 168 & อั7 & \\
\hline & & \\
\hline inus.... & peroula & Tussilago. \\
\hline ia........ 152 & Spergularia..... & Typha. . . \\
\hline$u m \ldots \ldots$. & Spinacia........ 163 & Typhacées. \\
\hline xifraga........ & Spiræa... . & \\
\hline AGCÉF: & Spiranthes..... & Ulex .... \\
\hline 104 & & IACÉES. \\
\hline $9 '$ & 1004 & \\
\hline 170 & & \\
\hline 193 & Symphoricarpus. 99 & Uro \\
\hline & $1 \mathrm{~m} . . \quad \ldots 13 j$ & \\
\hline 214 & Syriilga.... & \\
\hline 213 & & Utric \\
\hline rium .. & TAMariscinées.... & \\
\hline 128 & Tam & \\
\hline 126 & $\ldots \ldots \ldots 182$ & \\
\hline & Ta & \\
\hline 141 & 120 & \\
\hline & 218 & \\
\hline $21 \%$ & 33 & \\
\hline & T'́́ & \\
\hline$m \ldots$ & lobus.. & \\
\hline ra .. 32,223 & 167 & \\
\hline ....... 114 & 18 & Vib \\
\hline & 168 & $\mathrm{Vi}$ \\
\hline 119 & 33 & \\
\hline 93 & 120 & toxicum .. 1 \\
\hline 203 & 167 & $\ldots \ldots$ \\
\hline 102 & 151 & \\
\hline .. 93 & 46 & \\
\hline 40,224 & TiLI & \\
\hline …... 39 & Tilla & Vulpia. \\
\hline$\ldots \ldots \ldots 116$ & 127 & \\
\hline .. 3!) & Tor & \\
\hline 96 & Tor & Xeranthemum... \\
\hline 19 & 77 & \\
\hline 95 & 126 & \\
\hline & 51 & \\
\hline 138 & $\mathrm{~m} \ldots . .60$ & ZYGOI \\
\hline 13 & $11 a . . .$. & \\
\hline & & \\
\hline
\end{tabular}





\section{FLORULE \\ TOULOUSAINE \\ $\mathrm{OU}$}

\section{ANALYSE DESCRIPTIVE}

DES PLANTES QUI CROISSENT SPONTANEMENT OU SONT CULTIVÉES EN GRAND DANS LA RÉGION SOUS-PYRÉNÉENNE DE LA

\section{HAUTE-GARONNE}

avec l'indication de leurs propriétés les plus importantes

OUVRAGE CONTENANT 847 FiguRES DESSINÉES PAR L'AUTEUR

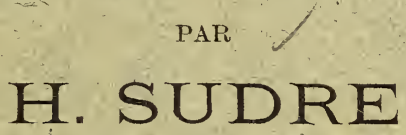

Prófesseur à l'Ecole normale d'Instituteurs de Toulousc, Nembre de la Société bolanique de France.

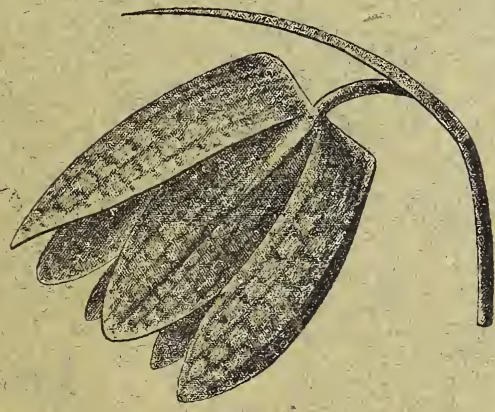

Paul KLINCKSIECK LIBRAIRIE DES SCIENCES NATURELLES

3 , rue Corneille, 3 PARIS VIe
J. MARQUESTE LIBRAIRIE ANCIENNE ET MODERNE

34 , rue Saint-Rome, 34 TOULOUSE

ALBI

IMPFIMERIE NOUGUIES

33, Rue de l'Hòtel-de-Ville, 33 


\section{DU MÊME AUTEUR}

Notes sur quelques plantes critiques de la Flore du Tarn, avec

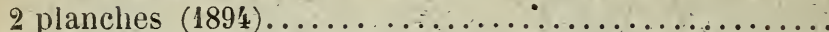

Revision des Rubus de l'Herbier du Tarn, de de MartrinDonos (1899)

Excursions batologiques dans les Pyrénées, ou description et analyse des Rubus des Pyrénées francaises ; 4 parties (1898-1903)

Les Rubus de l'Herbier Boreau, ou étude sur les espèces de G. Genevier (1902)

Les Hieracium du Centre de la France, daprès les types de Jordan et de Boreau, avec $32 \mathrm{pl}$. et plus de 200 fig. (19.J2)

Contributions a l'étude des RuBus du Plateau central de la

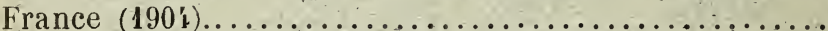

Notes sur quelques Hienacium des Pyrences (1903)............ $0 \quad 50$

Les Rubus du «Guide du botaniste dans le canton de Fribourg » de MN. Cottet et Castella (1904)............. 0 ว 0

Un bouquet de Ronces bretonnes (190') ............... 1 วั0

Observations sur «Set of British Rubi »(1904)......... 2 》

Révision des Rubus de l'Herbarium europeeum de V. C. Baenitz

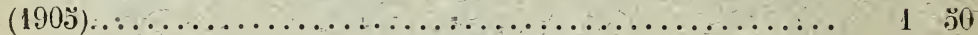

Diagnoses de Rubus nouveaux (1906)................ 2 》

Conspectus Ruborum Europe ap. Gandoger « Novus Conspectiss Florce Eürope $\gg(1905) \ldots \ldots \ldots \ldots \ldots \ldots \ldots \ldots \ldots \ldots .1$.

Observations sur deux Ronces curopéennes: Rubus vagus F., R. pilocarpus Grl. (1906)......................... $\theta \quad 00$

Batotheca europoea, paraissant par fascicules annuels de כ̋0 numéros. Prix du fascicule. 





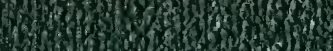

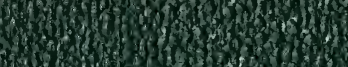

60 of

3. 6 on

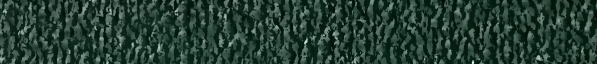

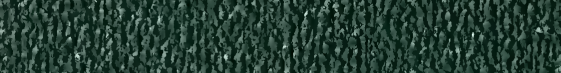

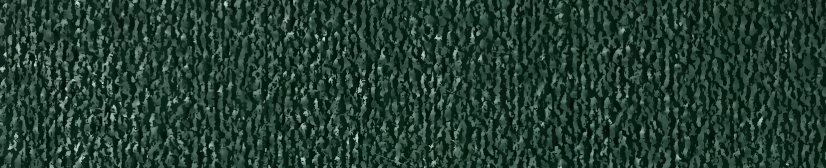

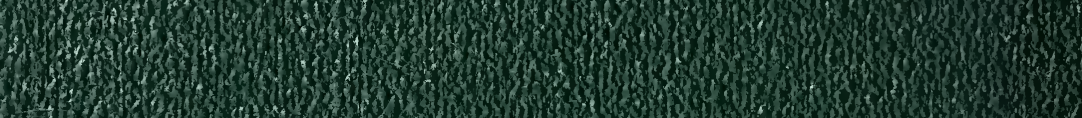

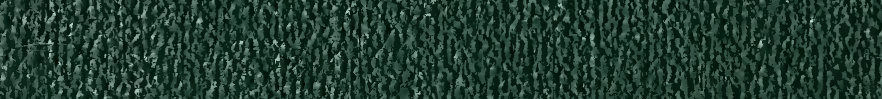

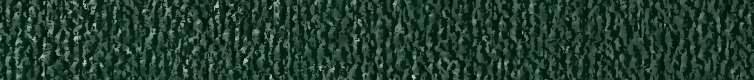

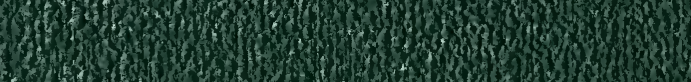

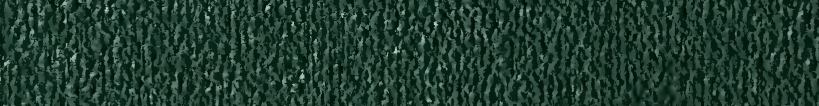

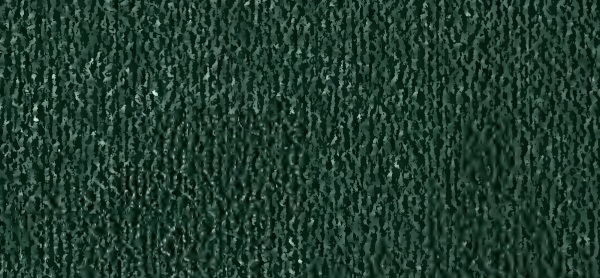

enthesto

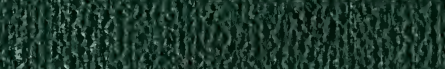

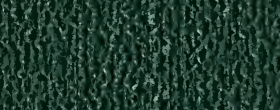

thes

if 100

3)

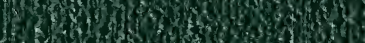

6ym

(3) 3

19.

7.

W. 